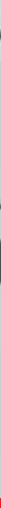

IntechOpen

\title{
Nanoparticles Technology
}

Edited by Mahmood Aliofkhazraei
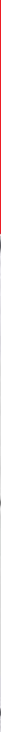



\section{NANOPARTICLES TECHNOLOGY}

Edited by Mahmood Aliofkhazraei 


\section{Nanoparticles Technology}

http://dx.doi.org/10.5772/59894

Edited by Mahmood Aliofkhazraei

\section{Contributors}

Kazutaka Hirakawa, Jakub Siegel, Tatiana Itina, Andrey Voloshko, T. Randall Lee, Reza Sabet Dariani, Zohreh Nafari Qaleh, Jagannathan Thirumalai

\section{(c) The Editor(s) and the Author(s) 2015}

The moral rights of the and the author(s) have been asserted.

All rights to the book as a whole are reserved by INTECH. The book as a whole (compilation) cannot be reproduced, distributed or used for commercial or non-commercial purposes without INTECH's written permission.

Enquiries concerning the use of the book should be directed to INTECH rights and permissions department (permissions@intechopen.com).

Violations are liable to prosecution under the governing Copyright Law.

\section{(cc) BY}

Individual chapters of this publication are distributed under the terms of the Creative Commons Attribution 3.0 Unported License which permits commercial use, distribution and reproduction of the individual chapters, provided the original author(s) and source publication are appropriately acknowledged. If so indicated, certain images may not be included under the Creative Commons license. In such cases users will need to obtain permission from the license holder to reproduce the material. More details and guidelines concerning content reuse and adaptation can be foundat http://www.intechopen.com/copyright-policy.html.

\section{Notice}

Statements and opinions expressed in the chapters are these of the individual contributors and not necessarily those of the editors or publisher. No responsibility is accepted for the accuracy of information contained in the published chapters. The publisher assumes no responsibility for any damage or injury to persons or property arising out of the use of any materials, instructions, methods or ideas contained in the book.

First published in Croatia, 2015 by INTECH d.o.o.

eBook (PDF) Published by IN TECH d.o.o.

Place and year of publication of eBook (PDF): Rijeka, 2019.

IntechOpen is the global imprint of IN TECH d.o.o.

Printed in Croatia

Legal deposit, Croatia: National and University Library in Zagreb

Additional hard and PDF copies can be obtained from orders@intechopen.com

Nanoparticles Technology

Edited by Mahmood Aliofkhazraei

p. $\mathrm{cm}$.

ISBN 978-953-51-2214-2

eBook (PDF) ISBN 978-953-51-5769-4 


\section{We are IntechOpen, \\ the world's leading publisher of Open Access books}

Built by scientists, for scientists

\section{$3,800+$}

Open access books available

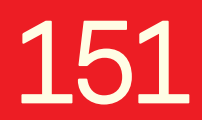

Countries delivered to

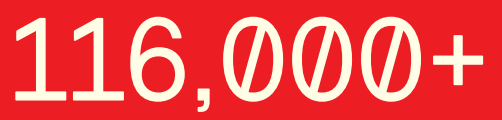

International authors and editors
$120 \mathrm{M}+$

Downloads

Our authors are among the

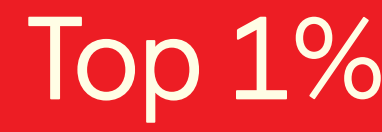

most cited scientists

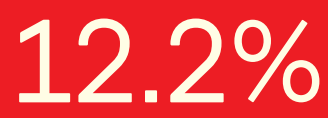

Contributors from top 500 universities

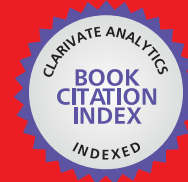

WEB OF SCIENCE ${ }^{\mathrm{TM}}$

Selection of our books indexed in the Book Citation Index in Web of Science ${ }^{\mathrm{TM}}$ Core Collection (BKCI)

Interested in publishing with us?

Contact book.department@intechopen.com

Numbers displayed above are based on latest data collected.

For more information visit www.intechopen.com

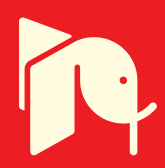





\section{Meet the editor}

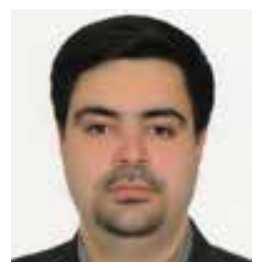

Dr. Mahmood Aliofkhazraei works in the Corrosion and Surface Engineering Group at the Tarbiat Modares University, Iran. He is the head of Aliofkhazraei research group (www.aliofkhazraei.com). Dr. Aliofkhazraei has received several honors, including the Khwarizmi award and the best young nanotechnologist award of Iran. He is a member of the National Association of Surface Sciences, Iranian Corrosion Association, and National Elite Foundation of Iran. His research focuses on materials science, nanotechnology and its use in surface and corrosion science. 



\section{Contents}

Preface XI

Chapter 1 Nanoparticle Formation by Laser Ablation and by Spark Discharges - Properties, Mechanisms, and Control Possibilities 1

Andrey Voloshko and Tatiana E. Itina

Chapter 2 Fundamentals of Medicinal Application of Titanium Dioxide Nanoparticles 13

Kazutaka Hirakawa

Chapter 3 Synthesis, Luminescence and Magnetic Properties of Novel Fe0.5Gd0.5(MoO4)1.5:Eu3+ Micro/Nano (3D) Structures 33 Rajagopalan Krishnan and Jagannathan Thirumalai

Chapter 4 Effect of Argon Carrier Gas Flux on TiO2 Nanostructures 49 Reza Sabet Dariani and Zohreh Nafari Qaleh

Chapter 5 Noble Metal Nanoparticles Prepared by Metal Sputtering into Glycerol and their Grafting to Polymer Surface $\mathbf{7 3}$ Jakub Siegel, Alena Řezníčková, Petr Slepička and Václav Švorčík

Chapter 6 The Development of Smart, Multi-Responsive Core@Shell Composite Nanoparticles 103

Bo Sang Kim and T. Randall Lee 



\section{Preface}

During the past years, scientists have achieved significant success in nano science and technology. Nanotechnology is a branch of science which deals with fine structures and the materials with very small dimensions - less than $100 \mathrm{~nm}$. Measurement unit of nano has been extracted from nano prefix, which is a Greek word meaning extremely fine. One nano $\left(10^{-9} \mathrm{~m}\right)$ is the length equivalent to 5 silicon atoms or 10 hydrogen atoms aligned side by side. In perspective, note the following examples: Hydrogen atom is about $0.1 \mathrm{~nm}$; a virus is about $100 \mathrm{~nm}$; diameter of a red blood cell is $7000 \mathrm{~nm}$; and diameter of a human hair is 10000nm. Nanotechnology is a field of applied sciences which is focused on design, production, detection, and employing the nano-size materials, pieces, and equipment. Advances in nanotechnology lead to improvement of tools and equipment as well as their application in human life. "Nano science" is study of the phenomena emerged by atomic or molecular materials with the size of several nanometers to less than $100 \mathrm{~nm}$. In the chemistry this size involves the range of colloids, micelles, polymer molecules, and structures such as very large molecules or dense accumulation of the molecules. In physics of electrical engineering, the nanoscience is strongly related to quantum behavior or electrons behavior in structures with nano sizes. In biology and biochemistry, also, interesting cellular components and molecular structures such as DNA, RNA, and intercellular components are considered as nanostructures.

This book collects new developments about nanoparticles. I like to express my gratitude to all of the contributors for their high quality manuscripts. I hope open access format of this book will help all researchers and that they will benefit from this collection.

Dr. Mahmood Aliofkhazraei

Tarbiat Modares University

Iran

www.aliofkhazraei.com 



\title{
Chapter 1
}

\section{Nanoparticle Formation by \\ Laser Ablation and by Spark Discharges - Properties, Mechanisms, and Control Possibilities}

\author{
Andrey Voloshko and Tatiana E. Itina \\ Additional information is available at the end of the chapter \\ http://dx.doi.org/10.5772/61303
}

\begin{abstract}
Laser ablation (LA) and spark discharge (SD) techniques are commonly used for nanoparticle (NP) formation. The produced NPs have found numerous applications in such areas as electronics, biomedicine, textile production, etc. Previous studies provide us information about the amount of NPs, their size distribution, and possible applications. On one hand, the main advantage of the LA method is in the possibilities of changing laser parameters and background conditions and to ablate materials with complicated stoichiometry. On the other hand, the major advantage of the SD technique is in the possibility of using several facilities in parallel to increase the yield of nanoparticles. To optimize these processes, we consider different stages involved and analyze the resulting plasma and nanoparticle (NP) parameters. Based on the performed calculations, we analyze nanoparticle properties, such as mean size and mean density. The performed analysis (shows how the experimental conditions are connected with the resulted nanoparticle characteristics in agreement with several previous experiments. Cylindrical plasma column expansion and return are shown to govern primary nanoparticle formation in spark discharge, whereas hemispherical shock describes quite well this process for nanosecond laser ablation at atmospheric pressure. In addition, spark discharge leads to the oscillations in plasma properties, whereas monotonous behavior is characteristic for nanosecond laser ablation. Despite the difference in plasma density and time evolutions calculated for both phenomena, after well-defined delays, similar critical nuclei have been shown to be formed by both techniques. This result is attributed to the fact that whereas larger evaporation rate is typical for nanosecond laser ablation, a mixture of vapor and background gas determines the supersaturation in the case of spark.
\end{abstract}

Keywords: Nanoparticles, laser ablation, plasma, spark discharge, synthesis, modeling, size distribution, nucleation, aggregation 


\section{Introduction}

Modern nanotechnology includes several promising areas such as nano-optics, nano-photonics, nanochemistry, nanobiology, and nanomedicine. During the past decade, we have witnessed a tremendous growth of nanoparticle applications that require particles of different materials with different size, dispersion, shape, and morphology. As a result, the development of new nanoparticle synthesis methods is particularly important. Among the rapidly immerged techniques, plasma-based synthesis has a number of advantages being both rather simple and allowing unique and well-controlled formation of nanoparticles.

In particular, plasmas created by both pulsed laser ablation and by spark discharges can be used for nanoparticle synthesis. That is why these two techniques have attracted particular attention and resulted in numerous experimental and theoretical investigations. On one hand, the main advantage of laser ablation method, as was demonstrated in these studies, is the possibility to preserve target stoichiometry. On the other hand, spark discharge allows one to produce a very large amount of nanoparticles by using parallel multidischarge set-up. However, the main physical mechanisms involved in these processes stay partly puzzling. That is why additional studies based on a detailed comparison of both methods are required for the determination of their main similarities and differences.

Starting from the early 1990s, laser ablation (LA) has been intensively studied first for long laser pulses and then for much shorter ones [1-2]. A number of experiments revealed that laser interactions with solid targets lead to the formation of nanoparticles. Furthermore, if femtosecond laser is used, an explosive ejection of a mixture of clusters and atoms was both theoretically predicted and experimentally observed [3]. It was found that the produced nanoparticles demonstrated either plasmonic or photoluminescent properties, as well as a capacity of field amplification. These properties are particularly interesting biomedical applications, such as imaging and photodynamic therapy. It should be noted that absence of incompatibility with biological tissues is crucial for further development of most of the applications where nanoparticles are used in vivo. However, toxicity is hard to avoid in traditional chemical methods. In addition, the stability of these nanoparticles is still not high enough. It was demonstrated, fortunately, that nanoparticles produced by laser ablation are better suitable for biomedical applications, in particular, when they are produced in liquids [4]. This advantage made LA a unique tool for nanoparticle synthesis.

In order to elucidate the physical mechanisms of LA, many analytical and numerical investigations were performed [5 -11]. In vacuum, self-similar adiabatic models with condensation were proposed [10-11]. In the presence of a gas, only either very low or high background pressure was used in most of the models for simplicity. Shock waves were shown to be produced during the plume expansion in a high-pressured background gas [3]. In this case, a system of Navier-Stocks equations well describes the first 1-2 $\mu$ s of the plasma plume expansion. It should be noted that such models are invalid at the later stages. To solve this issue, hydrodynamic calculations were switched to the direct Monte Carlo simulations where no such hypothesis is used at 1-2 $\mu$ s after the laser pulse [11,12]. Recently, such approaches as molecular dynamics (MD), hydrodynamics (HD), and combinations with the direct simulation 
Monte Carlo method (DSMC) were proposed for picosecond and femtosecond laser interactions [13-14]. The initial stage of laser ablation process can be examined by using either hydrodynamic models or atomistic simulation. On one hand, the main advantage of numerical hydrodynamics is in the calculation rapidity and in the possibility to reach rather larger scales $[10,13]$. Atomistic simulations, on the other hand, are not based on equilibrium assumptions and can more easily provide size distributions of nanoparticles. In particular, two-temperature molecular dynamics simulations (TTM-MD) were performed for femtosecond laser ablation of metals $[14,15]$.

In the presence of a sufficiently high-pressured background environment, such as atmospheric pressured gas or a liquid, diffusion-driven nucleation and aggregation processes start playing an important role (Figure 1) at longer delays [16].

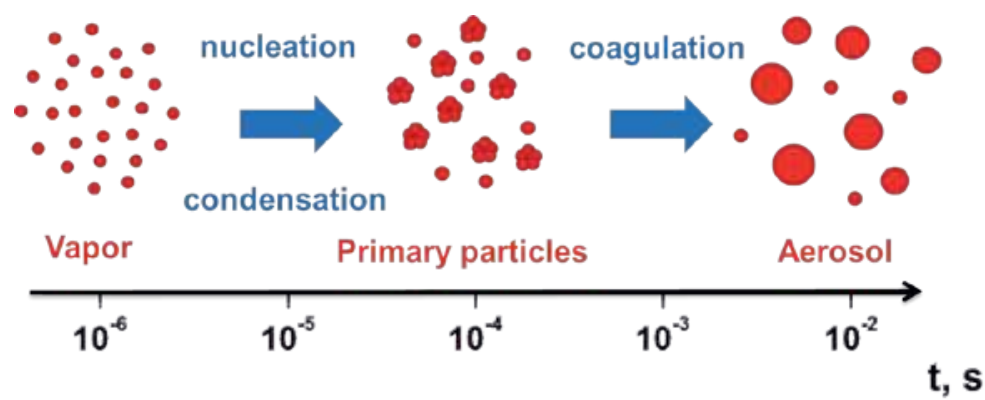

Figure 1. Nanoparticle formation and growth schematics.

However, despite a growing interest in LA, some of its basic mechanisms remain not enough understood. The challenge is that ablation processes strongly depend on the ensemble of such parameters as temporal pulse width and shape, on laser wavelength, on the size of the laser spot, laser intensity, repetition rate, as well on the target material and background conditions. [17]

In spark discharges (SD), a typical set-up consists of two electrodes connected to a charged capacitance [16]. When high enough voltage $V_{0}$ is applied, a so-called streamer is formed first. Once it reaches the opposite electrode, plasma breakdown takes place, followed by the streamer transition to an expanding plasma column. In this column, Joule heating of both plasma and electrodes take place. In addition, electrodes are bombarded by energetic ions that induce sputtering, which can be considered to be similar to laser ablation. If background gas is present, rapid thermalization of the sputtered material leads to primary nanoparticle formation that can then grow by collisions and form larger particles or aggregates.

Numerical modeling of spark discharge consists of several steps with rather different time scales [16]: (i) streamer formation and propagation between electrodes; (ii) streamer-to-spark transition; (iii) gas heating and cylindrical expansion, (iv) electrode evaporation and erosion; (v) nanoparticles formation. Nanoparticle formation, here as in the case of laser ablation in the presence of a gas or a liquid, includes nucleation and collisional growth (Figure 1). 
This work is aimed at the better understanding of the mechanisms involved in nanoparticle formation by laser ablation and by spark discharge. First, laser ablation is considered by using both atomistic and hydrodynamic numerical methods. In particular, mechanisms of nanoparticle formation and the corresponding conditions are analyzed. Then, attention is focused on the role of the background environment and its role in nanoparticle formation. These results are used to explain several recent experimental results.

Second, spark discharge is investigated. Plasma properties and conditions required for nanoparticle formation are examined. Finally, we compare laser ablation and spark discharge as promising methods of nanoparticle formation.

\section{Laser ablation}

To examine ultra-short, laser-ablated plume dynamics and nanoparticle evolution under realistic experimental conditions and to account for the fact that the ablated plume contains several components, DSMC calculations of the plume dynamics are first performed in the presence of an inert background gas (Ar) with pressure $P=300 \mathrm{~Pa}$. The initial conditions are set based on the parameterization of the MD results obtained at a delay of 200 ps after the beginning of the laser pulse (100 fs, $800 \mathrm{~nm}$ ) [16].

Figure 2 shows separately the density of atoms and clusters for two different delays after the laser pulse. Here, larger clusters were initially at the back of the plume. The obtained results demonstrate that plume front starts experiencing a pronounced deceleration and practically stops at both plume- and gas-dependent delay (here, $\sim 10 \mu \mathrm{s})$. Theoretically, the initial expansion stage is described by a so-called blast-wave (or, shock-wave) model when shock waves are degenerated.

The corresponding nanoparticle size distributions are presented in Figure 3. One can see that after a sufficient delay, a peaked distribution appears instead of a decreasing function. This effect can be explained by collisional growth that is described by the general rate equation having typically log-normal solutions. The amount of sufficiently large nanoparticles formed at such short delays is rather small and cannot explain the finally observed size distributions.

Longer stage includes plume mixing with the background followed by the rapid thermalization and a much more enhanced particle formation. Then, plume species are thermalized and a diffusion-driven regime enters into play.

\section{Spark discharge}

In our model developed for spark discharge (SD), the following stages are considered: (i) streamer formation and propagation between electrodes; (ii) streamer-to-spark transition; (iii) gas heating and cylindrical expansion; (iv) electrode evaporation and erosion; (v) nanoparticles formation [16]. 


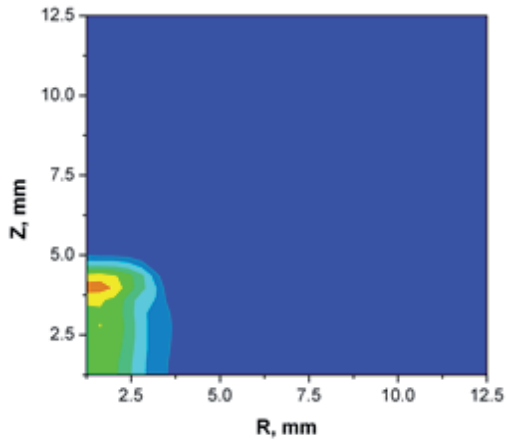

(a)

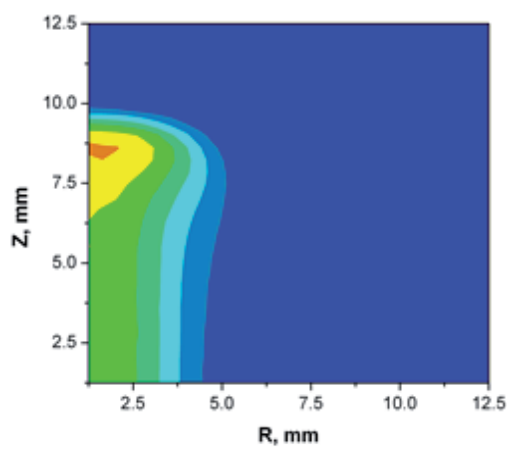

(c)

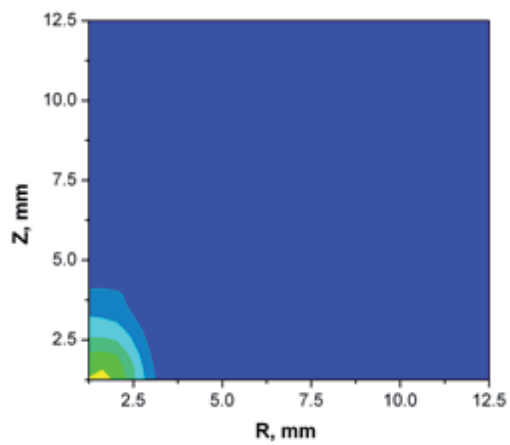

(b)

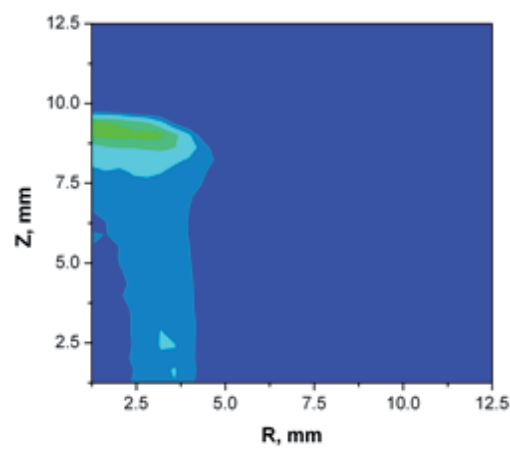

(d)

Figure 2. Calculated plume dynamics for $\mathrm{Ni}$ expansion in Ar gas at $300 \mathrm{~Pa}$, (a) density snapshot for atoms att $=0.55 \mu \mathrm{s}$, (b) the same for clusters at $t=0.55 \mu \mathrm{s}$; (c) the same for atoms at $t=10 \mu \mathrm{s}$, (d) the same for clusters at $t=10 \mu \mathrm{s}$.

Streamer formation is described numerically by using a system of drift-diffusion equations together with Poisson equation for electric potential with a particularly chosen set of boundary conditions. When streamer reaches the opposite electrode, electron emission increases dramatically, so that the streamer is transformed in a conductive plasma column. The oscillations of the electric charge $Q$ in the corresponding circuit with the total resistance $R_{\Sigma}$ is described by the Kirchhoff's voltage law.

The oscillating behavior of the discharge is presented in Figure 4, defining the properties of the following plasma column. According to this solution, both electrodes play a role at different delays leading to both evaporation and erosion of the electrodes. When polarity switches, a crater is formed at the surface of one of the electrodes due to both evaporation and erosion.

The erosion flux $j_{\text {surf }}^{\Sigma}$ is formed due to two main processes: (i) thermal evaporation caused by Joule heating, and (ii) sputtering due to ion bombardment. Similarly to nanosecond laser ablation, evaporation flux $j_{\text {surf }}^{T}$ is described by the Hertz-Knudsen equation, where surface temperature is calculated as follows [16] 


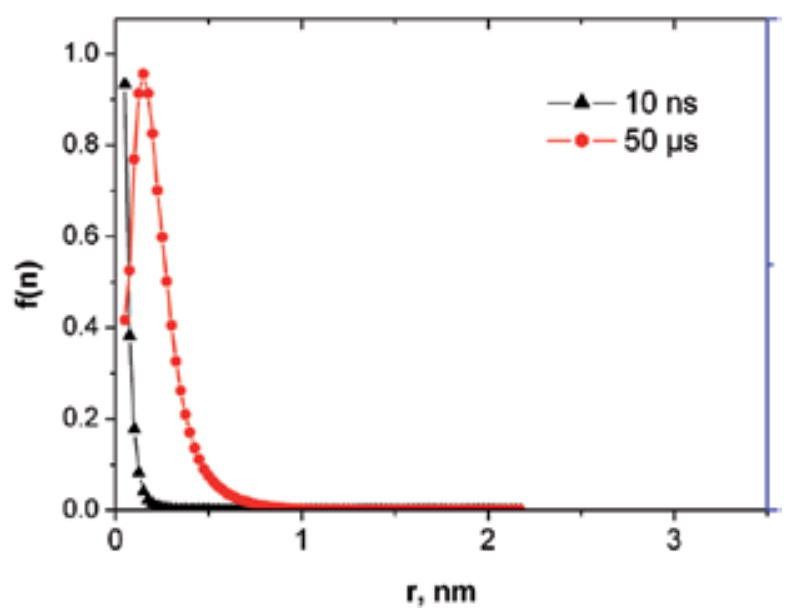

Figure 3. Size distributions calculated by using MD-DSMC model in the presence of $300 \mathrm{~Pa}$ of Ar at different time delays.

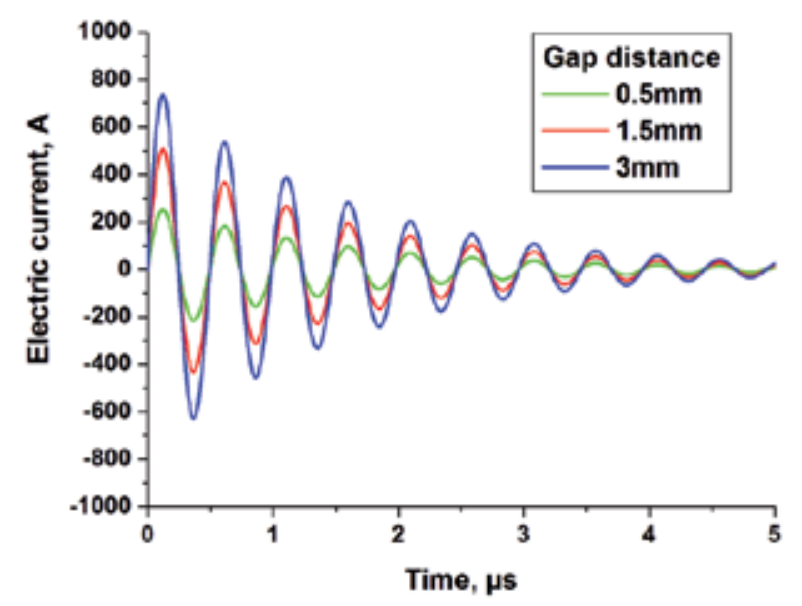

Figure 4. Typical time evolutions of voltage and electric current during a "single" spark event obtained in $\mathrm{N}_{2}$ for $C=8$ $\mathrm{nF} ; L=0.77 \mu \mathrm{H} ; R_{\Sigma}=1 \Omega$.

$$
\begin{aligned}
& c \rho_{s} \frac{\partial T_{s}}{\partial t}=\frac{\vec{j}_{e}^{2}}{\sigma_{s}}+\rho_{s} \vec{\nabla} \cdot\left(\chi_{s} \vec{\nabla}\left(k T_{s}\right)\right), \\
& \left.\frac{\partial T_{s}}{\partial z}\right|_{z=0}=0,\left.T_{s}\right|_{z=L}=300 K,\left.\frac{\partial T_{s}}{\partial r}\right|_{r=0}=0,\left.T_{s}\right|_{r=r_{\max }}=300 \mathrm{~K}, \\
& j_{\text {surf }}^{T}=\frac{\alpha\left(P_{\text {eq }}-P_{\text {surf }}\right)}{\sqrt{2 \pi m k T_{s}}}
\end{aligned}
$$


where $s$ corresponds to the cathode material (solid), $c$ is the specific heat of cathode material, $\rho_{s}$ is the density, $T_{s}$ is the temperature, $\sigma_{s}$ is the electric conductivity, $\chi_{s}$ is the thermal diffusivity coefficient, $k$ is the Boltzmann constant, $\alpha$ is the sticking coefficient for vapor molecules onto the surface, $P_{e q}$ is the equilibrium vapor pressure, and $P_{\text {surf }}$ is the hydrostatic pressure of gas applied on the surface.

The sputtering yield $Y Y$ and flux $j_{\text {surf }}^{\text {sput }}$ is given by

$$
\begin{gathered}
Y=\frac{3 \alpha_{\text {surf }}}{4 \pi^{2}} \frac{4 m M}{(m+M)^{2}} \frac{E_{+}}{U_{\text {surf }}}, \\
j_{\text {surf }}^{\text {sput }}=j_{+} Y, j_{\text {surf }}^{\Sigma}=j_{\text {surf }}^{T}+j_{\text {surf }}^{\text {sput }}
\end{gathered}
$$

where $\alpha_{\text {surf }}$ is a factor function of $m / M, m$ and $M$ are the atomic weights of cathode material and incident particles, respectively, $E_{+}$is the bombarding energy, $U_{\text {surf }}$ is the surface-binding energy, and $j_{+}$is the flux density of bombarding ions. The solution of Eqs (1-2) yields cathode erosion flow as a function of time. At the same time, plasma column also gains energy by Joule heating.

Once the amount of the ejected material is calculated, plasma dynamics is modeled by using Navier-Stokes equations [17]. The corresponding equations contain, in particular, Joule heating term, which determines plasma heating occurring mostly near its axis, where plasma pressure initially arises to several atmospheres. Figure 5 shows typical axial temperature evolution. After a delay of $0.5 \mu \mathrm{s}$, which corresponds to plasma expansion, pressure drops back to the values around the atmospheric pressure. Plasma temperature remains high during all the discharging process and drops below electrode boiling point only after $0.1-0.5 \mathrm{~ms}$. During cooling, gas density increases. Lager density and smaller temperature provide conditions required for nanoparticle formation.

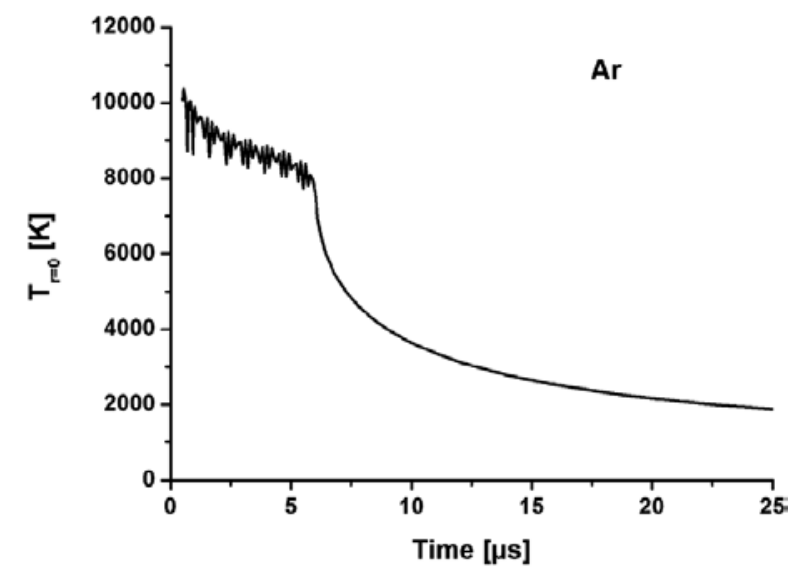

Figure 5. Typical time evolutions of the plasma temperature obtained for Ar for gap of $1 \mathrm{~mm}, R=1 \Omega, C=8 \mathrm{nF}$, and $L=$ $0.77 \mu \mathrm{H}$. 


\section{Spark discharge vs nanosecond laser ablation}

Typically, laser energy absorption leads to the target heating and thermal evaporation in the nanosecond laser ablation of metals. Plasma expansion stage is much longer than the evaporation stage, on the order of $\sim 10$ laser pulse temporal widths ( $\sim 300 \mathrm{~ns})$. Here, plasma electrons gain energy from laser radiation by inverse Bremsstrahlung effect, so that ionization takes place. Then, a so-called blast wave model describes hemispherical expansion as follows [16]:

$$
\begin{gathered}
R_{v}={ }^{\circ} \xi \circ\left(\frac{2 E_{0}}{\rho_{v}}\right)^{1 / 5} t^{2 / 5}, \\
\xi=\left\{\frac{75(\gamma-1)(\gamma+1)^{2}}{16^{\circ} \pi^{\circ}(3 \gamma-1)}\right\}^{1 / 5}, \\
T_{v}=T_{0}\left(\frac{R_{0}}{R_{v}}\right)^{3(\gamma-1)},
\end{gathered}
$$

where $R_{0}$ is the shock wave position, $\xi$ is a constant depending on the plume specific heat capacity, $E_{0}$ is the initial internal energy of vapor plume, $T_{0}$ is the initial temperature, and $\gamma$ is the adiabatic coefficient. This model is valid, if the external shock wave is present and if the mass of the background gas surrounding the shock wave is larger than the mass of the ablated material. During the expansion, both plume temperature and density rapidly decay. As a result, the condition of supersaturation is realized at a certain delay leading to the nanoparticle formation.

Time evolutions of plasma properties are obtained in [16]. For spark discharge, when gas density decreases, plasma resistivity drops down, thus preventing further energy absorption from the electric current. During the expansion, plasma cools down and gas goes back to the axis. These processes are repeated when the energy absorption is high enough for efficient expansion.

In the case of nanosecond laser ablation, laser energy absorption by the plume takes place. As a result, the ejected plasma is hot, but the energy input is limited in time by laser pulse duration. After the end of the laser pulse, the ablated plume expands and cools down. The critical nuclei sizes are calculated as a function of time (Figure 6).

The obtained results clearly demonstrate that, despite rather different plasma sources, the behavior of particle formation in spark discharge appears to be very similar to the one in laser ablation. The difference in time delays corresponds to the transition of the system to the supersaturated state. Primary NPs formed by nucleation can then evolve due to evaporation, condensation, and/or growth. 


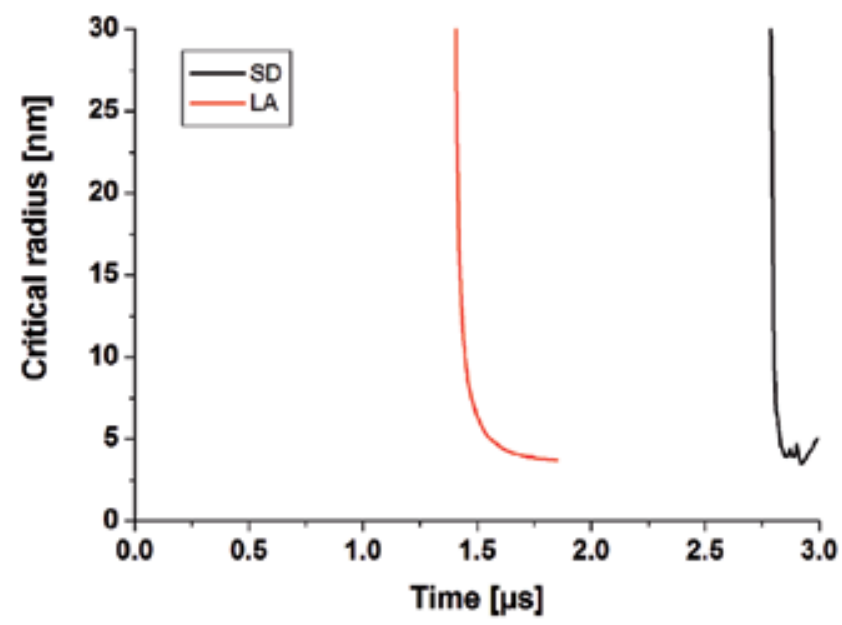

Figure 6. Typical time evolution of primary critical clusters size formed by spark discharge and by laser ablation.

Diffusion-driven nucleation leads to the formation of nucleus, whose size is controlled by the free energy as follows [18]:

$$
\Delta G(n, c)=-n k T \ln \left(c / c_{e q}\right)+4 \pi a^{2} n^{2 / 3} \sigma
$$

where $k$ is the Boltzmann constant; $T$ is the temperature in Kelvins; $a$ is the effective radius; $c_{e q}$ is the equilibrium concentration of atoms/monomers; $n$ is the number of atoms/monomers in the nuclei; and $\sigma$ is the effective surface tension. The peak of the nucleation barrier corresponds to the critical cluster size

$$
n_{c}=\left[\frac{8 \pi a^{2} \sigma}{3 k T \ln \left(c / c_{e q}\right)}\right]^{3} .
$$

The production rate of the supercritical nuclei is given by

$$
v(t)=K_{c} c^{2} \exp \left[\frac{-\Delta G\left(n_{c}, c\right)}{k T}\right] .
$$

As a result, narrow size distributions are produced. The formed particles can collide and aggregate. These collisional processes are described by simplified Smoluchowski equations [18]. Laser-induced fragmentation is neglected here.

Several calculations are performed to study time-evolution of the size distribution for multiple pulse cases. Because saturation is rather high, monomer radius here is as small as $a=1.59^{-10}$ and the radius of critical nuclei is recalculated at all the time-steps. 


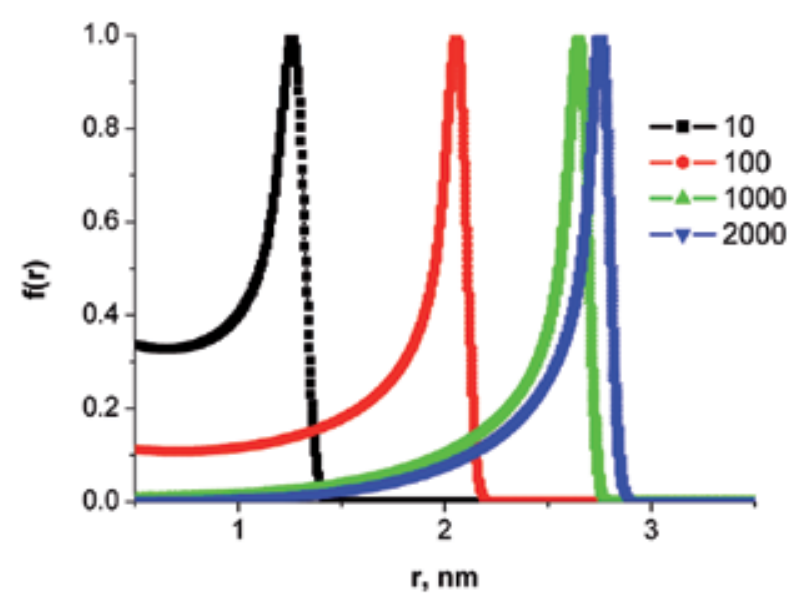

Figure 7. Calculated size distribution obtained for 10, 100, 1000, and 2000 pulses. Here, laser frequency is $1 \mathrm{kHz}$, gold solution in water is considered with $a=1.59^{-10} \mathrm{~m}$.

The obtained results (Figure 7) show that when several pulses are applied, these small nuclei grow for pulse number up to $10^{3}$ because tiny particles grow easier than larger ones. Here, collisions with atoms dominate in the growth process. The obtained results show that further increase in the number of pulses affects particle size distribution only slightly. This effect takes place if laser frequency is not too high, so that the ablated material has time to diffuse and concentration does not grow near the target. As a result, the mean radius can remain rather small (in the nanometer range, smaller than $\sim 3 \mathrm{~nm}$ here).

The criterion of the catastrophic nucleation due to thermalization can be derived based on the inequality $n_{c} \leq 1$. This means that

$$
N_{c}=\left[8 \pi a^{2} \sigma / 3 k_{B} T \ln \left(c / c_{e q}\right)\right]^{3} \sim 1
$$

Typically, at the beginning of the diffusional expansion stage, the condition $\ln (S)=\ln \left(c / c_{e q}\right)=8 \pi a^{2} \sigma / 3 k T \geq 1$ is valid, so that this mechanism prevails in the nanoparticle formation. Finally, at the last stage, ripening or sintering of the created particles eventually inters into play if the background density is sufficiently high. For instance, this process occurs in liquids, in particular, in the absence of the surface passivation by additional chemicals.

\section{Conclusions}

In this chapter, recent advancements in the modeling of laser ablation and spark discharges are summarized. In addition, we have compared processes leading to nanoparticle formation in laser ablation and in spark discharges. In particular, a comparison of the influence of plasma properties on nanoparticle formation has been performed. 
First, mechanisms of nanoparticle generation have been investigated for femtosecond laser interactions in the presence of a background environment. The obtained calculation results have demonstrated the long time-evolution of plume species involves nucleation and growth determining the final size distribution that tends to be a limited one with the increase in laser intensity. The obtained results explain several experimental observations including both longer time dynamics of nanoparticles and size distributions. Then, conditions are formulated for catastrophic nucleation to become the main mechanism of nanoparticle formation as a result of thermalization and collisions among the species in the presence of a background environment. The produced nanoparticles can be collected, form a colloid, or can be deposited at a substrate forming nanostructures. Therefore, the presented study is of interest for many applications where both metallic nanoparticles and nanostructures are used in nanophotonics, plasmonics, medicine, biological sensing, textile industry, and other promising fields.

Furthermore, cylindrical plasma column expansion has been shown to govern primary nanoparticle formation in spark discharge, whereas hemispherical shock describes quite well this process for nanosecond laser ablation at atmospheric pressure. In addition, spark discharge leads to oscillations in plasma properties, whereas monotonous behavior is a characteristic for nanosecond laser ablation.

Despite the difference in plasma density and time evolutions calculated for both phenomena, after well-defined delays, similar critical nuclei have been shown to be formed by both techniques. This result can be attributed to the fact that whereas larger evaporation rate is typical for nanosecond laser ablation, a mixture of vapor and background gas determines the supersaturation in the case of spark.

\section{Acknowledgements}

The research leading to these results received funding from the European Union Seventh Framework Programme (FP7/2007-2013) under Grant Agreement n 280765 (BUONAPARTE). Computer support is provided by CINES of France under the project C2015085015. Partial support from PALSE ERTIGO project (Lyon-Saint-Etienne) and PICS 6106 of CNRS, France, is also gratefully acknowledged.

\section{Author details}

Andrey Voloshko and Tatiana E. Itina*

*Address all correspondence to: tatiana.itina@univ-st-etienne.fr

Hubert Curien Laboratory, UMR 5516 CNRS/Lyon University, Saint-Etienne, France 


\section{References}

[1] T. Makimura, Y. Kunii, and K. Murakami, Jpn. J. Appl. Phys. Part 1, 35, 4780 (1996).

[2] C. Vivien, J. Hermann, A. Perrone, C. Boulmer-Leborgne, A. Luches: J. Phys. D: Appl. Phys. 31 (1998) 1263.

[3] L. V. Zhigilei, B. J. Garrison, J. Appl. Phys. 88, (3), 1281, (2000)

[4] S. Besner et al., Appl. Phys. A 93, 955-959 (2008)

[5] M. E. Povarnitsyn et al., Appl. Surf. Sci. 258(23) , 9480-9483, (2012)

[6] S. Amoruso, R. Bruzzese, M. Vitiello, N. N. Nedialkov, and P. A. Atanasov, J. Appl. Phys. 98, 044907 (2005).

[7] O. Albert, S. Roger, Y. Glinec, J. C. Loulergue, J. Etchepare, C. Boulmer-Leborgne, J. Perriere, E. Millon, Appl. Phys. A: Mater Sci. Process. 76, 319 (2003).

[8] S.I. Anisimov, D. Bäuerly and B.S. Luk'yanchuk, Phys. Rev. B 48, (1993) 12076.

[9] H.C. Le, D.E. Zeitoun, J.D. Parisse, M. Sentis, W. Marine: Phys. Rev. E. 62(3) (2000) 4152.

[10] S. I. Anisimov, Zh. Eksp. Teor. Fiz. 54, 339 (1968) [Sov. Phys. JETP, 27, 182 (1968)].

[11] T.E. Itina, J. Hermann, P. Delaporte, M. Sentis, Phys. Rev. E, 66, 066406 (2002).

[12] G. A. Bird, Molecular Gas Dynamics and the Direct Simulation of Gas Flows (Clarendon, Oxford, 1994).

[13] T. E. Itina, K. Gouriet, L. V. Zhigilei, S. Noel, J. Hermann, and M. Sentis, Appl. Surf. Sci. , 253, 7656-7661 (2007).

[14] D. S. Ivanov, and L.V. Zhigilei, Phys. Rev. B, 68, 064114 (2003).

[15] M.E. Povarnitsyn and T.E. Itina, Appl. Phys. A, DOI: 10.1007/s00339-014-8319-1.

[16] A. Voloshko, J-Ph.Colombier, T. E. Itina,. Appl. Surf. Sci.336, 143-149 (2014).

[17] M. Povarnitsyn, V. Fokin, P. Levashov, T. E. Itina, Phys Rev B, in press (2015).

[18] J. Park, V. Privman, E. Matijevic, J. Chem. Phys. B 105, 11603-11635 (2001). 
Chapter 2

\title{
Fundamentals of Medicinal Application of Titanium Dioxide Nanoparticles
}

\author{
Kazutaka Hirakawa \\ Additional information is available at the end of the chapter \\ http://dx.doi.org/10.5772/61302
}

\begin{abstract}
Titanium dioxide $\left(\mathrm{TiO}_{2}\right)$, a semiconducting material, is a well-known photocatalyst. A nanoparticle (NP) of $\mathrm{TiO}_{2}$ also demonstrates photocatalytic activity. Photo-irradiated $\mathrm{TiO}_{2}$ NPs induce the formation of various reactive species, leading to the damage of biomacromolecules. These reactive species include $\mathrm{h}^{+}$, either free or trapped hydroxyl radicals $(\mathrm{OH})$, superoxide $\left(\mathrm{O}_{2}^{-}\right)$, hydrogen peroxide $\left(\mathrm{H}_{2} \mathrm{O}_{2}\right)$, and singlet oxygen $\left({ }^{1} \mathrm{O}_{2}\right)$, among others. $\mathrm{TiO}_{2} \mathrm{NPs}$ photocatalyze DNA oxidation. A relatively small concentration of $\mathrm{TiO}_{2} \mathrm{NPs}$ frequently induces tandem base oxidation at guanine and thymine residues through $\mathrm{H}_{2} \mathrm{O}_{2}$ generation in the presence of a copper(II) ion. A copper-peroxo complex is considered to be an important reactive species responsible for this DNA damage. In the case of a high concentration of $\mathrm{TiO}_{2} \mathrm{NPs}, \mathrm{OH}$ contributes to DNA damage without sequence specificity. In the presence of sugars, $\mathrm{TiO}_{2} \mathrm{NPs}$ indirectly induce DNA damage by the secondary $\mathrm{H}_{2} \mathrm{O}_{2}$, which is produced through an autoxidation process of the product of sugar photooxidized by $\mathrm{TiO}_{2} \mathrm{NPs}$. Furthermore, ${ }^{1} \mathrm{O}_{2}$ is also produced by photo-irradiated $\mathrm{TiO}_{2} \mathrm{NPs}$. The photocatalyzed formation of ${ }^{1} \mathrm{O}_{2}$ might contribute to the oxidation of the membrane protein. These mechanisms of photocatalytic formation of the reactive species may be involved in the photocytotoxicity of $\mathrm{TiO}_{2} \mathrm{NPs}$.
\end{abstract}

Keywords: Titanium dioxide, Photocatalyst, Reactive oxygen species, Photomedicine, DNA damage

\section{Introduction}

Titanium dioxide $\left(\mathrm{TiO}_{2}\right)$, a semiconducting material, is a well-known photocatalyst [1-5]. Examples of previous studies about $\mathrm{TiO}_{2}$ photocatalytic reactions are listed in Table 1. A nanoparticle (NP) of $\mathrm{TiO}_{2}$ also demonstrates photocatalytic activity. Important applications of $\mathrm{TiO}_{2}$ photocatalysts are bactericidal activity [2-4, 6-12] and degradation of chemical pollutants 
[2-4, 13]. Related physical and chemical mechanisms have been also investigated [2-5, 14-17]. Photo-irradiated $\mathrm{TiO}_{2}$ NPs induce the formation of various reactive species, leading to the damage of biomacromolecules. These reactive species include hole $\left(\mathrm{h}^{+}\right)$, either free or trapped hydroxyl radicals $(\mathrm{OH})$, superoxide $\left(\mathrm{O}_{2}{ }^{-}\right)$, hydrogen peroxide $\left(\mathrm{H}_{2} \mathrm{O}_{2}\right)$, and singlet oxygen $\left({ }^{1} \mathrm{O}_{2}\right)$, among others. Hydroxyl radicals, $\mathrm{O}_{2}{ }^{-\cdot}, \mathrm{H}_{2} \mathrm{O}_{2}$, and ${ }^{1} \mathrm{O}_{2}$ are the typical reactive oxygen species. $\mathrm{TiO}_{2}$ photocatalysts have been found to kill cancer cells [18-21] other than bacteria, viruses, and algae under ultraviolet-A (wavelength: 315-400 nm) illumination [2-4, 6-12]. Therefore, one of the potential applications of the $\mathrm{TiO}_{2} \mathrm{NP}$ photocatalyst is photodynamic therapy (PDT), which is a promising treatment for cancer and some nonmalignant conditions [22-25]. In general, the mechanism of cytotoxicity by the photocatalysis of $\mathrm{TiO}_{2}$ is based on cell membrane damage via the generation of the aforementioned reactive oxygen species. Furthermore, DNA damage in human cells [26-28], mouse lymphoma cells [29], and phage [30] by the $\mathrm{TiO}_{2} \mathrm{NP}$ photocatalyst has been reported. Direct damage of isolated DNA by $\mathrm{TiO}_{2}$ photocatalyst in vitro has been also studied [31, 32]. However, the DNA-damaging mechanism in vivo is not well-understood, because the incorporation of the $\mathrm{TiO}_{2} \mathrm{NPs}$ in the nucleus is difficult [18]. A previous study has shown that $\mathrm{H}_{2} \mathrm{O}_{2}$ formation through the photocatalytic reaction of $\mathrm{TiO}_{2}$ may contribute to cellular DNA damage $[2,19]$. Hydrogen peroxide, a longlived reactive oxygen species, can penetrate the nucleus membrane and induce oxidation of the nucleobase and strand breakage through enhancement by metal ions. Iron or copper ions can enhance the activity of $\mathrm{H}_{2} \mathrm{O}_{2}$ to produce $\mathrm{OH}^{-}$[33] and copper-peroxide [34-36]. Furthermore, secondary generation of reactive oxygen species may contribute to cytotoxicity of $\mathrm{TiO}_{2}$ NPs photocatalyst [37]. Since the photocatalytic reaction will occur in a complex biological environment, an interaction between $\mathrm{TiO}_{2}$ NPs and biomaterials should participate in the generation of reactive species to induce DNA damage. For example, sugars photocatalyzed by $\mathrm{TiO}_{2}$ NPs may secondarily generate $\mathrm{H}_{2} \mathrm{O}_{2}$ through their further oxidation process by molecular oxygen in the presence of a metal ion [37]. In addition, the possibility of ${ }^{1} \mathrm{O}_{2}$-mediated cytotoxicity by $\mathrm{TiO}_{2} \mathrm{NPs}$ has been proposed [38]. Actually, ${ }^{1} \mathrm{O}_{2}$ generation by photo-irradiated $\mathrm{TiO}_{2}$ NPs was demonstrated by a near-infrared spectroscopy $[39,40]$. In this chapter, recent studies about photocatalytic biomacromolecule damage by $\mathrm{TiO}_{2} \mathrm{NPs}_{\mathrm{s}}$ are briefly reviewed.

\begin{tabular}{ll}
\hline Target & References \\
\hline Reviews & {$[2],[3],[4],[5]$} \\
\hline Physical experiment & {$[1],[16],[17],[39],[40]$} \\
\hline Chemical compounds & {$[13],[14],[15]$} \\
\hline Nucleic acids & {$[31],[32]$} \\
\hline Microorganism & {$[6],[7],[8],[9],[10],[11],[12],[30]$} \\
\hline Cancer cell & {$[18],[19],[20],[21]$} \\
\hline Mouse lymphoma cells & {$[29]$} \\
\hline Cancer treatment of mouse & {$[20]$} \\
\hline
\end{tabular}

Table 1. Summary of the examples of previous studies on $\mathrm{TiO}_{2}$ photocatalyst 


\subsection{General mechanism of photocatalysis of $\mathrm{TiO}_{2} \mathrm{NP}$}

The crystal of $\mathrm{TiO}_{2}$ is a semiconductor, and the two crystalline forms, anatase and rutile, are well-known (Figure 1) [2-5]. The values of the band gap energy of these crystal forms are 3.26 and $3.06 \mathrm{eV}$ for anatase and rutile, respectively. Photo-irradiation to a $\mathrm{TiO}_{2}$ crystal induces the formation of an excited electron ( $\left.\mathrm{e}^{-}\right)$in the conduction band and an $\mathrm{h}^{+}$in the valence band, leading to the redox reaction of materials adsorbing on the $\mathrm{TiO}_{2}$ surface, including water and/or molecular oxygen. The photocatalytic reactions with its surface water and oxygen cause the formation of various reactive oxygen species such as free or trapped $\mathrm{OH}^{\cdot}, \mathrm{O}_{2}{ }^{--}, \mathrm{H}_{2} \mathrm{O}_{2}$, and ${ }^{1} \mathrm{O}_{2}[2-5]$.

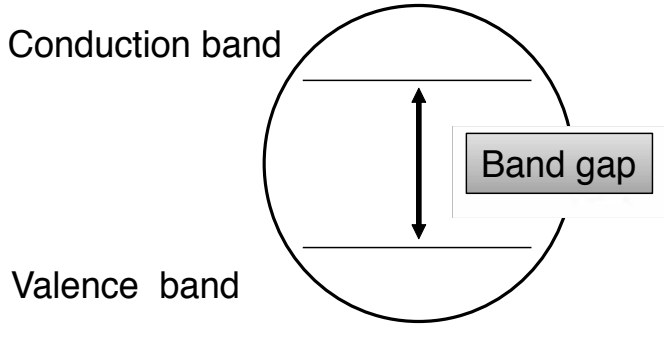

Crystal form and band gap energy (wavelength of the corresponding photon)

Anatase $3.26 \mathrm{eV}(380 \mathrm{~nm})$

Rutile $\quad 3.06 \mathrm{eV}(405 \mathrm{~nm})$

Figure 1. Band gap energy of the two crystalline forms of $\mathrm{TiO}_{2}$.

An excited electron in the conductive band reduces the oxygen molecule adsorbed on the surface of $\mathrm{TiO}_{2} \mathrm{NPs}$, leading to the generation of various reactive oxygen species as follows (Figure 2):

$$
\begin{gathered}
\mathrm{O}_{2}+\mathrm{e}^{-} \rightarrow \mathrm{O}_{2}^{--} \\
2 \mathrm{O}_{2}^{--}+2 \mathrm{H}^{+} \rightarrow \mathrm{H}_{2} \mathrm{O}_{2}+\mathrm{O}_{2} \\
\mathrm{H}_{2} \mathrm{O}_{2} \rightarrow 2 \mathrm{OH}
\end{gathered}
$$

The reaction (3) is mediated by ultraviolet radiation ( $\mathrm{h} v$, wavelength $<355 \mathrm{~nm}$ ), metal ions $\left(\mathrm{M}^{\mathrm{n}+}\right)$ such as $\mathrm{Fe}^{2+}$, and $\mathrm{O}_{2}{ }^{-\cdots}$, as follows [33]:

$$
\begin{gathered}
\mathrm{H}_{2} \mathrm{O}_{2}+\mathrm{h} v \rightarrow 2 \mathrm{OH}^{\cdot} \\
\mathrm{H}_{2} \mathrm{O}_{2}+\mathrm{M}^{\mathrm{n}+} \rightarrow \mathrm{OH}^{+}+\mathrm{OH}^{-}+\mathrm{M}^{(\mathrm{n}+1)+}
\end{gathered}
$$




$$
\mathrm{H}_{2} \mathrm{O}_{2}+\mathrm{O}_{2}^{--} \rightarrow \mathrm{OH}^{-}+\mathrm{OH}^{-}+\mathrm{O}_{2}
$$

On the other hand, the formed $\mathrm{h}^{+}$in the valence band can oxidize water to form $\mathrm{OH}^{-}$as follows:

$$
\mathrm{H}_{2} \mathrm{O}+\mathrm{h}^{+} \rightarrow \mathrm{OH}+\mathrm{H}^{+}
$$

Furthermore, $\mathrm{OH}$ can produce $\mathrm{H}_{2} \mathrm{O}_{2}$ as follows:

$$
2 \mathrm{OH}^{\cdot} \rightarrow \mathrm{H}_{2} \mathrm{O}_{2}
$$

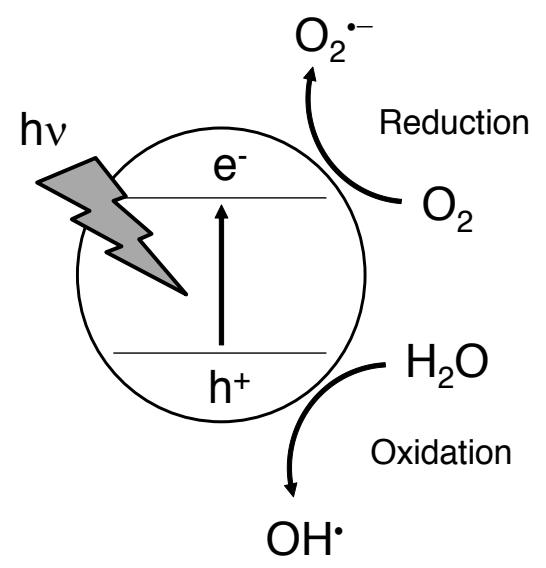

Figure 2. Photocatalytic reactive oxygen formation by $\mathrm{TiO}_{2}$.

A photo-irradiated $\mathrm{TiO}_{2} \mathrm{NP}$ can induce ${ }^{1} \mathrm{O}_{2}$ formation. The formation of ${ }^{1} \mathrm{O}_{2}$ is considered to be an important mechanism of PDT. This reaction can be explained by the following process: $\mathrm{O}_{2}{ }^{-}$- formed by $\mathrm{TiO}_{2}$ photocatalysis is reoxidized by the $\mathrm{h}^{+}$of $\mathrm{TiO}_{2}$ on the particle surface to form ${ }^{1} \mathrm{O}_{2}$ as follows (Figure 3):

$$
\begin{gathered}
\mathrm{O}_{2}{ }^{--}+\mathrm{h}^{+} \rightarrow{ }^{1} \mathrm{O}_{2}\left({ }^{1} \Sigma_{\mathrm{g}}{ }^{+} \text {or }{ }^{1} \Delta_{\mathrm{g}}\right)\left(\text { or }{ }^{3} \mathrm{O}_{2}\right) \\
{ }^{1} \mathrm{O}_{2}\left({ }^{1} \Sigma_{\mathrm{g}}{ }^{+}\right) \rightarrow{ }^{1} \mathrm{O}_{2}\left({ }^{1} \Delta_{\mathrm{g}}\right)
\end{gathered}
$$

These reactive oxygen species should contribute to the mechanism of the phototoxicity induced by $\mathrm{TiO}_{2} \mathrm{NPs}$. 


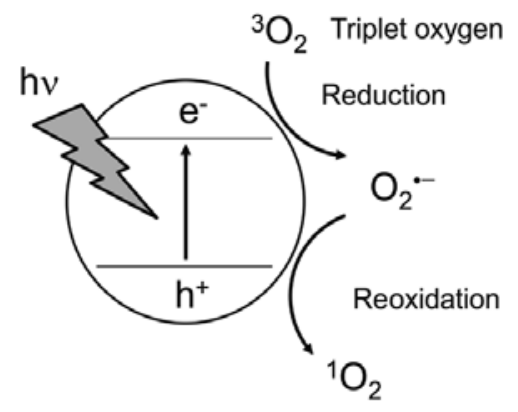

Singlet oxygen

Figure 3. Photocatalytic ${ }^{1} \mathrm{O}_{2}$ generation by $\mathrm{TiO}_{2}$

\subsection{Sterilization effect by $\mathrm{TiO}_{2}$}

One of the most important medicinal applications of $\mathrm{TiO}_{2} \mathrm{NPs}$ is to kill bacteria on its surfaces. $\mathrm{TiO}_{2}$ NPs under ultraviolet radiation produce a strong oxidative effect through the formation of above-mentioned reactive oxygen species and can be used as a photocatalytic disinfectant without other chemical reagents. Fujishima and coworkers reported the bactericidal effect of $\mathrm{TiO}_{2}$ photocatalysts against Escherichia coli under ultraviolet-A irradiation using black light [6]. This is the first report of the application of phototoxicity of $\mathrm{TiO}_{2} \mathrm{NPs}$. It was speculated that $\mathrm{H}_{2} \mathrm{O}_{2}$ was a reactive species responsible for this phototoxic effect [7]. Relevantly, the photocatalytic effect of $\mathrm{TiO}_{2}$ against methicillin-resistant Staphylococcus aureus (MRSA) and Clostridium difficile in hospitals has been reported [10]. The bactericidal effect of $\mathrm{TiO}_{2} \mathrm{NPs}$ could be enhanced by metal doping [9]. Furthermore, visible-light-induced $\mathrm{TiO}_{2}$ photocatalysts were developed and utilized in antibacterial applications. For example, sulfur-doped $\mathrm{TiO}_{2}$ demonstrates the killing effect on Escherichia coli under white-light irradiation commonly used in hospitals [11].

\subsection{Photodynamic therapy}

Photodynamic therapy, which is a promising and less-invasive treatment for cancer, employs a photosensitizer and visible light to produce oxidative stress in cells and ablate cancerous tumors [22-25]. Photodynamic therapy is also used for treating some nonmalignant conditions that are generally characterized by the overgrowth of unwanted or abnormal cells. In general, porphyrins are used as photosensitizers under visible-light irradiation, since the human tissue has relatively high transparency for visible light, especially red light, and visible light has hardly any side effects. In the case of visible light PDT, ${ }^{1} \mathrm{O}_{2}$ is considered an important reactive species for PDT because ${ }^{1} \mathrm{O}_{2}$ can be easily generated by visible light [41-44]. Critical targets of the generated ${ }^{1} \mathrm{O}_{2}$ include mitochondria and enzyme proteins. Moreover, DNA is also an important target biomolecule of photosensitized reactions [45-49]. Relevantly, photocatalytic ${ }^{1} \mathrm{O}_{2}$ generation by $\mathrm{TiO}_{2}$ has been reported [38-40]. 
$\mathrm{TiO}_{2}$, a nontoxic material, is chemically stable, and demonstrates a phototoxic effect. Therefore, an application of $\mathrm{TiO}_{2}$ for PDT has been investigated [2]. The cytotoxicity of an illuminated $\mathrm{TiO}_{2}$ film electrode for HeLa cells [18,19] and T-24 human bladder cancer cells [21] has been reported. Animal experiments also demonstrated the antitumor effect of $\mathrm{TiO}_{2} \mathrm{NPs}$ [20]. This report showed an antineoplastic effect on skin cancer in mouse models.

\section{Photocatalytic DNA damage by $\mathrm{TiO}_{2} \mathrm{NPs}$}

Cellular DNA damage photocatalyzed by $\mathrm{TiO}_{2} \mathrm{NPs}$ was demonstrated by the experiment using cancer cells $[18,19,21]$. $\mathrm{TiO}_{2}$ NPs can be taken into the cancer cell [27]; however, incorporation into the cell nucleus is difficult [18]. Therefore, it is speculated that the indirect mechanism contributes to DNA damage induced by photo-irradiated $\mathrm{TiO}_{2} \mathrm{NPs}_{\text {. Hence, model experiments }}$ using isolated DNA were performed [31,32]. In this section, an example of photocatalytic DNA damage by $\mathrm{TiO}_{2} \mathrm{NPs}$ was introduced.

\subsection{Isolated DNA damage photocatalyzed by $\mathrm{TiO}_{2} \mathrm{NPs}_{\text {and }}$ its sequence specificity}

Photo-irradiated $\mathrm{TiO}_{2}$ NPs catalyze DNA damage in the presence of copper(II) ion [31]. Relevantly, copper-aided photosterilization of microbial cells on $\mathrm{TiO}_{2}$ was reported [8]. DNA damage by anatase NPs is more severe than that by rutile NPs. The DNA damage is enhanced by piperidine treatment, because photo-irradiated $\mathrm{TiO}_{2} \mathrm{NPs}$ cause not only DNA strand breakage but also base oxidation. In general, hot piperidine cleaves DNA strand at modified base. Photo-irradiated $\mathrm{TiO}_{2}$ NPs induce the formation of piperidine-labile products at the bolded site of 5'-TG, 5'-TG, and 5'-TC (Figure 4). Furthermore, $\mathrm{TiO}_{2} \mathrm{NPs}$ photocatalyze DNA strand cleavage at the bolded guanines of $5^{\prime}-\mathrm{TG}$ and $5^{\prime}-\mathrm{TC}$ in a DNA fragment treated with $E$ coli formamidopyrimidine-DNA glycosylase (Fpg protein), which can catalyze the excision of piperidine-resistant 8-oxo-7,8-dihydro-2'deoxyguanine (8-oxo-G) [50,51]. The formation of 8oxo-G was confirmed by an analysis with a high-performance liquid chromatography (Figure 5). In addition, Fpg protein can cleave the oxidized cytosine, such as 5-hydroxy cytosine [52]. These results suggest that photo-irradiated $\mathrm{TiO}_{2}$ NPs induce 8-oxo-G formation adjacent to piperidine-labile thymine lesions. Such double-base lesions should be generated from one radical hit that leads through a secondary reaction to a tandem base damage at pyrimidine and adjacent residues [53-56]. Actually, it has been reported that $\mathrm{H}_{2} \mathrm{O}_{2}$ induces tandem mutations in human cells via vicinal or cross-linked base modification in the presence of copper(II) ion [57]. Since repairing of cluster DNA damage in living cells is difficult [58], such clustered base damage, including double-base lesions, appears to play an important role in the phototoxicity of $\mathrm{TiO}_{2}$ NPs.

\subsection{Mechanism of DNA damage photocatalyzed by $\mathrm{TiO}_{2} \mathrm{NPs}$}

Catalase, a well-known scavenger of $\mathrm{H}_{2} \mathrm{O}_{2}$, and bathocuproines, a copper(I) ion chelator, inhibit DNA damage photocatalyzed by $\mathrm{TiO}_{2} \mathrm{NPs}$, whereas, typical $\mathrm{OH}$ ' scavenger cannot inhibit the DNA damage. These results suggest that $\mathrm{H}_{2} \mathrm{O}_{2}$ and copper(I) ion participate in DNA damage 


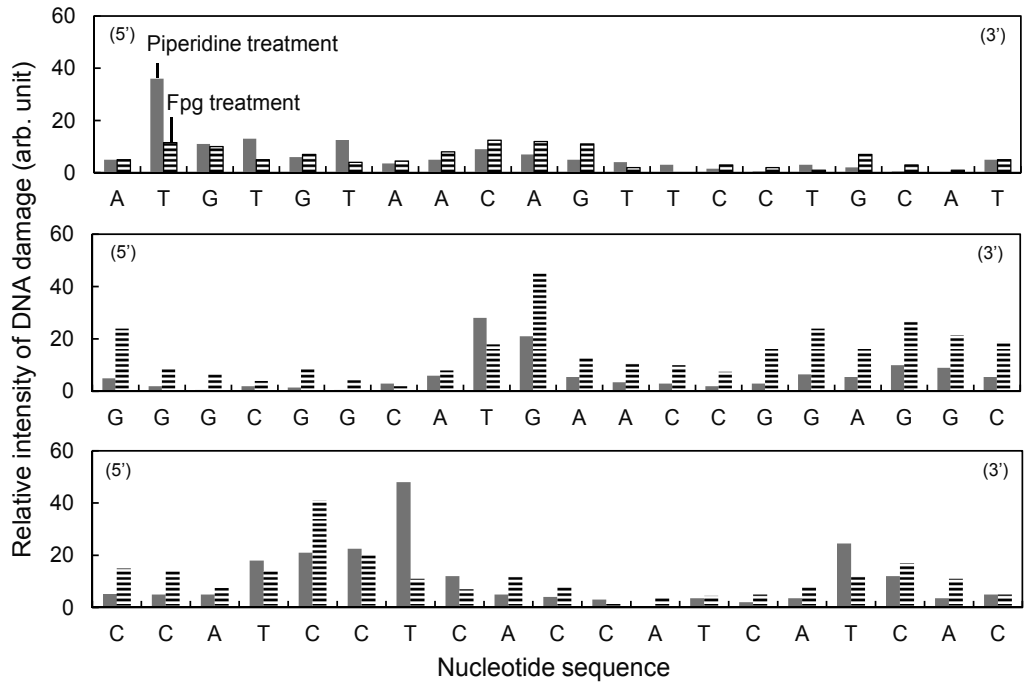

Figure 4. Sequence specificity of DNA damage photocatalyzed by anatase $\mathrm{TiO}_{2} \mathrm{NPs}$. The ${ }^{32} \mathrm{P}$-end-labeled 211 base pair DNA fragment ( $p 53$ tumor suppressor gene) and $8 \mu \mathrm{g} \mathrm{mL}^{-1}$ anatase was irradiated with ultraviolet light $(365 \mathrm{~nm}, 10 \mathrm{~J}$ $\mathrm{cm}^{-2}$ ) with $20 \mu \mathrm{M}$ copper(II) ion in a $10 \mathrm{mM}$ sodium phosphate buffer (pH 7.8). After the photocatalytic reaction, the DNA fragments were treated with hot piperidine or Fpg and analyzed by an electrophoresis.

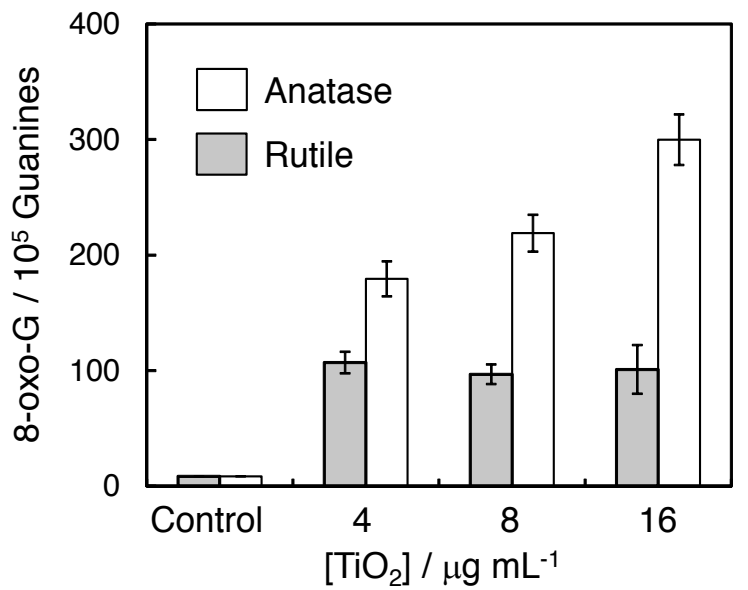

Figure 5. Formation of 8-oxo-G by the photocatalytic reaction of anatase or rutile NPs. Calf thymus DNA was treated by the photocatalytic reaction of anatase or rutile NPs $\left(365 \mathrm{~nm}, 10 \mathrm{~J} \mathrm{~cm}^{-2}\right)$ with $20 \mu \mathrm{M}$ copper(II) ion in a $10 \mathrm{mM}$ sodium phosphate buffer ( $\mathrm{pH}$ 7.8). After the photocatalytic reaction, the samples were analyzed with a high-performance liquid chromatography.

by photo-irradiated $\mathrm{TiO}_{2} \mathrm{NPs}$. It has been reported that $\mathrm{OH}^{\cdot}$ is not the main reactive species involved in DNA damage by $\mathrm{H}_{2} \mathrm{O}_{2}$ and copper(I) ions [34-36, 59]. DNA-associated copper(I) ions may generate other oxidants, including a copper-peroxo intermediate, such as $\mathrm{Cu}(\mathrm{I})$ $\mathrm{OOH}$, which is generated from the reaction of $\mathrm{H}_{2} \mathrm{O}_{2}$ and copper(I) ions [34-36, 59]. Indeed, 
methional, which can scavenge $\mathrm{Cu}(\mathrm{I})-\mathrm{OOH}[36,59]$, shows inhibitory effect on DNA damage photocatalyzed by $\mathrm{TiO}_{2}$ NPs. The generation of these reactive species may be responsible for the formation of piperidine-labile products and 8-oxo-G.

On the other hand, a high concentration of anatase NPs can catalyze DNA photodamage without copper(II) ions. Typical OH' scavengers, ethanol and sugars, effectively inhibit the DNA photodamage by a high concentration of anatase NPs. The DNA damage induced by photo-irradiated anatase NPs without copper(II) ions is observed at every nucleobases without site specificity. Such DNA damage without sequence-specificity is the typical pattern of $\mathrm{OH}$ mediated DNA damage [34].

A proposed mechanism of DNA damage photocatalyzed by $\mathrm{TiO}_{2} \mathrm{NPs}$ is shown in Figure 6 . The crystalline forms of $\mathrm{TiO}_{2}$, anatase and rutile, are semiconductors with band gap energies of 3.26 and $3.06 \mathrm{eV}$, which correspond to the following wavelengths of light: 385 and $400 \mathrm{~nm}$, respectively. When a $\mathrm{TiO}_{2}$ semiconductor NPs absorbs photon with energy greater than their band gap, electrons in the valence band are excited to the conduction band, creating electron$\mathrm{h}^{+}$pairs and causing various chemical reactions [2-5]. The electron acts as a reductant, whereas the $\mathrm{h}^{+}$is a powerful oxidant. In aqueous environments, oxygen molecule can be reduced by the electron into $\mathrm{O}_{2}{ }^{--}$, and water molecule can be oxidized by the $\mathrm{h}^{+}$into $\mathrm{OH} \cdot$. In general, formed $\mathrm{O}_{2}{ }^{-}$can be dismutated into $\mathrm{H}_{2} \mathrm{O}_{2}$ by proton. The oxygen reduction may precede the reduction of copper(II) ions under aerobic condition, since the concentration of dissolved oxygen is higher $(\sim 250 \mu \mathrm{M})$ than that of the copper(II) ion used in this study $(20 \mu \mathrm{M})$. The copper(II) reduction may be mediated by $\mathrm{O}_{2}{ }^{-}$. Hydrogen peroxide reacts with copper(I) ions to generate other oxidants, including a copper-peroxo intermediate, resulting in the oxidation of DNA bases. Copper ions, which are essential components of chromatin [60,61], are found to bind DNA with high affinity $[62,63]$. Therefore, copper ions may play an important role in reactive oxygen generation in vivo, although mammals have evolved means of minimizing the levels of free copper ions and most copper ions bind to protein caries and transporters [64]. Hydroxyl radicals formed by the reaction of water with an $\mathrm{h}^{+}$in the valence band of $\mathrm{TiO}_{2} \mathrm{NPs}$ also slightly participate in DNA damage photocatalyzed by anatase NPs. Because $\mathrm{OH}$ ' is a strong oxidative agent, $\mathrm{OH}^{\cdot}$ can damage every nucleobase [34]. The present results suggest that $\mathrm{H}_{2} \mathrm{O}_{2}$ mainly participate in the phototoxicity of $\mathrm{TiO}_{2} \mathrm{NPs}$ and the contribution of $\mathrm{OH}$ is relatively small. Fujishima et al. also reported the involvement of $\mathrm{H}_{2} \mathrm{O}_{2}$ generated from $\mathrm{O}_{2}{ }^{-\cdots}$ in the cytotoxicity of illuminated $\mathrm{TiO}_{2}$ NPs [2-4, 8-13].

$\mathrm{TiO}_{2}$ NPs might be a potential agent for PDT [22-25]. $\mathrm{TiO}_{2} \mathrm{NPs}_{\text {can }}$ be incorporated into cancer cells and demonstrate cytotoxicity under photo-irradiation [2-4, 26-28]. Photocatalytic reaction by $\mathrm{TiO}_{2} \mathrm{NPs}$ induces a number of functional changes in cell including altered permeability of cellular membranes to potassium and calcium ions, release of RNA and proteins and cytotoxicity [2,18-21]. It has been reported that DNA can be a target biomolecule of the photocatalytic reaction of $\mathrm{TiO}_{2} \mathrm{NPs}$ [26-30]. Although incorporation of $\mathrm{TiO}_{2} \mathrm{NPs}$ into cell nucleus is difficult [18], the generated $\mathrm{H}_{2} \mathrm{O}_{2}$ by a photocatalytic reaction of $\mathrm{TiO}_{2} \mathrm{NPs}$ can be easily diffused and incorporated in a cell nucleus, leading to DNA photodamage with metal ions. Relevantly, several studies demonstrated that DNA is a potential target of PDT $[47,65,66]$. Therefore, the 


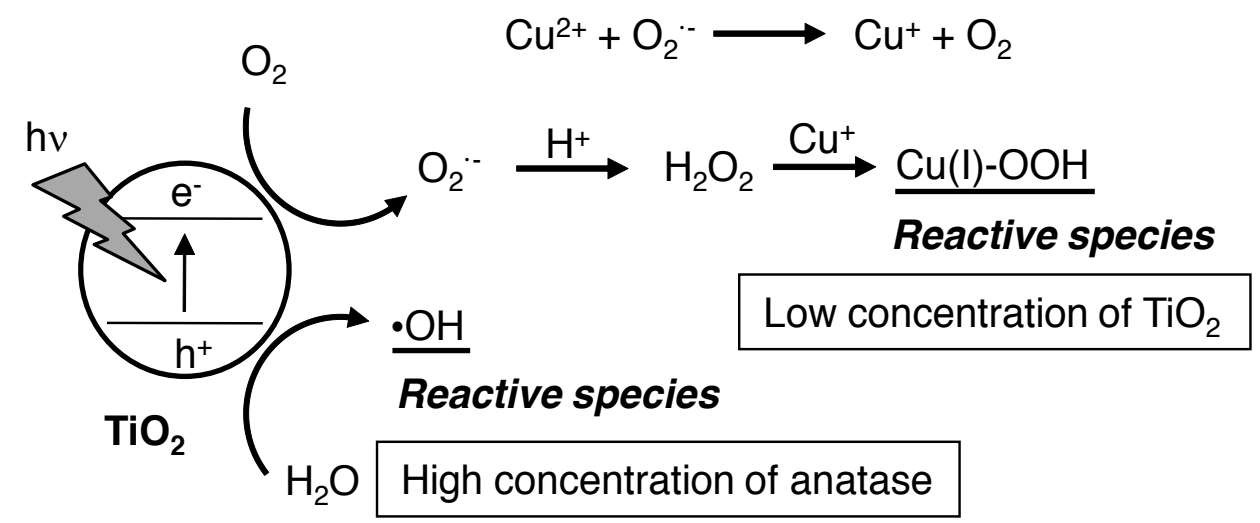

Figure 6. Proposed mechanism of DNA damage photocatalyzed by $\mathrm{TiO}_{2} \mathrm{NPs}$.

metal-mediated DNA damage through the photocatalysis of $\mathrm{TiO}_{2} \mathrm{NPs}$ may participate in cytotoxicity by photo-irradiated $\mathrm{TiO}_{2} \mathrm{NPs}$.

\section{Secondary production of reactive oxygen species from photocatalyzed materials by $\mathrm{TiO}_{2} \mathrm{NPs}$}

As mentioned above, DNA damage in human cells by $\mathrm{TiO}_{2} \mathrm{NPs}$ has also been reported [26-28]. The direct DNA damage by $\mathrm{TiO}_{2}$ NPs photocatalyst in vitro has been also studied [31, 32]. However, the DNA-damaging mechanism in vivo is not well-understood because the incorporation of the $\mathrm{TiO}_{2}$ NPs in the cell nucleus is difficult [18]. Since the $\mathrm{TiO}_{2}$ photocatalytic reaction occurs in a complex biological environment, an interaction between $\mathrm{TiO}_{2} \mathrm{NPs}$ and biomaterials may participate in the generation of reactive species to induce DNA damage. Hence, the effect of sugars, which are ubiquitous biomaterials, on DNA damage photocatalyzed by $\mathrm{TiO}_{2}$ NPs was examined [37].

In the case of anatase, a high concentration of $\mathrm{TiO}_{2} \mathrm{NPs}$ can damage DNA at every nucleobase by $\mathrm{OH}^{\cdot}$ generation in the absence of copper(II) ions. Typical free $\mathrm{OH}^{*}$ scavengers inhibited this copper(II)-independent DNA damage. These results indicate that free $\mathrm{OH}^{\cdot}$ partly contributes to DNA damage photocatalyzed by $\mathrm{TiO}_{2}$. On the other hand, scavengers of $\mathrm{OH}$, such as a sugar (mannitol), ethanol, and formate, enhanced the copper(II)-dependent DNA damage [31]. These scavengers themselves did not induce DNA damage. Since $\mathrm{OH}^{-}$can oxidize most biomaterials, the oxidized products of biomaterials by the $\mathrm{TiO}_{2}$ photocatalyst may damage DNA via the generation of secondary reactive oxygen species. The addition of sugars, glucose and galactose, which are ubiquitous biomolecules, enhanced the DNA damage photocatalyzed by $\mathrm{TiO}_{2} \mathrm{NPs}$. Enhancement of DNA damage by sugars has seldom been reported, and these sugars themselves could not induce DNA damage. Therefore, the products of the photocatalytic reaction of these sugars by $\mathrm{TiO}_{2} \mathrm{NPs}$ is responsible for the copper(II)-dependent damage to DNA. Indeed, the glucose and galactose oxidized by the $\mathrm{TiO}_{2}$ photocatalytic reaction caused 
DNA damage in the presence of copper(II) ion [37]. The inhibitory effect of various scavengers for DNA damage by the photo-oxidized products of sugars by $\mathrm{TiO}_{2}$ was examined. Catalase inhibited DNA damage by the photocatalyzed glucose, indicating the involvement of $\mathrm{H}_{2} \mathrm{O}_{2}$. Bathocuproine, which is a chelator of copper(I) ion, also inhibited DNA damage by the photocatalyzed glucose, suggesting the involvement of copper(I) ion. The free $\mathrm{OH}$ ' scavengers had no or little inhibitory effect on DNA damage. The inhibitory effect of superoxide dismutase (SOD) was weak, suggesting that $\mathrm{O}_{2}{ }^{-\cdots}$ itself is not the main reactive species for DNA damage. Similar results were observed in the case of galactose. Fluorometry using folic acid [67] demonstrated the formation of $\mathrm{H}_{2} \mathrm{O}_{2}$ from the photocatalyzed sugars (Figure 7). The amount of $\mathrm{H}_{2} \mathrm{O}_{2}$ generation was comparable with that of other $\mathrm{H}_{2} \mathrm{O}_{2}$-mediated DNA-damaging drugs [68]. $\mathrm{H}_{2} \mathrm{O}_{2}$ generation was not observed in the absence of copper(II) ions. These results showed that the oxidized products of sugars generate $\mathrm{H}_{2} \mathrm{O}_{2}$ during the reaction with copper(II) ions, resulting in secondary DNA damage.

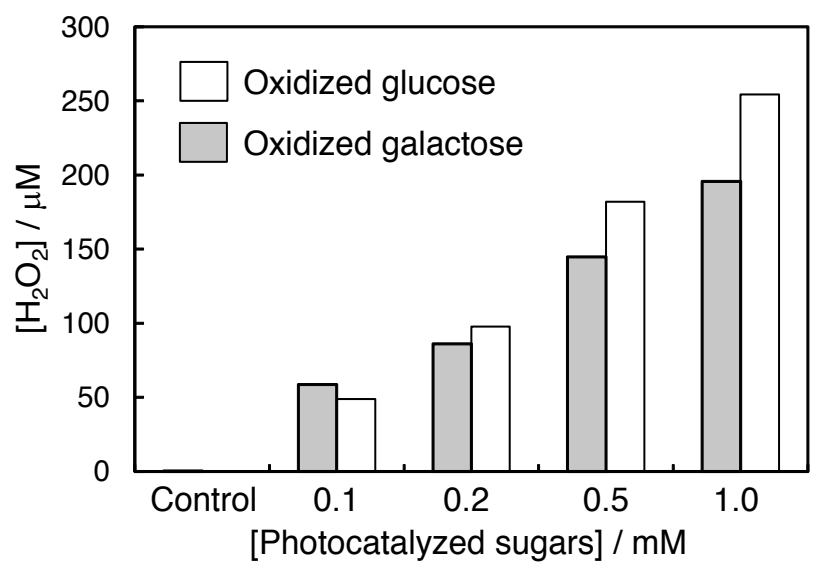

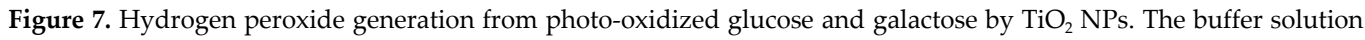
with $10 \mathrm{mM}$ sugars was previously irradiated $\left(365 \mathrm{~nm}, 6 \mathrm{~J} \mathrm{~cm}^{-2}\right)$ with $100 \mu \mathrm{g} \mathrm{mL}^{-1}$ anatase NPs. The $\mathrm{TiO}_{2} \mathrm{NPs}_{\text {were }}$ removed by centrifugation, and the solution containing the oxidized sugars was used. One $\mathrm{mL}$ of solution containing the treated sugars and $10 \mu \mathrm{M}$ of folic acid was incubated $\left(60 \mathrm{~min}, 37^{\circ} \mathrm{C}\right)$ in the presence of $20 \mu \mathrm{M}$ copper(II) chloride, and the fluorescence intensity was measured (excitation: $360 \mathrm{~nm}$, detection: $450 \mathrm{~nm}$ ). The concentration of the generated $\mathrm{H}_{2} \mathrm{O}_{2}$ was determined by the calibration curve method.

These sugars act as an electron donor for the photocatalytic reaction [15,37]. Partially oxidized sugars, such as aldehyde compounds, are possibly produced through this photocatalytic oxidation. The mechanism of DNA damage by the photocatalyzed product of sugars is proposed in Figure 8. Aldehydes can generate $\mathrm{H}_{2} \mathrm{O}_{2}$ via its further oxidation [69], though these sugars themselves are stable compounds. Many studies have reported DNA damage by $\mathrm{H}_{2} \mathrm{O}_{2}$ and copper(II) ions [34-36, 70]. Various chemical compounds, including aldehydes, easily produce $\mathrm{O}_{2}{ }^{--}$through their autoxidation process. The autoxidation is markedly enhanced by copper(II) ion, which is an essential component of chromatin [60,61]. The formed $\mathrm{O}_{2}{ }^{-\cdots}$ is rapidly dismutated into $\mathrm{H}_{2} \mathrm{O}_{2}$. Although the generated $\mathrm{H}_{2} \mathrm{O}_{2}$ itself cannot damage DNA, $\mathrm{H}_{2} \mathrm{O}_{2}$ reduces copper(II) into copper(I), leading to the activation of $\mathrm{H}_{2} \mathrm{O}_{2}$ through the formation of reactive 
species, such as $\mathrm{Cu}(\mathrm{I})-\mathrm{OOH}[34-36,59]$. Indeed, methional, a scavenger of $\mathrm{Cu}(\mathrm{I})-\mathrm{OOH}$, inhibited the DNA damage. This reactive species cannot be scavenged by the free $\mathrm{OH}$ ' scavengers; however, it can effectively oxidize the nucleobases [34-36, 59].

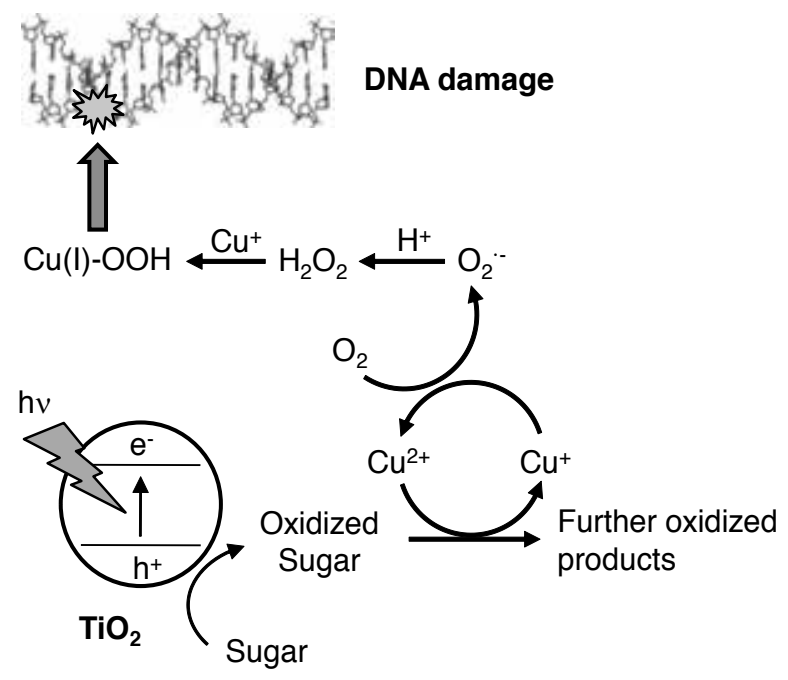

Figure 8. Proposed mechanism of secondary DNA damage by photocatalyzed sugars.

Although $\mathrm{TiO}_{2}$ is not likely to be incorporated in a cell nucleus [18], $\mathrm{H}_{2} \mathrm{O}_{2}$ generated via a photocatalytic reaction can be easily diffused and incorporated in a cell nucleus. This DNAdamaging mechanism via $\mathrm{H}_{2} \mathrm{O}_{2}$ generation may participate in the phototoxicity of $\mathrm{TiO}_{2}$. In vivo, the cell membrane is an important reaction field for the $\mathrm{TiO}_{2}$ photocatalyst because $\mathrm{TiO}_{2} \mathrm{NPs}$ show affinity with a cell membrane [18]. Further, a part of the $\mathrm{TiO}_{2} \mathrm{NPs}$ can become incorporated into the cell. Sugars on the cell membrane and cytoplasm may be oxidized by the $\mathrm{TiO}_{2}$ photocatalytic reaction. The generated $\mathrm{h}^{+}$and $\mathrm{OH} \cdot$ can oxidize these sugars, leading to the formation of secondary $\mathrm{H}_{2} \mathrm{O}_{2}$ from their photo-oxidized products.

In summary, sugars enhance the DNA damage photocatalyzed by $\mathrm{TiO}_{2} \mathrm{NPs}$. This enhancement of DNA damage is due to the secondary generation of a reactive oxygen species, $\mathrm{H}_{2} \mathrm{O}_{2}$, which can diffuse in the cell and damage cellular DNA. These findings suggest that the secondary $\mathrm{H}_{2} \mathrm{O}_{2}$ generation contributes to the phototoxicity of $\mathrm{TiO}_{2}$ more than the direct formation of reactive oxygen species does.

\section{Singlet oxygen formation through photocatalytic reaction of $\mathrm{TiO}_{2} \mathrm{NPs}$}

A contribution of ${ }^{1} \mathrm{O}_{2}$ in the $\mathrm{TiO}_{2}$ photocatalytic reaction was reported [38]. Singlet oxygen generation by $\mathrm{TiO}_{2}$ photocatalysis has been demonstrated by the emission measurement of ${ }^{1} \mathrm{O}_{2}$, which is assigned to the transition from ${ }^{1} \mathrm{O}_{2}\left({ }^{1} \Delta_{\mathrm{g}}\right)$ to ${ }^{3} \mathrm{O}_{2}\left({ }^{3} \sum_{\mathrm{g}}\right)[39,40]$. Because ${ }^{1} \mathrm{O}_{2}$ is considered to be an important reactive species in PDT process [22-25], the clarification of the 
contribution of ${ }^{1} \mathrm{O}_{2}$ generated by $\mathrm{TiO}_{2}$ photocatalysis is closely related to a design of photocatalyst for medicinal application. Thus, ${ }^{1} \mathrm{O}_{2}$ generation in the $\mathrm{TiO}_{2}$ photocatalysis and its importance on biomolecular damage was examined [40].

The typical emission of ${ }^{1} \mathrm{O}_{2}$ at around $1270 \mathrm{~nm}$ was observed during irradiation of $\mathrm{TiO}_{2} \mathrm{NPs}$. Relatively strong emission of ${ }^{1} \mathrm{O}_{2}$ was observed in nonpolar organic solvents such as dichloromethane. The quantum yield $\left(\Phi_{\Delta}\right)$ of ${ }^{1} \mathrm{O}_{2}$ generation by $\mathrm{TiO}_{2}$ photocatalysis in ethanol was estimated from the comparison of ${ }^{1} \mathrm{O}_{2}$ emission intensities by $\mathrm{TiO}_{2} \mathrm{NPs}$ and methylene blue $\left(\Phi_{\Delta}=0.52\right)$ [71] and the absorbance of the $\mathrm{TiO}_{2} \mathrm{NP}$ dispersions. Because the scattering by suspended $\mathrm{TiO}_{2}$ NPs makes the calculation of absorbed light intensity complex, the precise estimation of the $\Phi_{\Delta}$ is difficult. Thus, the $\Phi_{\Delta}$ was estimated using the apparent absorbance of $\mathrm{TiO}_{2}$ NPs. The calculated value indicates the lowest limit of the $\Phi_{\Delta}$ by $\mathrm{TiO}_{2}$ photocatalysis in ethanol. The reported lifetime of ${ }^{1} \mathrm{O}_{2}$ generated via $\mathrm{TiO}_{2}$ photocatalytic reaction is $5 \mu$ s [39]. This value is shorter than that by the photosensitized reaction of methylene blue (12 $\mu \mathrm{s})$ [72]. Since the emission intensity of ${ }^{1} \mathrm{O}_{2}$ is proportional to its lifetime, the $\Phi_{\Delta}$ was corrected by the lifetime of ${ }^{1} \mathrm{O}_{2}$. The estimated value of $\Phi_{\Delta}$ by both types of $\mathrm{TiO}_{2}$, anatase and rutile, was about 0.02 in ethanol. This value of $\Phi_{\Delta}$ is enough large to induce oxidative damage to biomolecules. The ${ }^{1} \mathrm{O}_{2}$ emission in $\mathrm{D}_{2} \mathrm{O}$ was completely quenched by the addition of $\mathrm{SOD}$, which is the enzyme to dismutate $\mathrm{O}_{2}{ }^{--}$into $\mathrm{H}_{2} \mathrm{O}_{2}$. These results can be explained by the fact that ${ }^{1} \mathrm{O}_{2}$ is formed by the reoxidation of $\mathrm{O}_{2}{ }^{--}$, generated from the photoreduction of oxygen molecules by $\mathrm{TiO}_{2} \mathrm{NPs}$ (Figure 3). The intensity of ${ }^{1} \mathrm{O}_{2}$ emission observed in the case of rutile was significantly larger than that by anatase in $\mathrm{D}_{2} \mathrm{O}$. The difference of the ${ }^{1} \mathrm{O}_{2}$ generation by these two types of $\mathrm{TiO}_{2}$ crystalline forms can be reasonably explained by that in aqueous solution. $\mathrm{H}_{2} \mathrm{O}_{2}$ generation proceeds in the photocatalysis of anatase rather than $\mathrm{O}_{2}{ }^{--}$generation, whereas $\mathrm{O}_{2}{ }^{-\cdots}$ is the main product from oxygen photoreduction mediated by rutile [17]. These results support the mechanism of ${ }^{1} \mathrm{O}_{2}$ generation via $\mathrm{O}_{2}{ }^{\cdot-}$ by $\mathrm{TiO}_{2}$ photocatalysis.

The emission spectrum of ${ }^{1} \mathrm{O}_{2}$ by $\mathrm{TiO}_{2}$ (in both, anatase and rutile type cases) slightly blueshifted $(\sim 4 \mathrm{~nm})$ compared with that by methylene blue. These results suggest that the surroundings of the ${ }^{1} \mathrm{O}_{2}$ generated on the $\mathrm{TiO}_{2}$ surface are different from that by methylene blue in solution. In the case of the photosensitization of methylene blue, the generated ${ }^{1} \mathrm{O}_{2}$ deactivates in the homogeneous media of solvents. A possible explanation of the blue-shift is that most of the ${ }^{1} \mathrm{O}_{2}$ generated by $\mathrm{TiO}_{2} \mathrm{NPs}$ deactivates on the $\mathrm{TiO}_{2}$ surface.

The intensity of ${ }^{1} \mathrm{O}_{2}$ emission by $\mathrm{TiO}_{2}$ photocatalysis in liposome was significantly larger than that in an aqueous solution in both, anatase and rutile type cases. The enhancement of the ${ }^{1} \mathrm{O}_{2}$ emission can be explained by the elongation of the lifetime of ${ }^{1} \mathrm{O}_{2}$ or the acceleration of the photocatalytic reaction. This result shows that phospholipids membrane is an important environment of the phototoxic reaction mediated by ${ }^{1} \mathrm{O}_{2}$ in the photocatalytic reactions of $\mathrm{TiO}_{2}$ NPs. Indeed, high affinity of $\mathrm{TiO}_{2} \mathrm{NPs}$ with a cell membrane was reported [18]. Consequently, an environmental effect of a cell membrane is important for the photocatalytic reaction of $\mathrm{TiO}_{2} \mathrm{NPs}$. Since amino acid residues in proteins can be oxidized by ${ }^{1} \mathrm{O}_{2}$ [42], a membrane protein should be the target biomolecule in cell membrane. Indeed, ${ }^{1} \mathrm{O}_{2}$ emission was quenched by the addition of bovine serum albumin, a typical water soluble protein, suggesting scavenging of the ${ }^{1} \mathrm{O}_{2}$ generated by $\mathrm{TiO}_{2}$ photocatalysis through oxidation of protein. 
In vivo, nicotinamide adenine dinucleotide (NADH) is one of the most important target biomolecule oxidized by ${ }^{1} \mathrm{O}_{2}[73,74]$. NADH demonstrates the typical absorption peak at around $340 \mathrm{~nm}$ in an ultraviolet absorption spectral measurement, and this absorption band is diminished by the oxidation. It has been reported that $\mathrm{TiO}_{2} \mathrm{NPs}$ hardly induce the oxidation of $\mathrm{NADH}$ in aqueous solution during ultraviolet irradiation. Since NADH hardly adsorbed on a surface of $\mathrm{TiO}_{2} \mathrm{NPs}$, the ${ }^{1} \mathrm{O}_{2}$ could not effectively oxidize $\mathrm{NADH}$ in solution. As mentioned above, it has been reported that photo-irradiated $\mathrm{TiO}_{2} \mathrm{NPs}$ can induce DNA damage mainly through $\mathrm{H}_{2} \mathrm{O}_{2}$ and $\mathrm{OH}^{\prime}$, and the ${ }^{1} \mathrm{O}_{2}$-mediated DNA damage could not be observed [31]. These reports concluded that the photocatalytic ${ }^{1} \mathrm{O}_{2}$ generation on the surface of $\mathrm{TiO}_{2} \mathrm{NPs}$ is not important in the damaging mechanism of the biomolecules such as DNA and NADH, of which the affinity with $\mathrm{TiO}_{2}$ surface is small.

In conclusion, photo-irradiated $\mathrm{TiO}_{2} \mathrm{NPs}$ can produce ${ }^{1} \mathrm{O}_{2}$ through reoxidation of $\mathrm{O}_{2}{ }^{-\cdot}$, which is formed by photocatalytic reduction of oxygen molecule on the surface of $\mathrm{TiO}_{2} \mathrm{NPs}^{- \text {Since }}$ most of the ${ }^{1} \mathrm{O}_{2}$ deactivated on $\mathrm{TiO}_{2}$ surface, the ${ }^{1} \mathrm{O}_{2}$ on $\mathrm{TiO}_{2}$ surface cannot induce the oxidation of DNA and NADH. However, the ${ }^{1} \mathrm{O}_{2}$ generation by $\mathrm{TiO}_{2}$ photocatalysis could be enhanced in the microenvironment of phospholipids membrane. These findings suggest that ${ }^{1} \mathrm{O}_{2}$ may contribute to phototoxicity of $\mathrm{TiO}_{2} \mathrm{NPs}$ through oxidation of membrane protein.

\section{Conclusions}

$\mathrm{TiO}_{2}$ NPs photocatalyze DNA oxidation. A relatively small concentration of $\mathrm{TiO}_{2} \mathrm{NPs}$ frequently induces tandem base oxidation at guanine and thymine residues through $\mathrm{H}_{2} \mathrm{O}_{2}$ generation in the presence of a copper(II) ion. A copper-peroxo complex is considered to be an important reactive species responsible for this DNA damage. In addition, cytosine residues are also photooxidized by $\mathrm{TiO}_{2} \mathrm{NPs}$. In the case of a high concentration of $\mathrm{TiO}_{2} \mathrm{NPs} \mathrm{OH}$. contributes to DNA damage without sequence specificity. In the presence of sugars, $\mathrm{TiO}_{2} \mathrm{NPs}$ indirectly induce DNA damage by the secondary $\mathrm{H}_{2} \mathrm{O}_{2}$, which is produced through an autoxidation process of the photo-oxidized products of sugars by $\mathrm{TiO}_{2} \mathrm{NPs}$. Furthermore, ${ }^{1} \mathrm{O}_{2}$ is also produced by photo-irradiated $\mathrm{TiO}_{2}$ NPs. The ${ }^{1} \mathrm{O}_{2}$ generation is explained by the reoxidation of $\mathrm{O}_{2}{ }^{-\cdot}$, which is produced by photocatalytic reduction of the oxygen molecule adsorbed on the surface of $\mathrm{TiO}_{2} \mathrm{NPs}$. The photocatalyzed formation of ${ }^{1} \mathrm{O}_{2}$ might contribute to the oxidation of the membrane protein. These mechanisms of photocatalytic reactive oxygen formation should be involved in the photocytotoxicity of $\mathrm{TiO}_{2} \mathrm{NPs}$. Because $\mathrm{TiO}_{2}$ is a chemically stable and nontoxic material, the bactericidal activity and cytotoxicity against cancer cells will play more important roles in the field of medical applications of nanomaterials.

\section{Acknowledgements}

The author wishes to thank Professor Shosuke Kawanishi (Suzuka University of Medical Science) for his helpful discussion about DNA damage. The reported works were supported 
by a Grant-in-Aid for Scientific Research on Priority Areas (417) from the Ministry of Education, Culture, Sports, Science, and Technology (MEXT) of the Japanese Government.

\section{Author details}

Kazutaka Hirakawa ${ }^{1,2}$

Address all correspondence to: hirakawa.kazutaka@shizuoka.ac.jp

1 Applied Chemistry and Biochemical Engineering Course, Department of Engineering, Graduate School of Integrated Science and Technology, Shizuoka University, Johoku, Nakaku, Hamamatsu, Shizuoka, Japan

2 Department of Optoelectronics and Nanostructure Science, Graduate School of Science and Technology, Shizuoka University, Johoku, Naka-ku, Hamamatsu, Shizuoka, Japan

\section{References}

[1] Fujishima A, Honda K. Electrochemical photolysis of water at a semiconductor electrode. Nature. 1972;238:37-38. DOI: 10.1038/238037a0

[2] Fujishima A, Rao TN, Tryk DA. Titanium dioxide photocatalysis. J Photochem Photobiol C: Photochem Rev. 2000;1:1-21. DOI: 10.1016/S1389-5567(00)00002-2

[3] Fujishima A, Zhang X, Tryk $\mathrm{DA}$. $\mathrm{TiO}_{2}$ photocatalysis and related surface phenomena. Surf Sci Rep. 2008;63:515-582. DOI: 10.1016/j.surfrep.2008.10.001

[4] Liu K, Cao M, Fujishima A, Jiang, J. Bio-inspired titanium dioxide materials with special wettability and their applications. Chem Rev. 2014;114:10044-10094. DOI: 10.1021/ cr4006796

[5] Tachikawa T, Fujitsuka M, Majima T. Mechanistic insight into the $\mathrm{TiO}_{2}$ photocatalytic reactions: design of new photocatalysts. J Physic Chem C. 2007;111:5259-5275. DOI: 10.1021/jp069005u

[6] Kikuchi Y, Sunada K, Iyoda T, Hashimoto K, Fujishima A. Photocatalytic bactericidal effect of $\mathrm{TiO}_{2}$ thin films: dynamic view of the active oxygen species responsible for the effect. J Photochem Photobiol A. 1997;106:51-56. DOI:10.1016/S1010-6030(97)00038-5

[7] Sunada K, Kikuchi Y, Hashimoto K, Fujishima A. Bactericidal and detoxification effects of $\mathrm{TiO}_{2}$ thin film photocatalysts. Environ Sci Technol. 1998;32:726-728. DOI: 10.1021/es970860o 
[8] Sato T, Taya M. Copper-aided photosterilization of microbial cells on $\mathrm{TiO}_{2}$ film under irradiation from a white light fluorescent lamp. Biochem Engin J. 2006;30: 199-204. DOI: 10.1016/j.bej.2006.04.002

[9] Page K, Palgrave RG, Parkin IP, Wilson M, Savin SLP, Chadwick AV. Titania and silver-titania composite films on glass-potent antimicrobial coatings. J Mater Chem. 2007;17:95-104. DOI: 10.1039/B611740F

[10] Page K, Wilson M, Parkin IP. Antimicrobial surfaces and their potential in reducing the role of the inanimate environment in the incidence of hospital-acquired infections. J Mater Chem. 2009;19:3819-3831. DOI: 10.1039/B818698G

[11] Dunnill CW, Aiken ZA, Kafizas A, Pratten J, Wilson M, Morgan DJ, Parkin IP. White light induced photocatalytic activity of sulfur-doped $\mathrm{TiO}_{2}$ thin films and their potential for antibacterial application. J Mater Chem. 2009;19:8747-8754. DOI: 10.1039/ B913793A

[12] Mansfield CM, Alloy MM, Hamilton J, Verbeck GF, Newton K, Klaine SJ, Roberts AP. Photo-induced toxicity of titanium dioxide nanoparticles to Daphnia magna under natural sunlight. Chemosphere. 2014;120:206-210. DOI:10.1016/j.chemosphere. 2014.06.075

[13] Ljubas D, Smoljanić G, Juretić H. Degradation of Methyl Orange and Congo Red dyes by using $\mathrm{TiO} 2$ nanoparticles activated by the solar and the solar-like radiation. $J$ Environ Manage. 2015;161:83-91. DOI: 10.1016/j.jenvman.2015.06.042

[14] St. John MR, Furgala AJ, Sammells AF. Hydrogen generation by photocatalytic oxidation of glucose by platinized n-titania powder. J Physic Chem. 1983;87:801-805. DOI: $10.1021 / \mathrm{j} 100228 \mathrm{a} 021$

[15] Enea O. Structural and $\mathrm{pH}$ effects on the photo- oxidation of some polyalcohols and sugars by the suspensions of $\mathrm{TiO}_{2}$ particles. Electrochim Acta. 1986;31:405. DOI: 10.1016/0013-4686(86)80098-6

[16] Ishibashi K, Fujishima A. Quantum yields of active oxidative species formed on $\mathrm{TiO}_{2}$ photocatalyst. J Photochem Photobiol A. 2000;134:139-142. DOI: 10.1016/ S1010-6030(00)00264-1

[17] Goto H, Hanada Y, Ohno T, Matsumura M. Quantitative analysis of superoxide ion and hydrogen peroxide produced from molecular oxygen on photo-irradiated $\mathrm{TiO}_{2}$ particles. J Catalysis. 2004;225:223-229. DOI: 10.1016/j.jcat.2004.04.001

[18] Cai R, Hashimoto K, Itoh K, Kubota Y, Fujishima A. Photokilling of malignant cells with ultra-fine $\mathrm{TiO}_{2}$ powder. Bull Chem Soc Jap. 1991;64:1268-1273. DOI: org/10.1246/ bcsj. 64.1268

[19] Cai R, Hashimoto K, Kubota Y, Fujishima A. Increment of photocatalytic killing of cancer cells using $\mathrm{TiO}_{2}$ with the aid of superoxide dismutase. Chem Lett. 1992:427-430. DOI: org/10.1246/cl.1992.427 
[20] Cai R, Kubota Y, Shuin T, Sakai H, Hashimoto K, Fujishima A. Induction of cytotoxicity by photoexcited $\mathrm{TiO}_{2}$ particles. Canc Res. 1992;52:2346-2348. DOI: org/content/ $52 / 8 / 2346$

[21] Kubota Y, Shuin T, Kawasaki C, Hosaka M, Kitamura H, Cai R, Sakai H, Hashimoto K, Fujishima A. Photokilling of T-24 human bladder cancer cells with titanium dioxide. Brit J Canc. 1994;70:1107-1111. PMCID: PMC2033697

[22] Dolmans DEJGJ, Fukumura D, Jain RK. Photodynamic therapy for cancer. Natur Rev Canc. 2003;3:380-387. DOI: 10.1038/nrc1071

[23] Castano AP, Mroz P, Hamblin MR. Photodynamic therapy and anti-tumour immunity. Natur Rev Canc. 2006;6:535-545. DOI: 10.1038/nrc1894

[24] Wilson BC, Patterson MS. The physics, biophysics and technology of photodynamic therapy. Phys Med Biol. 2008;53:R61-R109. DOI: 10.1088/0031-9155/53/9/R01

[25] Collins HA, Khurana M, Moriyama EH, Mariampillai A, Dahlstedt E, Balaz M, Kuimova MK, Drobizhev M, Yang VXD, Phillips D, Rebane A, Wilson BC, Anderson HL. Blood-vessel closure using photosensitizers engineered for two-photon excitation. Natur Photonics. 2008;2:420-424. DOI: 10.1038/nphoton.2008.100

[26] Dunford R, Salinaro A, Cai L, Serpone N, Horikoshi S, Hidaka H, Knowland J. Chemical oxidation and DNA damage catalysed by inorganic sunscreen ingredients. FEBS Lett. 1997;418:87-90. DOI: 10.1016/S0014-5793(97)01356-2

[27] Wamer WG, Yin Jj, Wei RR. Oxidative damage to nucleic acids photosensitized by titanium dioxide. Free Rad Biol Med. 1997;23:851-858. DOI: 10.1016/ S0891-5849(97)00068-3

[28] Meena R, Rani M, Pal P, Rajamani P. Nano- $\mathrm{TiO}_{2}$-induced apoptosis by oxidative stress-mediated DNA damage and activation of p53 in human embryonic kidney cells. Appl Biochem Biotechnol. 2012;167:791-808. DOI 10.1007/s12010-012-9699-3

[29] Nakagawa Y, Wakuri S, Sakamoto K, Tanaka N. The photogenotoxicity of titanium dioxide particles. Mutat Res. 1997;394:125-132. DOI: 10.1016/S1383-5718(97)00126-5

[30] Kashige N1, Kakita Y, Nakashima Y, Miake F, Watanabe K. Mechanism of the photocatalytic inactivation of Lactobacillus casei phage PL-1 by titania thin film. Curr Microbiol. 2001;42:184-189. DOI: 10.1007/s002840010201

[31] Hirakawa K, Mori M, Yoshida M, Oikawa S, Kawanishi S. Photo-irradiated titanium dioxide catalyzes site specific DNA damage via generation of hydrogen peroxide. Free Rad Res. 2004;38:439-447. DOI:10.1080/1071576042000206487

[32] Tachikawa T, Asanoi Y, Kawai K, Tojo S, Sugimoto A, Fujitsuka M, Majima T. Photocatalytic cleavage of single $\mathrm{TiO}_{2} / \mathrm{DNA}$ nanoconjugates. Chem Eur J. 2008;14:1492-1498. DOI: $10.1002 /$ chem. 200701030 
[33] Neyens E, Baeyens J. A review of classic Fenton's peroxidation as an advanced oxidation technique. J Hazardous Mater. 2003;98:33-50. DOI: 10.1016/S0304-3894(02)00282-0

[34] Kawanishi S, Hiraku Y, Oikawa S. Mechanism of guanine-specific DNA damage by oxidative stress and its role in carcinogenesis and aging. Mutat Res. 2001;488:65-76. DOI: 10.1016/S1383-5742(00)00059-4

[35] Hiraku Y, Ito K, Hirakawa K, Kawanishi S. Photosensitized DNA damage and its protection via a novel mechanism. Photochem Photobiol. 2007;83:205-212. DOI: 10.1562/2006-03-09-IR-840

[36] Hirakawa K, Oikawa S, Hiraku Y, Hirosawa I, Kawanishi S. Catechol and hydroquinone have different redox properties responsible for their differential DNA-damaging ability. Chem Res Toxicol. 2002;15:76-82. DOI: 10.1021/tx010121s

[37] Hirakawa K. Titanium dioxide photocatalyzes DNA damage via the secondary generation of hydrogen peroxide in the presence of sugars. Trends Photochem Photobiol. 2012;14:69-73.

[38] Konaka R, Kasahara E, Dunlap WC, Yamamoto Y, Chien KC, Inoue M. Irradiation of titanium dioxide generates both singlet oxygen and superoxide anion. Free Rad Biol Med. 1999;27:294. DOI: 10.1016/S0891-5849(99)00050-7

[39] Nosaka Y, Daimon T, Nosaka AY, Murakami Y. Singlet oxygen formation in photocatalytic $\mathrm{TiO}_{2}$ aqueous suspension. Physic Chem Chemic Physic. 2004;6:2917. DOI: 10.1039/B405084C

[40] Hirakawa K, Hirano T. Singlet oxygen generation photocatalyzed by $\mathrm{TiO}_{2}$ particles and its contribution to biomolecule damage. Chem Lett. 2006;35:832-833. DOI: $10.1246 / \mathrm{cl} .2006 .832$

[41] Foote CS. Definition of Type I and Type II photosensitized oxidation. Photochem Photobiol. 1991;54: 659. DOI: 10.1111/j.1751-1097.1991.tb02071.x

[42] DeRosa MC, Crutchley RJ. Photosensitized singlet oxygen and its applications. Coordination Chem Rev. 2002;233-234:351-371. DOI: 10.1016/S0010-8545(02)00034-6

[43] Schweitzer C, Schmidt R. Physical mechanisms of generation and deactivation of singlet oxygen. Chem Rev. 2003;103:1685-1758. DOI: 10.1021/cr010371d

[44] Ogilby PR, Foote CS. Chemistry of singlet oxygen. 42. effect of solvent, solvent isotopic substitution, and temperature on the lifetime of singlet molecular oxygen $\left({ }^{1} \Delta_{\mathrm{g}}\right)$. J Am Chem Soc. 1983;105:3423-3430. DOI: 10.1021/ja00349a007

[45] Ravanat JL, Sauvaigo S, Caillat S, Martinez GR, Medeiros MH, Di Mascio P, Favier A, Cadet J. Singlet oxygen-mediated damage to cellular DNA determined by the commet assay associated with DNA repair enzymes. Biol Chem. 2004;385:17-20. DOI: 10.1515/BC.2004.003 
[46] Cadet J, Ravanat JL, Martinez GR, Medeiros MH, Di Mascio P. Singlet oxygen oxidation of isolated and cellular DNA: product formation and mechanistic insights. Photochem Photobiol. 2006;82:219-225. DOI: 10.1562/2006-06-09-IR-914

[47] Hirakawa K. DNA damage through photo-induced electron transfer and photosensitized generation of reactive oxygen species. In: Kimura H, Suzuki A (eds.), New Research on DNA Damage. Nova Science Publishers Inc; 2008. p. 197-219. ISBN: 978-1-60456-581-2

[48] Hirakawa K, Hirano T, Nishimura Y, Arai T, Nosaka Y. Dynamics of singlet oxygen generation by DNA-binding photosensitizers. J Physic Chem B. 2012;116:3037-3044. DOI: $10.1021 /$ jp300142e

[49] Hirakawa K, Nishimura Y, Arai T, Okazaki S. Singlet oxygen generating activity of an electron donor-connecting porphyrin photosensitizer can be controlled by DNA. J Physic Chem B. 2013;117:13490-13496. DOI: org/10.1021/jp4072444

[50] Kasai H, Crain PF, Kuchino Y, Nishimura S, Ootsuyama A, Tanooka H. Formation of 8-hydroxyguanine moiety in cellular DNA by agents producing oxygen radicals and evidence for its repair. Carcinogenesis. 1986;7:1849-1851. DOI: 10.1093/carcin/7.11.1849

[51] Ito K, Inoue S, Yamamoto K, Kawanishi S. 8-Hydroxydeoxyguanosine formation at the 5' site of 5'-GG-3' sequences in double-stranded DNA by UV radiation with riboflavin. J Biologic Chem. 1993;268:13221-13227.

[52] D'Ham C, Romieu A, Jaquinod M, Gasparutto D, Cadet J. Excision of 5,6-dihydroxy-5,6-dihydrothymine, 5,6-dihydrothymine, and 5-hydroxycytosine from defined sequence oligonucleotides by Escherichia coli endonuclease III and Fpg proteins: kinetic and mechanistic aspects. Biochemistry. 1999;38:3335-3344. DOI: 10.1021/bi981982b

[53] David-Cordonnier MH, Laval J, O'Neill P. Clustered DNA damage, influence on damage excision by XRS5 nuclear extracts and Escherichia coli Nth and Fpg proteins. J Biologic Chem. 2000;275:11865-1873. DOI: 10.1074/jbc.275.16.11865

[54] Bourdat AG, Douki T, Frelon S, Gasparutto D, Cadet J. Tandem base lesions are generated by hydroxyl radical within isolated DNA in aerated aqueous solution. J Am Chemic Soc. 2000;122:4549-4556. DOI: 10.1021/ja994282i

[55] Box HC, Budzinski EE, Dawidzik JB, Gobey JS, Freund HG. Free radical-induced tandem base damage in DNA oligomers. Free Rad Biol Med. 1997;23:1021-1030. DOI: 10.1016/S0891-5849(97)00166-4

[56] Frelon S, Douki T, Favier A, Cadet J. Hydroxyl radical is not the main reactive species involved in the degradation of DNA bases by copper in the presence of hydrogen peroxide. Chem Res Toxicol. 2003;16:191-197. DOI: 10.1021/tx025650q

[57] Lee DH, O'Connor TR, Pfeifer GP. Oxidative DNA damage induced by copper and hydrogen peroxide promotes $\mathrm{CG} \rightarrow \mathrm{TT}$ tandem mutations at methylated $\mathrm{CpG}$ dinu- 
cleotides in nucleotide excision repair-deficient cells. Nucleic Acids Res. 2002;30:3566-3573.

[58] Blaisdell JO, Wallace SS. Abortive base-excision repair of radiation-induced clustered DNA lesions in Escherichia coli. Proc Natl Acad Sci USA. 2001;98:7426-7430. DOI: 10.1073/pnas.131077798

[59] Yamashita N, Murata M, Inoue. S, Burkitt MJ, Milne L, Kawanishi S. Alphatocopherol induces oxidative damage to DNA in the presence of copper(II) ions. Chem Res Toxicol. 1998;11:855-862. DOI: 10.1021/tx970129v

[60] Dijkwel PA, Wenink PW. Structural integrity of the nuclear matrix: differential effects of thiol agents and metal chelators. J Cell Sci. 1986;84:53-67.

[61] Saucier MA, Wang X, Re RN, Brown J, Bryan SE. Effects of ionic strength on endogenous nuclease activity in chelated and nonchelated chromatin. J Inorgan Biochem. 1991;41:117-124. DOI: 10.1016/0162-0134(91)80005-3

[62] Theophanides T, Anastassopoulou J. Copper and carcinogenesis. Crit Rev Oncol Hematol. 2002;42:57-64. DOI: 10.1016/S1040-8428(02)00007-0

[63] Bar-Or D, Thomas GW, Rael LT, Lau EP, Winkler JV. Asp-Ala-His-Lys (DAHK) inhibits copper-induced oxidative DNA double strand breaks and telomere shortening. Biochem Biophys Res Commun. 2001;282:356-360. DOI: 10.1006/bbrc.2001.4533

[64] Linder MC. Copper and genomic stability in mammals. Mutat Res. 2001;475:141-152. DOI: 10.1016/S0027-5107(01)00076-8

[65] Akhlynina TV, Jans DA, Rosenkranz AA, Statsyuk NV, Balashova IY, Toth G, Pavo I, Rubin AB, Sobolev AS. Nuclear targeting of chlorin e6 enhances its photosensitizing activity. J Biol Chem. 1997;272:20328-20331. DOI: 10.1074/jbc.272.33.20328

[66] Bisland SK, Singh D, Gariépy J. Potentiation of chlorin e6 photodynamic activity in vitro with peptide-based intracellular vehicles. Bioconjugate Chem. 1999;10:982-992. DOI: $10.1021 /$ bc $990020 u$

[67] Hirakawa K. Fluorometry of hydrogen peroxide using oxidative decomposition of folic acid. Anal Bioanal Chem. 2006;386:244-248. DOI: 10.1007/s00216-006-0649-1

[68] Hirakawa K, Midorikawa K, Oikawa S, Kawanishi S. Carcinogenic semicarbazide induces sequence-specific DNA damage through the generation of reactive oxygen species and the derived organic radicals. Mutat Res. 2003;536:91-101. DOI: 10.1016/ S1383-5718(03)00030-5

[69] Mizutani H, Oikawa S, Hiraku Y, Murata M, Kojima M, Kawanishi S. Distinct mechanisms of site-specific oxidative DNA damage by doxorubicin in the presence of copper(II) and NADPH-cytochrome P450 reductase. Canc Sci. 2003;94:686-691. DOI: 10.1111/j.1349-7006.2003.tb01503.x 
[70] Kawanishi S, Hiraku Y, Murata M, Oikawa S. The role of metals in site-specific DNA damage with reference to carcinogenesis. Free Rad Biol Med. 2002;32:822-832. DOI: 10.1016/S0891-5849(02)00779-7

[71] Usui Y, Kamogawa K. A standard system to determine the quantum yield of singlet oxygen formation in aqueous solution. Photochem Photobiol. 1974;19:245-247. DOI: 10.1111/j.1751-1097.1974.tb06506.x

[72] Merkel PB, Nilsson R, Kearns DR. Deuterium effects on singlet oxygen lifetimes in solutions. new test of singlet oxygen reactions. J Am Chem Soc. 1972;94:1030-1031. DOI: $10.1021 / j a 00758 \mathrm{a} 072$

[73] Petrat, F, Pindiur S, Kirsch M, de Groot H. NAD $(\mathrm{P}) \mathrm{H}$, a primary target of ${ }^{1} \mathrm{O}_{2}$ in mitochondria of intact cells. J Biologic Chem. 2003:278:3298-3307. DOI: 10.1074/ jbc.M204230200

[74] Petrat F, Pindiur S, Kirsch M, de Groot H. "Mitochondrial" photochemical drugs do not release toxic amounts of ${ }^{1} \mathrm{O}_{2}$ within the mitochondrial matrix space. Arch Biochem Biophysics. 2003;412:207-215. DOI: 10.1016/S0003-9861(03)00063-8 
Chapter 3

\title{
Synthesis, Luminescence and Magnetic Properties of Novel $\mathrm{Fe}_{0.5} \mathrm{Gd}_{0.5}\left(\mathrm{MoO}_{4}\right)_{1.5}: \mathrm{Eu}^{3+}$ Micro/Nano (3D) Structures
}

\author{
Rajagopalan Krishnan and Jagannathan Thirumalai
}

Additional information is available at the end of the chapter

http://dx.doi.org/10.5772/61323

\begin{abstract}
The controlled synthesis of $\mathrm{Fe}_{0.5} \mathrm{Gd}_{0.5}\left(\mathrm{MoO}_{4}\right)_{1.5}$ : $\mathrm{Eu}^{3+}$ microcrystals (self-aggregated 3D superstructures) using hydrothermal method by employing PVP as surfactant along with the state of the art of this field at present. By varying the reaction time, we have reported the morphology selection and the condition to derive novel nanoparticle sheathed bipyramid-like morphology. The rest of the parameters like, molar ratio between initial precursor / surfactant and temperature were kept as constant. The $\mathrm{Fe}_{0.5} \mathrm{Gd}_{0.5}\left(\mathrm{MoO}_{4}\right)_{1.5}$ : $\mathrm{Eu}^{3+}$ microcrystals are found to be an excellent matrix for photoluminescence property and the $\mathrm{Eu}^{3+}$ ion serves as a good red emitting luminescent center. Further, room temperature (RT) magnetic properties of $\mathrm{Fe}_{0.5} \mathrm{Gd}_{0.5}\left(\mathrm{MoO}_{4}\right)_{1.5}: \mathrm{Eu}^{3+}$ were investigated in detail.
\end{abstract}

Keywords: Chemical synthesis, Electron diffraction, Crystal structure, Optical properties, Magnetic measurements

\section{Introduction}

Size- and shape-controlled synthesis of self-organized, three-dimensional (3D) micro/nano architectures are still challenging and much attracted in the recent years owing to vast scientific and technological interest in multifaceted research areas [11,27, 14]. The growth and development of uniform, self-aggregated 3D super-structures through plane-to-plane coalition of the basic building blocks have been paid significant attention owing to their unusual physical, chemical properties [29, 3]. The development of self-organized architectures consents to find neoteric and diversified materials, causing momentous discovery that has been developed for the construction of a new class of micro/nanostructured devices [14, 15]. Self-aggregation of hierarchical architectures has proved to be a virtuous and expedient tool to control the 
structure and properties for the fabrication of intricate networks [15]. The peculiar size and morphology of the self-assembled 3D networks determine the attributes of a material which are important for the manufacture of a novel category of micro/nano-structured devices for advanced engineering and sciences [29, 14, 13]. The supreme and hopeful approach to synthesize self-assembled 3D networks is to use a solution-based technique which is a simple route to regulate the physicochemical properties of materials [3]. Specifically, in the hydrothermal method, numerous versatile morphologies have been described by using surfactants or chelating agents $[7,16,17]$. The surface capping agent used in the hydrothermal synthesis method positively assures an effective way to regulate the nucleation, controlled growth, oriented aggregation mechanism, and self-organized 3D morphology [15, 4].

\section{Recent research scenario}

A wide variety of 3D super-structures can be synthesized by using a suitable amount of surfactant which reduces the particle-particle amalgamation by steric effects, thereby controlling the size and shape [15]. Up till now, a number of research works have been reported on controlled synthesis of 3D hierarchical architectures using hydrothermal technique, for example, bowknot-like $\mathrm{Y}_{2}\left(\mathrm{WO}_{4}\right)_{3}: \mathrm{Ln}^{3+}$ [9], almond-like $\left(\mathrm{Na}_{0.5} \mathrm{La}_{0.5}\right) \mathrm{MoO}_{4}: \mathrm{RE}^{3+}$ [14], monodisperse $\mathrm{CaMoO}_{4}: \mathrm{Eu}^{3+}, \mathrm{M}^{+}(\mathrm{M}=\mathrm{Li}, \mathrm{Na}, \mathrm{K})$ microspheres [18], micron-sized flower-like $\mathrm{NaCe}\left(\mathrm{MoO}_{4}\right)_{2}$ architectures [27], tetragonal bipyramid-like $\left(\mathrm{Na}_{0.5} \mathrm{Gd}_{0.5}\right) \mathrm{MoO}_{4}: \mathrm{Ln}^{3+}$ [15], rugbylike $\mathrm{NaEu}\left(\mathrm{MoO}_{4}\right)_{2}$ microstructures [26], sheaf-like $\mathrm{Gd}_{2}\left(\mathrm{MoO}_{4}\right)_{3}$ [24], etc. Large-scale assert for phosphor materials as efficient sources of energy that can supply sustained proficiency is growing gradually. Current research in phosphors is focused on new materials having both luminescence and magnetic properties in a single entity based on the presence of trivalent lanthanide ions $\left(\mathrm{Ln}^{3+}\right)$ with magnetic $\mathrm{Fe}^{3+}$ ions. These bifunctional materials have attracted worldwide intense research, because their up/down conversion luminescence and para/ ferromagnetic properties are strongly required for therapeutics, contrast agents in magnetic resonance (MRI), fluorescent bioimaging in biophotonics, drug delivery and lumino-magnetic applications $[6,13,19]$. The phosphor particles can be magnetically directed, aligned, tracked, after applying the external magnetic fields. Subsequently, their luminescence can be visualized under optical excitation, which can be used widely for biological labeling, imaging of human and animal cells, tissues, and in vitro, in vivo applications [22, 25].

\begin{tabular}{cccc}
\hline Phosphor & $\begin{array}{c}\text { Type of luminescence } \\
\text { investigated }\end{array}$ & Observed magnetism & Reference \\
\hline $\mathrm{Gd}_{2} \mathrm{O}_{2} \mathrm{~S}: \mathrm{Yb} / \mathrm{Er}$ & Upconversion & Paramagnetic & {$[1]$} \\
\hline $\mathrm{NaGdF}_{4}: \mathrm{Yb}^{3+}, \mathrm{Ln}^{3+}$ & Upconversion & Paramagnetic & {$[8]$} \\
\hline${\mathrm{YAG}: \mathrm{Ce}^{3+}}_{\left(\mathrm{Na}_{0.5} \mathrm{La}_{0.5}\right) \mathrm{MoO}_{4}: \mathrm{Eu}^{3+}}$ & Downconversion & Ferromagnetism & {$[10]$} \\
\hline$\left(\mathrm{Na}_{0.5} \mathrm{Gd}_{0.5}\right) \mathrm{MoO}_{4}: \mathrm{Eu}^{3+}$ & Up/down conversion & Ferromagnetism & {$[15]$} \\
\hline
\end{tabular}

Table 1. Recent investigation of magnetic and luminescence properties of various phosphors. 
The luminescence and magnetic properties of lanthanide ions doped iron-based inorganic compounds that are synthesized by different research groups are detailed as follows. The novel $\mathrm{Fe}_{3} \mathrm{O}_{4} @ \mathrm{YPO}_{4}: \operatorname{Re}(\mathrm{Re}=\mathrm{Tb}, \mathrm{Eu})$ magnetic-fluorescent hybrid spheres were prepared using solvothermal and co-precipitation techniques [25]. The obtained nanostructures are an excellent platform to integrate fluorescent materials and magnetite into one single entity to exhibit both magnetic and fluorescent properties [25]. Wang et al. [25] reported that human cervical carcinoma Hela cells were successfully labeled by using the $\mathrm{Fe}_{3} \mathrm{O}_{4} @ \mathrm{YPO}_{4}: \mathrm{Re}$ hybrid spheres. Zhang et al. [29] synthesized orthorhombic cubic $\mathrm{GdFeO}_{3}$ particles by using a facile hydrothermal method. The emission color of cubic $\mathrm{GdFeO}_{3}$ particles could be adjusted effectively by doping different lanthanide activators [29]. Also, cubic $\mathrm{GdFeO}_{3}$ particles exhibiting paramagnetic properties are reported to be used as an excellent luminescence and magnetic material [29]. To replace the existing halide-based upconverting phosphors for infrared-based biomedical imaging [1], nontoxic $\mathrm{Gd}_{2} \mathrm{O}_{2} \mathrm{~S}: \mathrm{Yb} / \mathrm{Er}$ is synthesized using flux fusion method. The synthesized phosphor not only enables near-IR imaging features but also at the same time could be used as a contrast agent in MRI imaging [1]. Multifunctional luminescentmagnetic YAG:Ce nano-phosphors were synthesized by post-heat solidified combustion technique, post-heated hydrothermal-homogenous precipitation, and post-heated auto-clave techniques, respectively, using inexpensive aluminum and yttrium nitrates as the starting materials and urea as the homogenizing precipitant [10]. Since the yttrium and aluminium are non-magnetic elements, the origin of ferromagnetism of these nonmagnetic oxides could be attributed solely to the defects and/or oxygen vacancies [10]. The novel YAG:Ce nanophosphor exhibits the ferromagnetic behavior which finds the way for a new class of magneto-optic and spintronic materials for a wide variety of applications. The multicolor upconversion emissions and paramagnetic nature were observed in $\beta-\mathrm{NaGdF}_{4}$ crystals, which were synthesized by one-step precipitation method at room temperature [8]. To control the crystal size and morphology of the $\beta-\mathrm{NaGdF}_{4}$ crystals, different types of surfactants, namely $\mathrm{Na}_{2} \mathrm{EDTA}, \mathrm{PVP}$, SDS, and $\mathrm{Na}_{2}$ tar, were introduced during the synthesis procedure. Due to the presence of paramagnetic $\mathrm{Gd}^{3+}$ ions, $\beta-\mathrm{NaGdF}_{4}$ crystals exhibit paramagnetic behavior, which is a favorable bifunctional candidate for bioimaging applications [8].

Scheelite-type metal molybdates are considered as an ideal candidate, and are receiving accelerating interest due to their remarkable luminescence, magnetic, catalytic, sensing, and photocatalytic properties [13]. Scheelite-type crystalline structures, with the general chemical formula such as $\left(\mathrm{Na}_{0.5} \mathrm{R}_{0.5}\right) \mathrm{MoO}_{4}: \mathrm{Ln}^{3+}[15,14] ; \mathrm{BaMoO}_{4}: \mathrm{Ln}^{3+}\left[23 ; \mathrm{Ca}_{0.5} \mathrm{R}\left(\mathrm{MoO}_{4}\right)_{2}: \mathrm{Ln}^{3+}[20]\right.$; $\mathrm{Fe}_{0.5} \mathrm{R}_{0.5}(\mathrm{MoO} 4)_{1.5}: \mathrm{Ln}^{3+}$ [13] (where $\mathrm{R}=\mathrm{La}$ or $\mathrm{Gd}$ or $\mathrm{Y}$ and $\mathrm{Ln}=\mathrm{Eu}, \mathrm{Tb}$, Dy, etc.) etc., where molybdenum atoms are coordinated tetrahedrally, have recently attracted great attention because of their promising applications in the opto-electronics [14, 15]. In the crystal structure of $\mathrm{Fe}_{0.5} \mathrm{R}_{0.5}\left(\mathrm{MoO}_{4}\right)_{1.5}: \mathrm{Ln}^{3+}$, trivalent $\mathrm{Fe}^{3+}, \mathrm{R}^{3+} / \mathrm{Ln}^{3+}$ jointly occupy the dodecahedral positions and molybdenum $\left(\mathrm{Mo}^{6+}\right)$ atoms populated at the center of the tetrahedral symmetry coordinated with four equivalent oxygen atoms. Scheelite-type metal molybdates with the general formula have been synthesized by various techniques, which include hydrothermal method [14, 15], solid-state reaction technique [12], hydrothermal-assisted solid-state reaction [28], and pulsed laser deposition technique [21]. The random distribution of $\mathrm{R}^{3+}$ (La or Gd or Y) in the scheelite tetragonal structures show an intense and broad absorption band in the near UV- region [15]. 
Among all these molybdates, $\left(\mathrm{Fe}_{0.5} \mathrm{Gd}_{0.5}\right) \mathrm{MoO}_{4}: \mathrm{Eu}^{3+}$ is an important opto-magnetic material and possess good luminescence property. Due to the notable emission spectral lines in $\mathrm{Ln}^{3+}$ doped phosphors extending from ultraviolet to infra-red regionand its magnetic properties may open up a new platform to design and formulate other inorganic functional materials with for potential magnetic and luminescence applications [13], there is a great deal of scientific and technological interest in developing novel opto-electronic applications. In general, synthesis of any kind of phosphor materials using the conventional/sol-gel technique would require laborious conditions such as hefty manual grinding, annealing, or calcination of samples to high temperature, intermediate grinding process, and heat treatment for several times, etc. In order to avoid the above mentioned difficulties, hydrothermal technique is the alternative and most promising approach to synthesize the variety of phosphor materials with desired size, shape, and dimensions, crystallinity by changing the experimental parameters.

Herein, we report the controlled synthesis of $\left(\mathrm{Fe}_{0.5} \mathrm{Gd}_{0.5}\right) \mathrm{MoO}_{4}: \mathrm{Eu}^{3+}$ microcrystals (selfaggregated 3D superstructures) using hydrothermal method by employing PVP as the surfactant. By varying the reaction time, we have reported the morphology selection and the condition to derive novel nanoparticle sheathed bipyramid-like morphology. The rest of the parameters like molar ratio between initial precursor / surfactant and temperature were kept as constant. The $\left(\mathrm{Fe}_{0.5} \mathrm{Gd}_{0.5}\right) \mathrm{MoO}_{4}$ : $\mathrm{Eu}^{3+}$ microcrystals are found to be excellent matrix for photoluminescence property and the $\mathrm{Eu}^{3+}$ ion serves as a good red-emitting luminescent center. Further, room-temperature (RT) magnetic properties of $\mathrm{Fe}_{0.5} \mathrm{Gd}_{0.5}\left(\mathrm{MoO}_{4}\right)_{1.5}: \mathrm{Eu}^{3+}$ were investigated in detail.

\section{Synthesis, morphology, structure of the $\mathrm{Fe}_{0.5} \mathrm{Gd}_{0.5}\left(\mathrm{MoO}_{4}\right)_{1.5}: \mathrm{Eu}^{3+} 3 \mathrm{D}$ hierarchical microstructures}

\subsection{Synthesis procedure}

All the chemicals were purchased from Sigma Aldrich with $99.99 \%$ purity. In the typical synthesis, a stoichiometric amount of $\mathrm{FeCl}_{3} 6 \mathrm{H}_{2} \mathrm{O}$ was dissolved in $15 \mathrm{~mL}$ of double-distilled water through vigorous stirring. Then, the appropriate amount of $\mathrm{Na}_{2} \mathrm{MoO}_{4}$ was initially dissolved in $30 \mathrm{~mL}$ of double- distilled water under vigorous stirring. Then, $\mathrm{GdCl}_{3}$ and $\mathrm{EuCl}_{3}$ were prepared by dissolving the corresponding rare-earth sesquioxides $\left(\mathrm{Gd}_{2} \mathrm{O}_{3}, \mathrm{Eu}_{2} \mathrm{O}_{3}\right)$ in diluted hydrochloric acid and stirred for $15 \mathrm{~min}$. In order to remove the excess of $\mathrm{HCl}$, the solution was heated to $60-80^{\circ} \mathrm{C}$ for $30 \mathrm{~min}$. Then, the rare-earth chloride solution was carefully mixed into the $\mathrm{Na}_{2} \mathrm{MoO}_{4}$ solution. A white colloidal precipitate was obtained under vigorous stirring for $15 \mathrm{~min}$. Subsequently, iron chloride solution was gradually introduced into the above white precipitate solution, forming a brown mixture solution. Then, $0.1 \mathrm{mM}$ of polyvinylpyrrolidone (PVP40) was dissolved in $20 \mathrm{~mL}$ of double-distilled water, and was added to the resultant colloidal solution. Then, the $\mathrm{pH}$ value of the final product was consequently, adjusted to a value of $7-8$ by adding the proper amount of sodium hydroxide solution. After additional stirring for $30 \mathrm{~min}$, the acquired brown mixture solution was transferred into a 100 $\mathrm{mL}$ Teflon-lined stainless steel autoclave, and heated at $200^{\circ} \mathrm{C}$ for 6,12 , and $24 \mathrm{~h}$. Finally, the autoclave was allowed to cool at room temperature, and the final product was centrifugally 
cleaned (5, $000 \mathrm{rpm}$ for $30 \mathrm{~min}$ to remove organic containments and $\mathrm{NaCl})$, separated from the solution, rinsed with distilled water and absolute ethanol several times, and dried at $60^{\circ} \mathrm{C}$ in the air for $5 \mathrm{~h}$.

\subsection{Characterization}

XRD pattern of as-synthesized phosphor was analyzed using PANalytical's X'Pert PRO materials research, $X$-ray diffractometer equipped with a $\mathrm{Cu}-\mathrm{K} \alpha$ radiation $\left(\lambda=1.54060 \mathrm{~A}^{\circ}\right)$ at a scanning rate of $0.02^{\circ} \mathrm{s}^{-1}$ performed in the range of 20-60 degrees. Morphology and energydispersive X-ray spectra (EDX) of the product were investigated by scanning electron microscope (FESEM (Quanta 3D FEG)). The spacing between the two adjacent lattice planes was measured using high-resolution transmission electron microscope (HRTEM JEOL 3010). Furthermore, the room-temperature (RT) photoluminescence studies were carried out using Horiba-Jobin Yvon Fluromax-4P bench-top Spectrofluorometer. Room-temperature magnetic properties of the samples were analyzed using (Lake Shore 7307 model) vibrating sample magnetometer (VSM).

\subsection{Morphological investigations}

To explore the 3D surface morphology, particle size distribution, and formation mechanism for the evolution of nanoparticle sheathed bipyramid-like structures, a series of time-dependent experiments were carried out using a PVP employed hydrothermal route.

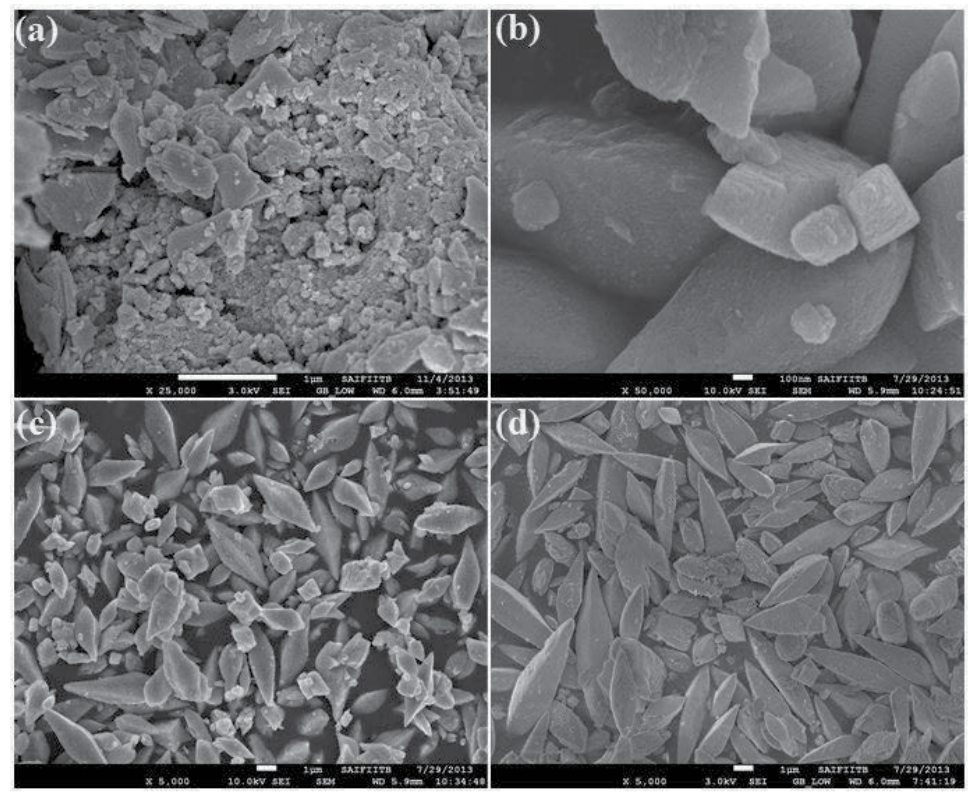

Figure 1. Field emission scanning electron microscopic images of $\mathrm{Fe}_{0.5} \mathrm{Gd}_{0.5}\left(\mathrm{MoO}_{4}\right)_{1.5}: \mathrm{Eu}^{3+}$ synthesized by PVP employed hydrothermal method with different time intervals, i.e., (a) $1 \mathrm{~h}$, (b) $2 \mathrm{~h}$, (c) $6 \mathrm{~h}$, (d) $12 \mathrm{~h}$ at $200^{\circ} \mathrm{C}$ with fixed $\mathrm{pH}(\sim 7)$. 
The FESEM and TEM analyses were used to characterize the morphology of the final products. By changing the experimental reaction time interval with fixed temperature $\left(200^{\circ} \mathrm{C}\right), \mathrm{pH}$ $(\sim 7)$, and molar concentration of the PVP $(0.1 \mathrm{mM})$, a substantial difference was observed in the final product. Figure (1-3)shows the low, high magnifications FESEM image of the $\mathrm{Fea}_{0.5} \mathrm{Gd}_{0.5}\left(\mathrm{MoO}_{4}\right)_{1.5}: \mathrm{Eu}^{3+}$ samples synthesized by hydrothermal route at different time intervals $(1,3,6,12,24$, and $48 \mathrm{~h})$ with fixed temperature $\left(200^{\circ} \mathrm{C}\right), \mathrm{pH}(\sim 7)$, and PVP molar concentration. During the initial period of $1 \mathrm{~h}$ time interval, numerous $2 \mathrm{D}$ nanoflakes with few tens of nanometer were observed, which acts as a primary building block for the subsequent growth of 3D microstructures (Figure $1(\mathrm{a})$ ). It was noticed from Figure $1(\mathrm{~b}, \mathrm{c})$, when the hydrothermal time period was increased to 3 and $6 \mathrm{~h}$, nanoflakes began to self-organize continuously through plane-to-plane coalition and try to form a bipyramidal morphology (average diameter of $1 \mu \mathrm{m}$ ). However, the morphology and size distribution was found to be less uniform. When the reaction time interval was kept at $12 \mathrm{~h}$, bipyramid-like morphology with an average of $1.0 \mu \mathrm{m}$ in length and an average of $1.2 \mu \mathrm{m}$ in diameter was obtained and shown in Fig. 1 (d). When the reaction time period was raised to $24 \mathrm{~h}$, highly ordered and self-assembled porous nanoparticle sheathed bipyramid-like morphology with the size approximately equal to 1.2 $\mu \mathrm{m}$ diameter was observed (Figure $2(\mathrm{a}, \mathrm{b})$ ). Further, increasing the reaction time to $48 \mathrm{~h}$, the final product morphology consisted of irregular porous bipyramid-like structures in which nanoparticles are sheathed and shown in Figure $2(\mathrm{c}, \mathrm{d})$. This may be due to the prolonged time interval, resulting in thermal collision between the particles (growth stage; the self-assembly process predominates between these crystals because of its high surface energies) [14].
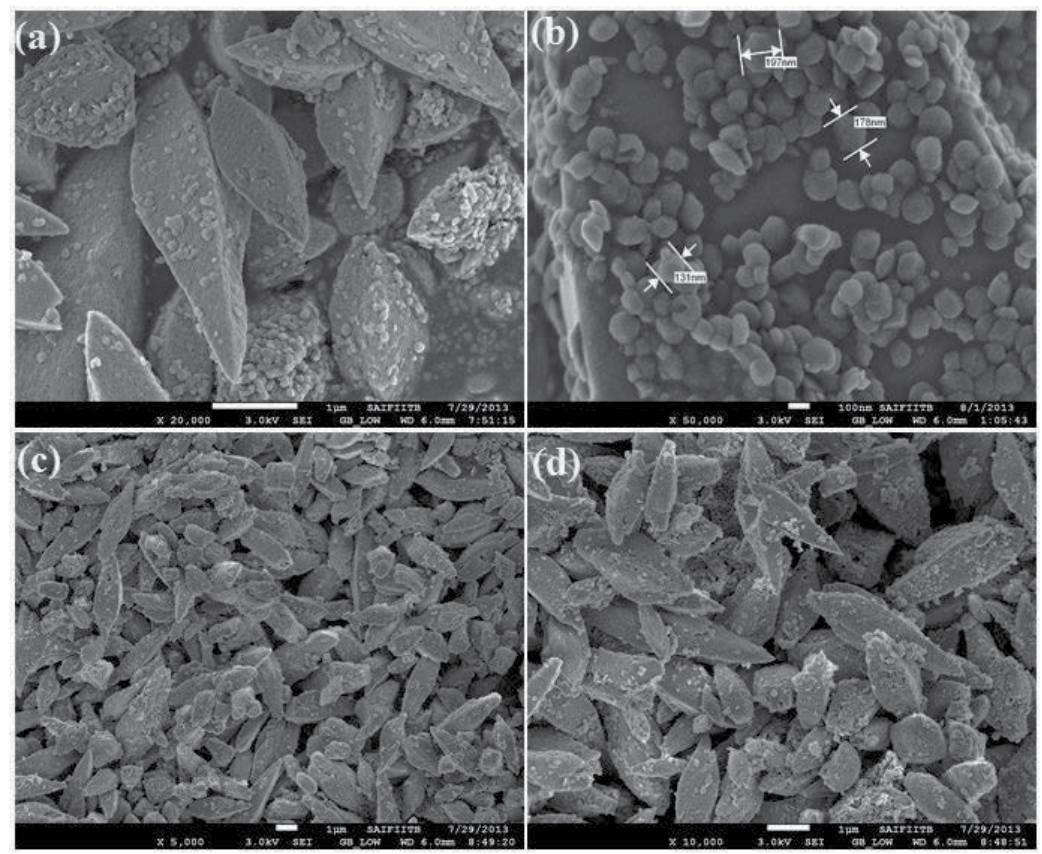

Figure 2. Low and high magnification SEM images of self-assembled nanoparticle sheathed $\mathrm{Fe}_{0} \mathrm{Gd}_{0.5}\left(\mathrm{MoO}_{4}\right)_{1.5}: \mathrm{Eu}^{3+}$ structures synthesized at (a, b) 24 and (c, d) $48 \mathrm{~h}$. 
This involves growth from 0D primary particles to 2D nanosheets, followed by the formation of 3D hierarchical networks through an assembly-disassembly process [14]. The TEM image of the sample synthesized at $24 \mathrm{~h}$ time interval with $0.1 \mathrm{mM}$ of PVP molar concentration is shown in Figure 3a and the corresponding inset shows the FFT pattern. The formation mechanism for the evolution of a nanoparticle-sheathed bipyramid-like $\mathrm{Fe}_{0.5} \mathrm{Gd}_{0.5}\left(\mathrm{MoO}_{4}\right)_{1.5}: \mathrm{Eu}^{3+}$ structure can be described as follows. Primarily, smaller crystalline nuclei formed in a supersaturated solution starts the crystallization process for subsequent growth of self-organization. During the self-organization process, smaller nanocrystals were grown-up constantly to form bigger particles via an Ostwald ripening phenomenon at higher reaction time intervals, due to interactions between the amorphous nanoparticles, resulting in 2D nanoflakes [14]. Initially, PVP acts as a surface capping agent to form a stable complex with $\mathrm{Gd}^{3+} / \mathrm{Fe}^{3+}$ and then kinetically controls the reaction rate, germination of nuclei, the growth rate, and the oriented aggregation mechanism. When the reaction temperature gradually increases to higher temperature, PVP would decompose gradually and has no obvious effect on the possible growth of nuclei. When the time period was increased, these 2D nanoflakes joined each other along a mutual crystallographic orientation through plane-to-plane conjunction of neighboring particles [14]. In general, such amalgamation process between the atoms/ions in molecules/crystals can induce dipole moments, which can be associated with certain specific crystallographic orientations [13]. The interaction among dipole moments in nearby nanoparticles is highly probable and acts as a driving factor for the oriented attachment procedure by allocation of a common crystallographic facet. The growth rate in $\mathrm{Fe}_{0} \mathrm{Gd}_{0.5}\left(\mathrm{MoO}_{4}\right)_{1.5}: \mathrm{Eu}^{3+}$ crystals is oriented preferentially along the [001] direction. Donnay-Harker et al. [5] reported that, for tetragonal structures, the surface free energy of the [001] face is larger than that of the [101] face [5, 2]. As a result, the faster growth rate in the [100], [010], and [001] faces in comparison with that in the [101] direction accelerates the formation of self-assembled structures.

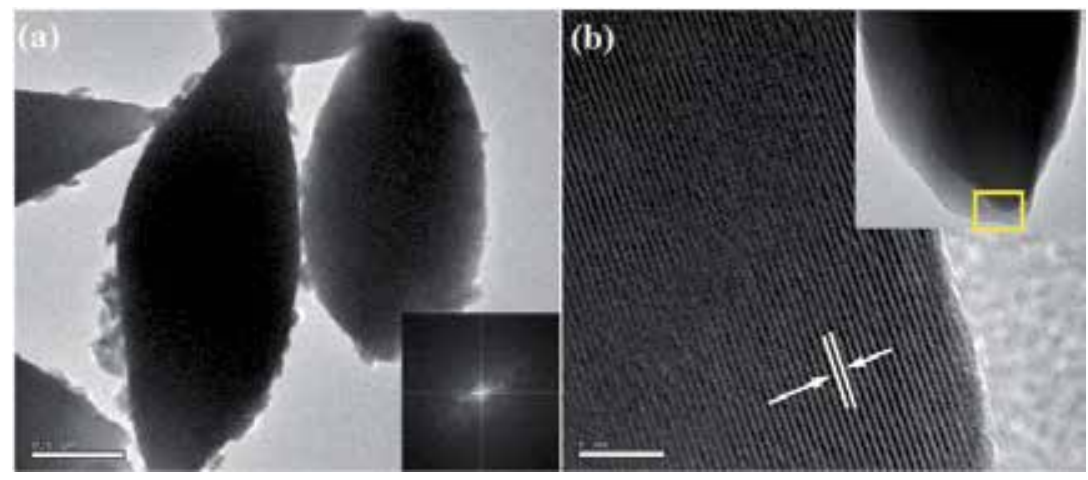

Figure 3. (a) TEM image of the $\mathrm{Fe}_{0} \mathrm{Gd}_{0.5}\left(\mathrm{MoO}_{4}\right)_{1.5}: \mathrm{Eu}^{3+}$ sample prepared at $24 \mathrm{~h}$ time interval and the corresponding inset shows the FFT pattern, (b) HRTEM image (inset typical HRTEM image taken on the marked part).

The as-grown 2D nanoflakes are continuously self-assembled via a layer-by-layer stacking process to form 3D bipyramid-like structures. Then, the completely developed bipyramid 
particles are readily disassembled into smaller nanoparticles, which are finally sheathed on individual bipyramid-like particles. After aging for a longer time period, the disassembly of well-organized structures could increase the entropy of the system and thus could decrease the free energy of the whole system [16], resulting in the nanoparticles arbitrarily sheathed on individual bipyramid-like particles. The assembly-disassembly process in $\mathrm{Fe}_{0} \mathrm{Gd}_{0.5}\left(\mathrm{MoO}_{4}\right)_{1.5}: \mathrm{Eu}^{3+}$ was described in our previous work [13] by using EDTA as a surface capping agent.

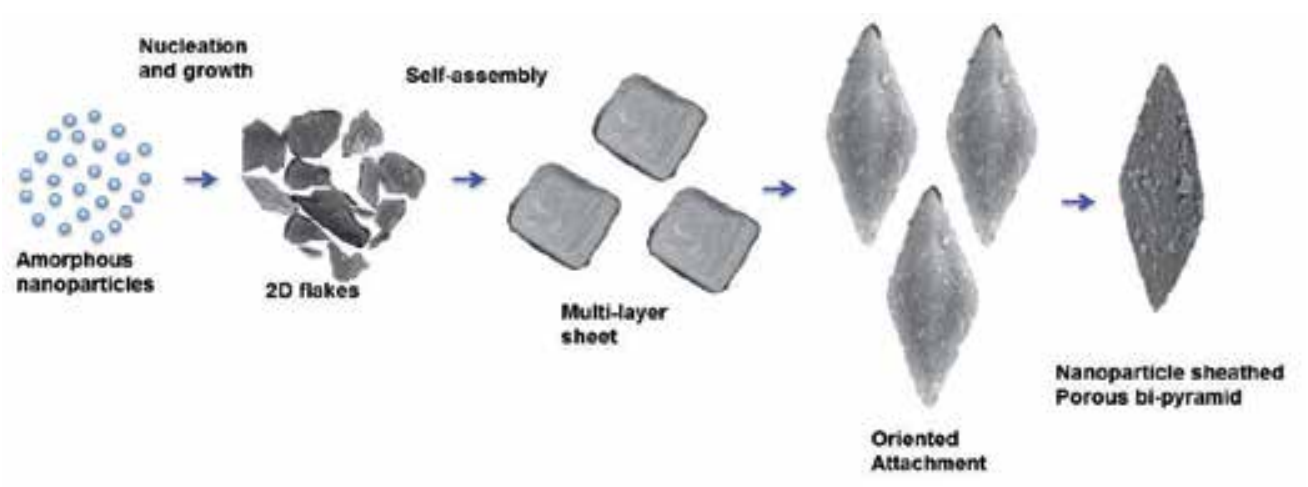

Figure 4. Schematic diagram illustrating the formation mechanism of nanoparticle sheathed $\mathrm{Fe}_{0} \mathrm{Gd}_{0.5}\left(\mathrm{MoO}_{4}\right)_{1.5}: \mathrm{Eu}^{3+} 3 \mathrm{D}$ hierarchical structures.

\subsection{Structural analysis}

The chemical phase purity and crystalline nature of the product were investigated using X-ray diffraction patterns. Figure 5 shows the XRD pattern of $\mathrm{Fe}_{0.5} \mathrm{Gd}_{0.5}\left(\mathrm{MoO}_{4}\right)_{1.5}: \mathrm{Eu}^{3+}$ samples synthesized by a facile hydrothermal route at different time intervals $(6,12,24$, and $48 \mathrm{~h})$. All the peaks are perfectly matched with the standard JCPDS card no. 25-0828 of $\left(\mathrm{Na}_{0.5} \mathrm{Gd}_{0.5}\right) \mathrm{MoO}_{4}$. It could be clearly observed that the XRD patterns of as-synthesized samples are highly crystalline, and the strongest intensity peak is observed at $2 \theta=28.67$ degrees analogous to (112) plane. The XRD pattern reveals that they belong to a tetragonal phase corresponding to the scheelite structure with the space group I41/a. In this crystal structure $\mathrm{Fe}^{3+}, \mathrm{Gd}^{3+} / \mathrm{Eu}^{3+}$ ions jointly occupy the dodecahedral sites of the tetrahedra. Molybdenum atoms $\left(\mathrm{Mo}^{6+}\right)$ populated in the center of tetrahedral symmetry is surrounded by four equivalent oxygen $\left(\mathrm{O}^{2-}\right)$ atoms [13] and forming isolated $\left[\mathrm{MoO}_{4}\right]^{2-}$ group. Owing to their similar ionic radius and valance state, the $\mathrm{Eu}^{3+}$ ion successfully replaces the $\mathrm{Gd}^{3+}$ ion and does not change the lattice site of the host $\mathrm{Fe}_{0.5} \mathrm{Gd}_{0.5}\left(\mathrm{MoO}_{4}\right)_{1.5}: \mathrm{Eu}^{3+}$ and the crystal phase is very much pure. Further, no other extra peaks of impurity were observed.

Figure $5(\mathrm{a}, \mathrm{b})$ shows the representative EDX analysis, taking single bipyramid-like particle and single nanoparticle sheathed on bipyramidal structure synthesized at $24 \mathrm{~h}$ time interval for $\mathrm{Eu}^{3+}$ doped $\mathrm{Fe}_{0.5} \mathrm{Gd}_{0.5}\left(\mathrm{MoO}_{4}\right)_{1.5}$. The energy-dispersive $\mathrm{X}$-ray spectrum was used to confirm the presence of iron $\left(\mathrm{Fe}^{3+}\right)$, gadolinium $\left(\mathrm{Gd}^{3+}\right)$, europium $\left(\mathrm{Eu}^{3+}\right)$, molybdenum $\left(\mathrm{Mo}^{6+}\right)$, and 


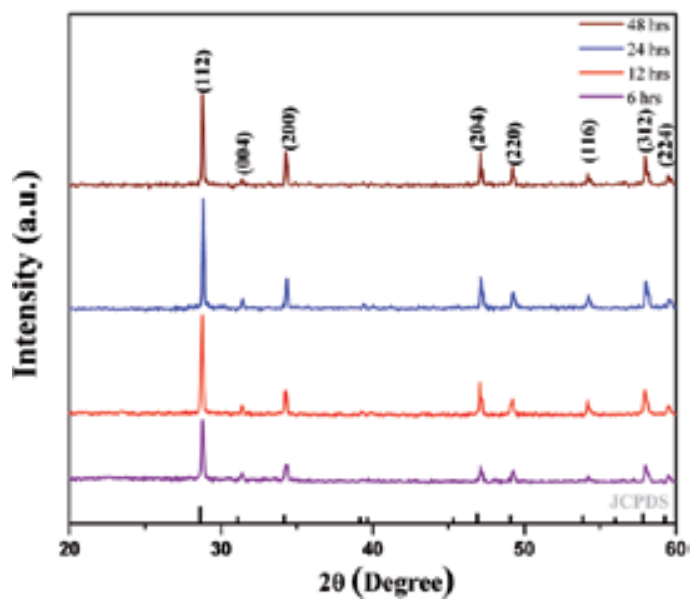

Figure 5. Powder X-ray diffraction (XRD) patterns of the $\mathrm{Fe}_{0} \mathrm{Gd}_{0.5}\left(\mathrm{MoO}_{4}\right)_{1.5}: \mathrm{Eu}^{3+}$ samples synthesized at different time intervals using the PVP-mediated hydrothermal method.
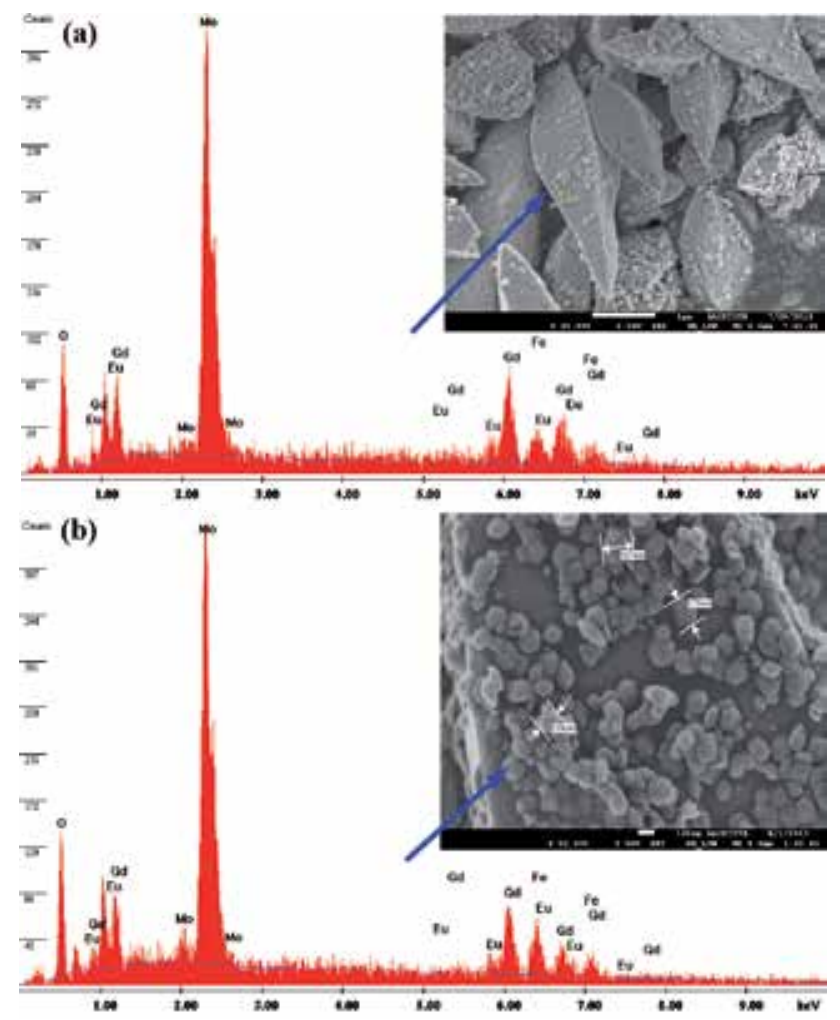

Figure 6. (a) EDX spectrum of single bipyramid-like $\mathrm{Fe}_{0.5} \mathrm{Gd}_{0.5}\left(\mathrm{MoO}_{4}\right)_{1.5}:$ Eu ${ }^{3+}$ particle, (b) EDX spectrum of single nanoparticle sheathed on a bipyramid-like particle. 
oxygen $\left(\mathrm{O}^{2-}\right)$ in the final product. The EDX spectrum shown in Figure $5(\mathrm{a}, \mathrm{b})$ confirms the presence of $\mathrm{Fe}, \mathrm{Gd}, \mathrm{Eu}, \mathrm{Mo}$, and $\mathrm{O}$ in the final product.

\subsection{Optical and magnetic properties of $\mathrm{Fe}_{0.5} \mathrm{Gd}_{0.5}\left(\mathrm{MoO}_{4}\right)_{1.5}: \mathrm{Eu}^{3+}$ structures}

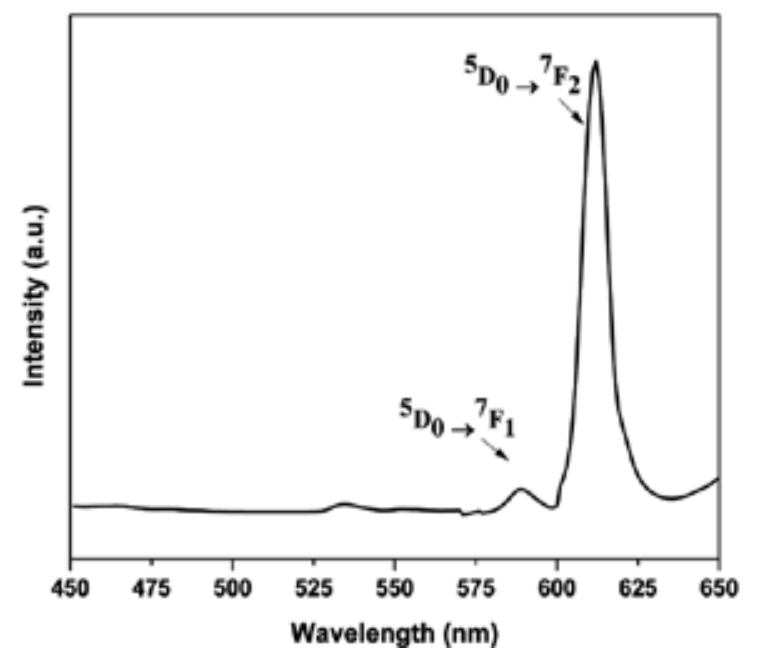

Figure 7. Room temperature emission spectra of $\mathrm{Eu}^{3+}$ doped $\mathrm{Fe}_{0.5} \mathrm{Gd}_{0.5}\left(\mathrm{MoO}_{4}\right)_{1.5}$ synthesized by the PVP-assisted hydrothermal route.

Figure 7 shows the PL excitation and emission spectra of nanoparticle sheathed bipyramidlike microstructures of $\mathrm{Fe}_{0.5} \mathrm{Gd}_{0.5}\left(\mathrm{MoO}_{4}\right)_{1.5}: \mathrm{Eu}^{3+}$. Emission $\left(\lambda_{\mathrm{ex}}=395 \mathrm{~nm}\right)$ spectra of the $\mathrm{Fe}_{0.5} \mathrm{Gd}_{0.5}\left(\mathrm{MoO}_{4}\right)_{1.5}$ doped with $\mathrm{Eu}^{3+}$ ions were recorded within the range from 575 to $700 \mathrm{~nm}$ at room temperature. Upon $395 \mathrm{~nm}$ UV irradiation, the emission spectrum was governed by the hypersensitive red emission, showing a transition ${ }^{5} \mathrm{D}_{0} \rightarrow{ }^{7} \mathrm{~F}_{2}$ (due to electric dipole transition) higher than ${ }^{5} \mathrm{D}_{0} \rightarrow{ }^{7} \mathrm{~F}_{1}$ (magnetic dipole). In the emission spectrum, the transitions ${ }^{5} \mathrm{D}_{0} \rightarrow{ }^{7} \mathrm{~F}_{\mathrm{J}}$ (where $\mathrm{J}=1,2,3,4$ ) were observed due to intra-configurational $\mathrm{f}-\mathrm{f}$ electronic transitions of $\mathrm{Eu}^{3+}$ ions. The presence of electric dipole transition confirmed that $\mathrm{Eu}^{3+}$ ions were located at sites without inversion symmetry $\left(\mathrm{C}_{3 \mathrm{v}}\right.$ symmetry). The other transitions ${ }^{5} \mathrm{D}_{0} \rightarrow{ }^{7} \mathrm{~F}_{3}$ and ${ }^{5} \mathrm{D}_{0} \rightarrow{ }^{7} \mathrm{~F}_{4}$ were comparatively very weak for all the samples (not shown in PL spectrum). However, the presence of magnetic iron $\left(\mathrm{Fe}^{3+}\right)$ in the $\mathrm{Fe}_{0.5} \mathrm{Gd}_{0.5}\left(\mathrm{MoO}_{4}\right)_{1.5}$ tetragonal crystal structure considerably decreases their luminescence, as $\mathrm{Fe}^{3+}$ ions share the dodecahedral sites with $\mathrm{Gd}^{3+} / \mathrm{Eu}^{3+}$ [13]. However, it is still unclear for the weak red emission in $\mathrm{Eu}^{3+}$ doped $\mathrm{Fe}_{0.5} \mathrm{Gd}_{0.5}\left(\mathrm{MoO}_{4}\right)_{1.5}$.

Figure 8 shows the room-temperature (RT) magnetic properties of hierarchically self-organized $\mathrm{Fe}_{0.5} \mathrm{Gd}_{0.5}\left(\mathrm{MoO}_{4}\right)_{1.5}: \mathrm{Eu}^{3+}$ 3D microstructures synthesized by the hydrothermal route at 24 $\mathrm{h}$ time interval. Magnetization as a function of applied magnetic field (from 15000 Oe to 15000 $\mathrm{Oe}$ ) was measured using a vibrating sample magnetometer. Due to the presence of $\mathrm{Gd}^{3+}$ ions, a magnetic hysteresis (M-H) loop was not observed in the case of $\mathrm{Eu}^{3+}$ doped $\mathrm{Fe}_{0.5} \mathrm{Gd}_{0.5}\left(\mathrm{MoO}_{4}\right)_{1.5}$. From Figure 8, it is clear that a straight line crosses the origin, indicating that the phosphor $\mathrm{Fe}_{0.5} \mathrm{Gd}_{0.5}\left(\mathrm{MoO}_{4}\right)_{1.5}: \mathrm{Eu}^{3+}$ exhibits a paramagnetic behavior due to the existence 
of paramagnetic $\mathrm{Gd}^{3+}$ ions and the saturation magnetization (Ms) value is found to be 0.028 emu/gm for RT. The extremely localized nature of the seven unpaired inner $4 \mathrm{f}$ electrons of $\mathrm{Gd}$ plays an important role which determines its magnetic properties [15]. These unpaired electrons in the outer orbital are closely bound to the nucleus and effectively shielded by the outer closed shell electrons $5 s^{2} 5 p^{6}$ from the crystal field [15]. Even though the $\mathrm{Gd}^{3+}$ ions jointly occupy the dodecahedral sites with $\mathrm{Fe}^{3+}$ ions, number of $4 \mathrm{f}$ electrons in the $\mathrm{Gd}^{3+}$ ions, atomic unit cell volume, direct $\mathrm{f}-\mathrm{f}$ exchange interactions between neighboring $\mathrm{Gd}^{3+}$ and $\mathrm{Fe}^{3+}$ atoms are responsible for setting up the magnetic moments $[15,14]$. Since, $\mathrm{Gd}^{3+}$ ions have total orbital angular momentum $L=0$ [13], the spin orbit coupling between the partially filled $4 \mathrm{f}$ electrons in the $\mathrm{Gd}^{3+}$ and $\mathrm{Fe}^{3+}$ ions is weak, which inhibits sufficient orbital overlaps [8].

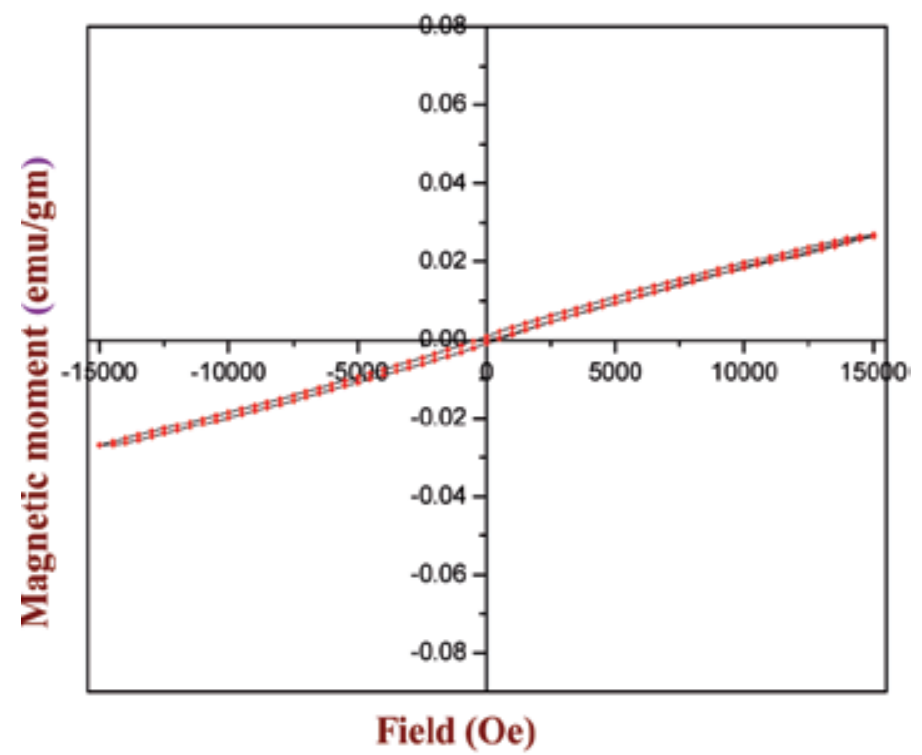

Figure 8. Magnetization vs. magnetic field of the as-synthesized bipyramid-like structures of $\mathrm{Fe}_{0.5} \mathrm{Gd}_{0.5}\left(\mathrm{MoO}_{4}\right)_{1.5}: \mathrm{Eu}^{3+}$ synthesized by hydrothermal treatment at $200^{\circ} \mathrm{C}$ for $24 \mathrm{~h}$.

\section{Conclusion}

In summary, the interaction between the $\mathrm{Gd}^{3+}$ and $\mathrm{Fe}^{3+}$ ions in the crystal structure $\mathrm{Fe}_{0.5} \mathrm{Gd}_{0.5}\left(\mathrm{MoO}_{4}\right)_{1.5}: \mathrm{Eu}^{3+}$ is weak and hence insufficient overlap of the orbitals associated with 4f shells gives rise to paramagnetism. Further, more detailed investigations are required to determine the magnetic behavior of $\mathrm{Fe}_{0.5} \mathrm{Gd}_{0.5}\left(\mathrm{MoO}_{4}\right)_{1.5}: \mathrm{Eu}^{3+}$ at various temperatures. The nanoparticle sheathed $\mathrm{Fe}_{0.5} \mathrm{Gd}_{0.5}\left(\mathrm{MoO}_{4}\right)_{1.5}$ : $\mathrm{Eu}^{3+}$ porous bipyramid-like structures were successfully synthesized using hydrothermal technique by employing PVP as the surfactant. The hydrothermal reaction time period was the key parameter and plays an important role for morphological evolution of self-aggregated 3D hierarchical networks. A possible growth 
mechanism for the formation of microstructures clearly involves the layer-by-layer selfassembly of 2D nanoflakes with successive disassembly, via an Ostwald ripening phenomena. The photoluminescence emission properties of $\mathrm{Eu}^{3+}$ doped $\mathrm{Fe}_{0.5} \mathrm{Gd}_{0.5}\left(\mathrm{MoO}_{4}\right)_{1.5}$ were investigated. Under the excitation of $395 \mathrm{~nm}$ UV light, the as-synthesized samples show red emission from the hypersensitive ${ }^{5} \mathrm{D}_{0} \rightarrow{ }^{7} \mathrm{~F}_{2}$ transition at $615 \mathrm{~nm}$. RT magnetic properties of the nanoparticles sheathed porous bipyramid-like $\mathrm{Fe}_{0.5} \mathrm{Gd}_{0.5}\left(\mathrm{MoO}_{4}\right)_{1.5}: \mathrm{Eu}^{3+}$ structures clearly exhibit the paramagnetic behavior due to the presence of paramagnetic $\mathrm{Gd}^{3+}$ ions. The current experimental results are important and may open up a new scope for the design and formulation of bifunctional magnetic and luminescence applications.

\section{Author details}

Rajagopalan Krishnan ${ }^{1}$ and Jagannathan Thirumalai ${ }^{*}$

*Address all correspondence to: thirumalaijg@gmail.com

1 Department of Physics, Rajalakshmi Institute of Technology, Kuthampakkam, Chennai, Tamil Nadu, India

2 Department of Physics, B. S. Abdur Rahman University, Vandalur, Chennai, Tamil Nadu, India

\section{References}

[1] Ajithkumar G, Yoo B, Goral DE, Hornsby PJ, Lin A-L, Ladiwala U, Dravid VP, \& Sardar DK. Multimodal bioimaging using a rare earth doped $\mathrm{Gd}_{2} \mathrm{O}_{2} \mathrm{~S}: \mathrm{Yb} /$ Er phosphor with upconversion luminescence and magnetic resonance properties. J Mater Chem B 2013;1(11):1561-72 (January 2013), ISSN: 2050-750X.

[2] Bu W, Chen Z, Chen F, Shi J. Oleic acid/oleylamine cooperative-controlled crystallization mechanism for monodisperse tetragonal bipyramid $\mathrm{NaLa}\left(\mathrm{MoO}_{4}\right)_{2}$ Nanocrystals. J Phys Chem C 2009;113(28):12176-85 (June 2009), ISSN: 1932-7447.

[3] Cavalcante L.S, Almeida MAP, Avansi W, Tranquilin RL, Longo E, Batista NC, Mastelaro VR, Li MS. Cluster coordination and photoluminescence properties of $\alpha$ $\mathrm{Ag}_{2} \mathrm{WO}_{4}$ microcrystals. Inorg Chem 2012a;51:10675-87 (September 2012), ISSN: 0020-1669.

[4] Cavalcante LS, Longo VM, Sczancoski JC, Almeida MAP, Batista AA, Varela JA, Orlandi MO, Longo E, Li MS. Electronic structure, growth mechanism and photoluminescence of $\mathrm{CaWO}_{4}$ crystals. Cryst Eng Comm 2012b;14:853-68 (November 2012), ISSN: 1466-8033. 
[5] Donnay JDH, Harker D. A new law of crystal morphology extending the law of Bravais. Am Mineral 1937;22(5):446-47 (May 1937), ISSN: 0003-004x.

[6] Gupta BK, Narayanan TN, Vithayathil SA, Lee Y, Koshy S, Reddy ALM, Saha A, Shanker V, Singh VN, Kaipparettu BA, Martí AA, Ajayan PM. Highly luminescentparamagnetic nanophosphor probes for in vitro high-contrast imaging of human breast cancer cells. Small 2012;19(8):3028-34 (October 2012), ISSN: 1613-6829.

[7] Han L, Xiaohong Y, Xiangfu W. Controllable synthesis and down-conversion properties of flower-like $\mathrm{NaY}\left(\mathrm{MoO}_{4}\right)_{2}$ microcrystals via polyvinylpyrrolidone-mediated. J Solid State Chem 2013;204:266-71 (June 2013), ISSN: 0022-4596.

[8] He F, Niu N, Wang L, Xu J, Wang Y, Yang G, Gai S Yang P. Influence of surfactants on the morphology, upconversion emission, and magnetic properties of $\beta$ $\mathrm{NaGdF}_{4}: \mathrm{Yb}^{3+}, \mathrm{Ln}^{3+}$ (Ln = Er, Tm, Ho). Dalton Trans 2013;42:(27)10019-28 (April 2013), ISSN: $1477-9226$.

[9] Huang S, Zhang X, Wang L, Bai L, Xu J, Li C, Yang P. Controllable synthesis and tunable luminescence properties of $\mathrm{Y}_{2}\left(\mathrm{WO}_{4}\right)_{3}: \mathrm{Ln}^{3+}(\mathrm{Ln}=\mathrm{Eu}, \mathrm{Yb} / \mathrm{Er}, \mathrm{Yb} / \mathrm{Tm}$ and $\mathrm{Yb} / \mathrm{Ho})$ 3D hierarchical architectures. Dalton Trans 2012;41(18):5634-42 (February 2012), ISSN: 1477-9226.

[10] Jayanthi K, Manorama, SV. Lumino-magnetic YAG:Ce nanophosphors: novel synthesis routes for efficient luminescence and magnetic properties. J Mater Chem C 2014;2 (48):10322-30 (October 2014), ISSN: 2050-7526.

[11] Kaczmareka AM, Deun RV. Rare earth tungstate and molybdate compounds from OD to 3D architectures. Chem Soc Rev 2013;42(23):8835-48 (September 2013), ISSN: 0306-0012.

[12] Krishnan R, Thirumalai J, Banu IBS, Chandramohan R. Influence of $\mathrm{Eu}^{3+}$ ions in $\mathrm{Na}_{0.5} \mathrm{La}_{0.5} \mathrm{MoO}_{4}$ : structural and optical investigation. J Mater Sci: Mater Electron 2013;24;(12):4774-81 (September 2013), ISSN: 0957-4522.

[13] Krishnan R, Thirumalai J, Kathiravan A. Luminescence and magnetic properties of novel nanoparticle-sheathed 3D micro-architectures of $\mathrm{Fe}_{0.5} \mathrm{R}_{0.5}\left(\mathrm{MoO}_{4}\right)_{1.5}: \mathrm{Ln}^{3+}(\mathrm{R}=$ $\left.\mathrm{Gd}^{3+}, \mathrm{La}^{3+}\right),(\mathrm{Ln}=\mathrm{Eu}, \mathrm{Tb}, \mathrm{Dy})$ for bi-functional application. Elect Mat Let 2015;11(1): 24-33 (January 2015) ISSN: 1738-8090.

[14] Krishnan R, Thirumalai J, Thomas S, Gowri M. Luminescence and magnetic behaviour of almond like $\left(\mathrm{Na}_{0.5} \mathrm{La}_{0.5}\right) \mathrm{MoO}_{4}: \mathrm{RE}^{3+}(\mathrm{RE}=\mathrm{Eu}, \mathrm{Tb}, \mathrm{Dy})$ nanostructures. J Alloys Compd 2014b;604:20-30 (March 2014), ISSN: 0925-8388.

[15] Krishnan $\mathrm{R}$, Thirumalai J. Up/down conversion luminescence properties of $\left(\mathrm{Na}_{0.5} \mathrm{Gd}_{0.5}\right) \mathrm{MoO}_{4}: \mathrm{Ln}^{3+}(\mathrm{Ln}=\mathrm{Eu}, \mathrm{Tb}, \mathrm{Dy}, \mathrm{Yb} / \mathrm{Er}, \mathrm{Yb} / \mathrm{Tm}$, and $\mathrm{Yb} / \mathrm{Ho})$ microstructures: synthesis, morphology, structural and magnetic investigation. New J Chem 2013a; 38(8):3480-91 (May 2014), ISSN: 1144-0546. 
[16] Li G, Li L, Li M, Bao W, Song Y, Gan S, Zou H, Xu X. Hydrothermal synthesis and luminescent properties of $\mathrm{NaLa}\left(\mathrm{MoO}_{4}\right)_{2}: \mathrm{Eu}^{3+}, \mathrm{Tb}^{3+}$ phosphors. J Alloys Compd 2013a; 550:1-8 (February 2013), ISSN: 0925-8388.

[17] Li Z, Li C, Mei Y, Wang L, Du G, Xiong Y. Synthesis of rhombic hierarchical $\mathrm{YF}_{3}$ nanocrystals and their use as upconversion photocatalysts after $\mathrm{TiO} 2$ coating. Nanoscale 2013b;5(7):3030-36 (February 2013), ISSN: 2040-3364.

[18] Liu X, Li L, Noh HM, Jeong JH, Jang H, Shin DS. Controllable synthesis of uniform $\mathrm{CaMoO}_{4}: \mathrm{Eu}^{3+}, \mathrm{M}^{+}(\mathrm{M}=\mathrm{Li}, \mathrm{Na}, \mathrm{K})$ microspheres and optimum luminescence properties. RSC Adv 2015;5(13):9441-54 (January 2015), ISSN: 2046-2069.

[19] Ma ZY, Dosev D, Nichkova M, Gee SJ, Hammock BD, Kennedy IM. Synthesis and bio-functionalization of multifunctional magnetic $\mathrm{Fe}_{3} \mathrm{O}_{4} @ \mathrm{Y}_{2} \mathrm{O}_{3}$ : Eu nanocomposites. J Mater Chem 2009:19(27):4695-700 (May 2009) ISSN: 0959-9428.

[20] Mahalingam V, Thirumalai J, Krishnan R, Chandramohan R. Potential visible light emitting rare-earth activated $\mathrm{Ca}_{0.5} \mathrm{Y}_{1-\mathrm{x}}\left(\mathrm{MoO}_{4}\right)_{2}: \mathrm{xRE}^{3+}(\mathrm{RE}=\mathrm{Pr}, \mathrm{Sm}, \mathrm{Eu}, \mathrm{Tb}, \mathrm{Dy})$ phosphors for solid state lighting applications. J Mater Sci: Mater Electron 2014;26(2):84252 (November 2014), ISSN: 0957-4522.

[21] Park SW, Moon BK, Choi BC, Jeong JH, Bae JS, Kim KH. Red photoluminescence of pulsed laser deposited Eu:NaY $\left(\mathrm{MoO}_{4}\right)_{2}$ thin film phosphors on sapphire substrates. Curr Appl Phys 2012;12(2):S150-5 (February 2012), ISSN: 1567-1739.

[22] Shi J, Liu D, Tong L, Yang X, Yang H. Magnetic and photoluminescence properties of $\mathrm{Fe}_{3} \mathrm{O}_{4} @ \mathrm{SiO}_{2} @ \mathrm{YP}_{1-\mathrm{x}} \mathrm{V}_{\mathrm{x}} \mathrm{O}_{4}: \mathrm{Dy}^{3+}$ nanocomposites. J Alloys Compd 2011;509(42):10211-16 (October 2011), ISSN: 0925-8388.

[23] Thirumalai J, Chandramohan R, Basheer Ahamed M, Ezhilvizhian S, Vijayan TA. Pr ${ }^{3+}$ doped $\mathrm{BaMoO}_{4}$ octahedron to shuttle-like microcrystals: synthesis and luminescence properties. J Mater Sci: Mater Electron 2012;23(1):325-33 (May 2012), ISSN: 0957-4522.

[24] Thirumalai J, Krishnan R, Banu IBS, Chandramohan R. Controlled synthesis, formation mechanism and luminescence properties of novel 3-dimensional $\mathrm{Gd}_{2}\left(\mathrm{MoO}_{4}\right)_{3}$ : $\mathrm{Eu}^{3+}$ nanostructures. J Mater Sci: Mater Electron 2013;24(1):253-59 (January 2013), ISSN: 0957-4522.

[25] Wang W, Zou M, Chen K. Novel $\mathrm{Fe}_{3} \mathrm{O}_{4} @ \mathrm{YPO}_{4}: \operatorname{Re}(\mathrm{Re}=\mathrm{Tb}, \mathrm{Eu})$ multifunctional magnetic-fluorescent hybrid spheres for biomedical applications. Chem Commun 2010;46(28):5100-102 (May 2010) ISSN: 1359-7345.

[26] Xu L, Yang X, Zhai Z, Chao X, Zhang Z, Hou W. EDTA-mediated hydrothermal synthesis of $\mathrm{NaEu}\left(\mathrm{MoO}_{4}\right)_{2}$ microrugbies with tunable size and enhanced luminescence properties. Cryst Eng Comm 2011;13(15):4921-29 (June 2011), ISSN: 1466-8033.

[27] Xu L, Yang X, Zhai Z, Gu D, Pang H, Hou W. Self-assembled 3D architectures of $\mathrm{NaCe}\left(\mathrm{MoO}_{4}\right)_{2}$ and their application as absorbents. Cryst Eng Comm 2012;14(21): 7330-37 (August 2012), ISSN: 1466-8033. 
[28] Yan B, Wu J. Facile composite synthesis and photoluminescence of $\mathrm{NaGd}\left(\mathrm{MoO}_{4}\right)_{2}$ : $\mathrm{Ln}^{3+}(\mathrm{Ln}=\mathrm{Eu}, \mathrm{Tb})$ submicrometer phosphors. J Mater Res 2011;24(1):32-38 (January 2011), ISSN: 0884-2914.

[29] Zhang L, Cao XF, Ma Y-L, Chen X-T, Xue Z-L. Pancake-like $\mathrm{Fe}_{2}\left(\mathrm{MoO}_{4}\right)_{3}$ microstructures: microwave-assisted hydrothermal synthesis, magnetic and photocatalytic properties. New J Chem 2010;34(9):2027-33 (May 2010), ISSN: 1144-0546.

[30] Zhang Y, Zheng A, Yang X, He H, Fan Y, Yao C. Cubic $\mathrm{GdFeO}_{3}$ particle by a simple hydrothermal synthesis route and its photoluminescence and magnetic properties. Cryst Eng Comm 2012;14(24):8432-39 (September 2012), ISSN: 1466-8033. 

Chapter 4

\title{
Effect of Argon Carrier Gas Flux on $\mathrm{TiO}_{2}$ Nanostructures
}

\author{
Reza Sabet Dariani and Zohreh Nafari Qaleh \\ Additional information is available at the end of the chapter \\ http://dx.doi.org/10.5772/61639
}

\begin{abstract}
$\mathrm{TiO}_{2}$ nanowires (NWs) have been fabricated by thermal evaporation method, using the vapor-liquid-solid (VLS) growth method and Au thin layer as a catalyst which were coated on titanium/quartz substrate. Optical and microstructure properties of $\mathrm{TiO}_{2} \mathrm{NWs}$ have been reviewed under different argon carrier gas flows. The gas flow was varied from 60 to $170 \mathrm{sccm}$. The X-ray diffraction patterns showed that $\mathrm{TiO}_{2} \mathrm{NWs}$ formed in rutile phase and their preferred orientation was in (110). The field emission scanning electron microscope figures indicated that with increasing gas flow, nanowires became thinner and longer. The absorbance curve of $\mathrm{TiO}_{2}$ nanowires has been drawn by using spectrophotometer and their band gap was measured. Our results showed that the band gap has been enhanced in comparison with bulk one due to the quantum confinement. Also, the band gap enhanced from 3.35 to $3.45 \mathrm{eV}$ by increasing the argon flow, since the wires became thinner and longer. The Williamson-Hall mechanism was applied as the vital tools for characterization of crystallite size and microstrain. Also, microstructure properties have been studied by $\mathrm{X}$-ray diffraction analysis such as; dislocation density and texture coefficient. The crystallinity of $\mathrm{TiO}_{2} \mathrm{NWs}$ has been made better by enhancing $\mathrm{Ar}$ flow due to increasing of VLS growth method.
\end{abstract}

Keywords: TiO2, Nanostructure, Absorption coefficient

\section{Introduction}

\subsection{Semiconducting nanowires}

Based on the geometry, 1D nanostructures typically consist of four categories: nanowire (NW), nanorod (NR), nanobelt (NB), and nanotube. The first three categories all possess a solid structure, while the nanotube has a hollow center. There is a significant different in geometry, property, and synthesis strategies between the nanotube and the first three categories, i.e., NW, NR, and NB. In general, NRs are NWs with a small aspect ratio (i.e., short NWs), which 
typically appear rigid and straight. NB is a special NW structure with a rectangular crosssection. Typical NB structures are single crystals with well-defined side crystal facets. Sometimes, nanofibers were also used to describe the NW morphology, particularly when the NWs are very long and not single crystalline [1]. Nanoscaled materials are of great interest for their unique structure and properties. Compared to isotropic nanoparticles and two dimensional thin films, one dimensional nanostructures such as nanofibers and nanowires are much more anisotropic, i.e., the aspect ratio of length to diameter can attain very high values.

Semiconductor one-dimensional structures, i.e., nanorods and nanowires with diameters ranging from 1 to $400 \mathrm{~nm}$ and lengths of up to hundreds of micrometers, are known to have many interesting physical properties and great potential applications in semiconductor and electronic technologies, which have stimulated intensive, worldwide research activities. They are perhaps the most versatile building blocks for optical and (opto-)electronic circuits at the nanoscale. Preliminary studies of some of these one-dimensional nanostructures indicate that they may be used as microscopic probes, field emission sources, storage materials, and lightemitting devices with extremely low power consumption. Among these semiconductors, some metal oxides, for instance, stannic oxide, titanium oxide, cuprous oxide, and vanadium pentoxide are the most important base materials in industry for gas sensors, transistors, and electrode material as well as catalysts. There has been extensive research into various "topdown" and "bottom-up" methods to create these nanostructures. In order to investigate their properties, many methods have been developed to synthesize one-dimensional nanomaterials, such as carbon nanotubes confined chemical reaction, Chemical Vapor Deposition (CVD), Molecular Beam Epitaxy (MBE), vapor-liquid-solid (VLS), solution-liquid-solid (SLS), and template-based synthetic approaches. However, complicated apparatus, complex process control, and special condition may be required for these approaches [2, 3]. Here we will describe VLS method in details.

\subsection{Titanium dioxide $\left(\mathrm{TiO}_{2}\right)$}

Based on the geometry, 1D nanostructures typically consist of four categories: nanowire (NW), nanorod (NR), nanobelt (NB), and nanotube. The first three categories all possess a solid structure, while the nanotube has a hollow center. There is a significant difference in geometry, property, and synthesis strategies between the nanotube and the first three types, i.e., NW, NR, and NB. Generally, NRs are NWs with a small aspect ratio (short NWs), which typically become rigid and straight. NB is a special NW structure with a rectangular cross- section. Typical NB structures are single crystals with well-defined side crystal facets. Sometimes, nanofibers were also used to explain the NW morphology, particularly when the NWs are very long and not single crystalline.

Since Fujishima and Honda (1972) reported that n-type titanium dioxide $\left(\mathrm{TiO}_{2}\right)$ could be used as a photo anode for a photo electrochemical cell, titanium oxide has been comprehensively investigated owing to its great applications in many fields [4].

$\mathrm{TiO}_{2}$ naturally exhibits four different types of polymorphs, i.e., rutile, anatase, brookite, and $\mathrm{TiO}_{2}(\mathrm{~B})$. In addition, several metastable polymorphs, such as $\mathrm{TiO}_{2}(\mathrm{H}), \mathrm{TiO}_{2} \mathrm{II}$, and perovskite, have been produced synthetically. Different phases have different properties and thus require 
different conditions to form desired morphologies and offer different performance. In general, rutile is the most stable phase, while the anatase, brookite, and $\mathrm{TiO}_{2}(\mathrm{~B})$ are metastable and will transform into rutile under high temperature. This phase stability relationship also exists in $\mathrm{TiO}_{2}$ nanomaterial formations. Anatase phased nanomaterials were commonly obtained but always found in solution-based or low-temperature vapor deposition systems. High- temperature deposition or annealing would usually yield rutile $\mathrm{TiO}_{2}$ nanostructures. Brookite and $\mathrm{TiO}_{2}$ (B) phases were less common and typically obtained from solution-based growth systems. Other metastable phases have to be synthesized using particular types of precursors and under restrict conditions. They were very rarely observed as a stable nanomaterial phase $[1,5,6]$.

Indeed among the semiconductor oxides, titanium oxide $\left(\mathrm{TiO}_{2}\right)$ has received more attention during the last decade because of its high refractive index (2.5), high band gap ( $3 \mathrm{eV})$, transparency throughout the visible and infrared region, high chemical stability, and hardness [7]. Crystal structures of the two most important phases are anatase $(a=3.78 \AA, c=9.51 \AA$; space group of $\left.\mathrm{I}_{1} / \mathrm{amd}\right)$ and rutile $\left(a=4.59, c=2.96\right.$, space group of $\left.\mathrm{P}_{2} / \mathrm{mnm}\right)$. Each cell of rutile consists of two $\mathrm{TiO}_{2}$ molecules, while anatase has four $\mathrm{TiO} 2$ molecules. Figure 1 gives crystal structures of rutile (a) and anatase (b). The common features for these structures are as follows: $\mathrm{Ti}$ atom is positioned at the center of six $\mathrm{O}$ atoms, forming a deformed Ti-O octahedron. The octahedral share top points and a rhombic side join together and thus construct a crystal. The differences between them exist: three sides shared for the brookite, four for anatase and two for rutile. Among them rutile is the most stable and anatase is less while brookite is not stable. Therefore, the first two are commonly concerned in nanomaterials [4].
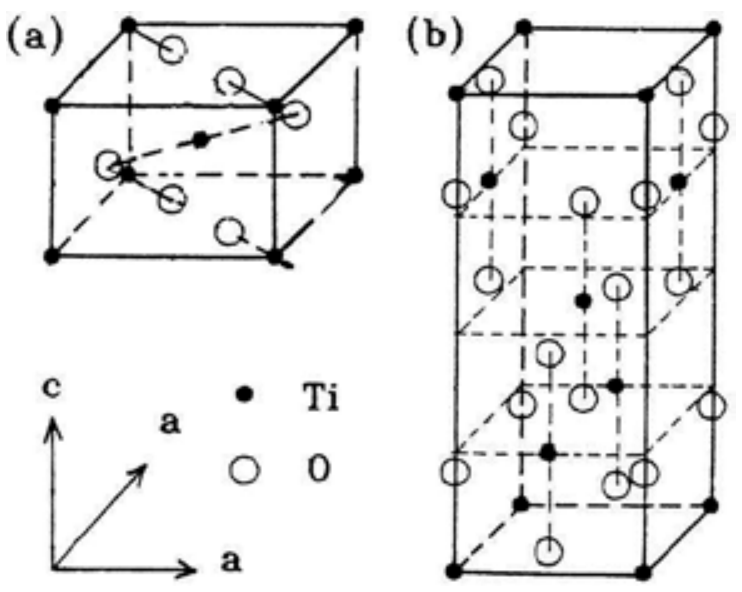

Figure 1. Two kinds of $\mathrm{TiO}_{2}$ crystal structures: (a) rutile, (b) anatase.

$\mathrm{TiO}_{2}$ has showed a wide range of applications in hydrogen production, lithium-ion batteries, fuel cells, gas sensors, detoxification, photovoltaics, photocatalysts, and super capacitors due to its excellent solid-state physical properties [8]. Over the past two decades, there have been remarkable advances in the expansion of one-dimensional (1D) nanostructures. The wire-like structure not only introduces significant enlarged and well-defined crystal surfaces over 
planar structures but also provides 1D confined channel, which could basically tailor the transportation of electrons, phonons, and photons [9]. The one-dimensional structure such as $\mathrm{TiO}_{2}$ nanowire is considered as a good candidate for getting higher performance in those applications compared to the bulk one. For example, a $\mathrm{TiO}_{2}$ nanowire based electrode can provide a large surface area for effectively collecting photons and electrons [8]. Tao et al. [10] used $\mathrm{TiO}_{2} \mathrm{NW}$ array as photo anodes of back-illuminated dye-sensitized solar cells. Shi et al. [11] grew $\mathrm{TiO}_{2}$ nanorods uniformly on dense Si NW array backbones, by using surfacereaction-limited pulsed chemical vapor deposition technique. They developed a 3D highdensity heterogeneous NW architecture, which is useful for photo electrochemical electrodes. Wang et al. [12] reported hydrogen-treated $\mathrm{TiO}_{2} \mathrm{NW}$ arrays for photo electrochemical water splitting. Mandal and Bhattacharyya [13] presented through systematic studies the performance of $\mathrm{TiO}_{2} \mathrm{NWs}$ in sensing, quantification, and photocatalytic degradation of cationic dyes in aqueous solution. Wang et al. [14] indicated that $\mathrm{TiO}_{2} \mathrm{NWs}$ have promising application for high energy density lithium-ion batteries. $\mathrm{Xi}$ et al. [15] grew single-crystalline rutile $\mathrm{TiO}_{2}$ nanorods on fluorine doped tin oxide glass for organic-inorganic hybrid solar cells by means of hydrothermal mechanisms.

Numerous routes have been explored to the synthesis of $1 \mathrm{D} \mathrm{TiO}_{2}$ nanostructures from both bottom up and top down. Representative bottom-up approaches include a large variety of solution- and vapor-based growth strategies. Although bottom-up approaches remain as the major synthesis efforts, several top-down procedures have also been explored for $1 \mathrm{D} \mathrm{TiO}_{2}$ growth, such as direct oxidation and electrochemical etching techniques. In general, there are four main approaches, which include solution-based synthetic approaches (such as hydrothermal/ solvothermal and sol-gel methods), vapor-based approaches (chemical/physical vapor deposition, atomic layer deposition-related methods and pulsed laser deposition), templated growth, and top-down fabrication techniques. Solution-based growth techniques offer several major advantages for mass production of nanomaterials including low-cost, simple processing, and good scalability. Vapor deposition is typically conducted in vacuum and under high temperature. Compared to the wet chemistry methods, it offers several unique advantages. First, the high quality of NW's crystallinity is secured due to the utilization of high-temperature and high-vacuum deposition conditions. Second, since the vapor deposition processes are typically performed in conventional thin film deposition systems, the knowledge of thin film growth techniques can be adopted to understanding the NW growth behaviors. Lastly, by engineering catalysts, growth sites, or precursors, the control of location, composition, dimension, and organization of NWs could be achieved via vapor deposition processes. Nevertheless, vapor deposition is usually associated with high cost and small- scale production. Template growth is a very versatile synthesis technique that forms nanostructure with a morphology that follows the porous template. Top-down fabrication techniques describe the creation of nanostructures from the bulk form. This approach typically is able to process a large quantity of nanostructures with uniform morphology and orientation. For $\mathrm{TiO}_{2} 1 \mathrm{D}$ nanostructures, a top-down process usually starts from a bulk Ti foil followed by selective etching and/ or oxidization. In the following section, the vapor- liquid- solid mechanism is described [1]. 


\subsection{VLS mechanism of nanowire growth}

Nanowires are commonly grown using vapor, solution or (template directed) electrodeposition methods. High- temperature growth from the vapor phase is often preferred due to the high crystal quality that can be obtained and the ability to grow large quantities of wires at once. A key factor in most vapor- and solution-based methods is the presence of small metal droplets during synthesis. Analysis of the growth of silicon whiskers (hairs) from the vapor phase using gold catalyst particles leads to the postulation of the vapor- liquid- solid (VLS) mechanism of growth. The VLS mechanism consists of three stages which are illustrated in figure 2A. First, a metal particle absorbs semiconductor material and forms an alloy. In this step, the volume of the particle increases and the particle often transition from a solid to a liquid state. Second, the alloy particle absorbs more semiconductor material until it is saturated. The saturated alloy droplet becomes in equilibrium with the solid phase of the semiconductor and nucleation occurs (i.e., solute/solid phase transition). During the final phase, a steady state is formed in which a semiconductor crystal grows at the solid/liquid interface. The precipitated semiconductor material grows as a wire because it is energetically more favorable than extension of the solid- liquid interface. The semiconductor material is precipitated at the existing solid/liquid interface as opposed to the formation of a new interface.
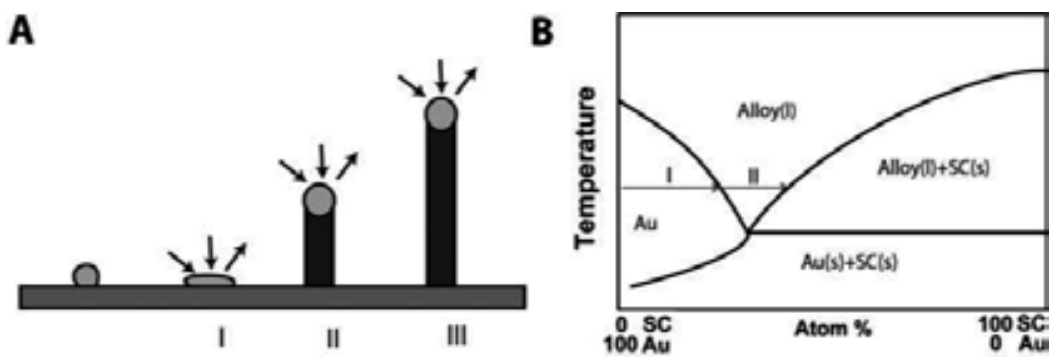

Figure 2. (A) The stages of (I) alloying, (II) nucleation, and (III) growth of nanowire synthesis according to the VLS growth mechanism. (B) Pseudobinary phase diagram of a semiconductor-gold system. The arrows indicate the subsequent phases when a gold droplet absorbs semiconductor material at a constant temperature. (1) At first, the gold particle is in the solid or liquid state. By absorbing semiconductor material, a liquid alloy is formed. (II) Subsequent absorption of more semiconductor material allows the liquid alloy to be in equilibrium with the solid semiconductor [2].

In the VLS mechanism, the wire diameter is determined by the diameter of the alloy particle which is in turn determined by the low temperature size of the metal particle and the temperature. The wire length is determined by the growth rate and time. When the system is cooled, the alloy droplet solidifies at the wire tip. To examine the feasibility of VLS wire growth from a certain semiconductor/metal combination, it is essential to study the (pseudo)binary phase diagram (figure 2B); the metal should form an alloy with the semiconductor at a temperature that also allows the semiconductor to exist in the solid phase. The validity of the VLS mechanism of wire growth has been proven for germanium nanowires by in- situ high- temperature TEM measurements. Heating neighboring gold and germanium clusters to growth temperatures and selectively evaporating the germanium clusters with an electron beam are allowed for the direct imaging of the successive steps of alloying and melting, nucleation and wire growth. A study using colloidal gold catalyst particles showed that using the VLS method, 
(single) crystalline nanowires with diameters as small as $5 \mathrm{~nm}$ could be obtained. In addition, it has been shown that by increasing the VLS growth rate by modulating the temperature, crystallization only takes place at the surface of the catalyst particle resulting in the growth of nanotubes. Since the late 1990's, semiconductor nanowire growth using the VLS method has enjoyed an increasing popularity with researchers and industry [2].

Some of studies on $\mathrm{TiO}_{2}$ nanowires are listed in Table 1.

\begin{tabular}{|c|c|c|c|c|}
\hline Year & Researcher & Fabrication method & Carrier gas & References \\
\hline 2002 & Zhang et al. & Hydrothermal synthesis & None & [16] \\
\hline 2003 & Pradhan et al. & $\begin{array}{l}\text { Metalorganic chemical vapor } \\
\text { deposition }\end{array}$ & $500-800 \mathrm{sccm}$ (Ar) & [17] \\
\hline 2006 & Lee et al. & VLS & $100 \mathrm{sccm}(\mathrm{Ar})+0.5 \mathrm{sccm}\left(\mathrm{O}_{2}\right)$ & {$[18]$} \\
\hline 2006 & Wu et al. & Thermal evaporation & $20 \mathrm{sccm}(\mathrm{Ar})+1 \mathrm{sccm}\left(\mathrm{O}_{2}\right)$ & [19] \\
\hline 2006 & Gyorgy et al. & Pulsed laser deposition & None & [20] \\
\hline 2007 & Amin et al. & VLS & $\begin{array}{c}10 \mathrm{sccm}(\mathrm{Ar}) / \\
10 \mathrm{sccm}(\mathrm{Ar})+1 \mathrm{sccm}\left(\mathrm{O}_{2}\right)\end{array}$ & [21] \\
\hline 2007 & Berger et al. & Chemical bath deposition & None & [22] \\
\hline 2008 & Huo et al. & Thermal & $150 \mathrm{sccm}(\mathrm{Ar})$ & [23] \\
\hline 2008 & Baik et al. & VLS & $200 \mathrm{sccm}$ (Ar) & [24] \\
\hline 2009 & Huo et al. & Direct Growth on ti foil & $50 \mathrm{sccm}$ (Ar) & [25] \\
\hline 2011 & RamezaniSani et al. & Thermal evaporation & $50-150 \mathrm{sccm}(\mathrm{Ar})$ & [26] \\
\hline 2011 & Liu et al. & $\begin{array}{l}\text { water-assisted chemical } \\
\text { vapor deposition }\end{array}$ & $400 \mathrm{sccm}$ (Ar) & {$[4]$} \\
\hline 2011 & Park et al. & VLS and VS & $200 \mathrm{sccm}(\mathrm{Ar})$ & [27] \\
\hline 2011 & Ha et al & VLS & Ar with $2 \% \mathrm{H}_{2}$ upon reaching $1 \mathrm{~atm}$ & [28] \\
\hline 2012 & Wu et al. & Solvothermal method & None & [29] \\
\hline 2012 & Shang et al. & Thermal Evaporation & $100 \mathrm{sccm}(\mathrm{Ar})$ & [30] \\
\hline 2013 & Liu et al. & $\begin{array}{l}\text { Low-temperature } \\
\text { hydrothermal method. }\end{array}$ & None & [31] \\
\hline 2013 & Dariani et al. & VLS & 60- $170 \mathrm{sccm}(\mathrm{Ar})$ & [32] \\
\hline 2013 & Tian et al. & Electron beam lithography & None & [33] \\
\hline 2013 & Liu et al & Molten-salt flux method & None & [34] \\
\hline 2014 & Nechache et al. & Pulsed laser deposition & 300 mTorr $\left(\mathrm{O}_{2} / \mathrm{Ar}\right)$ & [35] \\
\hline 2015 & Wang et al. & $\begin{array}{c}\text { Confined-space synthesis at } \\
\text { low temperature }\end{array}$ & None & [36] \\
\hline
\end{tabular}

Table 1. Some of works on the fabrication of $\mathrm{TiO}_{2}$ nanowires 
The vapor-liquid-solid and the vapor-solid growth mechanisms have been used to fabricate high-quality oxide NWs with short heating times. Ha et al. [28] synthesized single-crystalline rutile $\mathrm{TiO}_{2} \mathrm{NWs}$ by VLS method on Ti foil substrates patterned with catalytic Sn nano-islands, Lee et al. [18] grew $\mathrm{TiO}_{2}$ NWs in this way but used $\mathrm{Au}$ as catalysts, and Park and Lee [27] reported synthesis of $\mathrm{TiO}_{2} \mathrm{NWs}$ by $\mathrm{Ni}$ as catalysts.

$\mathrm{TiO}_{2}$ nanowire is typically achieved using either of the two different synthetic methods developed over the past few years: one is the wet-chemistry method such as electrochemical, sol-gel electrophoresis, hydrothermal growth on $\mathrm{Ti}$ substrates at $180{ }^{\circ} \mathrm{C}$ utilizing various organic solvents to oxidize Ti [37], direct oxidizing Ti substrate with aqueous hydrogen peroxide solutions [10], and solvothermal method [38]. The other is the dry method such as, growth single-crystalline $\mathrm{TiO}_{2}$ nanowires by thermal evaporation in atmospheric-pressure (101325 Pa) [30], metal-organic chemical vapor deposition [39], pulsed chemical vapor deposition [8], chemical vapor transport process by evaporating Ti metal powders [18], heating titanium grids (substrate) by ethanol-embedding followed by an annealing in the air [40], and by a facile water- assisted chemical vapor deposition method based on commercial metal titanium [4]. $\mathrm{TiO}_{2}$ nanowires produced by the wet-chemistry method due to poor crystallinity have difficulty integrating into device fabrication. Also, they need additional processes in order to improve their crystallinity [27].

In this work, $\mathrm{TiO}_{2}$ nanowires were synthesized by a carbothermal evaporation process on quartz substrate at $850{ }^{\circ} \mathrm{C}$ for $1 \mathrm{~h}$ at atmospheric pressure (101325 Pa), and Au was used as a catalyst. Also, the influence of argon flow as carrier gas on microstructural and optical characteristics was measured. We have been characterized some microstructural parameters like crystallite size, microstrain within the crystallite, dislocation density, and texture coefficient by the diffraction pattern.

\section{Experimental details}

In this study, pieces of quartz with dimensions of $1 \times 15 \times 15 \mathrm{~mm}^{3}$ are used. Initially, the substrates were ultrasonically cleaned with acetone and ethanol for 10 minutes, respectively. Then a layer of titanium was deposited on substrates by electron beam evaporation technique with the evaporation rate of $0.2 \AA / s$ under the pressure of $1.5 \times 10^{-5} \mathrm{mbar}$. In this step, voltage and current were kept $4 \mathrm{kV}$ and $100 \mathrm{~mA}$, respectively. The electron beam evaporation device is specified by: HIND HIGH VACUUM CO. Model 12A4D. After removing the samples, a gold thin layer with $3 \mathrm{~nm}$ thickness was coated on the titanium layer by sputtering method.

In next step, a tablet containing of titanium and graphite with the ratio of 1:1 as a source material was placed in the center of horizontal furnace. The center of the furnace was heated to $1050^{\circ} \mathrm{C}$ with heating rate of $20^{\circ} \mathrm{C} / \mathrm{min}$. According to phase diagram of the Au-Ti system, the eutectoid temperature is about $832^{\circ} \mathrm{C}$ [30]. The eutectoid temperature is a point in which two metals in solid phase form an alloy in solid phase (no in liquid phase). Thus, the sample was placed in distance of $12-13 \mathrm{~cm}$ (with about $850{ }^{\circ} \mathrm{C}$ temperature) from the center of the furnace for $1 \mathrm{~h}$ at atmospheric pressure and under argon flow. The vapor was generated from source 


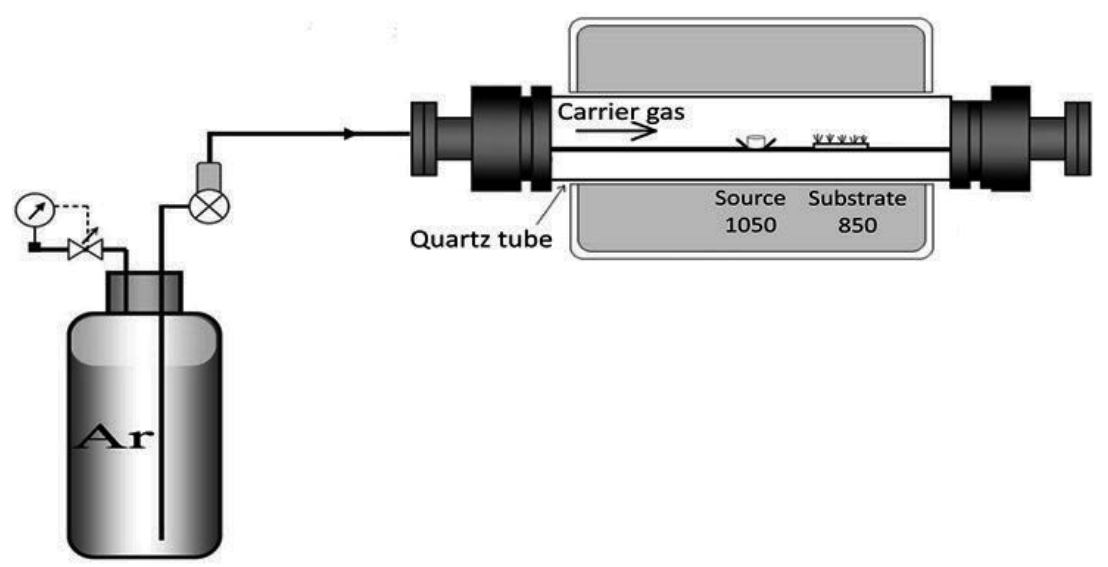

Figure 3. A schematic of CVD system.

material transported to the substrate and at last condensed on the surface of substrate (see figure 3). Then the substrate was naturally cooled down to room temperature. In this study, three samples under different argon gas flows $(60 \mathrm{sccm}, 110 \mathrm{sccm}$, and $170 \mathrm{sccm}$ ) were fabricated. Argon gas was also used to control the oxygen content of experiment. It is believed that oxygen comes from leaked air during heating process. Content of argon was kept constant during heating process by using bubbling trap at the end of the vent line. The microstructure and the morphology of the samples were analyzed by x-ray diffraction (XRD: Philips X-Pert PW 3040/60, $\lambda(\mathrm{Cuk} \alpha)=1.54^{\circ} \mathrm{A}$ ) and field emission scanning electron microscope (FESEM: Hitachi S4160 with operating voltage of $15 \mathrm{kV}$ ), respectively. The absorption spectrum of $\mathrm{TiO}_{2}$ nanostructures was evaluated by spectrophotometer (Ocean Optics, Model HR4000 CGUV-NIR).

\section{Results and discussion}

\subsection{SEM observations}

The morphologic characteristics of the samples under different carrier gas flows are determined by SEM images. The cross-sectional views of the samples are shown in figure 4 .

The average range of length and diameter of nanowires are given in Table 2. It can be seen that nanowires become thinner and longer with increasing the carrier gas flow. Since fabrication parameters except argon flow were fixed, it can be concluded that the amount of $\mathrm{O}_{2}$ inside the reaction chamber plays a vital role in the growth of $\mathrm{TiO}_{2} 1 \mathrm{D}$ nanostructures. When the $\mathrm{O}_{2}$ concentration was high, i.e., Ar flow was low, the VLS growth (will describe later) was suppressed because Ti vapor could readily react with $\mathrm{O}_{2}$ before forming alloy droplets with $\mathrm{Au}$ as catalyst [12]. Therefore, in this condition, a relatively low concentration of $\mathrm{O}_{2}$ is necessary [13]. 

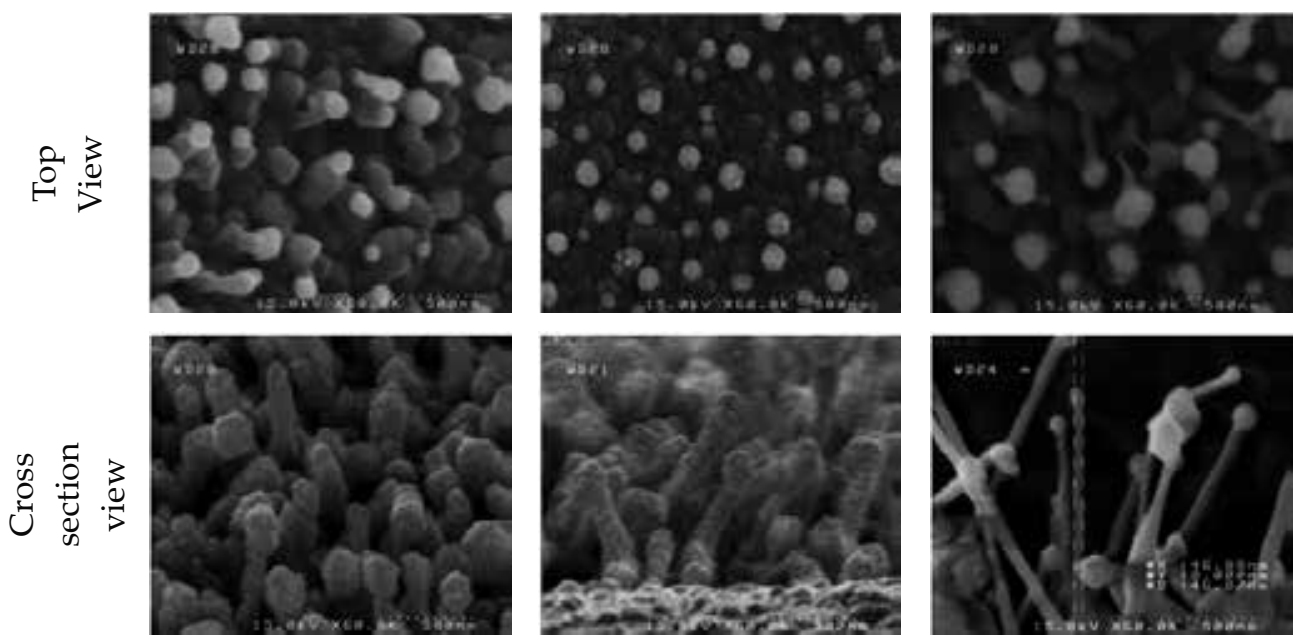

Figure 4. Top and cross-sectional SEM views of $\mathrm{TiO}_{2}$ nanostructures. Argon gas flow increases from left to right.

\begin{tabular}{cccc}
\hline Sample & Argon flow (sccm) & Average Diameter (nm) & Average Length (nm) \\
\hline S1 & 60 & 121 & 390 \\
\hline S2 & 110 & 117 & 648 \\
\hline S3 & 170 & 72 & 1021 \\
\hline
\end{tabular}

Table 2. Average values of diameter and length of nanowires.

Figure 5 shows compositional energy-dispersive $X$-ray spectroscopy (EDAX) analysis of the NW tip and the confirmation of the existence of Au alloy.

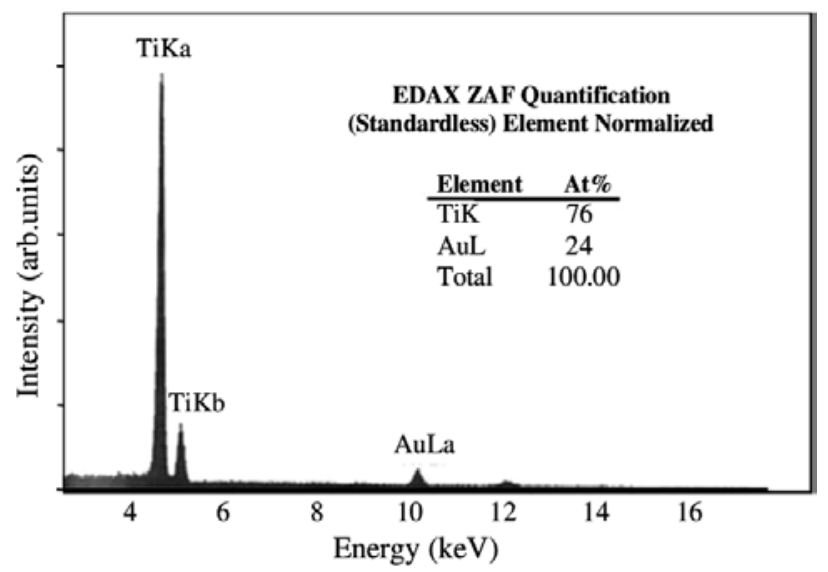

Figure 5. A typical EDAX of our samples which shows the existence of Au. 


\subsection{XRD studies}

To examine the effect of argon flow on structural properties of $\mathrm{TiO}_{2} 1 \mathrm{D}$ nanostructure, the XRD analyses were performed. Figure 6 shows $\mathrm{XRD}$ patterns of $\mathrm{TiO}_{2}$ grown on Ti/quartz substrates.

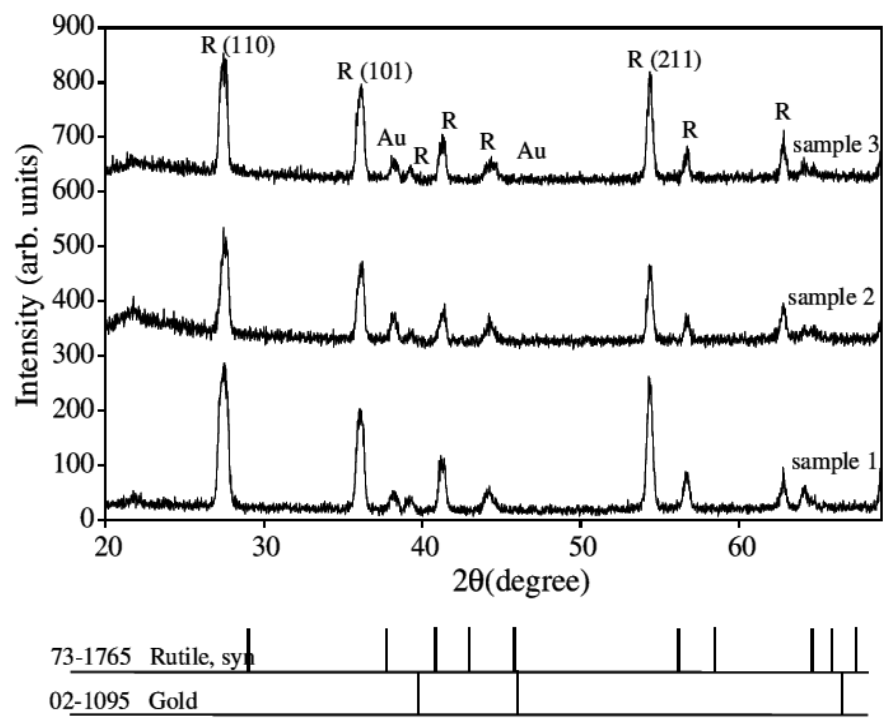

Figure 6. XRD patterns of $\mathrm{TiO}_{2}$ nanowires at different carrier gas flows.

Rutile phase is formed on the samples and (110) direction is preferred direction which is consistent with SEM images. In the $\mathrm{TiO}_{2}$ tetragonal structure, the plane spacing $(d)$ is related to lattice constants ( $a$ and $c$ ) and the Miller indices $(h, k$, and $l$ ) by the following relation [42]:

$$
1 /\left(d_{h k l}\right)^{2}=h^{2}+k^{2} / a^{2}+l^{2} / c^{2}
$$

The results are presented in Table 3 and are consistent with standard card of JCPDS (73-1765).

\begin{tabular}{cllc}
\hline Sample & $a(\AA)$ & $c(\AA)$ & $E g(e V)$ \\
\hline S1 & 4.586 & 2.951 & $3.35 \pm 0.02$ \\
\hline S2 & 4.583 & 2.955 & $3.39 \pm 0.02$ \\
\hline S3 & 4.589 & 2.949 & $3.45 \pm 0.02$ \\
\hline JCPDS & 4.589 & 2.954 & \\
\hline
\end{tabular}

Table 3. Lattice constants and $\mathrm{E} g$ of nanowires at different carrier gas flows. 


\subsection{Optical properties}

The absorbance spectrum of $\mathrm{TiO}_{2}$ nanowires is measured by spectrophotometer. According to Beer-Lambert's law (Eq. 2), transmittance (Eq. 3), and absorbance (Eq. 4) definitions [43], the absorption coefficients of samples according to absorbance are obtained by Eq. 5 :

$$
\begin{gathered}
I(\lambda)=I_{0}(\lambda) e^{-\alpha(\lambda) d} \\
T(\lambda)=I(\lambda) / I_{0}(\lambda) \\
A(\lambda)=-\log \left(T_{\lambda}\right) \\
\alpha=(-1 / d) \operatorname{Ln}\left(10^{-\mathrm{A}}\right)=(\mathrm{A} / \mathrm{d}) \operatorname{Ln}(10)
\end{gathered}
$$

where $d$ is the thickness of samples derived from the cross-sectional images of SEM and $A$ is the absorbance of samples.

It is known that the relationship between absorption coefficient $\alpha$ near the absorption edge and the optical band gap $E_{g}$ is determined by Tauc relation [15]:

$$
\alpha h v=C\left(h v-E_{g}\right)^{n}
$$

where $C$ is a constant, $n$ is equal to 0.5 or 2 for direct and indirect allowed transitions, respectively, and $h v$ is photon energy. The $E_{g}$ can be graphically estimated by a linear fit of the highenergy tail of $(\alpha h v)^{1 / n}$. Since the samples have rutile structure, rutile titania has direct band gap $(n=0.5)$.

Figure 7 shows $(\alpha h v)^{2}$ plots versus photon energy $h v$ for direct transition and intercepts value of the linear-fit extrapolations with the horizontal axes. The values of $E_{g}$ are given in Table 2 .

The optical results have shown that all the samples are characterized by energy gap higher than bulk rutile $\mathrm{TiO}_{2}\left(E_{g}=3 \mathrm{eV}\right.$ for bulk) [28]. As the carrier gas concentration increases, the band gap increases from 3.35 to $3.45 \mathrm{eV}$. The higher value of the rutile titania energy gap are attributable to the well-known relationship between band gap and crystallites size. The appearance of quantum confinement effect in small sized nano crystalline titania is resulting in a blue shift of the band gap [37]. Among the samples, sample 3 has the highest $E_{g}$ value which is the thinnest one. 


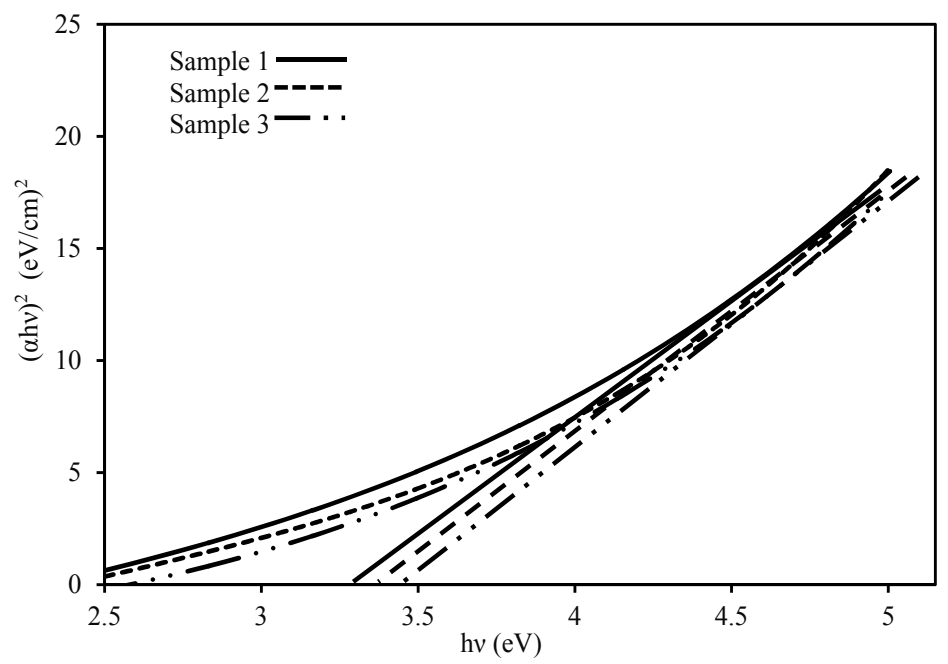

Figure 7. $(\alpha h v)^{2}$ curves versus photon energy $(h v)$ for the samples.

\subsection{Growth mechanism}

One-dimensional nanostructures are grown in this study by VLS mechanism. In the mechanism, the role of the impurity (catalyst) is to form a liquid alloy droplet of eutectoid temperature. Metal catalyst used in the mechanism was gold with $3 \mathrm{~nm}$ thickness. At high temperatures (about $850^{\circ} \mathrm{C}$ ) alloy liquid droplets of Au-titanium form. On the other hand, during the thermal evaporation process, at first, titanium powder in the presence of oxygen atmosphere was converted toTiO ${ }_{2}$ powder (see Eq. 7) [44], then the $\mathrm{TiO}_{2}$ powder was reduced by graphite to produce Ti vapor as the following chemical reaction [45].

$$
\begin{gathered}
\mathrm{Ti}(\mathrm{s})+\mathrm{O}_{2}(\mathrm{~g})=\mathrm{TiO}_{2}(\mathrm{~s})(298-2500) \\
\mathrm{TiO}_{2}(\mathrm{~s})+\mathrm{C}(\mathrm{s})=\mathrm{Ti}(\mathrm{g})+\mathrm{CO}_{2}(\mathrm{~g})
\end{gathered}
$$

We have used $\mathrm{Ti}$ metal and carbon instead of $\mathrm{TiO}_{2}$ in carbothermal reduction process. In fact, $\mathrm{Ti}$ in the tablet converts to $\mathrm{TiO}_{2}$ by oxygen in air (Eq. 7), and then $\mathrm{TiO}_{2}$ is reduced in carbothermal reduction process by carbon (Eq. 8). Indeed, carbon mainly was used for $\mathrm{TiO}_{2}$ reduction. Also there are some papers that have used titanium and carbon as a source material $[26,46]$. Previously, $\mathrm{TiO}_{2}$ and $\mathrm{C}$ as a source material were examined in our lab but NWs did not grow. Amin et al. [21] also reported that continuous increase of the amount of oxygen further reduced the yield of $\mathrm{TiO}_{2} 1 \mathrm{D}$ nanostructures. When the $\mathrm{O}_{2}$ concentration was high, the VLS growth was suppressed because Ti vapor could readily react with $\mathrm{O}_{2}$ before forming alloy droplets with catalytic materials. 
Since the adsorption of liquid is more than solid, the reactant components (vapor of titanium and oxygen) absorbed into the alloy. The liquid alloy acts as a preferred sink for arriving nanostructure components. The $\mathrm{Ti}$ and $\mathrm{O}_{2}$ are dissolved into the mediating alloy liquid droplets. When alloy droplets reach to saturation of reactive component, the $1 \mathrm{D}$ nanostructures grow by precipitation of $\mathrm{TiO}_{2}$ from the droplets in the interface liquid- solid to minimize free energy of alloy system. The 1D nanostructure grows in length by the mechanism until the $\mathrm{Au}$ is consumed or until the growth conditions are changed [47]. Here, by over an hour, furnace temperature began to reduce and growth condition of one-dimensional titanium dioxide nanostructures is stopped.

Usually droplets of catalyst are observed on the top of the nanostructures in a VLS- based growth system. However, the position of catalyst at the tip or root of the nanostructure depends on the interaction of catalyst nanoparticles and the substrate [48].

SEM images (Figure 4) show by increasing argon flow or decreasing oxygen (one of reactants), nanowires become thinner and longer. $\mathrm{O}_{2}$ plays a main role in the growth of $\mathrm{TiO}_{2}$ nanowires. When $\mathrm{O}_{2}$ concentration is high, i.e., Ar flow is low, Ti vapor could readily react with $\mathrm{O}_{2}$, before they adsorb on alloy droplets [30]. Therefore, in this condition, a relatively low concentration of $\mathrm{O}_{2}$ is necessary $[15,31]$. According to other findings [17, 27, 48], we suggest that thinner and longer NWs with increasing Ar flow are due to the following reasons:

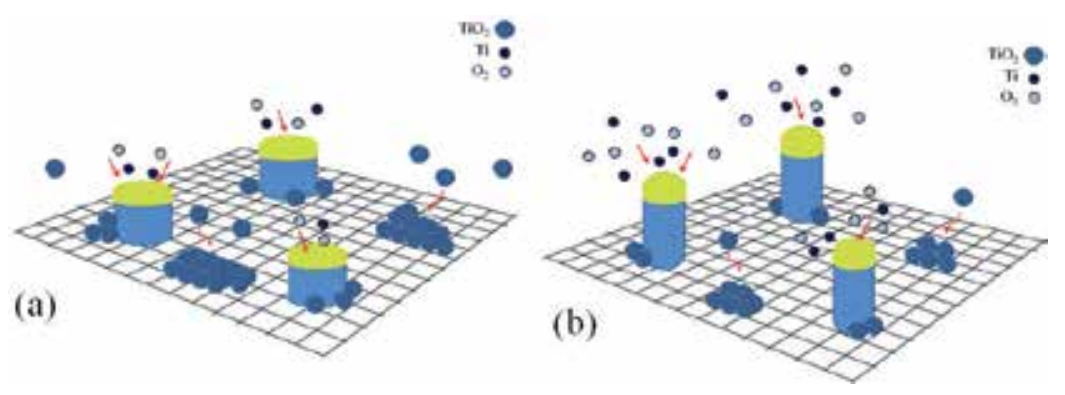

Figure 8. Schematic illustration of growth procedure for $\mathrm{TiO}_{2}$ nanowires on Ti/quartz substrate in (a) low and (b) high argon carrier gas flow [32].

Argon flux plays a major role in combining $\mathrm{Ti}$ and $\mathrm{O}_{2}$ and producing $\mathrm{TiO}_{2}$. A schematic of the proposed growth mechanism is shown in Figure 8. When Ar flux is low (Figure 8a), the possibility of producing $\mathrm{TiO}_{2}$ is much higher than when Ar flux is high (Figure $8 \mathrm{~b}$ ). The reason could be due to moving Ti and $\mathrm{O}_{2}$ gases from furnace tube when Ar flux is high and so the possibility of producing $\mathrm{TiO}_{2}$ becomes lower. On the other hand, in presence of $\mathrm{O}_{2}$, titanium layer on the substrate surface in $850^{\circ} \mathrm{C}$ is easily converted to $\mathrm{TiO}_{2}$ (according to XRD diffraction patterns and Eq. 7). Thus, there is a competitive growth between $\mathrm{TiO}_{2}$ layer (epitaxial growth: $\mathrm{TiO}_{2}$ molecules on $\mathrm{TiO}_{2}$ layer) and alloy droplets (VLS growth). $\mathrm{TiO}_{2}$ islands that are formed around the NWs by VLS method become larger with decreasing Ar flow. Since the other parameters of growth, such as source and time are constant, NW diameters and lengths become larger and shorter, respectively. 
Moreover, $\mathrm{TiO}_{2}$ is heavier than $\mathrm{Ti}$ and $\mathrm{O}_{2}$, so probably exists in lower height than them. Therefore, $\mathrm{TiO}_{2}$ can be absorbed into the nanostructure bodies more likely than their tips (alloy droplets), to be absorbed, so when $\mathrm{TiO}_{2}$ is more than $\mathrm{Ti}$ and $\mathrm{O}_{2}$, nanostructures will be shorter and thicker. Therefore, with increasing Ar gas flow, the crystallinity improves due to VLS growth method.

RamezaniSani et al. [26] have grown $\mathrm{TiO}_{2}$ nanowires by thermal evaporation on a silicon substrate with the major reflection along (101) direction. Their results indicate that a convenient gas flow for controlling diameter size of nanowires is about $100 \mathrm{sccm}$, While our substrate is quartz and the major reflection growth along is (110) direction. Also we see that with increasing gas flow from 60 to $170 \mathrm{sccm}$, nanowires become thinner and longer.

\subsection{Microstructure characterization (theoretical background)}

Deviation from the ideal crystallinity such as finite crystallite size, strain (at the atomic level), and extended defects (stacking faults and dislocations) leads to broadening of the diffraction lines. Crystallite size is a measure of the size of coherently diffracting domains and is not generally the same as particle size due to polycrystalline aggregates. Strain is defined as change in length per unit length and is measured as the change in d spacing of a strained sample compared to the unstrained state [49].

According to Scherrer [50], the apparent crystallite size can be obtained as follows:

$$
D_{V}=(K \lambda / \mathrm{FWHM}) \cos \theta
$$

where $K$ is a constant close to unity, $\theta$ is the Bragg angle of the $(h k l)$ reflection, and $\lambda$ is the wavelength of X-rays used. $D_{V}$ is a volume-weighted quantity. Wilson in 1963 used integral breadth $\beta$ instead of FWHM in Eq. (9).

The dependence of strain $\varepsilon$ to line broadening is defined as follows [51]:

$$
\varepsilon=(\beta / 4) \cot \theta=\beta /(4 \tan \theta)
$$

When the XRD patterns are adjusted to a combination of Cauchy and Gaussian line shapes, the Halder and Wagner approximation is better suited for obtaining the physical broadening [52]:

$$
\beta_{f} \approx\left(\left(\beta_{h}\right)^{2}-\left(\beta_{g}\right)^{2}\right) / \beta_{h}
$$

where $\beta_{g^{\prime}} \beta_{h}$ and $\beta_{f}$ refer to the integral breadths of the instrumental, observed, and measured (physical) profiles, respectively. 


\subsubsection{The Williamson-Hall integral breadth method}

Williamson and Hall in 1953 proposed a method for resolving size and strain broadening. Williamson-Hall plots can be applied to a Gaussian profile as follows [53]:

$$
\left(\beta_{f}^{*}\right)^{2}=\left(\beta_{f} \cos \theta / \lambda\right)^{2}=\left(1 /\left(D_{v}\right)^{2}\right)+4 \varepsilon^{2} d^{* 2}
$$

A plot of $\left(\beta_{f}^{*}\right)^{2}$ against $4 d^{* 2}$ gives a straight line. From the intercept and slope of line size, strain can be calculated.

\subsection{Microstructure study in $\mathrm{TiO}_{2}$ nanowires}

X-ray diffraction (XRD), in which strong scattered intensity is observed at specific angles of scattering, has been widely used for decades in the determination of structural and microstructural parameters. By the diffraction pattern, we have characterized some microstructural parameters like crystallite size, microstrain within the grain, dislocation density, and texture coefficient.

\subsection{The Williamson-Hall integral breadth method}

From an analysis of XRD line broadening, the contributions due to crystallite size and lattice strain can be determined. Here, crystallite size and microstrain contributions are separated using the Williamson-Hall (W-H) method. Assuming contribution to the Bragg peak having both Lorentz and Gauss profile [54]:

$$
\begin{gathered}
\text { Lorentz fit : } \beta_{h}=\beta_{f}+\beta_{g} \beta \cos \theta / \lambda=1 / D+4 \varepsilon \sin \theta / \lambda \\
\text { Gauss fit: } \beta_{h}{ }^{2}=\beta_{f}{ }^{2}+\beta_{g}{ }^{2}(\beta \cos \theta / \lambda)^{2}=(1 / D)^{2}+16 \varepsilon^{2}(\sin \theta / \lambda)^{2}
\end{gathered}
$$

By plotting $\beta \cos \theta / \lambda$ vs $\sin \theta / \lambda$ (Lorentz) or $(\beta \cos \theta / \lambda)^{2}$ vs $(\sin \theta / \lambda)^{2}$ (Gauss), one can estimate the microstrain from the line slope and inverse of the crystallite size from its $y$-intercept. Figures 9 and 10 indicate W-H curves for the samples in Lorentz and Gauss fits, respectively. The obtained values from $\mathrm{W}-\mathrm{H}$ curves are given in Table 4 . The plotted $\mathrm{W}-\mathrm{H}$ curves indicate that strain and size contributions exist simultaneously in the samples.

\begin{tabular}{cccccc}
\hline $\boldsymbol{\theta}(\%)$ & $\boldsymbol{D}(\mathrm{nm})$ (Guass) & $\boldsymbol{D}(\mathrm{nm})$ (Lorentz) & $\boldsymbol{\varepsilon}(\%)($ Guass) & $\boldsymbol{\varepsilon}$ (\%) (Lorentz) & Sample \\
\hline 0.232 & $14.14 \pm 0.42$ & $14.28 \pm 0.38$ & $0.448 \pm 0.020$ & $0.375 \pm 0.015$ & $\mathrm{~S} 1$ \\
\hline 0.228 & $15.58 \pm 0.53$ & $15.16 \pm 0.52$ & $0.359 \pm 0.012$ & $0.251 \pm 0.008$ & $\mathrm{~S} 2$ \\
\hline 0.169 & $15.85 \pm 0.53$ & $15.27 \pm 0.51$ & $0.427 \pm 0.014$ & $0.361 \pm 0.012$ & $\mathrm{~S} 3$ \\
\hline
\end{tabular}

Table 4. Crystallite size, mean microstrain, and dilatation values of the samples. 


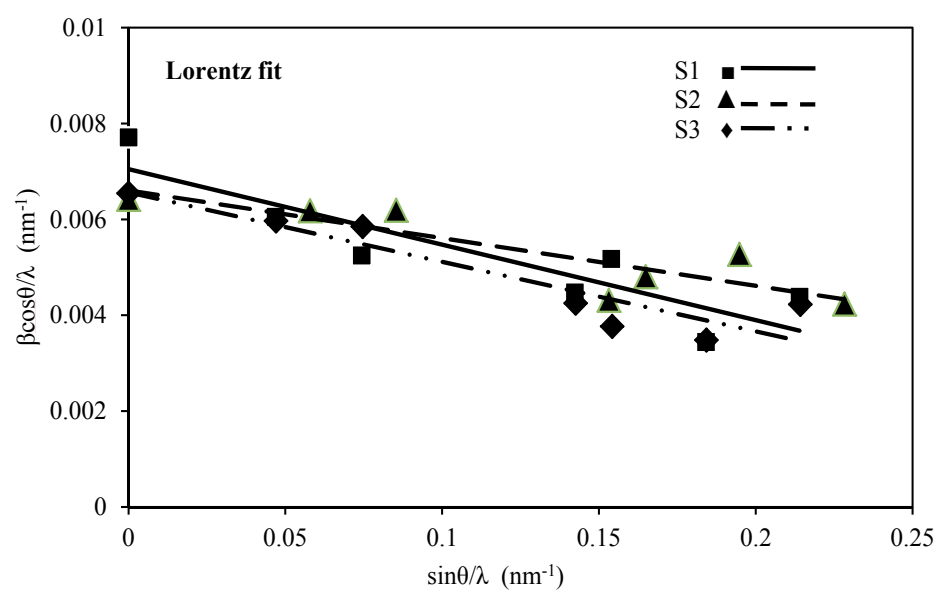

Figure 9. Williamson-Hall curves for the samples: Lorentz fit.

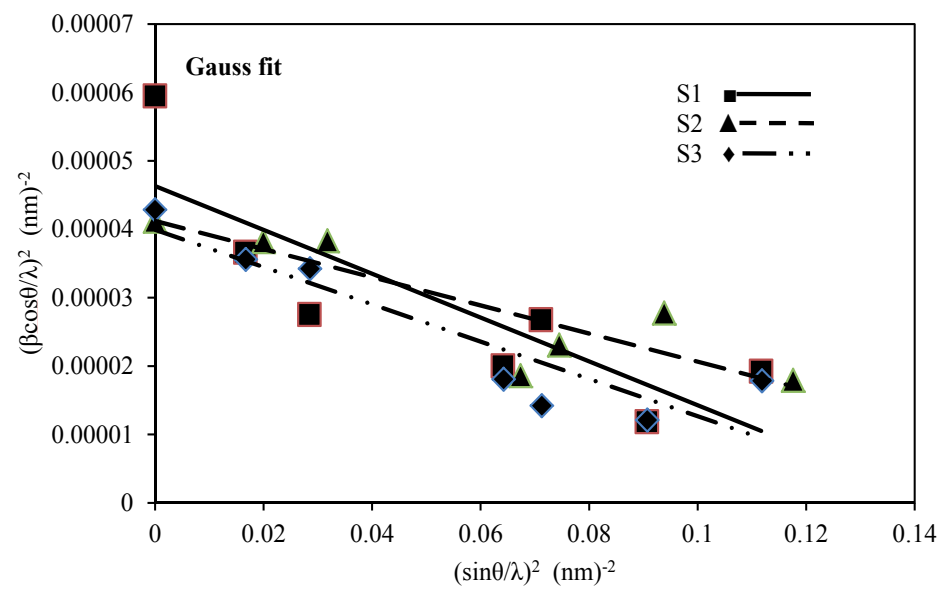

Figure 10. Williamson-Hall curves for the samples: Gauss fit.

\subsection{Dilatation}

Volume strain or dilatation is a change in volume that defines as [55]:

$$
\theta \equiv \Delta v / v
$$

If three strain $\varepsilon_{\mathrm{xx}}, \varepsilon_{\mathrm{yy}}$, and $\varepsilon_{\mathrm{zz}}$ have been treated as small quantities, the dilatation is [55]

$$
\theta=\partial \xi / \partial x+\partial \eta / \partial y+\partial \zeta / \partial z=\varepsilon_{\mathrm{xx}}+\varepsilon_{\mathrm{yy}}+\varepsilon_{\mathrm{zz}}
$$


The horizontal strain $\varepsilon_{11}$ and vertical strain $\varepsilon_{\perp}$ are calculated by the expression as follows: $\varepsilon_{11}=\left(a_{\mathrm{epi}}-a_{0}\right) / a_{0}$ and $\varepsilon_{\perp}=\left(c_{\mathrm{epi}}-c_{0}\right) / c_{0}[56]$, where $\mathrm{a}_{0}$ and $\mathrm{c}_{0}$ are the lattice constants of bulk $\mathrm{TiO}_{2}\left(a_{0}=\right.$ $4.587 \AA, c_{0}=2.954 \AA$ [57]). Here $\varepsilon_{\mathrm{xx}}=\varepsilon_{\mathrm{yy}}=\varepsilon_{11}$ and $\varepsilon_{\mathrm{zz}}=\varepsilon_{\perp}$; thus, the dilatation becomes.

$$
\theta=2 \varepsilon_{11}+\varepsilon_{\perp}
$$

The calculated dilatations are given in Table 4. The slopes of the $\mathrm{W}-\mathrm{H}$ curve for the samples are negative, i.e., their strain is negative and there is a contraction of epilayer on substrates which means compressive stress. The different slopes represent different mean microstrains.

It is well known that strain has direct relation with elastic energy [55]. Evaporated particles from source due to their temperature have certain kinetic energy. In low Ar flow (60 sccm), Ar particles is lower than evaporated particles then collision between them is negligible. However, with increasing Ar flow to $110 \mathrm{sccm}$, collision between Ar particles and evaporated particles increases therefore it could have reduced the evaporated particles energies and microstrain. However, with increasing Ar flow up to $170 \mathrm{sccm}$, the number of Ar particles enhanced compared to evaporated particles, so they can help to increase the evaporated particles movement. Therefore, their velocity and energy increase and also mircostrain increases.

Both dilatation and microsrain are negative and at the same order. We compare these two quantities, because the microstrain (obtained from $\mathrm{W}-\mathrm{H}$ curve) is average of strain in volume not in specific direction. Thus, calculated strain from main definition must consider in volume.

We can compare volume strain (which found from lattice parameters) and microstrain (which found from XRD pattern) because the microstrain from the $\mathrm{W}-\mathrm{H}$ curve does not have any particular direction. By comparing them, it reveals that they have approximately good agreement both in magnitude and sign.

\subsection{Dislocation density}

To estimate the dislocation density, $\rho_{D}$ (dislocation density due to domain size), $\rho_{\varepsilon}$ (dislocation density due to strain) and $\rho$ (real dislocation density), the simple approach of Williamson and Smallman (1956) is followed, relating $\rho$ to crystallite size $D$ and strain $<\varepsilon^{2}>^{1 / 2}$ [58]:

$$
\begin{gathered}
\rho_{D}=3 / D^{2} \\
\rho_{\varepsilon}=4<\varepsilon^{2}>/ b^{2} \\
\rho=\left(\rho_{D} . \rho_{\varepsilon}\right)^{1 / 2}=2 \sqrt{3}<\varepsilon^{2}>^{1 / 2} /(b D)
\end{gathered}
$$


where $b$ is the Burger's vector, which determines distance and direction of displacement. We assumed that the magnitude of Burger's vector is calculated by $\left[\left(a^{2} / 4\right)+\left(a^{2} / 4\right)+\left(c^{2} / 4\right)\right]^{1 / 2}$, where $a$ and $c$ are lattice parameters. Dislocation densities in actual crystals depend on the preparation of the specimen, but can range from $10^{2}$ to $10^{12} \mathrm{~cm}^{-2}$ [59], and the dislocation values of our samples are in the same range (Table 5).

According to Eq. 16, behavior of dislocation density is similar to microstrain, i.e., the value of dislocation density decreases from sample S1 to S2, 4and then increases from S2 to S3, since dislocation density and microstrain are related to displacement. It is noted that the results of Lorentz and Gauss fits for our samples are the same.

\begin{tabular}{cccc}
\hline$\varrho\left(\mathrm{cm}^{-2}\right) \times \mathbf{1 0 ^ { 1 1 }}$ - Lorentz & $\boldsymbol{\rho ( \mathrm { cm } ^ { - 2 } ) \times \mathbf { 1 0 ^ { 1 1 } } \text { -gauss }}$ & $\boldsymbol{b}(\AA)$ & Sample \\
\hline 2.55 & 3.08 & 3.563 & $\mathrm{~S} 1$ \\
\hline 1.61 & 2.24 & 3.562 & $\mathrm{~S} 2$ \\
\hline 2.30 & 2.62 & 3.564 & $\mathrm{~S} 3$ \\
\hline
\end{tabular}

Table 5. Burger's vectors and dislocation densities of the samples.

\subsection{Texture coefficient}

In order to clearly understand the preferred orientation of the samples, the texture coefficient $\mathrm{TC}(h k l)$ of each XRD pattern is calculated according to the following formula [60]:

$$
\mathrm{TC}(h k l)=\left[I(h k l) / I_{0}(h k l)\right] /(1 / N) \sum_{\mathrm{N}} I(h k l) / I_{0}(h k l)
$$

where $I(h k l)$ is measured intensity of the $(h k l)$ diffraction peak and $N$ is the amount of crystal directions which is 11,10 , and 12 for samples 1,2 , and 3 , respectively. If TC $(h k l)$ equals to 1 , there is no preferred orientation on $(h k l)$ direction of the film. When this value is larger than 1 , a preferred orientation exists along the $(h k l)$ plane. The standard deviation TC $(h k l)$ of the TC values from powder condition is [60]:

$$
\sigma=\left[(1 / N) \sum_{\mathrm{N}}\{\mathrm{TC}(h k l)\}^{2}-1\right]^{1 / 2}
$$

If $\sigma$ equals to zero, the crystallite orientation of a film sample is the same as that of the related powder-shaped sample and there is no preferred direction. Therefore, $\sigma$ value indicates the preferred orientation level of thin film samples [61]. The values of texture coefficient and its standard deviation for the samples are shown in Table 6. As expected, the preferred direction in the samples is (110). It is concluded that the different carrier gas flows do not influence the preferential orientation. The rutile (110) surface is the most stable crystal face and has lowest surface energy [62]. 
According to Table 6, the behavior of TC (110) is similar to dislocation density, i.e., dislocation helps the growth of (110) plane, which is the most stable plane in the rutile phase.

\begin{tabular}{cccccc}
\hline TC(110)/STC(hkl) & $\sigma$ & TC (211) & TC (101) & TC (110) & Sample \\
\hline 38.9 & 0.68 & 2.32 & 1.81 & 2.63 & S1 \\
\hline 38.5 & 0.53 & 1.69 & 1.89 & 2.24 & S2 \\
\hline 35.3 & 0.68 & 2.32 & 2.25 & 2.49 & S3 \\
\hline
\end{tabular}

Table 6. Texture coefficient and its standard deviation for the samples.

In order to better determine the contribution of TC (110) to other TC $(h k l)$, the proportion of its value to total value of all TC $(h k l)$ was calculated, (i.e., TC $\left.(110) / \sum \mathrm{TC}(h k l)\right)$. The values obtained for samples 1, 2 and, 3 were 38.9, 38.5, and 35.3, respectively. It is observed that by increasing argon flow, the value of TC $(110) / \sum \mathrm{TC}(h k l)$ is decreased. Since in the case of argon with $60 \mathrm{sccm}$ flow, epitaxial growth has occurred more than the others, so it can make possible growth in the (110) plane, which is the most stable one in rutile $\mathrm{TiO}_{2}$. However, in further argon flow, the epitaxial growth becomes lower which causes the reduction of TC (110).

\section{Conclusion}

In this study, single-crystalline rutile $\mathrm{TiO}_{2}$ nanowires were fabricated under different argon gas flows. The results indicated that $\mathrm{TiO}_{2}$ nanowires form in rutile phase and their preferred growth is in the (110) direction, since (110) plane in rutile phase has lowest surface energy. The band gap energy of $\mathrm{TiO}_{2}$ nanowires have increased due to the quantum confinement compared with bulk one. The wires become thinner and longer by increasing the argon flow. In $170 \mathrm{sccm}$, which has the least amount of oxygen, the average value of diameter and the length of $\mathrm{TiO}_{2}$ were respectively 72 and $1020 \mathrm{~nm}$. The band gap of $\mathrm{TiO}_{2}$ nanowires has increased from 3.35 to $3.45 \mathrm{eV}$ and their crystallinity has improved by increasing argon flux due to enhancement of VLS growth mechanism.

The advantage of our method is to fabricate $\mathrm{TiO}_{2}$ nanostructures without contamination and impurities. These materials can be used for photovoltaic and gas sensor applications due to their large surface to volume ratio.

\section{Author details}

Reza Sabet Dariani* and Zohreh Nafari Qaleh

*Address all correspondence to: dariani@alzahra.ac.ir

Department of Physics, Alzahra University, Tehran, Iran 


\section{References}

[1] X. Wang, Z. Li, J. Shi, and Y. Yu, One-Dimensional Titanium Dioxide Nanomaterials: Nanowires, Nanorods, and Nanobelts, American Chemical Society, 2014, 114(19), p. 9346-9384.

[2] L. Karel van Vugt. Optical Properties of Semiconducting Nanowires. PhD thesis. Utrecht University; 2007.

[3] Z. Lin Wang. Nanowires and nanobelts materials, properties and devices. Volume 2: nanowires and nanobelts of Functional materials, Springer; 2006.

[4] H. Liu, Y. Zhang, R. Li, M. Cai, and X. Sun, J. Nanopart. Res. 13 (2011) 385-391.

[5] Y. Bai, I. Mora-Sero', F. De Angelis, J. Bisquert, and P. Wang, Titanium Dioxide Nanomaterials for Photovoltaic Applications, American Chemical Society, 2014, 114(19), p.10095-10130.

[6] L. Liu and X. Chen, Titanium Dioxide Nanomaterials: Self-Structural Modifications, American Chemical Society, 2014, 114(19), p. 9890-9918.

[7] L. V. Saraf, S. I. Patil and S. B. Ogale. Synthesis of nanophase $\mathrm{TiO}_{2}$ by ion beam sputtering and cold condensation technique. Int. J. Mod. Phys. B. 12, (1998) 2635-2647.

[8] J. Shi, X. Wang, J. Cryst. Growth 11 (2011) 949-954.

[9] J. Shi, C. Sun, M.B. Starr, and X. Wang, Nano Lett. 11 (2011), 624-631.

[10] R. Tao, J. Wu, H. Xue, X. Song, Xu Pan, X. Q. Fang, X.D. Fang, S.Y. Dai, J. Power Sources 195 (2010) 2989-2995.

[11] J. Shi, Y. Hara, C. Sun, M.A. Anderson, X. Wang, Nano Lett. 11 (2011) 3413-3419.

[12] G. Wang, H. Wang, Y. Ling, Y. Tang, X. Yang, R. C. Fitzmorris, C. Wang, J.Z. Zhang, and Y. Li, Nano Lett. 11 (2011) 3026-3033.

[13] S.S. Mandal, and A.J. Bhattacharyya, Talanta 82 (2010) 876-884.

[14] Y. Wang, M. Wu, and W.F. Zhang, Electrochim. Acta 53 (2008) 7863-7868.

[15] G.K. Mor, O.K. Varghese, M. Paulose, K. Shankar, C.A. Grimes, Sol. Energy Mater. Sol. Cells 90 (2006) 2011-2075.

[16] Y.X. Zhang,G.H. Li, Y.X. Jin,Y. Zhang, J. Zhang, L.D. Zhang, Chem. Phys. Lett. 2002; 365:300e4.

[17] S.K. Pradhan, P.J. Reucroft, F. Yang, and A. Dozier, J. Cryst. Growth 256 (2003) 83-88.

[18] J. Lee, K. Park, T. Kim, H. Choi and Y. Sung, Nanotechnology 17 (2006) 4317-4321. 
[19] J.M. Wu, H. C. Shih, and W.T. Wu, Formation and photoluminescence of single-crystalline rutile $\mathrm{TiO} 2$ nanowires synthesized by thermal evaporation, Nanotechnology 17 (2006) 105-109.

[20] E. György, et al., Growth of $\mathrm{Au}-\mathrm{TiO}_{2}$ nanocomposite thin films by a dual-laser, dualtarget system, J. Appl. Phys. 100, 114302. 2006.

[21] S.S. Amin, A.W. Nicholls, and T.T. Xu., Nanotechnology 18 (2007) 445609-445609.

[22] T. Berger, T. Lana-Villarreal, D. Monllor-Satoca, R. Go'mez, The electrochemistry of transparent quantum size rutile nanowire thin films prepared by one-step low temperature chemical bath deposition, Chem. Phys. Lett. 447 (2007) 91-95.

[23] K. Huo, X. Zhang, L. Hu, X. Sun, J. Fu, et al., One-step growth and field emission properties of quasialigned $\mathrm{TiO}_{2}$ nanowire/carbon nanocone core-shell nanostructure arrays on Ti substrates, Appl. Phys. Lett. 93 (2008) p. 013105.

[24] Jeong Min Baik, et al, High-yield TiO2 nanowire synthesis and single nanowire fieldeffect transistor fabrication, Appl. Phys. Lett. 92 (2008) 242111.

[25] K. Huo, et al., Synthesis and Field Emission Properties of Rutile $\mathrm{TiO}_{2}$ Nanowires Arrays Grown Directly on a Ti Metal Self-Source Substrate, J. Nanosci. Nanotechnol, (2009) 3341-3346.

[26] S. RamezaniSani, A. Morteza Ali and R. Jafari, Physica E 43 (2011) 1809-1812.

[27] Y.S. Park, and J.S. Lee, Bull. Korean Chem. Soc. 32 (2011) 3571-3574.

[28] J.Y. Ha, B.D. Sosnowchik, L. Lin, D.H. Kang and A.V. Davydov, Appl. Phys. Express 4 (2011) 065002-065004.

[29] H.B. Wu, H.H. Hng, and X.W. Lou, Direct Synthesis of Anatase $\mathrm{TiO}_{2}$ Nanowires with Enhanced Photocatalytic Activity, Adv. Mater., 24, 2567-2571, 2012.

[30] Z.G. Shang, Z.Q. Liu, P.J. Shang, J.K. Shang, J. Mater. Sci. Technol. 28 (2012) 385-390.

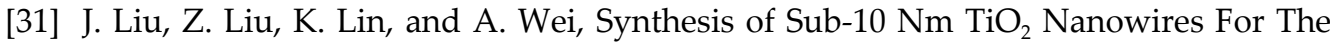
Application of Dye-Sensitized Solar Cells, Func. Mater. Lett, 6, No. 2 (2013) 1350017.

[32] R.S. Dariani, Z. Nafari Qaleh, Microstructure characterization of $\mathrm{TiO}_{2}$ nanowires fabricated by thermal evaporation process, Thin Solid Films 542 (2013) 192.

[33] W.C. Tian, Yu-Hsuan Ho, Chao-Hao Chen and Chun-Yen Kuo, Sensing Performance of Precisely Ordered $\mathrm{TiO}_{2}$ Nanowire Gas Sensors Fabricated by Electron-Beam Lithography, Sensors 2013, 13, 865-874.

[34] B. Liu, et al., Large-Scale Synthesis of Transition-Metal-Doped $\mathrm{TiO}_{2}$ Nanowires with Controllable Over potential, American Chemical Society, 135, 9995-9998, 2013. 
[35] R. Nechache, M. Nicklaus, N. Diffalah, A. Ruediger and F. Rosei, Pulsed laser deposition growth of rutile $\mathrm{TiO}_{2}$ nanowires on Silicon substrates, Appl. Surf. Sci. 313 (2014) $48-52$.

[36] X. Wang, et al., Confined-space synthesis of single crystal $\mathrm{TiO}_{2}$ nanowires in atmospheric vessel at low temperature: a generalized approach, Sci. Rep. 5 (2015) 8129.

[37] A. Hu, X. Zhang, K.D. Oakes, P. Peng, Y.N. Zhou, M.R. Servos, J. Hazard. Mater. 189 (2011) 278-285.

[38] Z. Wei, Y. Yao, T. Huang, A. Yu, Int. J. Electrochem. Sci. 6 (2011) 1871-1879.

[39] J.J. Wu, C.C. Yu, J. Phys. Chem. B 108 (2004) 3377-3379.

[40] Y. Huang, Y. Lee, V. Yeh, C. Cheng, J. Lumin. 129 (2009) 1762-1766.

[41] W. Luo, Z. Jin, H. Liu, and T. Wang, Calphad, 25 (2001) 19-26.

[42] Y. Waseda, E. Matsubara, and K. Shinoda, X-Ray Diffraction Crystallography: Introduction, Examples and Solved Problems, Springer-Verlag, Berlin, 2011.

[43] R.J.D. TILLEY, Colour and the Optical Properties of Materials, second ed., John Wiley \& Sons Ltd, West Sussex, 2011.

[44] D.R. Gaskell, Introduction to the Thermodynamics of Materials, fourth ed., Taylor \& Francis Publication, New York, 2009.

[45] F. Habashi, Handbook of Extractive Metallurgy, Vol II, Wiley publication, Weinheim, 1998.

[46] J.M. Wu, H.C. Shih, W.T. Wu, Y.K. Tseng, and I.C. Chen, Journal of Crystal Growth, 281 (2005) 384-390.

[47] R.S. Wagner, W.C. Ellis, Appl. Phys. Lett. 4 (1964) 89-90.

[48] M. NorouziBanis, Y. Zhang, R. Li, X. Sun, X. Jiang, and D. Nikanpour, Particuology 9(2011) 458-464.

[49] P. Pourghahramani, E. Forssberg. Microstructure characterization of mechanically activated hematite using XRD line broadening. Int. J. Miner. Process. 79 (2006) 106-11

[50] Scherrer, P., 1918. Bestimmung der Grösse und der inneren Structure von Kollooidteilchen mittels Röntgenstrahlung. Nachr. Ges. Wiss. Gött. 2, 98-100.

[51] Stokes, A.R., Wilson, A.J.C., 1944. The diffraction of X-rays by distorted crystal aggregates I. Proc. Phys. Soc. Lond. 56, 174.

[52] N.C. Halder, C.N.J. Wagner, 1966. Separation of particle size and lattice strain in integral breadth measurements. Acta Crystallogr. 20, 312-313. 
[53] K. Santra, P. Chatterjee, S.P. Sen Gupta, 2002. Voigt modeling of size-strain analysis: application to $\alpha-\mathrm{Al}_{2} \mathrm{O}_{3}$ prepared by combustion technique. Bull. Mater. Sci. 25 (3), 251-257.

[54] R. Guinebretiere, X-ray Diffraction by Polycrystalline Materials, Antony Rowe Ltd, Chippenham, 2007.

[55] W.C. Elmore and M.A. Heald, Physics of Waves, McGraw-Hill Book Company, USA, 1969.

[56] J. Xiong, J. Tang, T. Liang, Y. Wang, C. Xue, W. Shi, and W. Zhang, Appl. Surf. Sci. 257 (2010) 1161-1165.

[57] J. Muscat, V. Swamy, and N.M. Harrison, Phys. Rev. B 65(22) (2002) 224112-224112.

[58] P. Pourghahramani, E. Forssberg, Int. J. Miner. Process. 79 (2006) 120-139.

[59] N.W. Ashcroft, N.D. Mermin, Solid State Physics, Harcourt College Publishing, Fort Worth, 1976.

[60] K.H. Kim and J.S. Chun, Thin Solid Films 141 (1986) 287-295.

[61] L. Feng, J. Zhang, B. Li, W. Cai, Y. Cai, L. Wu, W. Li, J. Zheng, Q. Yan, G. Xia, and D. Cai, Thin Solid Films 491 (2005) 104-109.

[62] U. Diebold, Surf. Sci. Rep. 48 (2003) 53-229. 

Chapter 5

\title{
Noble Metal Nanoparticles Prepared by Metal Sputtering into Glycerol and their Grafting to Polymer Surface
}

\author{
Jakub Siegel, Alena Řezníčková, Petr Slepička and Václav Švorčík \\ Additional information is available at the end of the chapter
}

http://dx.doi.org/10.5772/61403

\begin{abstract}
This chapter summarizes the basic information about elementary characteristics and technology of preparation of noble metal nanoparticles. The introduction gives some basic information on the history of development in this area, especially in terms of dimensionality of metal nanostructures and their possible applications. The first subsection is devoted to the preparation and characterization of $\mathrm{Au}, \mathrm{Ag}, \mathrm{Pt}$, and Pd nanoparticles (NPs), which were synthesized by direct metal sputtering in liquid propane-1,2,3,triole (glycerol). This method provides an interesting alternative to time-consuming, wetbased chemical synthesis techniques. Moreover, the suggested technique allows targeted variation of metal nanoparticle size, which is demonstrated in detail in case of AuNPs by variation of capturing media temperature. Nanoparticle size and shape were studied by transmission electron microscopy and dynamic light scattering. Optical properties of nanoparticle solution were determined by measuring its UV-Vis spectra. Concentration of metal nanoparticles in prepared solutions was determined by atomic absorption spectroscopy. Antibacterial properties were tested against two common pollutants (Escherichia coli, a Gram-negative bacteria, and Staphylococcus epidermidis, a Gram-positive bacteria). In the presence of Ag nanoparticles, the growth of E. coli and S. epidermidis was completely inhibited after $24 \mathrm{~h}$. Any growth inhibition of E. coli was observed neither in the presence of "smaller" (4-6 nm, AuNP ${ }_{4-6}$ ) nor "bigger" (9-12 nm, AuNP ${ }_{8-12}$ ) AuNPs during the whole examination period. $\mathrm{AuNP}_{4-6}$, but not $\mathrm{AuNP}_{8-12}$, was able to inhibit the growth of. $S$ epidermidis. We also observed significant difference in biological activities of $\mathrm{Pt}$ and PdNPs. More specifically, PdNPs exhibited considerable inhibitory potential against both E. coli and S. epidermidis, which was in contrast to ineffective PtNPs. Our results indicate that $\mathrm{Ag}, \mathrm{Pd}$, and partially AuNPs have high potential to combat both Gram-positive and Gram-negative bacterial strains.The second subsection describes the effort to anchor metal nanoparticles onto polyethyleneterephthalate (PET) carrier. Two different procedures of grafting of polymeric carrier, activated by plasma treatment, with Au and AgNPs are described. In the first procedure, the PET foil was grafted with biphenyl-4,4'-dithiol (BPD) and subsequently with Au and AgNPs. In the second one, the PET foil was grafted with $\mathrm{Au}$ and AgNPs previously coated by the same BPD. X-ray photoelectron spectrosco-
\end{abstract}


py, Fourier transform infrared spectroscopy, and electrokinetic analysis were used for characterization of the polymer surface at different modification steps. Au and AgNPs were characterized by UV-Vis spectroscopy. In case of both types of nanoparticles, the first procedure was found to be more effective. It was proved that the BPD was chemically bonded to the surface of the plasma-activated PET and it mediates subsequent grafting of the AuNPs.

Keywords: Nanoparticles, sputtering, antibacterial effect, chemical anchoring, polymer

\section{Introduction}

Metal nanoparticles (NPs) nowadays represent the key material in vast range of industrial applications ranging from rough industry to fine medical or biochemical utilization. Gold and silver NPs and their applications are currently of great interest. In recent years, rapid developments in nanotechnology have evolved to the point where inclusion of those entities into smart systems and related technologies has become quite easy. Nowadays, NPs and NPs-embedded materials cover broad spectrum of functional devices with promising properties, which are used in many fields including optoelectronics or catalysis [1]. They are employed in modern nanobiotechnology for the production of biosensors, visualization of cellular structures [2], and targeted transporting of drugs [3]. Colloidal nanoparticles are studied because they have unique physical and chemical properties that are different from "bulk" materials [4]. In all applications of nanotechnology, the size and shape of the nanoparticles play an important role [5]. Numerous studies [6] describe the unique properties of gold nanoparticles which can be used in applications such as fuel cells, environmental, and other chemical processes [7]. Various preparation techniques have been proposed to cover specific requirements of those man-made entities. Besides classical wetbased preparation techniques of which the pioneering one is that proposed by Turkevich [8], others are intensely studied which would open up new potential applications of NPs in the development of new technologies.

NPs are entities ranging in size between 1 to 100 nanometres. These materials behave as a whole unit in terms of transportation and properties that highly depend on their shape, size, and morphological substructure $[9,10]$. Those materials are characterized by high surface areato-volume ratio, high chemical reactivity and physical affinity, as well as other interesting physico-chemical properties (optical, electrical, and magnetic) [11-14]. In addition, different NPs show various properties; likewise, different synthesis techniques of the same type of particle tend to alter or introduce new properties to the material. Consequently, the applications of these materials are unlimited and significantly remarkable in human life and in industries. Each nanomaterial with its distinct properties independently finds its way into practical applications such as: drug delivery [15], waste treatment [16], lubricant and surfactant production [17], electrical and sensor devices [18, 19], as well as membrane fuel cells [20]. Noble metal NPs have been widely studied in the past few decades because of their applications in 
various areas including catalysis, gas and biological sensors, drug delivery, and antimicrobial agents. In specific, due to their biocompatibility and photo-optical distinctiveness, gold NPs (AuNPs) have proven to be very useful tools in several biomedical applications dealing with different aspects of detection, analysis, and treatment.

Recent advances in the study of noble metal NPs have led to their utilization in a number of very important applications including antimicrobial coatings, biosensing, diagnostic imaging, and cancer diagnosis and therapy [21-24]. This chapter surveys the various synthetic methods of broad spectrum of metallic NPs as well as most recent experimental studies focusing on the use of gold, silver, palladium, platinum, and ruthenium NPs in catalysis, food industry, and environmental applications. Moreover, the potent in vitro and in vivo antimicrobial and cytogenotoxic effects of various gold and silver nanomaterials are underlined. Finally, recent advances in functionalization of various solid substrates with gold and silver NPs as effective antimicrobial coatings and promising cell-stimulating agents are summarized. Despite their use in remediating numerous medical and health-related conditions, the efficacy and safety of many gold, silver, palladium, and platinum NPs are still under some scrutiny.

\section{Nanoparticle synthesis}

One of the most common nanoparticle synthesis of noble metals are those developed by BrustSchiffrin [25]. The technique is based on reduction of AuIII' complex compound with $\mathrm{NaBH}_{4}$ stabilized by thiols. This technique enables preparation of highly stable particles with narrow distribution and possibility to control their sizes. Also, Ag particles have already been synthesized on the basis of reduction reactions $[7,8]$. Concurrently, due to specific requirements on newly synthesized NPs, there have arisen other numerous techniques based on both wet and dry processes. Nowadays, most of the wet-based preparation techniques exploit confined reaction area inside which metal ions are reduced to zerovalent metals forming nanoparticles. The smaller and uniform the reaction cavity is, the smaller the dimension and narrower the size distribution of the resulting NPs. Different types of polymer-based agents have been investigated for preparation of metal and non-metal particles [26-31]. Metal NPs, semiconductors, inorganic oxides, and quantum dots synthesis were also investigated, especially in the confined space of surfactants, inorganic templates, and polymeric stabilizing agents [32-35]. The structure of the metal particles can be significantly affected by the preparation technique [36-39]. Their size, shape, and geometry strongly depend on the applied technique. Therefore, it is very important to use a template that is modifiable in terms of functional groups and is adjustable with respect to its shape or size. Polymeric hydrogels are able to fulfil these parameters, and they can be also successfully prepared in various sizes with different functional groups $[26,40]$.

Butun and Sahiner [41] reported synthesis of a novel bulk hydrogel based on acrylamidoglycolic acid and its use as a template in the preparation of different metal NPs ( $\mathrm{Ag}, \mathrm{Cu}, \mathrm{Ni}, \mathrm{Co})$. Nanoparticle synthesis is based on reduction of the captured metal ions inside the hydrogel. 
Hydrogels play a key role in tissue engineering because of the resemblance of the threedimensional network structure to the extracellular matrix environment [42-44]. The bulk hydrogels consist mostly of macropores $(>50 \mathrm{~nm})$ and even superpores with the pore sizes of up to several microns. The porosity can be modified by the degree of functional groups hydrophilicity or by the cross-linker used during preparation. The tune capability of the pore structure also provides specific advantages for the absorption and desorption of various species [45].

Completely new possibilities for the preparation of metal NPs open up utilization of PVD techniques. The most common capturing media for direct metal sputtering represent ion liquids (ILs) and their significantly less-toxic alternative - vegetable oils. First metal deposition onto liquid substrate was conducted in 1996 by the mean of radiofrequency (RF) magnetron sputtering. Silver was deposited into pure silicon oil [46]. The process went through two stages: (i) creation of percolation structure and (ii) nucleation of first metal clusters on the oil surface. With ongoing deposition, individual clusters spread out over the liquid surface and mutually interconnected forming continuous silver coverage floating on the oil surface. Such Ag layer exhibited considerable roughness with typical morphology. Sputtering process was strongly dependent on deposition conditions; when the sputtering power was held below $30 \mathrm{~W}$, no silver layer was formed. Most probably, the drop of the sputtering power resulted in penetration of silver atoms into the liquid volume and formation of silver NPs (AgNPs). Nevertheless, this finding was not confirmed by the authors since their intention was to prepare ultra-thin silver layers on the surface of liquid [47].

Vegetable oils represent perspective liquid substrates for sputtering of metals, since they are commonly available, cheap, biocompatible, and have the ability to stabilize metal NPs [48] (e.g., by the way of chemical reduction [49]). Thus, for the successful preparation of nanoparticles, no other toxic reducing agents are required, which is very desirable for further in vivo applications. Direct sputtering of $\mathrm{Au}$ into castor oil results in formation of biocompatible AuNPs. Application of higher voltage led to creation of larger particles, while the prolongation of deposition time had no impact on nanoparticle size, which was proved by transmission electron microscopy (TEM) and small angle Y-ray scattering (SAXS) [48]. Wender et al. [50] published interesting work correlating the properties of specific oil used with the deposition conditions with regards to formation of thin layers on the surface or in the volume of the oil. Authors showed that formation of AgNPs depends crucially on the applied voltage and specific surface coordination ability of the oil used (castor, canola, and kapron oil). Both lower voltage and weak coordination ability led to formation of continuous coatings on the oil surface. On contrary, higher voltage and strong coordination ability enable preparation of NPs. Higher voltage means higher diffusivity of adsorbed particles (metal atoms) on the surface of liquid which enables (i) particle penetration into the volume of liquid and (ii) anchoring of atoms/clusters to active functional groups. AgNPs were easily formed in castor oil (which contains solely hydroxyl groups) in wide range of applied voltage. On contrary, when using canola oil (which is predominately formed by unsaturated aliphatic chains) and kapron oil, 
thin silver layer was deposited on the oil surface at lower voltages, while AgNPs were formed only at higher discharge voltage.

Much more aggressive media (from the toxicity point of view) for potential biomedical application of prepared NPs are already mentioned ILs. Those liquids can be defined as liquid electrolytes exclusively composed of ions. Currently, the most common ILs are pure substances or eutectic mixtures of organic-inorganic salts, which melts at temperatures below $100^{\circ} \mathrm{C}$ [51]. Among the most widespread ILs belong derivates of organic molecules, e.g., pyrrolidine, imidazole, and pyridine [52]. ILs' attractiveness in the process of NPs preparation consists in unusual physical-chemical properties. In addition to their extreme polarity, they also exhibit very low value of interface tension. Considering this, relatively high speed of nucleation can be achieved during the deposition process, which results in formation of small NPs without undesirable perturbations (Ostwald ripening ${ }^{1}$ ) [53]. Moreover, ILs very easily change their molecular arrangement so that to adapt to nucleation centres of emerging NPs, which leads to their stabilization. This high degree of adaptability consists in the presence of both hydrophilic and hydrophobic segments together with strong polarization force of ILs, which enables their orientation both perpendicular and parallel to the particles [13].

A large number of authors regard the value of surface tension and viscosity of liquid as critical in the process of preparation of metal NPs in liquid media. However, as evidenced in the work [52], in particular in the case of ILs, other parameters such as composition and the coordinating ability of the used liquid also play a significant role. If in addition the NPs growth occurs in the liquid volume, increase in the NPs size with increasing volume (size) of ILs anionic part can be expected [54-57]. Furthermore, it appears that the difference in size of the synthesized particles cannot be correlated with macroscopic characteristics of ILs, such as surface tension and viscosity [54]. In this connection, a very interesting medium for preparation of NPs by metal sputtering into liquid is pure propane-1,2,3-triole (glycerol) [31]. This substance combines physical properties comparable to those of ILs (i.e., low vapor pressure, thermally manageable viscosity, high coordination ability - per one glycerol molecule falls three hydroxyl groups) with minimal toxicity to living tissues. Biocompatibility of glycerol allows subsequent application of prepared NPs in bioengineering [58]. Additionally, one can easily control the size of emerging particles by the temperature of the capturing media (glycerol). Recent advances in preparation ways of selected noble metal NPs are summarized in Table 1.

Besides all other noble metals, silver in the form of AgNPs possesses strong antimicrobial specificity. The AgNPs use is of great importance, since several pathogenic bacteria have developed resistance to different types of antibiotics. That is why AgNPs have emerged up with varied medical applications reaching from silver-based dressings, silver-coated medicinal devices (nanogels, nanolotions), etc. The antibacterial effects of Ag salts have been noticed since antiquity [59], and Ag is currently used to control bacterial growth in a wide spectrum of applications, including dental work, catheters, and burn wounds [60,61]. In fact, it is well

1 Mass transfer from smaller particles to larger particles extending in real polydisperse systems as a result of higher vapour pressure or greater solubility of smaller particles. This reduction of the degree of dispersion proceeds until the conversion of disperse systems into the system with sufficiently coarse dispersion in which the differences in solubility or vapour pressure of particles of different sizes are a very slight, and the process speed is negligibly small. 
known that Ag ions and Ag-based compounds are highly toxic to microorganisms, showing strong biocidal effects on as many as more than ten species of bacteria including E. coli [62, 63].

\begin{tabular}{|c|c|c|c|c|c|c|c|}
\hline \multicolumn{5}{|c|}{ Type of NPs } & \multirow[t]{2}{*}{ Synthetic method } & \multirow{2}{*}{$\begin{array}{l}\text { NP size } \\
(\mathrm{nm})\end{array}$} & \multirow[t]{2}{*}{ References } \\
\hline $\mathrm{Au}$ & $\mathrm{Ag}$ & $\mathrm{Pd}$ & $\mathrm{Pt}$ & $\mathrm{Cu}$ & & & \\
\hline$\bullet$ & & & & & Sol-gel microreactors & $5-50$ & {$[64,65]$} \\
\hline \multirow[t]{2}{*}{ - } & $\bullet$ & $\bullet$ & $\bullet$ & & PVD into liquid substrate & $2-5$ & {$[21,31]$} \\
\hline & & $\bullet$ & $\bullet$ & & Reduction in acidic environment & $3-40$ & {$[66]$} \\
\hline$\bullet$ & & & & & Reduction process & $2-40$ & {$[25,67-70]$} \\
\hline \multirow[t]{2}{*}{ - } & & & & $\bullet$ & $\gamma$-Irradiation & $3-30$ & {$[71]$} \\
\hline & & & & $\bullet$ & $\mathrm{pH}$ control of $\mathrm{Cu}$ complexes & $48-150$ & {$[72]$} \\
\hline \multirow[t]{2}{*}{ • } & $\bullet$ & $\bullet$ & & & Biosynthesis & $9-25$ & [73-77] \\
\hline & $\bullet$ & & & & Wet chemistry & $20-60$ & {$[78,79]$} \\
\hline
\end{tabular}

Table 1. Preparation techniques of selected noble metals with their typical size distributions.

Particle size reduction is an efficient and dependable tool to improve their bactericidal action and cytocompatibility. Nanotechnology techniques are of great assistance in the process of overcoming the limitations of size of nanoparticles [80]. Nanomaterials can be modified with the aim of better efficiency to facilitate their applications in various fields, e.g., bioscience and medicine.

\section{Gold, silver, platinum, and palladium nanoparticles physically deposited into glycerol}

In this section, a brief overview on results published by our group in the field of noble metal nanoparticles synthesis and investigation of their antibacterial action is introduced. The antimicrobial effects of $\mathrm{Au}, \mathrm{Ag}, \mathrm{Pt}$, and PdNPs were tested against representative microorganisms of public concern. When applying metal NPs into living tissues, fundamental attention must be paid to their synthesis process itself. For successive, non-invasive application of metal NPs into living microorganisms, our group has developed a novel, unconventional approach for the physical synthesis of gold, silver, platinum, and palladium NPs based on direct metal sputtering into the liquid media (glycerol) [21,31]. Considering this, direct metal deposition into the glycerol seems to be a promising technique combining the advantages of non-toxic and environmentally friendly process completely omitting the usage of solvents or reduction agents compared to classical wet-based methods. Furthermore, the possibility of tailoring the NP size via controlling the temperature of capturing media as well as the investigation of the functions of NP size and metal type (gold and silver) on the antibacterial activity are demonstrated. The antibacterial properties of these NPs were tested against two 
common pollutants of Escherichia coli (E. coli, Gram-negative bacteria) and Staphylococcus epidermidis (S. epidermidis, Gram-positive bacteria) naturally occurring on the skin and mucous membranes of human and frequently involved in infections associated with a biofilm formation. Prepared NPs were characterized by transmission electron microscopy with or without high-resolution (HRTEM, TEM) and UV-Vis spectroscopy.

TEM images of $\mathrm{Au}$ and Ag NPs are shown in Figure 1 [31]. Both Au and Ag NPs possess spherical shape with average diameter of about 3.5 and $2.4 \mathrm{~nm}$, respectively. It was shown that the NPs size distribution and uniformity remain untouched even in diluted aqueous solutions up to glycerol:water ratio of 1:20. It is a well-known fact that the presence of glycerol $-\mathrm{OH}$ group stabilizes aqueous solution of AgNPs [81]. But the stabilization role of glycerol $-\mathrm{OH}$ groups in AuNPs is not yet fully understood. Inset in Figure 1A introduces TEM image of AuNPs, which were stored 3 months at ambient conditions. The agglomeration of particles can be seen, which is in accordance with UV-Vis analysis. Contrary to that, this phenomenon was not found in case of AgNPs.
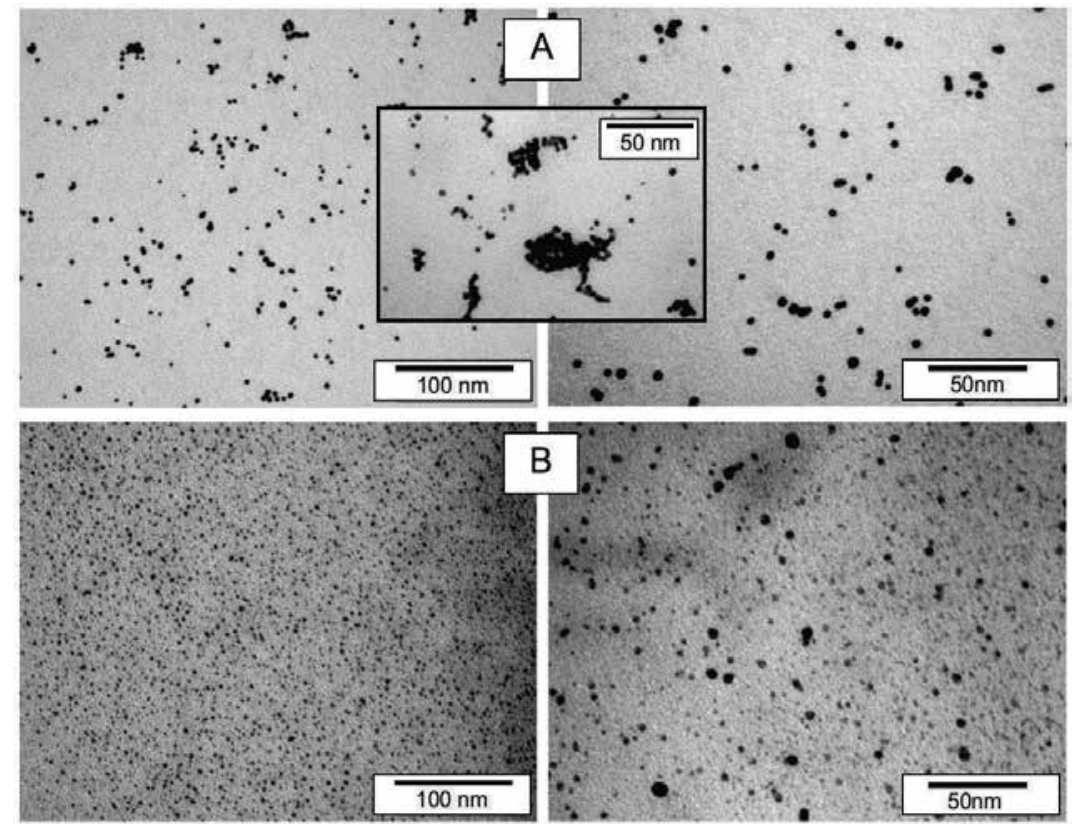

Figure 1. TEM images of $\mathrm{Au}(\mathrm{A})$ and $\mathrm{Ag}(\mathrm{B})$ nanoparticles. Inset in (A) shows TEM image of Au nanoparticles after 3 months storage at laboratory conditions [31].

UV-Vis absorption spectra measured on Au and AgNPs solutions promptly after deposition (solid lines) and after 3 month storage at ambient conditions (dash lines) are introduced in Figure 2 and discussed in detail in [31]. UV-Vis is often used to estimate size, shape, and particle size distribution of colloidal solutions of metal nanoparticles as they show specific absorption band corresponding to localized surface plasmon resonance (LSPR) [82, 83]. Nevertheless, this method must be conducted under precise and reproducible conditions, since the position and 
intensity of LSPR absorption peak are affected by many factors, e.g., used solvents, type of stabilizers, and counter ions. The shape of the spectra exhibiting significant LSPR peaks corresponds to uniform nanoparticle colloidal solutions and also corresponds to the narrow size distribution [12, 84]. UV-Vis absorption spectrum of Au sample measured directly after deposition (solid line) shows diminishing LSPR peak with maximum at $512 \mathrm{~nm}$. The shape and position of this peak suggest the particle sizes to be in interval from 2 to $10 \mathrm{~nm}$ [82], which corresponds with the sample's type (aqueous solution). Nevertheless, the influence of the AuNPs stabilization by -OH groups on the peak shift is not yet fully known. Mild red shift in spectrum after 3 month storage indicates both agglomeration effect and less narrow distribution compared to original sample. Narrow and high-intensity peak occurring at $400 \mathrm{~nm}$ together with the pure yellow coloration of the colloid solution indicates the presence of zerovalent Ag. Oxidized AgNPs do not exhibit this peak in their UV-Vis spectrum [85]. Contrary to AuNPs, AgNPs solution is much more stable even after 3 months storage. The corresponding spectrum exhibits almost the same peak position with pretty narrow distribution.

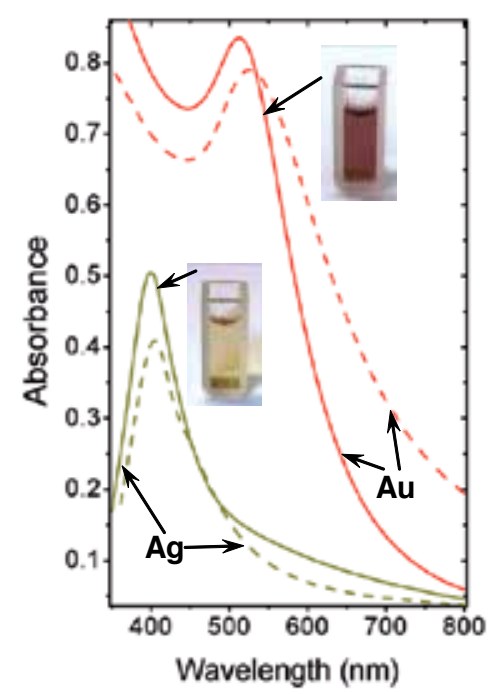

Figure 2. UV-Vis absorption spectra of $\mathrm{Au}$ and $\mathrm{Ag}$ aqueous nanoparticle solutions together with the photographs of corresponding NP solutions. Dash lines represent UV-Vis spectra of Au and Ag aqueous nanoparticle solutions stored for 3 months at laboratory conditions [31].

Targeted variation of metal nanoparticle size belongs to the great challenges of current science. Variation of capturing media temperature may provide a broad spectrum of nanoparticle diameters. The control of nanoparticle size through the capturing media temperature may be expressed upon a simple, generally known approach [86], which states that nanoparticle growth is governed by diffusion from the bulk of colloidal dispersion to the solution/particle interphase. When applied this approach, both $\mathrm{AgNP}_{4-6}$ and $\mathrm{AuNP}_{4-6}$ (indexes refer to average nanoparticle size) exhibit distinctive narrow peaks with maximum absorption at 400 and 520 $\mathrm{nm}$, respectively (see Figure 3) [58]. These spectra are almost identical to those obtained in our former study on $\mathrm{Ag}$ and Au with average diameter of 3-5 nm, indicating stable solutions with 
minimal particle dispersion. Considerable broadening with pronounced red shift of absorption peek occurs at $\mathrm{AuNP}_{9-12}$. This phenomenon originates from both, increase in dimensions of individual $\mathrm{Au}$ particles and broader size distribution compared to $\mathrm{AuNP}_{4-6}$. Distinctive red coloration of $\mathrm{AuNP}_{4-6}$ turns into purple one, belonging to $\mathrm{AuNP}_{9-12}$, as the average size increases from ca 5 to $10 \mathrm{~nm}$ (see Figure 4).

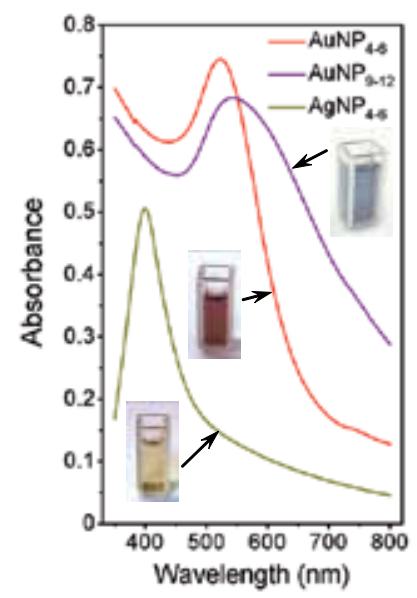

Figure 3. UV-Vis absorption spectra of $\mathrm{Ag}\left(\mathrm{AgNP}_{4-6}\right)$ and $\mathrm{Au}\left(\mathrm{AuNP}_{4-6}, \mathrm{AuNP}_{9-12}\right)$ aqueous solutions of different nanoparticle size together with the photographs of corresponding NP solutions (indexes refer to average NP diameter in nm) [58].

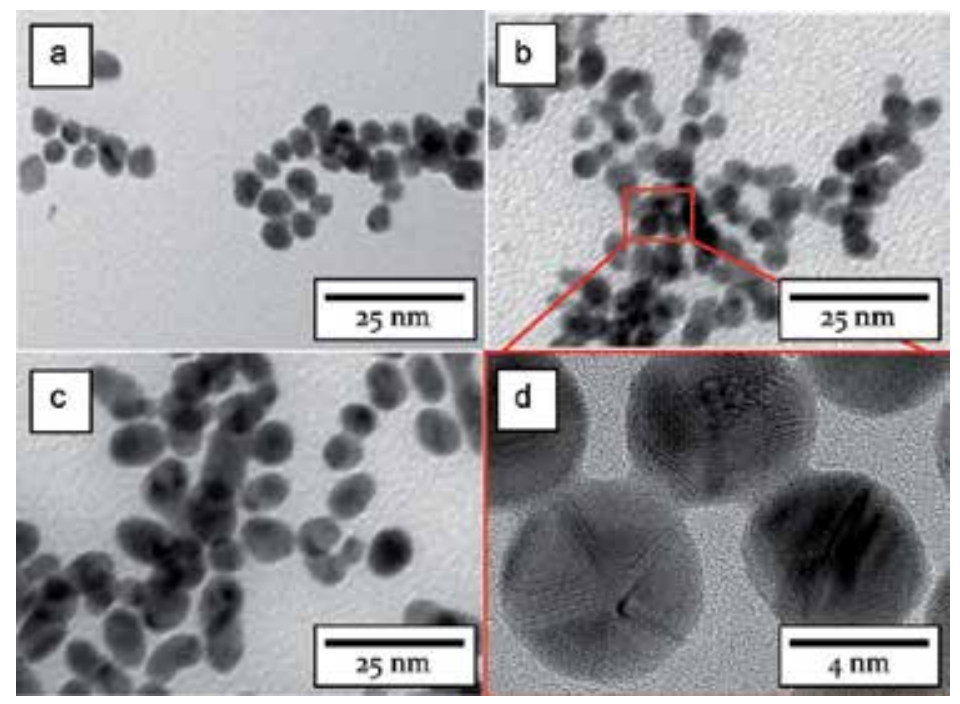

Figure 4. TEM images of nanoparticles of different composition and size $\mathrm{AgNP}_{4-6}(\mathrm{a}), \mathrm{AuNP}_{4-6}(\mathrm{~b})$, and $\mathrm{AuNP}_{9-12}(\mathrm{c})$, together with detailed HRTEM image of corresponding area (d). Indexes refer to NP diameter in nm [58]. 
Generally, two major aspects determine whether the growth of NPs during metal sputtering into liquids will take a place rather than formation of thin film on the liquid surface [52]. Firstly, the kinetic energy of sputtered atoms or clusters must be sufficient to penetrate the surface of capturing media. Secondly, the first condition may be fulfilled only in the limited range of media viscosity; thus, the liquid media cannot be too viscous. When those conditions are met, the formation of NPs occurs. Figure 5 shows TEM and HRTEM images of diluted aqueous solutions of Pt and PdNPs. Image analysis of more than 500 particles from 10 different areas of TEM pictures proved that prepared PtNPs and PdNPs have average diameter of $(1.7 \pm 0.3)$ $\mathrm{nm}$ and $(2.4 \pm 0.4) \mathrm{nm}$, respectively. Apparent aggregation of particles is due to the preparation method of samples for TEM (HRTEM) analysis. Observed discrepancy in particle size is probably due to different sputtering yield of both metals ( $\mathrm{Pt} \sim 1.27, \mathrm{Pd} \sim 2.09$ ) [87], which is in accordance with supposed growth mechanism causes considerably slower growth of $\mathrm{Pt}$ particles (lower concentration gradient).

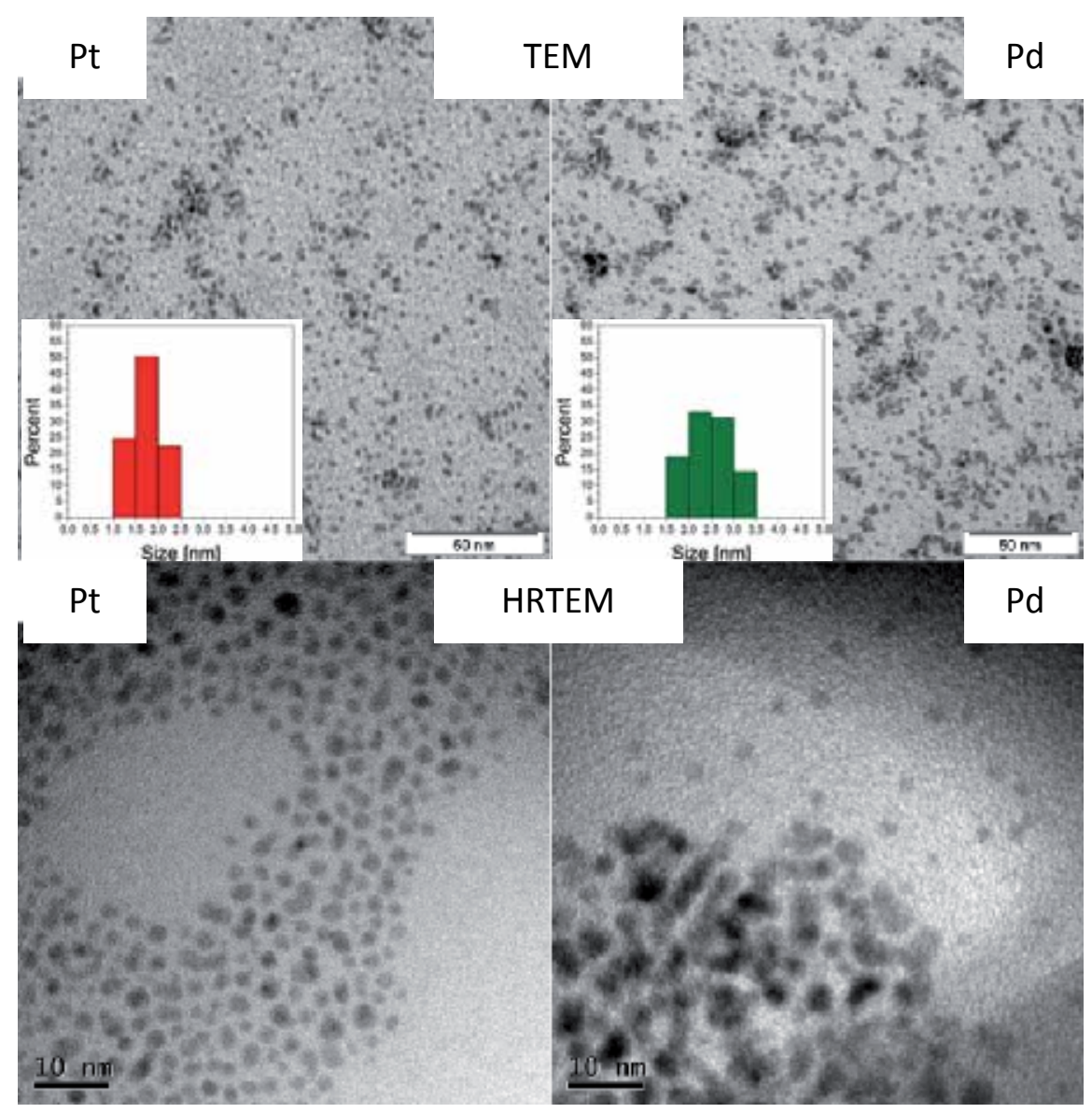

Figure 5. TEM and HRTEM images of diluted aqueous solutions of Pt and PdNPs insets show histogram of corresponding particle size and distribution [21]. 


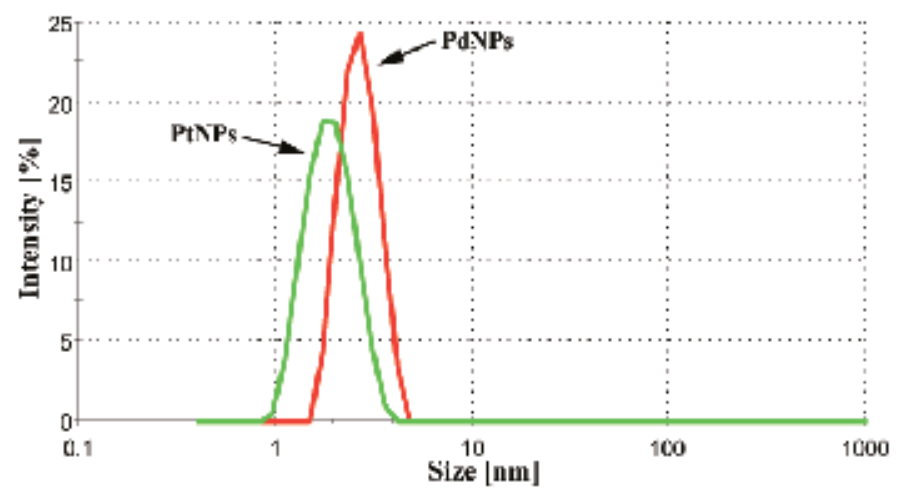

Figure 6. Characterization of aqueous solutions with metal nanoparticles by dynamic light scattering. Green line refers to PtNPs and red one PdNPs [21].

Additionally to TEM analysis, DLS measurement was accomplished to determine average size and size distribution of prepared NPs (see Figure 6, previous page). DLS measurements indicates that both particles are about $7 \%$ bigger compared to TEM-based analysis, which is in a good agreement with the published results [88], since DLS technique provides hydrodynamic diameter. Moreover, observed size discrepancy is inherently caused by intensity weighted mean particle diameter in case of DLS contrary to number weighted diameter obtained by TEM analysis [11]. More importantly, DLS proves that prepared NPs are not agglomerated, which is of crucial importance for evaluation of their bactericidal effects.

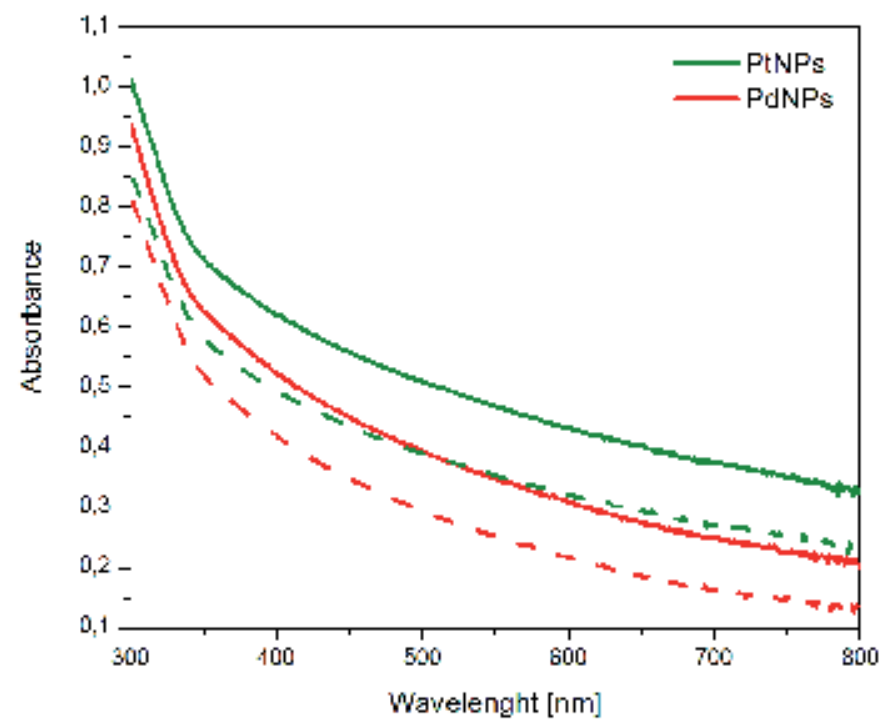

Figure 7. UV-Vis absorption spectra of Pt and Pd aqueous nanoparticle solutions. Dash lines represent UV-Vis spectra of $\mathrm{Pt}$ and $\mathrm{Pd}$ aqueous nanoparticle solutions stored for 3 months at laboratory conditions [21]. 
Formation and stability of metal NPs in aqueous colloidal solution were confirmed by UV-Vis spectroscopy. Figure 7 shows the UV-Vis spectra recorded from the Pd and PtNPs immediately after NPs preparation (solid lines) and after 3 months storage at laboratory conditions (dashed lines). It can be seen that apart from a distinct surface plasmon resonance (SPR) characteristic for other noble metal NPs (Au and Ag) [58], no distinctive SPR peaks occur in case of both Pd and PtNPs, which is in accordance with the earlier reports [89, 90]. Studied metal NPs exhibit increasing absorption toward shorter wavelengths [89, 91-93]. The course of dependence in case of both Pt and PdNPs indicates the presence of zerovalent metals in the solution [91]. Slight shift of the curves to lower absorbances at red region of visible spectrum (dashed lines) refers to mild agglomeration of individual particles in the solution after 3 months of storage. Bactericidal potency of various metal NPs has been previously reported [94-97]. It is known that their antimicrobial potency is governed by their size, composition, surface area, and charge [98, 99].

\section{Antibacterial effects of noble metal nanoparticles}

Antibacterial properties of $\mathrm{Ag}, \mathrm{Au}, \mathrm{Pd}$, and PtNPs were examined using two bacterial strains, E. coli and S. epidermidis, frequently involved in infections associated with a biofilm formation. Demonstration of inhibition effect of $\mathrm{AgNP}_{4-6}$ on S. epidermidis is shown in Figure 8. The growth of E. coli and S. epidermidis was completely inhibited in the presence of $\mathrm{AgNP}_{4-6}$ after $24 \mathrm{~h}$ (for both 6 and $24 \mathrm{~h}$ incubated samples) when compared to the control samples (bacteria incubated in glycerol or physiological saline solution [PBS]), see Table 2 and Figure 8 [58].

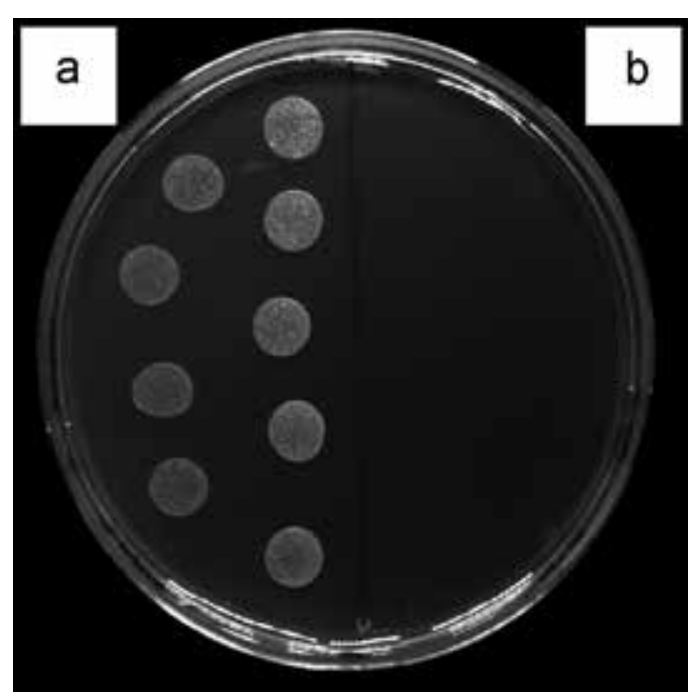

Figure 8. Photograph showing the inhibition effect of $\mathrm{AgNP}_{4-6}$ on Staphylococcus epidermidis (a) positive control of bacterial colonies growing on agar plate, (b) bacterial sample treated with silver nanoparticles [58]. 


\begin{tabular}{lllllll}
\hline Bacteria & \multicolumn{2}{l}{ E. coli } & \multicolumn{3}{c}{ S. epidermidis } \\
\hline Growth Time (h) $^{\mathrm{a}}$ & $\mathbf{2 4}$ & $\mathbf{3 0}$ & $\mathbf{4 8}$ & $\mathbf{2 4}$ & $\mathbf{3 0}$ & $\mathbf{4 8}$ \\
\hline $\mathrm{AgNP}_{4-6}$ & $\mathrm{O}^{\mathrm{b}}$ & 0 & 0 & 0 & 0 & 0 \\
\hline $\mathrm{AuNP}_{4-6}$ & $\bullet$ & $\bullet$ & $\bullet$ & 0 & 0 & 0 \\
\hline $\mathrm{AuNP}_{9-12}$ & $\bullet$ & $\bullet$ & $\bullet$ & 0 & 0 & 0 \\
\hline $\mathrm{Glycerol}^{\mathrm{c}}$ & $\bullet$ & $\bullet$ & $\bullet$ & 0 & 0 & 0 \\
\hline $\mathrm{PBS}^{\mathrm{d}}$ & $\bullet$ & $\bullet$ & $\bullet$ & $\bullet$ & 0 & 0 \\
\hline
\end{tabular}

Table 2. Inhibitory effect of silver and gold nanoparticles against Gram-negative (E. coli) and Gram-positive (S. epidermidis) bacteria (atime length of bacterial growth on LB plates after inoculation, ban empty circle indicates inhibition effect, ca full circle indicates positive growth, ${ }^{\mathrm{d}}$ physiological saline solution, ${ }^{\mathrm{e}}$ a half full circle indicates $50 \%$ growth) [58].

The growth inhibition of both bacterial strains was further maintained even after 30 and $48 \mathrm{~h}$ of growth, suggesting strong bactericidal activity of $\mathrm{AgNP}_{4-6}$. This is in contrary to generally accepted fact that Gram-negative bacteria are more susceptible to the inhibitory action of silver [100] caused probably by more facile penetration of silver through their thinner cell wall. On contrary, any growth inhibition was observed toward E. coli neither in the presence of $\mathrm{AuNP}_{4-6}$ nor in the presence of $\mathrm{AuNP}_{9-12}$ during the whole experiment. Surprisingly, $\mathrm{AuNP}_{4-}$ ${ }_{6}$, but not $\mathrm{AuNP}_{9-12}$, were able to inhibit the growth of $S$. epidermidis and the effect was preserved for whole tested period $(48 \mathrm{~h})$, when compared to control samples. The antibacterial action of Ag+ ions has been broadly reported so far [101], also AgNPs repeatedly showed their potency against bacteria [102]. Thus, our results (growth inhibition of both bacterial strains by $\mathrm{AgNP}_{4-}$ ${ }_{6}$ ) are in agreement with other groups results. Biocidal properties of AuNPs of similar size (5 $\mathrm{nm}$ ) as prepared by our group (4-6 nm), were observed by Lima et al. [103]. Their AuNPs dispersed on zeolites were effective against Gram-negative E. coli and Salmonella typhi (90-95\% growth inhibition). It has been reported that the antibacterial activity of AgNP is dependent on particle size and shape [104, 105]. Thus, it is very likely that also the size of AuNP plays significant role in the antimicrobial action.

Although there has been increased interest in studying bactericidal properties of noble metals over the past decades, only few have been reported on Pt and PdNPs. The inhibitory effect of one NPs concentration and four concentrations of bacteria was examined after $4 \mathrm{~h}$ in contact with NPs and $24 \mathrm{~h}$ of further post-incubation. From Figure 9, it is apparent that incubation of PdNPs with $E$. coli had pronounced effect on its growth up to $110^{5} \mathrm{CFU}$ per sample when compared to untreated control cells.

This remarkable antibacterial activity of Pd was diminished at higher bacterial concentrations ranging from $110^{6} \mathrm{CFU}$ per sample. Similar potency of PdNPs was observed against $S$. epidermidis (see Figure 9), even up to $110^{6} \mathrm{CFU}$. Since PtNPs had very similar size as the first examined particles, the palladium ones, we expected comparable antimicrobial potential. Nevertheless, we detected only insignificant inhibition of bacterial growth induced by PtNPs at a concentration of $110^{5} \mathrm{CFU}$ of $E$. coli when compared to the control samples. Interestingly, 


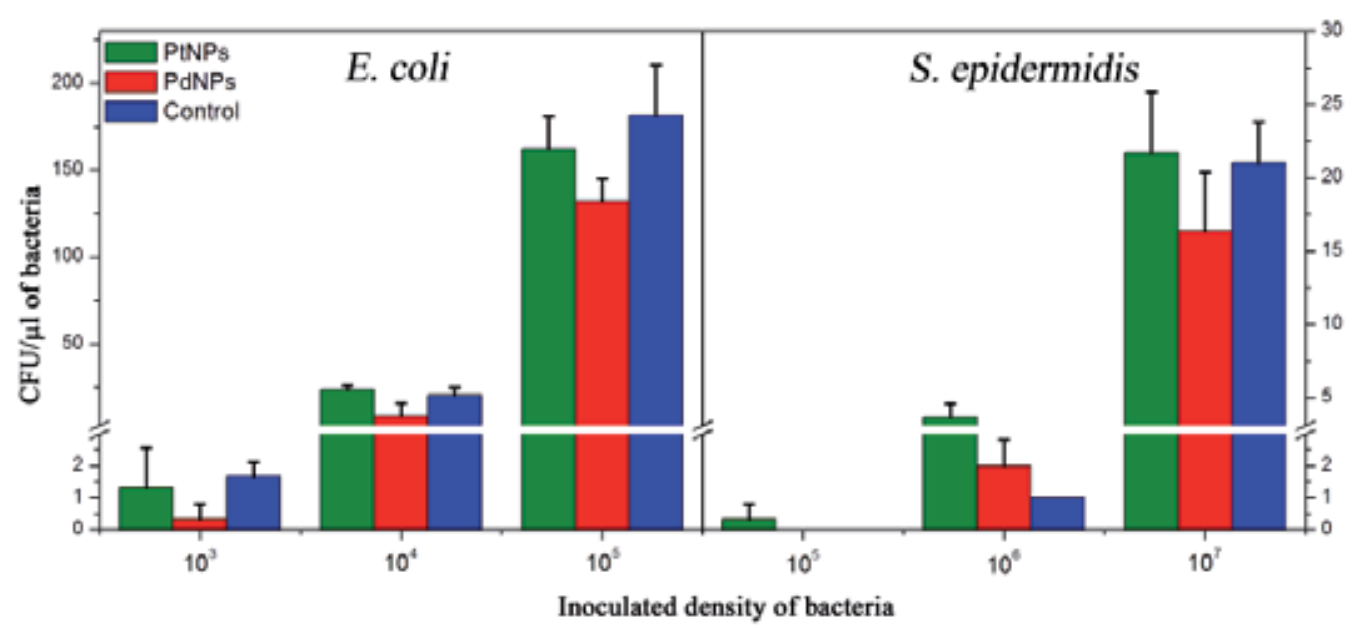

Figure 9. Inhibition effect of PtNPs and PdNPs toward bacterial strains of E. coli and S. epidermidis with different bacteria concentrations [21].

we did not observe any growth inhibition of S. epidermidis in the presence of PtNPs. More importantly, we even recorded slight stimulation of their growth.

\section{Grafting of noble metal nanoparticles to plasma-activated polymer carriers}

Polymer surface can be considered as the phase boundary between the bulk polymer and the ambient environment. The application of polymeric materials depends significantly on the boundaries' conditions. The most of polymeric materials, nevertheless, have chemically inert surface, mostly hydrophobic. Non-treated polymer surfaces exhibit very often poor performance in adhesion, coating, packaging, or colloid stabilization. [106-109].

During the past few decades, the modifications of polymer surface were under intensive research for applications in various fields of industry. Different improved techniques including chemical or physical enhancements were applied. Physical processes possess the advantage of surface interaction with radiation of electromagnetic waves, and oxidation with gases. On the contrary, chemical modifications use wet-treatment, such as blending. This part of manuscript is focused on the review of recent advances in surface grafting of polymer substrates which can be performed by the combination of physical and chemical processes $[107,110]$. The advantages of grafting procedures in comparison to other procedures may be summarized to several points, such as controllable introduction of graft chains with a high density, the precise localization of graft chains to the surface with almost no change in bulk's surface properties. In contrast to physically coated polymer chains, covalent anchoring of graft 
chains onto a polymer surface avoids their delamination and assures their long-term chemical stability [111].

Minimally four strategies can be used for creation of functionalized polymer surfaces with gold nanostructures: (i) "grafting from procedure" is based on polymer chain growth from small initiators connected to AuNPs $[112,113]$. This procedure leads to a very dense polymer brush construction. Other methods are based on radical polymerization (LRP) [114] and atomtransfer radical polymerization (SI-ATRP) $[115,116]$ (ii) "grafting to" enables one-pot synthesis of AuNPs stabilized by sulphur-containing polymers [10, 117], and generally produces a sparser coverage [118] (iii) physisorption using block copolymer micelles (nanoreactors), water-soluble polymers, or star block copolymers [119, 120] (iv) "post-modification of preformed AuNPs". In this method, AuNPs are generated in the first stage through conventional methods such as Brust-Schiffrin synthesis, followed by the exchange or modification with polymers [121, 122].

This section is dedicated to description of two procedures of Au and AgNPs grafting on plasma-modified PET developed by our group. In the first procedure, Au and AgNPs were deposited on PET, beforehand grafted with biphenyl-4,4'-dithiol (BPD). In the second procedure, the Au and AgNPs (both denoted with*), beforehand grafted with BPD, were coated onto plasma-modified PET (see Figure 10).

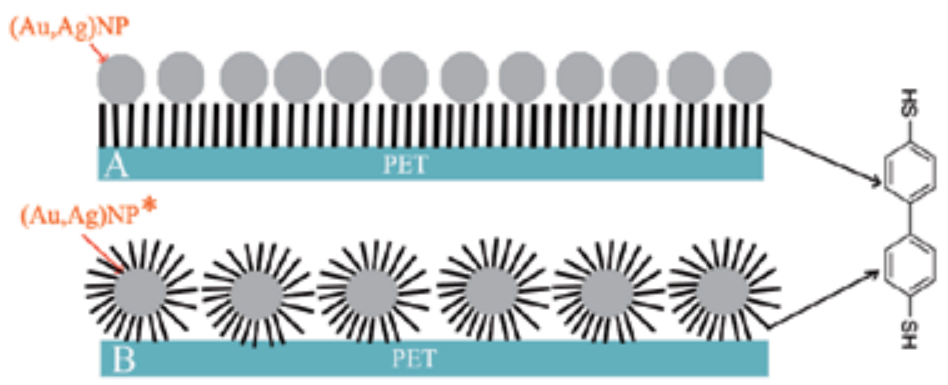

Figure 10. Scheme of PET modification: (A) plasma treatment, grafting with biphenyl-4,4'-dithiol (BPD) and then with AuNP or AgNP. (B) Plasma treatment, grafting with AuNP* or AgNP* covered with BPD [126].

In Figure 11, one can see the images of AuNPs obtained by TEM and HRTEM. It is evident that the AuNPs size is the same before and after BPD coating and their average diameter is 14.7 nm. Grafting with BPD does not lead to AuNPs aggregation, thanks to the presence of hydrophilic groups on the NP surface. It is known that the gold grows in a square $f c c$ crystal structure with dominant plane (111) [123]. At higher HRTEM resolution (Figure 11C,E), it is seen that the AuNPs are in the form of decahedral particles. As a result of deficiency, real AuNPs should contain defects or be intrinsically strained [124]. In Figure 10E, gold atoms arranged in (111) plane are clearly seen. From Figure 11D, it is seen that some of the form of BPD-coated AuNPs differs from that of uncoated AuNPs and they are not in the form of decahedral particles due to the decrease of the surface tension [125]. It is apparent that the behavior of pristine AgNPs (AgNP in Figure 11F) and AgNPs modified with BPD (AgNP* in 
Figure 11G) is significantly changed. AgNPs form uniform aggregates with nonspherical shape. On the contrary, AgNPs* form structures with spherical character which are well dispersed. Surface modification technique with BPD application does not result in AgNPs aggregation due to the presence of hydrophilic (-SH) and hydrophobic groups the nanoparticle's surface. The calculated diameters of AgNP and $\mathrm{AgNP}^{*}$ were $(55 \pm 10)$ and $(45 \pm 10) \mathrm{nm}$, respectively [126].

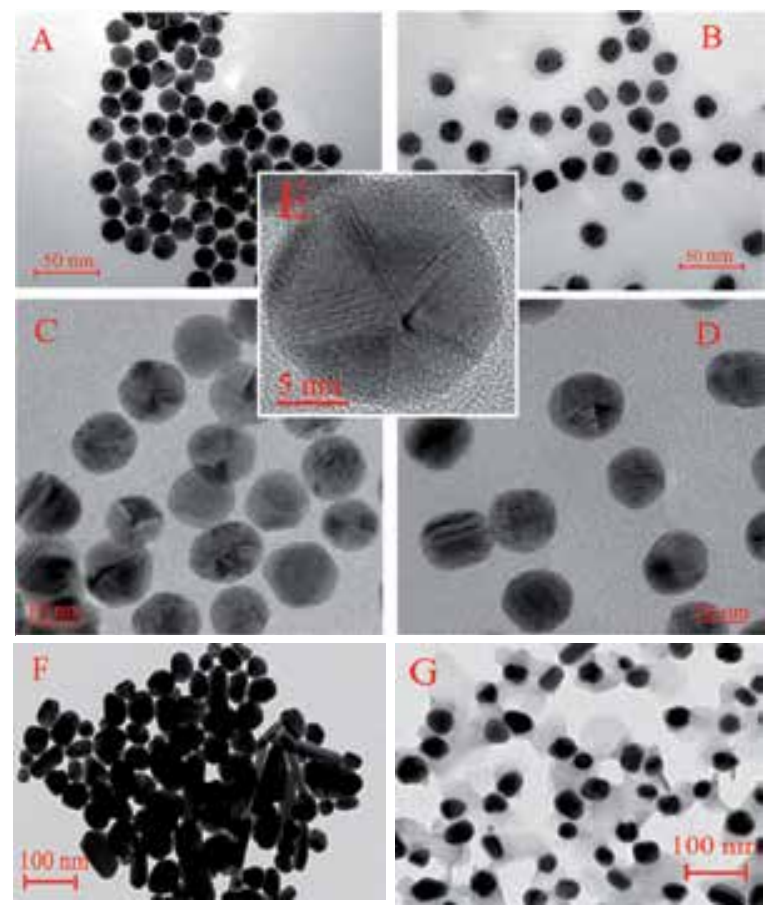

Figure 11. Images of the Au nanoparticles. TEM: (A) AuNPs and (B) AuNPs coated with dithiol (AuNP*). HRTEM: (C) AuNPs, (D) AuNPs coated with BPD (AuNP*), and (E) detail of AuNP; TEM images of the silver nanoparticles: (F) AgNP and $(G)$ AgNPs coated with BPD (AgNP*) $[125,126]$.

Both $(\mathrm{Au}, \mathrm{Ag}) \mathrm{NPs}$ and $(\mathrm{Au}, \mathrm{Ag}) \mathrm{NPs}^{*}$ in solution were characterized by UV-Vis spectroscopy (see Figure 12). The absorption spectrum of the AuNPs solution (see Figure 12A) shows a maximum around $521 \mathrm{~nm}$, corresponding to the transverse plasmon oscillation band. The wavelength of the surface plasmon resonance (SPR) [127] corresponds well with the average diameter estimated from TEM images. SPR absorption wavelength is known to increase with nanoparticle size [124]. From Figure 12, it is obvious that the absorption maximum of AuNP* is shifted toward larger wave lengths. This finding is in accordance with the above mentioned fact that the BPD-coated AuNPs (AuNPs*) exhibit enlarged surface [128]. The UV-Vis absorption spectra of AgNPs and AgNPs* suspensions (Figure 12B) exhibit well-defined plasmon bands at about 455 and $413 \mathrm{~nm}$, which is characteristic of nano-sized silver [31, 97, 129]. Observed wavelengths correspond well with average diameters of AgNPs estimated from TEM images (Figure 11F,G). 

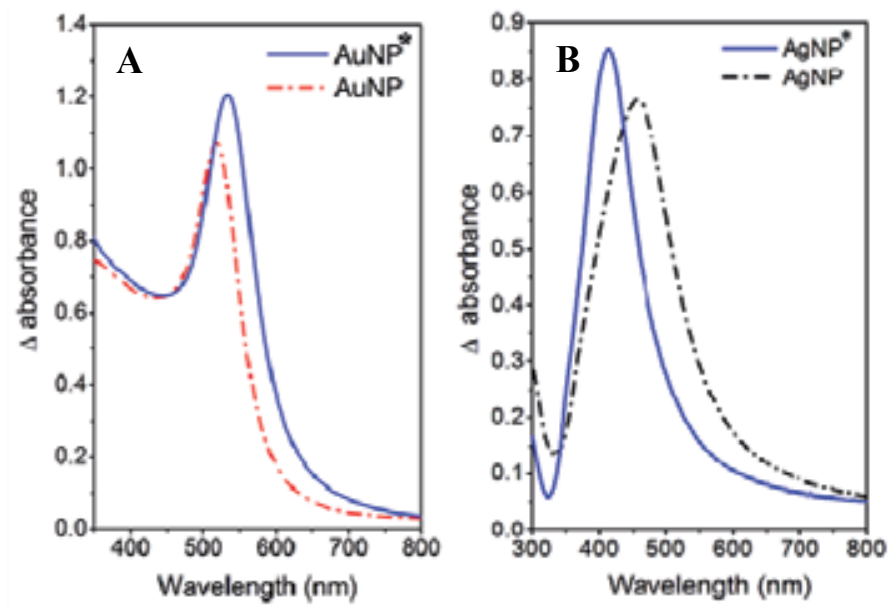

Figure 12. UV-Vis spectra of water solutions of (A) AuNPs (red) and AuNPs covered with BPD (AuNP*, blue); (B) AgNPs (black) and AgNPs covered with BPD (AgNP*, blue) [125, 126].

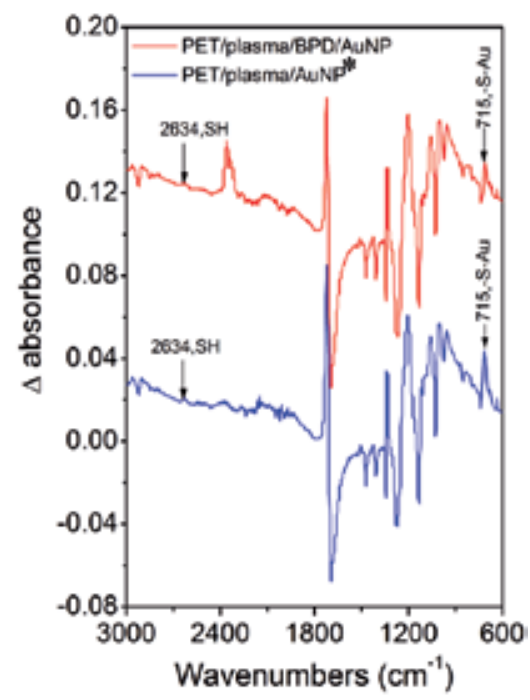

Figure 13. Differential FTIR spectra of plasma-treated PET grafted with BPD and then with AuNPs (PET/plasma/BPD/ AuNP, red) or plasma-treated PET and grafted with AuNPs covered with BPD (PET/plasma/AuNP*, blue) [125].

Differential FTIR spectroscopy was used for the characterization of pristine PET, plasmatreated PET, and PET grafted with BPD and AuNPs using both techniques described above. Typical difference FTIR spectra are shown in Figure 13. The band at $2634 \mathrm{~cm}^{-1}$ corresponds to residual dithiol group. The band at $715 \mathrm{~cm}^{-1}$ corresponds to the $-\mathrm{S}-\mathrm{Au}$ group. So that, the FTIR measurement proves that the AuNPs, deposited using both procedures examined, are chemically bound to the plasma-activated PET surface. 
XPS analysis was used to monitor the change in the surface chemical composition after subsequent preparation steps. Element concentration of $\mathrm{C}, \mathrm{O}, \mathrm{S}$, and $\mathrm{Au}$ on the surface of all samples (using both grafting techniques) is summarized in Table 3. After the plasma treatment, the PET surface is oxidized dramatically. The polymer oxidation after the plasma treatment and creation of oxygen-containing groups $(\mathrm{C}-\mathrm{O} \sim 286.0 \mathrm{eV}, \mathrm{O}-\mathrm{C}=\mathrm{O} \sim 288.8 \mathrm{eV})$ at the polymer surface is well known [130]. Polymer chain is characterized by the $\mathrm{C} 1 \mathrm{~s}$ component centered at $284.7 \mathrm{eV}$ due to $\mathrm{C}-\mathrm{C}$ group. There is a change in the contribution of the shake-up satellite 290.9 $\mathrm{eV}$ due to the attachment of aromatic species (BPD) to the plasma-treated PET, see references $[125,131]$. After grafting of plasma-treated PET with BPD, the oxygen concentration decreases dramatically. The attachment of BPD to the surface of PET (PET/BPD) was evidenced by the detection of the sulphur with concentration of 5.7 at. \%. The concentration of bonded AuNP and $\mathrm{AuNP}^{*}$ varies from 0.1 to 0.02 at. \%, respectively. Atomic concentrations of $\mathrm{C}(1 \mathrm{~s}), \mathrm{O}(1 \mathrm{~s})$, $\mathrm{S}(2 \mathrm{p})$, and $\mathrm{Ag}(3 \mathrm{~d})$ in pristine, plasma-modified PET and after grafting with BPD and silver nanoparticles are summarized in Table 3. After the next grafting procedure realized with AgNP and AgNP* particles, the concentration of sulphur decreased and silver was confirmed for the PET/plasma/BPD/AgNP samples, which indicates the presence of AgNPs on the surface of treated PET. In the case of PET/plasma/AgNP* samples, the silver concentration is presumably below the detection limit of XPS method. However, the evidence of successful AgNP* attachment was confirmed by the presence of sulphur on the treated surface.

\begin{tabular}{lllll}
\hline Sample & \multicolumn{4}{l}{ Element concentration (at. \%) } \\
\hline PET & $\mathrm{C}(1 \mathrm{~s})$ & $\mathrm{O}(1 \mathrm{~s})$ & $\mathrm{S}(2 \mathrm{p})$ & $\mathrm{Au}(4 \mathrm{f})$ \\
\hline PET/plasma & 72.5 & 27.5 & - & - \\
\hline PET/plasma/BPD & 29.0 & 71.0 & - & - \\
\hline PET/plasma/BPD/AuNP & 75.4 & 18.9 & 5.7 & - \\
\hline PET/plasma/AuNP* & 72.6 & 24.6 & 2.7 & 0.1 \\
\hline
\end{tabular}

Table 3. Atomic concentration of $\mathrm{C}, \mathrm{O}, \mathrm{S}$, and Au measured with XPS in surface polymer layer for: pristine (PET), plasma exposed (PET/plasma), plasma exposed and grafted with BPD (PET/plasma/BPD) and then grafted with AuNP (PET/plasma/BPD/AuNP) and grafted with AuNP* (PET/plasma/AuNP*) 4 days after the exposure [125].

It is known that the thiol groups bond to double bonds created on surface by plasma treatment by free radical chain mechanism [132]. Radicals created after plasma activation of PET are located mainly at heteroatoms (e.g., oxygen of ester or hydroxyl group). Therefore, these radicals are stable and do not stabilize by creation of double bonds on surface [133]. In our previous study [134], it has been proved the amount of free radicals created on PET surface modified by plasma is very low. That is the reason why more double bonds are not available on PET, and therefore the amount of bonded thiol groups is not much higher $[125,126]$.

\section{Conclusions}

This chapter attempts to provide a comprehensive insight into the problems of new techniques of preparation of noble metal NPs. It summarizes the basic information about the elementary 
characteristics and technology of preparation of those man-made materials. The introduction gives some basic information on the history of development in this area, especially in terms of dimensionality of metal nanostructures and their possible applications. General overview is supported by the specific research of the author team in this field. Presented findings support the hypothesis that $\mathrm{Au}, \mathrm{Ag}, \mathrm{Pd}$, and PtNPs can be prepared in a simple and cost-effective manner and are suitable for formulation of new types of bactericidal materials. Presented approach is based on temperature control of capturing media during the sputtering deposition process into propane-1,2,3-triol, allowing targeted variation of NPs size. Bactericidal action of such synthesized NPs was examined against two common pollutants (E. coli and S. epidermidis). While $\mathrm{AgNP}_{4-6}$ exhibit strong potential to completely inhibit both bacterial strains after 24 $h$, AuNPs showed pronounced inhibition selectivity regarding the specific NP size. Regardless of AuNP size, any growth inhibition of E. coli was observed. Contrary to that, AuNP $4-6$ were able to inhibit the growth of S. epidermidis. We have also illustrated a significant difference in biological activities of Pt and PdNPs. More specifically, PdNPs exhibited considerable inhibitory potential against both E. coli and S. epidermidis, which was in contrast to ineffective PtNPs. Those findings indicate that palladium has high potential to combat both Grampositive and Gram-negative bacterial strains. Understanding of nanoparticle-bacteria interactions is a key issue in their potential applications in clinics on everyday basis. Observed discrepancy in bactericidal action between $\mathrm{Pt}$ and $\mathrm{Pd}$ nanoparticles could be attributed to different size of individual particles. Finally, we have introduced procedures for PET surface coating with noble metal nanoparticles. The techniques were based on activation of PET surface with Ar plasma discharge and consequent application of dithiol as binding reagent between Au and Ag nanoparticles and plasma-treated PET. The introduction of gold and silver nanoparticle-thiol layer on the activated PET surface was confirmed with XPS analysis. Higher concentration of Au and AgNPs was achieved by deposition on PET grafted beforehand with dithiol.

\section{Acknowledgements}

Financial support of this work under the GACR projects Nos. 14-18131S, 14-18149P, and 13-06609S is gratefully acknowledged.

\section{Author details}

Jakub Siegel*, Alena Řezníčková, Petr Slepička and Václav Švorčík

*Address all correspondence to: jakub.siegel@vscht.cz

Department of Solid State Engineering, University of Chemistry and Technology Prague, Prague, Czech Republic 


\section{References}

[1] Zhou J, Ralston J, Sedev R, Beattie DA. Functionalized gold nanoparticles: synthesis, structure and colloid stability. J Colloid Interface Sci 2009;331:251-62. 10.1016/j.jcis. 2008.12.002

[2] Zhang L, Wang E. Metal nanoclusters: new fluorescent probes for sensors and bioimaging. Nano Today 2014;9:132-57. 10.1016/j.nantod.2014.02.010

[3] Ghosh P, Han G, De M, Kim CK, Rotello VM. Gold nanoparticles in delivery applications. Adv Drug Delivery Rev 2008;60:1307-15. 10.1016/j.addr.2008.03.016

[4] Kamat PV. Photophysical, photochemical and photocatalytic aspects of metal nanoparticles. J Phys Chem B 2002;106:7729-44. 10.1021/jp0209289

[5] Cheng H-W, Luo J, Zhong C-J. An aggregative growth process for controlling size, shape and composition of metal, alloy and core-shell nanoparticles toward desired bioapplications. J Mater Chem B 2014;2:6904-16. 10.1039/c4tb00962b

[6] Sahoo GP, Basu S, Samanta S, Misra A. Microwave-assisted synthesis of anisotropic gold nanocrystals in polymer matrix and their catalytic activities. J Exp Nanosci 2015;10:690-702. 10.1080/17458080.2013.877163

[7] El Roustom B, Foti G, Comninellis C. Preparation of gold nanoparticles by heat treatment of sputter deposited gold on boron-doped diamond film electrode. Electrochem Commun 2005;7:398-405. 10.1016/j.elecom.2005.02.014

[8] Turkevich J, Stevenson PC, Hillier J. A study of the nucleation and growth processes in the synthesis of colloidal gold. Discuss Faraday Soc 1951:55.

[9] Grzelczak M, Perez-Juste J, Mulvaney P, Liz-Marzan LM. Shape control in gold nanoparticle synthesis. Chem Soc Rev 2008;37:1783-1791. 10.1039/b711490g

[10] Hussain I, Graham S, Wang ZX, Tan B, Sherrington DC, Rannard SP, Cooper AI, Brust M. Size-controlled synthesis of near-monodisperse gold nanoparticles in the 1-4 nm range using polymeric stabilizers. J Am Chem Soc 2005;127:16398-9. 10.1021/ ja055321v

[11] Uskokovic V. Dynamic light scattering based microelectrophoresis: main prospects and limitations. J Dispersion Sci Technol 2012;33:1762-86. 10.1080/01932691.2011.625523

[12] Zhang Q, Tan YN, Xie J, Lee JY. Colloidal synthesis of plasmonic metallic nanoparticles. Plasmonics 2009;4:9-22. 10.1007/s11468-008-9067-x

[13] Migowski P, Dupont J. Catalytic applications of metal nanoparticles in imidazolium ionic liquids. Chem Eur J 2007;13:32-39. 10.1002/chem.200601438 
[14] Soto-Aquino D, Rinaldi C. Nonlinear energy dissipation of magnetic nanoparticles in oscillating magnetic fields. J Magn Magn Mater 2015;393:46-55.

[15] Zhang X, Wu F-G, Liu P, Wang H-Y, Gu N, Chen Z. Synthesis of ultrastable and multifunctional gold nanoclusters with enhanced fluorescence and potential anticancer drug delivery application. J Colloid Interface Sci 2015;455:6-15. 10.1016/j.jcis. 2015.05.029

[16] Joshi MK, Pant HR, Liao N, Kim JH, Kim HJ, Park CH, Kim CS. In-situ deposition of silver-iron oxide nanoparticles on the surface of fly ash for water purification. J Colloid Interface Sci 2015;453:159-68. 10.1016/j.jcis.2015.04.044

[17] Taaber T, Enok AE, Joost U, Oras S, Jaervekuelg M, Lohmus R, Maeeorg U, Saal K. Tribological properties of protic ionic liquid and functionalized copper oxide nanoparticles as additives to base oil. Mechanika 2015:148-153. 10.5755/j01.mech. 21.2.11723

[18] Vallejos S, Gracia I, Bravo J, Figueras E, Hubalek J, Cane C. Detection of volatile organic compounds using flexible gas sensing devices based on tungsten oxide nanostructures functionalized with $\mathrm{Au}$ and Pt nanoparticles. Talanta 2015;139:27-34. 10.1016/j.talanta.2015.02.034

[19] Melo Ferreira DC, Giordano GF, dos Santos Penteado Soares CC, Afonso de Oliveira JF, Mendes RK, Piazzetta MH, Gobbi AL, Cardoso MB. Optical paper-based sensor for ascorbic acid quantification using silver nanoparticles. Talanta 2015;141:188-94. 10.1016/j.talanta.2015.03.067

[20] Kannan R, Kim AR, Lee H-K, Yoo DJ. Coordinated fast synthesis of electrocatalytic palladium nanoparticles decorated graphene oxide nanocomposite for fuel cell applications. J Nanosci Nanotechnol 2015;15:5711-17. 10.1166/jnn.2015.10042

[21] Staszek M, Siegel J, Kolarova K, Rimpelova S, Svorcik V. Formation and antibacterial action of Pt and Pd nanoparticles sputtered into liquid. Micro Nano Lett 2014;9:77881. 10.1049/mnl.2014.0345

[22] Siegel J, Kvitek O, Lyutakov O, Reznickova A, Svorcik V. Low pressure annealing of gold nanostructures. Vacuum 2013;98:100-5. 10.1016/j.vacuum.2013.03.019

[23] Yang X. Nano- and microparticle-based imaging of cardiovascular interventions: overview. Radiology 2007;243:340-7. 10.1148/radiol.2432060307

[24] Lanza GM, Winter PM, Caruthers SD, Hughes MS, Cyrus T, Marsh JN, Neubauer AM, Partlow KC, Wickline SA. Nanomedicine opportunities for cardiovascular disease with perfluorocarbon nanoparticles. Nanomed 2006;1:321-9. 10.2217/17435889.1.3.321

[25] Brust M, Walker M, Bethell D, Schiffrin DJ, Whyman R. Synthesis of thiol-derivatized gold nanoparticles in a 2-phase liquid-liquid system. J Chem Soc Chem Comm 1994:801-2. 10.1039/c39940000801 
[26] Sahiner N. Soft and flexible hydrogel templates of different sizes and various functionalities for metal nanoparticle preparation and their use in catalysis. Prog Polym Sci 2013;38:1329-56. 10.1016/j.progpolymsci.2013.06.004

[27] Sahiner N, Singh M. In situ micro/nano-hydrogel synthesis from acrylamide derivates with lecithin organogel system. Polymer 2007;48:2827-34. 10.1016/j.polymer. 2007.01.005

[28] Jayamurugan G, Umesh CP, Jayaraman N. Preparation and catalytic studies of palladium nanoparticles stabilized by dendritic phosphine ligand-functionalized silica. J Mol Catal A-Chem 2009;307:142-8. 10.1016/j.molcata.2009.03.020

[29] Costi R, Saunders AE, Banin U. Colloidal hybrid nanostructures: a new type of functional materials. Angew Chem-Int Edit 2010;49:4878-97. 10.1002/anie.200906010

[30] Ahn H, Park MJ. Facile one-pot synthesis of functional gold nanoparticle-polymer hybrids using ionic block copolymers as a nanoreactor. Macromol Rapid Commun 2011;32:1790-7. 10.1002/marc.201100449

[31] Siegel J, Kvitek O, Ulbrich P, Kolska Z, Slepicka P, Svorcik V. Progressive approach for metal nanoparticle synthesis. Mater Lett 2012;89:47-50. 10.1016/j.matlet. 2012.08.048

[32] Metin O, Dinc M, Eren ZS, Ozkar S. Silica embedded cobalt(0) nanoclusters: efficient, stable and cost effective catalyst for hydrogen generation from the hydrolysis of ammonia borane. Int J Hydrogen Energy 2011;36:11528-35. 10.1016/j.ijhydene. 2011.06.057

[33] Sutton A, Franc G, Kakkar A. Silver metal nanoparticles: facile dendrimer-assisted size-controlled synthesis and selective catalytic reduction of chloronitrobenzenes. J Polymer Sci Part A Polymer Chem 2009;47:4482-93. 10.1002/pola.23501

[34] Li Y, Pan Y, Zhu L, Wang Z, Su D, Xue G. Facile and controlled fabrication of functional gold nanoparticle-coated polystyrene composite particle. Macromol Rapid Commun 2011;32:1741-47. 10.1002/marc.201100377

[35] Goyal A, Kumar A, Patra PK, Mahendra S, Tabatabaei S, Alvarez PJJ, John G, Ajayan PM. In situ synthesis of metal nanoparticle embedded free standing multifunctional PDMS films. Macromol Rapid Commun 2009;30:1116-22. 10.1002/marc.200900174

[36] Suzuki D, Kawaguchi H. Gold nanoparticle localization at the core surface by using thermosensitive core-shell particles as a template. Langmuir 2005;21:12016-24. 10.1021/la0516882

[37] Lu Y, Mei Y, Schrinner M, Ballauff M, Moeller MW. In situ formation of Ag nanoparticles in spherical polyacrylic acid brushes by UV irradiation. J Phys Chem C 2007;111:7676-81. 10.1021/jp070973m

[38] Konishi N, Fujibayashi T, Tanaka T, Minami H, Okubo M. Effects of properties of the surface layer of seed particles on the formation of golf ball-like polymer particles by 
seeded dispersion polymerization. Polym J (Tokyo, Jpn) 2010;42:66-71. 10.1038/pj. 2009.313

[39] Frattini A, Pellegri N, Nicastro D, de Sanctis O. Effect of amine groups in the synthesis of Ag nanoparticles using aminosilanes. Mater Chem Phys 2005;94:148-52. 10.1016/j.matchemphys.2005.04.023

[40] Liu H, Wang C, Gao Q, Liu X, Tong Z. Fabrication of novel core-shell hybrid alginate hydrogel beads. Int J Pharm 2008;351:104-12. 10.1016/j.ijpharm.2007.09.019

[41] Butun S, Sahiner N. A versatile hydrogel template for metal nano particle preparation and their use in catalysis. Polymer 2011;52:4834-40. 10.1016/j.polymer. 2011.08.021

[42] Nguyen LH, Kudva AK, Saxena NS, Roy K. Engineering articular cartilage with spatially-varying matrix composition and mechanical properties from a single stem cell population using a multi-layered hydrogel. Biomaterials 2011;32:6946-52. 10.1016/ j.biomaterials.2011.06.014

[43] Nuttelman CR, Rice MA, Rydholm AE, Salinas CN, Shah DN, Anseth KS. Macromolecular monomers for the synthesis of hydrogel niches and their application in cell encapsulation and tissue engineering. Prog Polym Sci 2008;33:167-79. 10.1016/j.progpolymsci.2007.09.006

[44] Nicodemus GD, Bryant SJ. Cell encapsulation in biodegradable hydrogels for tissue engineering applications. Tissue Eng Part B Rev 2008;14:149-65. 10.1089/ten.teb. 2007.0332

[45] Ozay O, Aktas N, Sahiner N. Hydrogels as a potential chromatographic system: absorption, speciation, and separation of chromium species from aqueous media. Sep Sci Technol 2011;46:1450-61. 10.1080/01496395.2011.560918

[46] Ye GX, Zhang QR, Feng CM, Ge HL, Jiao ZK. Structural and electrical properties of a metallic rough-thin-film system deposited on liquid substrates. Phys Rev B. 1996;54:14754-7. 10.1103/PhysRevB.54.14754

[47] Ye GX, Geng CM, Zhang ZR, Ge HL, Zhang XJ. Structural and critical behaviors of ag rough films deposited on liquid substrates. Chin Phys Lett 1996;13:772-4. 10.1088/0256-307x/13/10/016

[48] Wender H, de Oliveira LF, Feil AF, Lissner E, Migowski P, Meneghetti MR, Teixeira SR, Dupont J. Synthesis of gold nanoparticles in a biocompatible fluid from sputtering deposition onto castor oil. Chem Commun 2010;46:7019-21. 10.1039/c0cc01353f

[49] da Silva EC, da Silva MGA, Meneghetti SMP, Machado G, Alencar MARC, Hickmann JM, Meneghetti MR. Synthesis of colloids based on gold nanoparticles dispersed in castor oil. J Nanoparticle Res 2008;10:201-8. 10.1007/s11051-008-9483-Z 
[50] Wender H, Goncalves RV, Feil AF, Migowski P, Poletto FS, Pohlmann AR, Dupont J, Teixeira SR. Sputtering onto liquids: from thin films to nanoparticles. J Phys Chem C 2011;115:16362-7. 10.1021/jp205390d

[51] Dupont J, de Souza RF, Suarez PAZ. Ionic liquid (molten salt) phase organometallic catalysis. Chem Rev 2002;102:3667-91. 10.1021/cr010338r

[52] Wender H, Migowski P, Feil AF, Teixeira SR, Dupont J. Sputtering deposition of nanoparticles onto liquid substrates: recent advances and future trends. Coord Chem Rev 2013;257:2468-83. 10.1016/j.ccr.2013.01.013

[53] Antonietti M, Kuang DB, Smarsly B, Yong Z. Ionic liquids for the convenient synthesis of functional nanoparticles and other inorganic nanostructures. Angew Chem-Int Edit 2004;43:4988-92. 10.1002/anie.200460091

[54] Wender H, de Oliveira LF, Migowski P, Feil AF, Lissner E, Prechtl MHG, Teixeira SR, Dupont J. Ionic liquid surface composition controls the size of gold nanoparticles prepared by sputtering deposition. J Phys Chem C 2010;114:11764-8. 10.1021/ jp102231x

[55] Migowski P, Zanchet D, Machado G, Gelesky MA, Teixeira SR, Dupont J. Nanostructures in ionic liquids: correlation of iridium nanoparticles' size and shape with imidazolium salts' structural organization and catalytic properties. Phys Chem Chem Phys 2010;12:6826-33. 10.1039/b925834e

[56] Redel E, Thomann R, Janiak C. Use of ionic liquids (ILs) for the IL-anion size-dependent formation of $\mathrm{Cr}, \mathrm{Mo}$ and $\mathrm{W}$ nanoparticles from metal carbonyl $\mathrm{M}(\mathrm{CO})(6)$ precursors. Chem Commun 2008:1789-91. 10.1039/b718055a

[57] Redel E, Thomann R, Janiak C. First correlation of nanoparticle size-dependent formation with the ionic liquid anion molecular volume. Inorg Chem 2008;47:14-6. 10.1021/ic702071w

[58] Siegel J, Kolarova K, Vosmanska V, Rimpelova S, Leitner J, Svorcik V. Antibacterial properties of green-synthesized noble metal nanoparticles. Mater Lett 2013;113:5962. 10.1016/j.matlet.2013.09.047

[59] Silver S, Phung LT. Bacterial heavy metal resistance: new surprises. Annu Rev Microbiol 1996;50:753-89. 10.1146/annurev.micro.50.1.753

[60] Samuel U, Guggenbichler JP. Prevention of catheter-related infections: the potential of a new nano-silver impregnated catheter. Int J Antimicrob Agents 2004;23:S75-8. 10.1016/j.ijantimicag.2003.12.004

[61] Catauro M, Raucci MG, De Gaetano F, Marotta A. Antibacterial and bioactive silvercontaining $\mathrm{Na} 2 \mathrm{O}$ center dot $\mathrm{CaO}$ center dot $2 \mathrm{SiO}(2)$ glass prepared by sol-gel method. J Mater Sci Mater Med 2004;15:831-7. 10.1023/b:jmsm.0000032825.51052.00 
[62] Lee W, Kim K-J, Lee DG. A novel mechanism for the antibacterial effect of silver nanoparticles on Escherichia coli. BioMetals 2014;27:1191-201. 10.1007/ s10534-014-9782-z

[63] Ansari MA, Khan HM, Khan AA, Ahmad MK, Mahdi AA, Pal R, Cameotra SS. Interaction of silver nanoparticles with Escherichia coli and their cell envelope biomolecules. J Basic Microbiol 2014;54:905-15. 10.1002/jobm.201300457

[64] Mikhlin Y, Karacharov A, Likhatski M, Podlipskaya T, Zubavichus Y, Veligzhanin A, Zaikovski V. Submicrometer intermediates in the citrate synthesis of gold nanoparticles: new insights into the nucleation and crystal growth mechanisms. J Colloid Interface Sci 2011;362:330-6. 10.1016/j.jcis.2011.06.077

[65] Wagner J, Kohler JM. Continuous synthesis of gold nanoparticles in a microreactor. Nano Lett 2005;5:685-91. 10.1021/nl050097t

[66] Zhang A, Liu M, Liu M, Xiao Y, Li Z, Chen J, Sun Y, Zhao J, Fang S, Jia D, Li F. Homogeneous Pd nanoparticles produced in direct reactions: green synthesis, formation mechanism and catalysis properties. J Mater Chem A 2014;2:1369-74. 10.1039/ c3ta14299j

[67] Liu Y, Liu L, Yuan M, Guo R. Preparation and characterization of casein-stabilized gold nanoparticles for catalytic applications. Colloids Surfaces Physicochem Eng Asp 2013;417:18-25. 10.1016/j.colsurfa.2012.08.050

[68] Doyen M, Bartik K, Bruylants G. UV-Vis and NMR study of the formation of gold nanoparticles by citrate reduction: Observation of gold-citrate aggregates. J Colloid Interface Sci 2013;399:1-5. 10.1016/j.jcis.2013.02.040

[69] De S, Kundu R, Biswas A. Synthesis of gold nanoparticles in niosomes. J Colloid Interface Sci 2012;386:9-15. 10.1016/j.jcis.2012.06.073

[70] Wangoo N, Bhasin KK, Mehta SK, Suri CR. Synthesis and capping of water-dispersed gold nanoparticles by an amino acid: Bioconjugation and binding studies. J Colloid Interface Sci 2008;323:247-54. 10.1016/j.jcis.2008.04.043

[71] Hori T, Nagata K, Iwase A, Hori F. Synthesis of Cu nanoparticles using gamma-ray irradiation reduction method. Japanese Journal of Applied Physics. 2014;53. 10.7567/ jjap.53.05fc05

[72] Yokoyama S, Takahashi H, Itoh T, Motomiya K, Tohji K. Synthesis of metallic Cu nanoparticles by controlling $\mathrm{Cu}$ complexes in aqueous solution. Advanced Powder Technology. 2014;25:999-1006. 10.1016/j.apt.2014.01.024

[73] Bankar A, Joshi B, Kumar AR, Zinjarde S. Banana peel extract mediated synthesis of gold nanoparticles. Colloids and Surfaces B-Biointerfaces. 2010;80:45-50. 10.1016/ j.colsurfb.2010.05.029 
[74] Bankar A, Joshi B, Kumar AR, Zinjarde S. Banana peel extract mediated novel route for the synthesis of palladium nanoparticles. Mater Lett 2010;64:1951-53. 10.1016/ j.matlet.2010.06.021

[75] Bankar A, Joshi B, Kumar AR, Zinjarde S. Banana peel extract mediated novel route for the synthesis of silver nanoparticles. Colloids Surfaces A Physicochem Eng Aspects 2010;368:58-63. 10.1016/j.colsurfa.2010.07.024

[76] Das RK, Sharma P, Nahar P, Bora U. Synthesis of gold nanoparticles using aqueous extract of Calotropis procera latex. Mater Lett 2011;65:610-3. 10.1016/j.matlet. 2010.11.040

[77] Ren F, He X, Wang K, Yin J. Biosynthesis of gold nanoparticles using catclaw buttercup (Radix Ranunculi Ternati) and evaluation of its colloidal stability. J Biomed Nanotechnol 2012;8:586-93. 10.1166/jbn.2012.1417

[78] Im H-J, Lee BC, Yeon J-W. Preparation and characterization of Ag nanoparticle-embedded blank and ligand-anchored silica gels. J Nanosci Nanotechnol 2013;13:7643-7. 10.1166/jnn.2013.7824

[79] Sarkar P, Bhui DK, Bar H, Sahoo GP, De SP, Misra A. Synthesis and photophysical study of silver nanoparticles stabilized by unsaturated dicarboxylates. J Lumin 2009;129:704-9. 10.1016/j.jlumin.2009.02.002

[80] Mirkin CA, Taton TA. Materials chemistry - semiconductors meet biology. Nature 2000;405:626-7. 10.1038/35015190

[81] Sarkar A, Kapoor S, Mukherjee T. Synthesis and characterisation of silver nanoparticles in viscous solvents and its transfer into non-polar solvents. Res Chem Intermed 2010;36:411-421. 10.1007/s11164-010-0151-4

[82] Daniel MC, Astruc D. Gold nanoparticles: assembly, supramolecular chemistry, quantum-size-related properties, and applications toward biology, catalysis, and nanotechnology. Chem Rev 2004;104:293-346. 10.1021/cr030698+

[83] Li X, Jiang L, Zhan Q, Qian J, He S. Localized surface plasmon resonance (LSPR) of polyelectrolyte-functionalized gold-nanoparticles for bio-sensing. Colloids Surfaces APhysicochem Eng Aspects 2009;332:172-9. 10.1016/j.colsurfa.2008.09.009

[84] Link S, El-Sayed MA. Size and temperature dependence of the plasmon absorption of colloidal gold nanoparticles. J Phys Chem B 1999;103:4212-7. 10.1021/jp984796o

[85] Varkey AJ, Fort AF. Some optical properties of silver peroxide (Ago) and silver-oxide (AG2O) films produced by chemical bath deposition. Sol Energy Mater Sol Cells 1993;29:253-9. 10.1016/0927-0248(93)90040-a

[86] Park J, Joo J, Kwon SG, Jang Y, Hyeon T. Synthesis of monodisperse spherical nanocrystals. Angew Chem-Int Edit. 2007;46:4630-60. 10.1002/anie.200603148 
[87] Cabrini S, Kawata S. Nanofabrication Handbook. Boca Raton: Taylor\&Francis; 2012. $546 \mathrm{p}$.

[88] Baalousha M, Ju-Nam Y, Cole PA, Gaiser B, Fernandes TF, Hriljac JA, Jepson MA, Stone V, Tyler CR, Lead JR. Characterization of cerium oxide nanoparticles Part 1: size measurements. Environ Toxicol Chem 2012;31:983-93. 10.1002/etc.1785

[89] Chen L, Zhao W, Jiao W, He X, Wang J, Zhang Y. Characterization of Ag/Pt coreshell nanoparticles by UV-vis absorption, resonance light-scattering techniques. Spectrochim Acta Part A Molecul Biomolecul Spectrosc 2007;68:484-90. 10.1016/j.saa. 2006.12.014

[90] Patel K, Kapoor S, Dave DP, Mukherjee T. Synthesis of Pt, Pd, Pt/Ag and Pd/Ag nanoparticles by microwave-polyol method. J Chem Sci (Bangalore, India). 2005;117:311-6. 10.1007/bf02708443

[91] Guo L, Bai J, Li C, Meng Q, Liang H, Sun W, Li H, Liu H. A novel catalyst containing palladium nanoparticles supported on PVP composite nanofiber films: synthesis, characterization and efficient catalysis. Appl Surf Sci 2013;283:107-14. 10.1016/ j.apsusc.2013.06.046

[92] Kalbasi RJ, Negandari M. Synthesis and characterization of mesoporous poly(N-vinyl-2-pyrrolidone) containing palladium nanoparticles as a novel heterogeneous organocatalyst for Heck reaction. J Mol Struct 2014;1063:259-68. 10.1016/j.molstruc. 2014.01.071

[93] Vinod VTP, Saravanan P, Sreedhar B, Devi DK, Sashidhar RB. A facile synthesis and characterization of $\mathrm{Ag}, \mathrm{Au}$ and $\mathrm{Pt}$ nanoparticles using a natural hydrocolloid gum kondagogu (Cochlospermum gossypium). Colloids and Surfaces B-Biointerfaces. 2011;83:291-8. 10.1016/j.colsurfb.2010.11.035

[94] Adams CP, Walker KA, Obare SO, Docherty KM. Size-dependent antimicrobial effects of novel palladium nanoparticles. PLoS One 2014;9:1-6. 10.1371/journal.pone. 0085981

[95] Panacek A, Kvitek L, Prucek R, Kolar M, Vecerova R, Pizurova N, Sharma VK, Nevecna Tj, Zboril R. Silver colloid nanoparticles: Synthesis, characterization, and their antibacterial activity. J Phys Chem B 2006;110:16248-53. 10.1021/jp063826h

[96] Rai M, Yadav A, Gade A. Silver nanoparticles as a new generation of antimicrobials. Biotechnol Adv 2009;27:76-83. 10.1016/j.biotechadv.2008.09.002

[97] Kim JS, Kuk E, Yu KN, Kim J-H, Park SJ, Lee HJ, Kim SH, Park YK, Park YH, Hwang C-Y, Kim Y-K, Lee Y-S, Jeong DH, Cho M-H. Antimicrobial effects of silver nanoparticles. Nanomed Nanotechnol Biol Med 2007;3:95-101. 10.1016/j.nano.2006.12.001

[98] Nel A, Xia T, Madler L, Li N. Toxic potential of materials at the nanolevel. Science 2006;311:622-7. 10.1126/science.1114397 
[99] Singh S, Nalwa HS. Nanotechnology and health safety - Toxicity and risk assessments of nanostructured materials on human health. J Nanosci Nanotechnol 2007;7:3048-70. 10.1166/jnn.2007.922

[100] Jung WK, Koo HC, Kim KW, Shin S, Kim SH, Park YH. Antibacterial activity and mechanism of action of the silver ion in Staphylococcus aureus and Escherichia coli. Appl Environ Microbiol 2008;74:2171-8. 10.1128/aem.02001-07

[101] Klaus T, Joerger R, Olsson E, Granqvist CG. Silver-based crystalline nanoparticles, microbially fabricated. Proc Natl Acad Sci U S A 1999;96:13611-4. 10.1073/pnas. 96.24.13611

[102] Raffi M, Hussain F, Bhatti TM, Akhter JI, Hameed A, Hasan MM. Antibacterial characterization of silver nanoparticles against E. coli ATCC-15224. J Mater Sci Technol 2008;24:192-6.

[103] Lima E, Guerra R, Lara V, Guzman A. Gold nanoparticles as efficient antimicrobial agents for Escherichia coli and Salmonella typhi. Chem Cent J 2013;7:1-5. 10.1186/1752-153x-7-11

[104] Darroudi M, Ahmad MB, Mashreghi M. Gelatinous silver colloid nanoparticles: synthesis, characterization, and their antibacterial activity. J Optoelectron Adv Mater 2014;16:182-7.

[105] Pal S, Tak YK, Song JM. Does the antibacterial activity of silver nanoparticles depend on the shape of the nanoparticle? A study of the gram-negative bacterium Escherichia coli. Appl Environ Microbiol 2007;73:1712-20. 10.1128/aem.02218-06

[106] Ozdemir M, Yurteri CU, Sadikoglu H. Physical polymer surface modification methods and applications in food packaging polymers. Crit Rev Food Sci Nutr 1999;39:457-77. 10.1080/10408699991279240

[107] Huang X, Jiang P, Yin Y. Nanoparticle surface modification induced space charge suppression in linear low density polyethylene. Appl Phys Lett 2009;95:1-6. $10.1063 / 1.3275732$

[108] Jacobs T, Morent R, De Geyter N, Dubruel P, Leys C. Plasma surface modification of biomedical polymers: influence on cell-material interaction. Plasma Chem Plasma Process 2012;32:1039-73. 10.1007/s11090-012-9394-8

[109] Yoshida S, Hagiwara K, Hasebe T, Hotta A. Surface modification of polymers by plasma treatments for the enhancement of biocompatibility and controlled drug release. Surf Coat Technol 2013;233:99-107. 10.1016/j.surfcoat.2013.02.042

[110] Zhang T, Wu Y, Pan X, Zheng Z, Ding X, Peng Y. An approach for the surface functionalized gold nanoparticles with $\mathrm{pH}$-responsive polymer by combination of RAFT and click chemistry. Eur Polym J 2009;45:1625-33. 10.1016/j.eurpolymj.2009.03.016 
[111] Kato K, Uchida E, Kang ET, Uyama Y, Ikada Y. Polymer surface with graft chains. Prog Polym Sci 2003;28:209-59. 10.1016/s0079-6700(02)00032-1

[112] Kim DJ, Kang SM, Kong B, Kim WJ, Paik HJ, Choi H, Choi IS. Formation of thermoresponsive gold nanoparticle/PNIPAAm hybrids by surface-initiated, atom transfer radical polymerization in aqueous media. Macromol Chem Phys 2005;206:1941-6. 10.1002/macp.200500268

[113] Raula J, Shan J, Nuopponen M, Niskanen A, Jiang H, Kauppinen EI, Tenhu H. Synthesis of gold nanoparticles grafted with a thermoresponsive polymer by surface-induced reversible-addition-fragmentation chain-transfer polymerization. Langmuir 2003;19:3499-504. 10.1021/la026872r

[114] Mandal TK, Fleming MS, Walt DR. Preparation of polymer coated gold nanoparticles by surface-confined living radical polymerization at ambient temperature. Nano Lett 2002;2:3-7. 10.1021/nl015582c

[115] Yoon KR, Ramaraj B, Lee SM, Kim D-P. Surface initiated-atom transfer radical polymerization of a sugar methacrylate on gold nanoparticles. Surf Interface Anal 2008;40:1139-43. 10.1002/sia.2847

[116] Li D, He Q, Cui Y, Li J. Fabrication of pH-responsive nanocomposites of gold nanoparticles/poly(4-vinylpyridine). Chem Mater 2007;19:412-7. 10.1021/cm062290+

[117] Suzuki D, Kawaguchi H. Modification of gold nanoparticle composite nanostructures using thermosensitive core-shell particles as a template. Langmuir 2005;21:8175-9. 10.1021/la0504356

[118] Corbierre MK, Cameron NS, Sutton M, Laaziri K, Lennox RB. Gold nanoparticle/ polymer nanocomposites: Dispersion of nanoparticles as a function of capping agent molecular weight and grafting density. Langmuir 2005;21:6063-72. 10.1021/la047193e

[119] Wang L, Kariuki NN, Schadt M, Mott D, Luo J, Zhong C-J, Shi X, Zhang C, Hao W, Lu S, Kim N, Wang J-Q. Sensing arrays constructed from nanoparticle thin films and interdigitated microelectrodes. Sensors 2006;6:667-79. 10.3390/s6060667

[120] Salvati R, Longo A, Carotenuto G, De Nicola S, Pepe GP, Nicolais L, Barone A. UVvis spectroscopy for on-line monitoring of $\mathrm{Au}$ nanoparticles size during growth. Appl Surf Sci 2005;248:28-31. 10.1016/j.apsusc.2005.03.075

[121] Saha K, Agasti SS, Kim C, Li X, Rotello VM. Gold nanoparticles in chemical and biological sensing. Chem Rev 2012;112:2739-79. 10.1021/cr2001178

[122] Kang YJ, Taton TA. Core/shell gold nanoparticles by self-assembly and crosslinking of micellar, block-copolymer shells. Angew Chem-Int Edit 2005;44:409-12. 10.1002/ anie.200461119 
[123] Chui YH, Grochola G, Snook IK, Russo SP. Molecular dynamics investigation of the structural and thermodynamic properties of gold nanoclusters of different morphologies. Phys Rev B 2007;75:1-8. 10.1103/PhysRevB.75.033404

[124] Mayoral A, Barron H, Estrada-Salas R, Vazquez-Duran A, Jose-Yacaman M. Nanoparticle stability from the nano to the meso interval. Nanoscale 2010;2:335-42. 10.1039/b9nr00287a

[125] Reznickova A, Kolska Z, Zaruba K, Svorcik V. Grafting of gold nanoparticles on polyethyleneterephthalate using dithiol interlayer. Mater Chem Phys 2014;145:484-90. 10.1016/j.matchemphys.2014.03.001

[126] Reznickova A, Novotna Z, Kolska Z, Svorcik V. Immobilization of silver nanoparticles on polyethylene terephthalate. Nanoscale Res Lett 2014;9:1-6. 10.1186/1556-276x-9-305

[127] Rezanka P, Rezankova H, Matejka P, Kral V. The chemometric analysis of UV-visible spectra as a new approach to the study of the $\mathrm{NaCl}$ influence on aggregation of cysteine-capped gold nanoparticles. Colloids Surfaces A Physicochem Eng Aspects 2010;364:94-8. 10.1016/j.colsurfa.2010.05.001

[128] Luis Elechiguerra J, Reyes-Gasga J, Jose Yacaman M. The role of twinning in shape evolution of anisotropic noble metal nanostructures. J Mater Chem 2006;16:3906-19. $10.1039 / \mathrm{b} 607128 \mathrm{~g}$

[129] Yin J, Yang Y, Hu Z, Deng B. Attachment of silver nanoparticles (AgNPs) onto thinfilm composite (TFC) membranes through covalent bonding to reduce membrane biofouling. J Membr Sci 2013;441:73-82. 10.1016/j.memsci.2013.03.060

[130] Chu PK, Chen JY, Wang LP, Huang N. Plasma-surface modification of biomaterials. Mat Sci Eng R 2002;36:143-206. 10.1016/s0927-796x(02)00004-9

[131] Gam-Derouich S, Mahouche-Chergui S, Truong S, Ben Hassen-Chehimi D, Chehimi MM. Design of molecularly imprinted polymer grafts with embedded gold nanoparticles through the interfacial chemistry of aryl diazonium salts. Polymer 2011;52:4463-70. 10.1016/j.polymer.2011.08.007

[132] Guerrouache M, Mahouche-Chergui S, Chehimi MM, Carbonnier B. Site-specific immobilisation of gold nanoparticles on a porous monolith surface by using a thiol-yne click photopatterning approach. Chem Commun 2012;48:7486-8. 10.1039/c2cc33134a

[133] Carey FA, Sundberg RJ. Advanced Organic Chemistry. 4 ed. New York: Plenum Press; 1993. 286 p.

[134] Reznickova A, Kolska Z, Hnatowicz V, Stopka P, Svorcik V. Comparison of glow argon plasma-induced surface changes of thermoplastic polymers. Nucl Instrum Methods Phys Res, Sect B 2011;269:83-8. 10.1016/j.nimb.2010.11.018 
Chapter 6

\title{
The Development of Smart, Multi-Responsive Core@Shell Composite Nanoparticles
}

\author{
Bo Sang Kim and T. Randall Lee \\ Additional information is available at the end of the chapter \\ http://dx.doi.org/10.5772/61262
}

\begin{abstract}
The unique optical, magnetic, and electronic properties of metal nanoparticles (NPs) give rise to photothermal, therapeutic, and electronic device applications, correspondingly. On the other hand, the limited range of the properties of simple spherical metal NPs has complicated their ability to function in many of these applications. Therefore, this chapter starts by reviewing a specific type of NP that can be classified into three main groups: silica coated with metal (silica@metal) NPs, metal coated with silica (metal@silica) NPs, and other similar forms of core@shell structures. The objective of this review is to introduce the concept of multi-responsive core@shell nanoparticles. More specifically, this chapter highlights "smart" core@shell composite NPs having multiple response mechanisms (e.g., temperature, light, and/or an applied magnetic field) due to the ability of these systems to perform a task by remotely responding to stimuli. Additionally, hydrogel-coated metal@silica NPs, with the ability to store drugs in a mesoporous silica ( $\mathrm{m}$-silica) interlayer, are examined because these nanomaterials potentially provide substantial advantages for carrying cargos to targeted sites. To demonstrate this capability, we examine recent research that provided initial tests of composite NPs with a $\mathrm{pH}$ - and temperature-responsive hydrogel coating, including the application of an underlying $\mathrm{m}$-silica interlayer to improve the capacity of these NPs to load and release small molecules.
\end{abstract}

Keywords: Nanoshells, core@shell nanoparticles, surface plasmon resonance, smart multi-responsive nanoparticles

\section{Introduction}

Metal nanoparticles (NPs) provide optical, magnetic, and electronic properties which are different from the corresponding bulk metal materials, leading to photothermal, therapeutic, and electronic device applications, respectively. Recent research efforts have explored NPs 
having complex compositions with controllable sizes and morphologies. Special attention has been given to metal NPs for use as optical materials (i.e., using palladium [1, 2], silver [3-12], copper [13-18], and particularly gold [19-31]). This is due to the ease of fabrication of these metal nanoparticles and their unique physical properties [32-34], such as the ability to absorb or scatter light $[25,35,36]$. However, the narrow scope of simple spherical metal NPs' optical properties has limited their use in practical applications. Thus, investigators have pursued new classes of nanostructured materials such as triangular prisms [37-40], disks [41, 42], nanorods [43-46], nanocubes [47-51], and NPs coated with a shell (core@shell NPs) [52-58], to overcome the restrictions on the optical properties associated with simple spherical metal NPs. Among these, core@shell NPs represent a promising nanoscale tool for biomedical research [59-63]. A number of metals have been used as the shell for these NPs (as detailed in Table 1), but silica has proven to be the favorite core for such structures [64-76].

\begin{tabular}{ll}
\hline Core@Shell Nanoparticles & References \\
\hline gold@silica & {$[57,64-68]$} \\
silver@silica & {$[54,69-73]$} \\
palladium@silica & {$[53,74]$} \\
gold alloy@silica & {$[53,54,75,76]$} \\
\hline
\end{tabular}

Table 1. References for core@shell nanoparticles with silica cores and metal shells.

Recent research has also centered on the capacity of core@shell NPs containing metal/metal oxide cores to respond to an external stimulus (e.g., a magnetic field or near IR light) and to affect their local surroundings, resulting in their use in diagnostic, therapeutic, and drug delivery applications utilizing either a polymer coating or a more complex shell design [77-80]. The development of these more sophisticated NP structures has been presaged by a number of simpler particle architectures.

\section{Types of Core@Shell nanoparticles}

Core@shell NPs can be categorized according to their material properties (e.g., dielectric, semiconductor, etc.) and form (e.g., single-layered shell, multilayered shell, etc.). In this chapter, the core or shell materials in a core@shell NP are considered in terms of their constitution or shape. For this report, the core@shell NPs of interest are classified into three main groups: (i) silica@metal NPs; (ii) metal@silica NPs; and (iii) other forms of core@shell NPs.

Silica@Metal Nanoparticles. Since the publication of the "Stöber Method" of preparing silica particles, various metals and metal oxide shell materials have been deposited on silica spheres [81]. Because of the unique qualities of gold, silica-based core@shell NPs with gold as the shell material became the focus of efforts to produce the first of these structures in the late 1990's [64, $68,82]$. A gold coating on the silica core provides improved biocompatibility, photonic energy absorption, catalytic properties, chemical stability, bio-affinity (through greater diversity in 
the functionalization of the surface), and tunable optical properties [64]. Similar to the sizedependent color of pure gold NPs, the optical response of gold nanoshells (GNSs) depends dramatically on the relative size of the core NP as well as the thickness of the gold shell [67, 83]. Importantly, the surface-enhanced Raman scattering (SERS) activity of GNSs can be increased or decreased by decreasing or increasing the thickness of the gold shell material [84, 85]. By adjusting the relative core size and shell thickness, an intense light absorption associated with the gold in the GNSs can be varied across a broad range of the optical spectrum, spanning the visible and the near-infrared spectral regions. This phenomenon is known as surface plasmon resonance (SPR) and its impact upon the extinction spectra of GNSs is illustrated in Figure 1 with regards to changes in shell thickness.

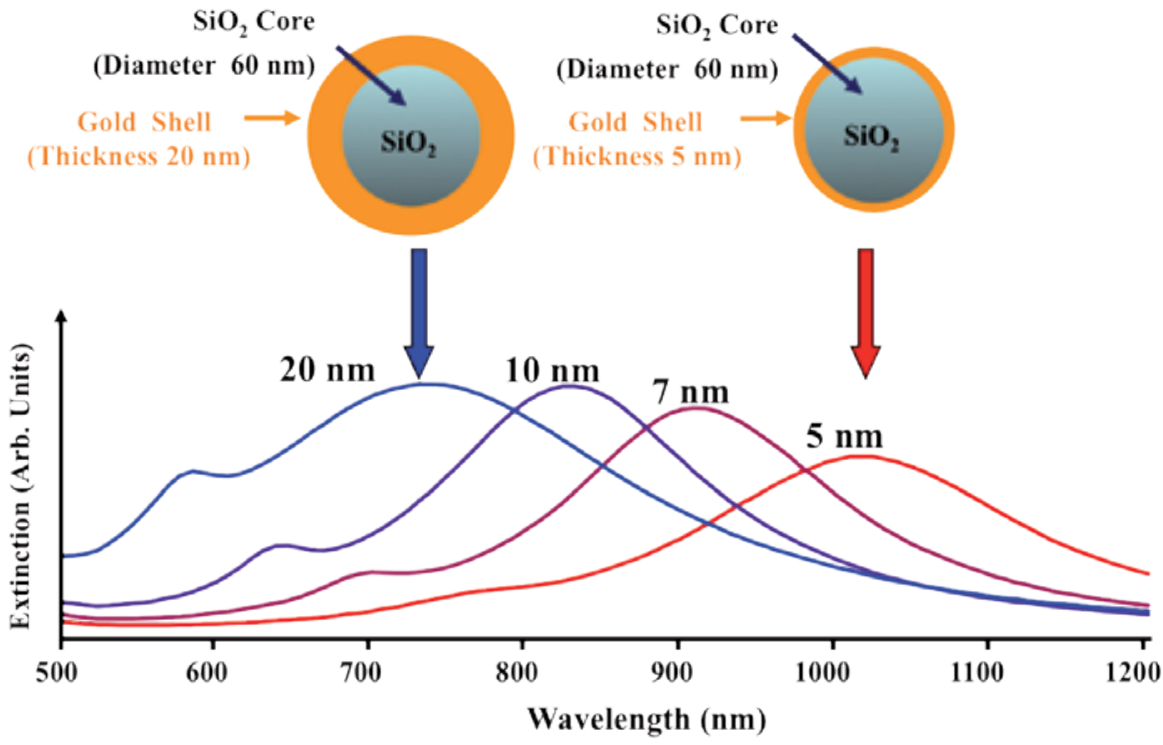

Figure 1. Illustration of the optical resonances of various sizes of silica@gold composite particles (gold nanoshells) as a function of their shell thickness. Reproduced with permission from reference [67].

The development of these gold shells has been followed by a number of alternative metal and metal oxide coatings, broadening the number of applications for such core@shell structures $[53,54,69,74]$. These data indirectly indicate that GNSs with a silica core ( $\left.\mathrm{SiO}_{2} @ \mathrm{Au} \mathrm{NPs}\right)$ may be useful for biomedical imaging, cancer treatment, and optical materials in future applications owing to the ability of certain wavelengths of light to penetrate human tissue.

Metal@ Silica Nanoparticles. Using a silica coating as the shell on a metal core to form NPs with core@shell architectures offers several benefits. First, a silica shell diminishes the bulk metal conductivity and improves the chemical and physical stability of the core component [86]. Second, silica particles produced via the Stöber Method have been shown to be chemically biocompatible $[87,88]$. And silica can be used to block the core surface from making contact with a biological environment without disrupting key phenomena involving the core surface, 
such as light absorption. This is an important feature for metals/metal oxides that have been shown to be cytotoxic. Third, the silica coating can be used to modulate the position and intensity of the surface plasmon absorption band due to both the optical transparency of silica at technologically important wavelengths of light and the shift in these bands associated with a small change in the metal's optical properties because of the material in contact with their surfaces [89]. And the fourth point is that an outer silica shell on a metal nanoshell can help stabilize the metal shell when it is generating intense localized heat in response to intense light absorption [90,91]. Therefore, scientists have recently focused more on silica coatings as a shell for a variety of core materials such as metals [92-99] and metal oxides [100-103], than on any other material. Many research groups have investigated the use of silica on coinage metals such as gold [92, 93] and silver [98]. Silica-coated gold or silver NPs are synthesized by using a slightly modified Stöber (or sol-gel) Method. The resulting coating does not interfere with the intensity of the light absorption for targeted wavelengths, and only produces a minor shift in the absorption band toward the higher wavelength region, as compared to an uncoated NP, as shown in Figure 2 [104]. This coating method has been adjusted further to control the uniformity of the thickness of the silica layer on gold NP cores [105].

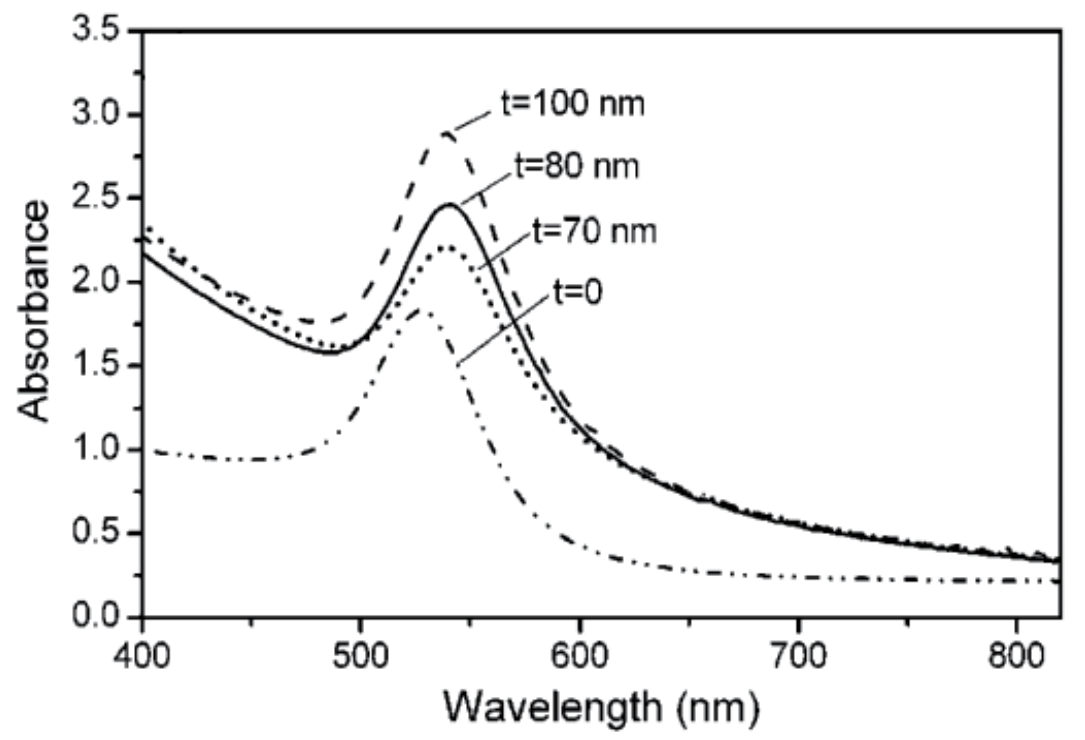

Figure 2. UV-visible absorption spectra of aqueous dispersions that contained gold@silica NPs with different shell thicknesses ( $\mathrm{t}$ ). The gold cores were $50 \mathrm{~nm}$ in diameter for all samples. Reproduced with permission from reference [104].

Figure 2 provides the absorption spectra of aqueous dispersions of gold@silica $\left(\mathrm{Au} @ \mathrm{SiO}_{2}\right) \mathrm{NP}$ colloids with different shell thicknesses. The characteristic surface plasmon peak of the core of these NPs is $\sim 528 \mathrm{~nm}$ before adding the silica coating to the gold cores. After coating with silica, the metal's plasmon peak red-shifted to $\sim 540 \mathrm{~nm}$. This is because the refractive index of silica $(n=1.52)$ is slightly higher than that of water $(n=1.31)$, the solvent used to suspend the 
nanoparticles for collecting spectroscopic data [106]. The optical intensity of these $\mathrm{Au} @ \mathrm{SiO}_{2}$ NPs was increased correspondingly when thicker silica shells were created. But the specific positioning of this peak was not sensitive to the change in the silica coating thickness.

In the report by Lu et al. referenced above, the silica-coated gold NPs were assembled into ordered arrays [104]. The transmission spectra collected from these lattices of $\mathrm{Au} @ \mathrm{SiO}_{2} \mathrm{NPs}$ are shown in Figure 3. All samples were wet with the hollow spaces between NPs being completely filled with water, when these spectra were measured. The incident light was kept vertical to the (111) planes of these face-center-cubic lattices $(\mathrm{Au})$.

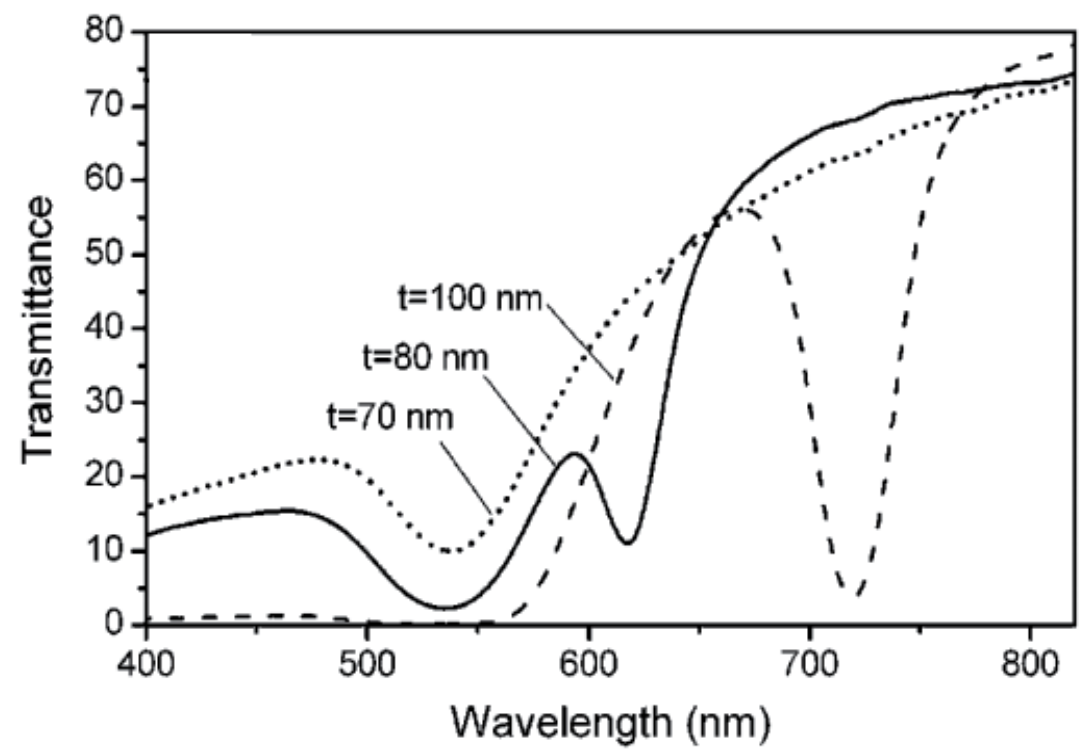

Figure 3. Transmission spectra taken from the arrays produced from $\mathrm{Au} @ \mathrm{SiO}_{2} \mathrm{NPs}$ with different shell thicknesses (t). The incident light was perpendicular to the (111) planes of these face-center-cubic crystalline lattices for all measurements. The gold cores were $50 \mathrm{~nm}$ in diameter for all samples. Reproduced with permission from reference [104].

These transmission spectra show two peaks resulted from the surface plasmon resonance of the gold core NPs around $\sim 540 \mathrm{~nm}$ and the Bragg diffraction of each opaline lattice. Depending on the changes in the silica shell's thickness, the position of the Bragg diffraction peak varied. For example, the Bragg diffraction peak overlapped with the surface plasmon resonance band when the silica shell was $70 \mathrm{~nm}$ in thickness, as shown Figure 3. In this case, only one broad absorption peak was observed at $\sim 540 \mathrm{~nm}$.

Figure 4 demonstrates the reflection spectra acquired from the surface array of $\mathrm{Au} @ \mathrm{SiO}_{2} \mathrm{NPs}$. All samples were wet with the hollow spaces between NPs being completely filled with water when these spectra were measured. The incident light was kept vertical to the (111) planes of these face-center-cubic lattices $(\mathrm{Au})$.

For the reflectance spectra, the Bragg diffraction features were the only peaks detected, and they aligned with the features in the transmission spectra. Additionally, the peaks in Figure 


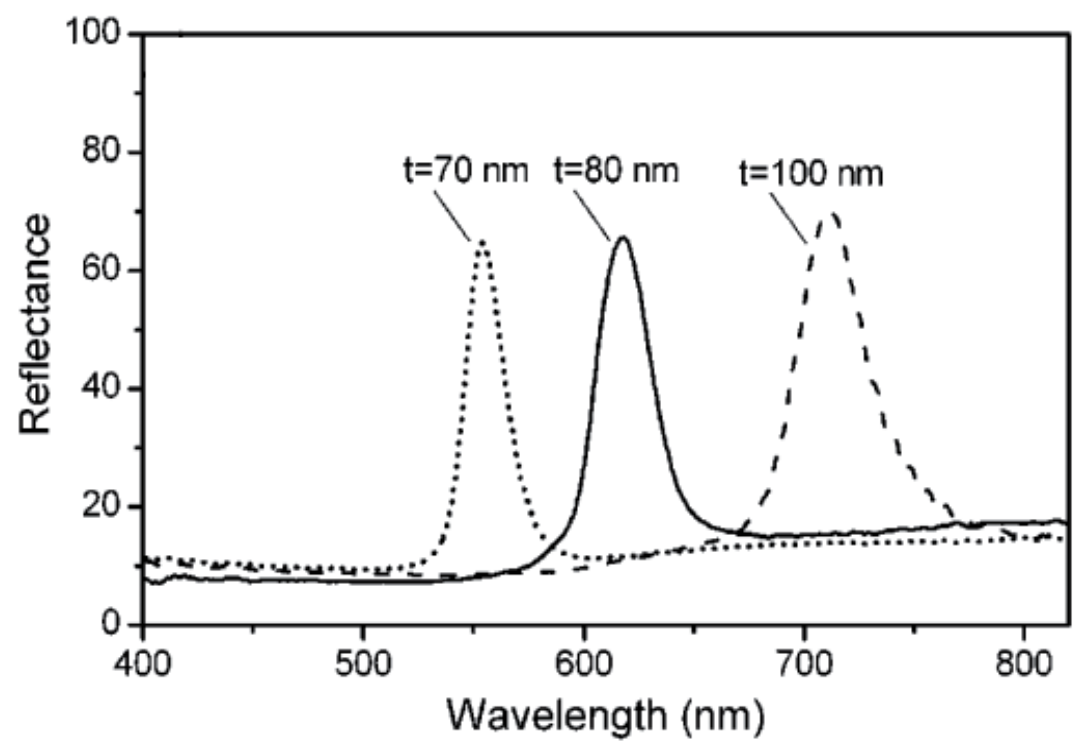

Figure 4. Reflectance spectra taken from the arrays produced from $\mathrm{Au} @ \mathrm{SiO}_{2} \mathrm{NPs}$ with different shell thicknesses (t). The incident light was perpendicular to the (111) planes of these face-center-cubic crystalline lattices for all measurements. The gold cores were $50 \mathrm{~nm}$ in diameter for all samples. Reproduced with permission from reference [104].

4 associated with particles that possessed various shell thicknesses, were narrow and wellresolved. This shows that such core@shell nanoparticle arrays provide two pathways for modulating their interaction with light. Liz-Marzan et al. also recently illustrated the fabrication of 3D crystalline lattices from $\mathrm{Au} @ \mathrm{SiO}_{2} \mathrm{NP}$ colloids; however, these authors failed to provide similar optical characterization [95]. Above all, the spectra displayed in Figures 2, 3, and 4 provide perspective regarding the potential for utilizing the optical properties of $\mathrm{Au} @ \mathrm{SiO}_{2} \mathrm{NP}$ colloids, and their crystalline lattices.

To tune the shell thickness from 20 to $100 \mathrm{~nm}$, the experimental parameters (e.g., coating time and concentration of reactants, catalyst, or other precursors) can be precisely and systematically controlled. Li et al. demonstrated how the shell thickness for $\mathrm{Ag} @ \mathrm{SiO}_{2} \mathrm{NPs}$ can be tuned by controlling certain parameters, the molar volume ratio of water to surfactant, $\mathrm{R}(\mathrm{R}=[$ water $] /$ [surfactant]), and the molar volume ratio of water to TEOS, $\mathrm{H}(\mathrm{H}=$ [water]/[TEOS]) [98]. The manipulation of these parameters provides control over the availability of water molecules for the hydrolysis of TEOS (tetraethyl othosilicate).

Other researchers have developed the magnetic properties of alternative silica-coated cores (e.g., $\mathrm{Fe}, \mathrm{Ni}, \mathrm{Co}$, and alloyed metal compounds) to be used in the presence of external magnetic fields for the improvement of bio-imaging, biological labeling, information storage, catalysis, etc. [101, 107-109]. Magnetic NPs can be easily synthesized by using wet chemical processes in aqueous systems, but there is a disadvantage; the difficulty of making a stable dispersion of these NPs for use in aqueous environments or biological systems. To resolve this restriction, a silica-coating on the magnetite core NPs offers excellent dispersion and improved biocompatibility [110]. More recently, magnetic NPs formed from different core and shell magnetic 
materials have been reported [111]. These unique core@shell structures allow the magnetic properties of the resulting assembly to be more precisely tuned through the choice of magnetic materials and the dimensions of the component parts.

Other Forms of Core@Shell Nanoparticles. Various shaped core@shell NPs have proven to be similarly important in research because of their potential applications in the fields of catalysis [112], nanoelectronics [113], information storage [114], and sensors [115]. To synthesize these variously shaped core@shell NPs, researchers have employed a soft or hard core NP template particle to establish the physical shape [116, 117]. The most familiar examples are the use of a firm core NP of a specific shape as the template. Therefore, a soft shell material on a rigid core NP is deposited evenly to present a core@shell NP resembling the shape of the template core. Researchers synthesize core NPs through careful control of the reaction parameters, a process that relies upon controlled crystal growth using surfactants to manipulate the resulting structure $[113,116]$. Examples of the types of shapes that can be made (cubic, cuboctahedral, and octahedral) are shown in Figure 5 [113]. These specific examples are $\mathrm{Cu} @ \mathrm{Cu}_{2} \mathrm{O}$ NPs and such shaped NPs can be synthesized on a similarly formed core by electro-deposition with a free capping agent.
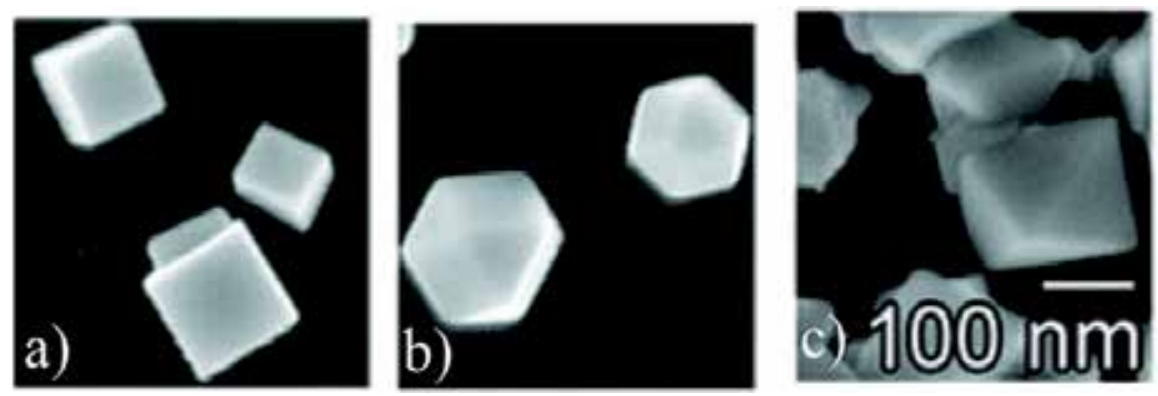

Figure 5. SEM images of $\mathrm{Cu} @ \mathrm{Cu}_{2} \mathrm{O}$ NPs in the form of a) cubic, b) cuboctahedral, and c) octahedral shapes. Reproduced with permission from reference [114].

The fitness of the coating of the shell material can be impacted by the shape of the core NP or the nature of the materials used. This means that the production of a uniform coating might be reduced with shape distortions from spherical or when the material used to form the shell reacts with the core material [118]. In the case of the octahedral gold@platinum NPs, the shell material is incompletely coated on the octahedral core because there is an incomplete reduction of the salt by the core material. Additionally, in some bimetallic "core@shell" structures, the shell is formed by a reduction-transmetalation process which fails to produce a distinguishable shell [119]. On the other hand, with the example given above, a spherical core can be more completely coated with a shell material due to a more perfect reduction of the salt and a more uniform exposure of the metal core surface in solution. These examples highlight the importance of the choice of materials used to prepare core@shell composite NPs. 


\section{Smart, multi-responsive Core@Shell nanoparticles}

The development of a stimuli-responsive composite nanoparticle requires an efficient trigger mechanism. One such trigger is the heat generated by the light absorption of metal nanostructures. The optical properties of GNSs can be specifically controlled to maximize the absorption/ scattering of light in the wavelength range of 700 to $1000 \mathrm{~nm}[64,83]$. This is advantageous because light at wavelengths between $800 \mathrm{~nm}$ and $1200 \mathrm{~nm}$, a range called the "water window", can penetrate human tissue, enabling its use in biomedical applications [59]. Several studies have pursued the use of this technology in combination with mesoporous silica shells that can carry model drugs. This drug carrying capacity exists in part because of the large pore volume in the etched silica surface, a feature that is tunable to achieve a specific mesopore diameter $(2-50 \mathrm{~nm})$. However, mesoporous silica nanoparticles by themselves are not "smart" materials because these NPs cannot release drugs in a precise and controlled manner at a specific location (i.e., they have irreversible pore openings). To overcome this drawback, our research group has explored the growth of a stimuli-responsive hydrogel polymer coating on gold nanoshells that can release a model drug upon the collapse of the hydrogel matrix. These hydrogel polymers are very useful materials in a variety of applications such as drug delivery, chemical separations, and catalysis. But such polymers need an appropriate stimulus to initiate the release of a drug remotely. For many hydrogel applications, heat is used to initiate the collapse of the polymer hydrogel. Since specific frequencies of light can be used to generate heat at the surface of GNSs that are responsive to such light, the combination of a well-tuned nanoshell for specific light absorption and a thermally-responsive hydrogel provide the potential for remotely controlled drug delivery, a smart, multi-responsive core@shell nanoparticle system.

Additionally, core@shell composite particles that respond to magnetic stimuli can also be used to perform useful tasks in controlled drug delivery [77, 78], bio-separation [120], chemical catalysis [121, 122], and electronics [1,3]. By integrating the application of both their physical and chemical properties, these magnetic core@shell materials can become multifunctional devices that enable a variety of advanced applications that cannot be accomplished by simple magnetic NPs alone. Recent examples of the application of magnetic NPs in research have demonstrated their usefulness because of their capacity to produce heat under an external oscillating magnetic field or to be manipulated remotely, allowing for their use as an antitumor treatment, cell tracking tag, or drug delivery vehicle [123-125]. These core@shell composite particles that respond to both a magnet and other external stimuli, typically consist of a magnetic core encapsulated in a stimuli-responsive hydrogel copolymer layer that responds rapidly to changes in temperature slightly above that of the body. And such a coating heightens the particles' biocompatibility and chemical stability in an aqueous medium [126-138].

Core@shell composite particles that respond to optical, magnetic, and other external stimuli (e.g., temperature, ionic strength, and $\mathrm{pH}$ ), can be used to perform more useful tasks in research. For this project, we employed a biocompatible mesoporous silica interlayer between the magnetic core and the hydrogel copolymer outer layer to improve the composite particle's loading capacity and payload release effectiveness. The advantages that such porous struc- 
tures provide is their high surface area (ca. $1000 \mathrm{~m}^{2} / \mathrm{g}$ ), large pore volume (ca. $1 \mathrm{~cm}^{3} / \mathrm{g}$ ), tunable mesopore diameter $(2-50 \mathrm{~nm})$ and biocompatibility $[139,140]$. Thus, impregnation of these mesoporous silica and poly(N-isopropylacrylamide-co-acrylic acid; NIPAM-co-AAc)-coated magnetic NPs (or gold GNSs as the core) with drugs produces a nanoscale drug-delivery system that can be specifically targeted and magnetically (or phothermally) activated. We call them "smart" core@shell NPs.

\section{Synthesis of smart multi-responsive Core@Shell nanoparticles}

To accomplish the research goals described above, hydrogel-based core@shell composite NPs were fabricated by encapsulating a mesoporous silica-coated GNS (or $\mathrm{Fe}_{3} \mathrm{O}_{4} \mathrm{NP}$ ) as the core with a PNIPAM-co-AAc copolymer coating [141]. The oleylamine-functionalized mesoporous silica-coated GNS (or $\mathrm{Fe}_{3} \mathrm{O}_{4} \mathrm{NP}$ ) was used as a nano-template for the shell layer growth of a hydrogel copolymer. Ammonium persulfate (APS) was used as a polymerization initiator to produce a hydrogel-encapsulated composite NP. The amount of NIPAM monomer was optimized for the hydrogel-encapsulated mesoporous silica-coated composite NPs [142]. The shell layer thickness was increased with an increase in polymerization time until no further increase in the shell layer thickness was clearly observed [143]. Hydrogel-encapsulated mesoporous silica-coated composite NPs exhibited systematic changes in particle size corresponding to the variation of temperature, which originates from hydrogen-bonding interactions between PNIPAM amide groups and water, as well as electrostatic forces attributed to the ionization of carboxylic groups in the acrylic acid.

\section{Long term research objectives}

Lee and co-workers recently reported the initial methodology to precisely control drug delivery by employing gold NPs and GNSs coated with a $\mathrm{pH}$ - and temperature-responsive hydrogel originating from the co-polymerization of NIPAM and acrylic acid [142-144]. These nontoxic composite NPs were designed to be loaded with drug molecules, providing the ability for the NP cores to be photothermally activated, initiating collapse of the hydrogel coating and releasing the drug molecules, as illustrated in Figure 6.

Furthermore, we have been working to employ a mesoporous silica interlayer between a goldcoated silica core and a hydrogel outer layer to prevent unwanted structural changes to the gold shell during photomodulation and to assist in the carrying of hydrophobic or hydrophilic drugs to targeted sites [141]. The advantages that such porous structures provide is their high surface area (ca. $1000 \mathrm{~m}^{2} / \mathrm{g}$ ), large pore volume (ca. $\left.1 \mathrm{~cm}^{3} / \mathrm{g}\right)$, tunable mesopore diameter (2-50 $\mathrm{nm}$ ) and biocompatibility $[139,140]$. By using smart hydrogel technology as an outer layer and a mesoporous silica coating as an interlayer, GNSs that are activated by tissue-transparent near-IR light can be more effectively used for advanced medicinal applications. With our initial investigation, once these nontoxic composite NPs were loaded with methylene blue (MB; a 


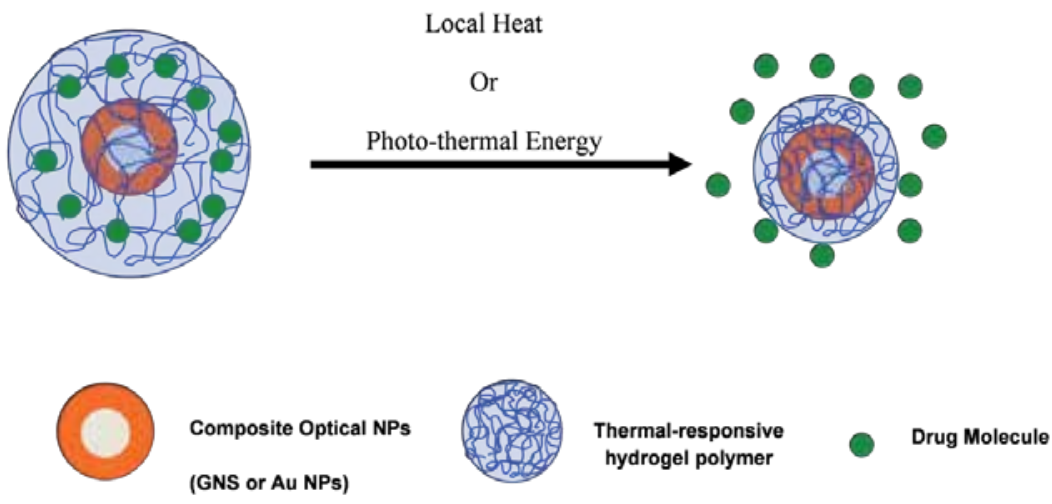

Figure 6. Illustration of drug release by increasing the environmental temperature or by generating heat through an SPR response in these optically active composite particles to a near IR laser.

dye used as a model drug), and the NPs thermally activated, the hydrogel coating collapsed and released the test molecules. The potential for such smart, multi-responsive core@shell nanoparticles for use as drug delivery carriers, contrast agents, and therapeutic entities will clearly encourage the application of this new technology in future research projects.

\section{Acknowledgements}

The Robert A. Welch Foundation (Grant No. E-1320) and the Texas Center for Superconductivity at the University of Houston provided generous support for this research.

\section{Author details}

Bo Sang Kim and T. Randall Lee*

*Address all correspondence to: trlee@uh.edu

Department of Chemistry and the Texas Center for Superconductivity, University of Houston, Houston, Texas, USA

\section{References}

[1] Teranishi T, Miyake M. Size control of palladium nanoparticles and their crystal structures. Chem Mater. 1998;10:594-600. DOI: 10.1021/cm9705808. 
[2] Shen L, Luo M, Huang L, Feng P, Wu L. A Clean and General Strategy To Decorate a Titanium Metal-Organic Framework with Noble-Metal Nanoparticles for Versatile Photocatalytic Applications. Inorg Chem. 2015;54:1191-1193. DOI: 10.1021/ic502609a.

[3] Quaroni L, Chumanov G. Preparation of Polymer-Coated Functionalized Silver Nanoparticles. J Am Chem Soc. 1999;121:10642-10643. DOI: 10.1021/ja992088q.

[4] Wei L, Lu J, Xu H, Patel A, Chen Z-S, Chen G. Silver nanoparticles: synthesis, properties, and therapeutic applications. Drug Discovery Today. 2015;20:595-601. DOI: 10.1016/j.drudis.2014.11.014.

[5] Fukuura T. Plasmons excited in a large dense silver nanoparticle layer enhance the luminescence intensity of organic light emitting diodes. Appl Surf Sci. 2015;346:451-457. DOI: 10.1016/j.apsusc.2015.04.044.

[6] Zhan Z, Xu R, Mi Y, Zhao H, Lei Y. Highly Controllable Surface Plasmon Resonance Property by Heights of Ordered Nanoparticle Arrays Fabricated via a Nonlithographic Route. ACS Nano. 2015;9:4583-4590. DOI: 10.1021/acsnano.5b01226.

[7] Ranjan M, Bhatnagar M, Mukherjee S. Localized surface plasmon resonance anisotropy in template aligned silver nanoparticles: A case of biaxial metal optics. J Appl Phys. 2015;117:103106/103101-103106/103107. DOI: 10.1063/1.4914408.

[8] Fojan P, Hanif M, Bartling S, Hartmann H, Barke I, Popok VN. Supported silver clusters as nanoplasmonic transducers for protein sensing. Sens Actuators, B. 2015;212:377-381. DOI: 10.1016/j.snb.2015.01.131.

[9] Su Y-A, Lin W-C, Wang H-J, Lee W-H, Lee R-H, Dai SA, et al. Enhanced photovoltaic performance of inverted polymer solar cells by incorporating graphene nanosheet/ AgNPs nanohybrids. RSC Adv. 2015;5:25192-25203. DOI: 10.1039/c4ra16855k.

[10] Yang Y, Matsubara S, Xiong L, Hayakawa T, Nogami M. Solvothermal Synthesis of Multiple Shapes of Silver Nanoparticles and Their SERS Properties. J Phys Chem C. 2007;111:9095-9104. DOI: 10.1021/jp068859b.

[11] Temple TL, Mahanama GDK, Reehal HS, Bagnall DM. Influence of localized surface plasmon excitation in silver nanoparticles on the performance of silicon solar cells. Sol Energy Mater Sol Cells. 2009;93:1978-1985. DOI: 10.1016/j.solmat.2009.07.014.

[12] Amendola V, Bakr OM, Stellacci F. A Study of the Surface Plasmon Resonance of Silver Nanoparticles by the Discrete Dipole Approximation Method: Effect of Shape, Size, Structure, and Assembly. Plasmonics. 2010;5:85-97. DOI: 10.1007/ s11468-009-9120-4.

[13] Chen S, Sommers JM. Alkanethiolate-protected copper nanoparticles: spectroscopy, electrochemistry, and solid-state morphological evolution. J Phys Chem B. 2001;105:8816-8820. DOI: 10.1021/jp011280n. 
[14] Chan GH, Zhao J, Hicks EM, Schatz GC, Van Duyne RP. Plasmonic Properties of Copper Nanoparticles Fabricated by Nanosphere Lithography. Nano Lett. 2007;7:1947-1952. DOI: 10.1021/nl070648a.

[15] Yaduvanshi P, Mishra A, Kumar S, Dhar R. Enhancement in the thermodynamic, electrical and optical properties of hexabutoxytriphenylene due to copper nanoparticles. J Mol Liq. 2015;208:160-164. DOI: 10.1016/j.molliq.2015.04.030.

[16] Zhang S, Peng B, Yang S, Wang H, Yu H, Fang Y, et al. Non-noble metal copper nanoparticles-decorated $\mathrm{TiO}_{2}$ nanotube arrays with plasmon-enhanced photocatalytic hydrogen evolution under visible light. Int J Hydrogen Energy. 2015;40:303-310. DOI: 10.1016/j.ijhydene.2014.10.122.

[17] Guo X, Hao C, Jin G, Zhu H-Y, Guo X-Y. Copper Nanoparticles on Graphene Support: An Efficient Photocatalyst for Coupling of Nitroaromatics in Visible Light. Angew Chem, Int Ed. 2014;53:1973-1977. DOI: 10.1002/anie.201309482.

[18] Heo M, Cho H, Jung J-W, Jeong J-R, Park S, Kim JY. High-Performance Organic Optoelectronic Devices Enhanced by Surface Plasmon Resonance. Adv Mater. 2011;23:5689-5693. DOI: 10.1002/adma.201103753.

[19] Clark HA, Campagnola PJ, Wuskell JP, Lewis A, Loew LM. Second harmonic generation properties of fluorescent polymer-encapsulated gold nanoparticles. J Am Chem Soc. 2000;122:10234-10235. DOI: 10.1021/ja002223v.

[20] Zhou N, Polavarapu L, Wang Q, Xu Q-H. Mesoporous $\mathrm{SnO}_{2}$-Coated Metal Nanoparticles with Enhanced Catalytic Efficiency. ACS Appl Mater Interfaces. 2015;7:4844-4850. DOI: 10.1021/am508803c.

[21] Lee K-S, El-Sayed MA. Gold and Silver Nanoparticles in Sensing and Imaging: Sensitivity of Plasmon Response to Size, Shape, and Metal Composition. J Phys Chem B. 2006;110:19220-19225. DOI: 10.1021/jp062536y.

[22] Al-Azawi MA, Bidin N, Ali AK, Bououdina M. The effects of gold colloid concentration on photoanode electrodes to enhance plasmonic dye-sensitized solar cells performance. J Mater Sci: Mater Electron. 2015;26:6276-6284. DOI: 10.1007/ s10854-015-3214-x.

[23] Yockell-Lelievre H, Bukar N, McKeating KS, Arnaud M, Cosin P, Guo Y, et al. Plasmonic sensors for the competitive detection of testosterone. Analyst. 2015;140:5105-5111. DOI: 10.1039/c5an00694e.

[24] Hwang JD, Wang FH, Kung CY, Chan MC. Using the surface plasmon resonance of $\mathrm{Au}$ nanoparticles to enhance ultraviolet response of $\mathrm{ZnO}$ nanorods-based Schottkybarrier photodetectors. IEEE Trans Nanotechnol. 2015;14:318-321. DOI: 10.1109/ tnano.2015.2393877.

[25] Jain PK, Lee KS, El-Sayed IH, El-Sayed MA. Calculated Absorption and Scattering Properties of Gold Nanoparticles of Different Size, Shape, and Composition: Applica- 
tions in Biological Imaging and Biomedicine. J Phys Chem B. 2006;110:7238-7248. DOI: $10.1021 / j p 057170$ o.

[26] Hu M, Chen J, Li Z-Y, Au L, Hartland GV, Li X, et al. Gold nanostructures: engineering their plasmonic properties for biomedical applications. Chem Soc Rev. 2006;35:1084-1094. DOI: 10.1039/b517615h.

[27] Liu Z, Hou W, Pavaskar P, Aykol M, Cronin SB. Plasmon Resonant Enhancement of Photocatalytic Water Splitting Under Visible Illumination. Nano Lett. 2011;11:1111-1116. DOI: 10.1021/nl104005n.

[28] Nath N, Chilkoti A. Label-Free Biosensing by Surface Plasmon Resonance of Nanoparticles on Glass: Optimization of Nanoparticle Size. Anal Chem. 2004;76:5370-5378. DOI: $10.1021 / \mathrm{ac} 049741 \mathrm{z}$.

[29] Reinhard BM, Siu M, Agarwal H, Alivisatos AP, Liphardt J. Calibration of Dynamic Molecular Rulers Based on Plasmon Coupling between Gold Nanoparticles. Nano Lett. 2005;5:2246-2252. DOI: 10.1021/n1051592s.

[30] Tokareva I, Minko S, Fendler JH, Hutter E. Nanosensors Based on Responsive Polymer Brushes and Gold Nanoparticle Enhanced Transmission Surface Plasmon Resonance Spectroscopy. J Am Chem Soc. 2004;126:15950-15951. DOI: 10.1021/ja044575y.

[31] Kowalska E, Mahaney OOP, Abe R, Ohtani B. Visible-light-induced photocatalysis through surface plasmon excitation of gold on titania surfaces. Phys Chem Chem Phys. 2010;12:2344-2355. DOI: 10.1039/b917399d.

[32] Alivisatos AP. Semiconductor clusters, nanocrystals, and quantum dots. Science. 1996;271:933-937. DOI: 10.1126/science.271.5251.933.

[33] Daniel M-C, Astruc D. Gold Nanoparticles: Assembly, Supramolecular Chemistry, Quantum-Size-Related Properties, and Applications toward Biology, Catalysis, and Nanotechnology. Chem Rev. 2004;104:293-346. DOI: 10.1021/cr030698+.

[34] Burda C, Chen X, Narayanan R, El-Sayed MA. Chemistry and Properties of Nanocrystals of Different Shapes. Chem Rev. 2005;105:1025-1102. DOI: 10.1021/cr030063a.

[35] Bohren CF, Huffman DR. Absorption and Scattering of Light by Small Particles: John Wiley and Sons; 1983.

[36] Qin Z, Bischof JC. Thermophysical and biological responses of gold nanoparticle laser heating. Chem Soc Rev. 2012;41:1191-1217. DOI: 10.1039/c1cs15184c.

[37] Kim F, Song JH, Yang P. Photochemical Synthesis of Gold Nanorods. J Am Chem Soc. 2002;124:14316-14317. DOI: 10.1021/ja028110o.

[38] Xue B, Wang D, Zuo J, Kong X, Zhang Y, Liu X, et al. Towards high quality triangular silver nanoprisms: improved synthesis, six-tip based hot spots and ultra-high local surface plasmon resonance sensitivity. Nanoscale. 2015;7:8048-8057. DOI: 10.1039/ c4nr06901c. 
[39] Sherry LJ, Jin R, Mirkin CA, Schatz GC, Van Duyne RP. Localized Surface Plasmon Resonance Spectroscopy of Single Silver Triangular Nanoprisms. Nano Lett. 2006;6:2060-2065. DOI: 10.1021/n1061286u.

[40] Chan GH, Zhao J, Schatz GC, Van Duyne RP. Localized Surface Plasmon Resonance Spectroscopy of Triangular Aluminum Nanoparticles. J Phys Chem C. 2008;112:13958-13963. DOI: 10.1021/jp804088z.

[41] Sun Y, Mayers B, Xia Y. Transformation of Silver Nanospheres into Nanobelts and Triangular Nanoplates through a Thermal Process. Nano Lett. 2003;3:675-679. DOI: 10.1021/nl034140t.

[42] O'Brien MN, Jones MR, Kohlstedt KL, Schatz GC, Mirkin CA. Uniform Circular Disks With Synthetically Tailorable Diameters: Two-Dimensional Nanoparticles for Plasmonics. Nano Lett. 2015;15:1012-1017. DOI: 10.1021/nl5038566.

[43] Hao E, Kelly KL, Hupp JT, Schatz GC. Synthesis of Silver Nanodisks Using Polystyrene Mesospheres as Templates. J Am Chem Soc. 2002;124:15182-15183. DOI: 10.1021/ ja028336r.

[44] Hou H, Chen L, He H, Chen L, Zhao Z, Jin Y. Fine-tuning the LSPR response of gold nanorod-polyaniline core-shell nanoparticles with high photothermal efficiency for cancer cell ablation. J Mater Chem B. 2015;3:5189-5196. DOI: 10.1039/c5tb00556f.

[45] Huang X, Neretina S, El-Sayed MA. Gold Nanorods: From Synthesis and Properties to Biological and Biomedical Applications. Adv Mater. 2009;21:4880-4910. DOI: 10.1002/adma.200802789.

[46] Mayer KM, Lee S, Liao H, Rostro BC, Fuentes A, Scully PT, et al. A Label-Free Immunoassay Based Upon Localized Surface Plasmon Resonance of Gold Nanorods. ACS Nano. 2008;2:687-692. DOI: 10.1021/nn7003734.

[47] Jiang T, Wang B, Zhang L, Zhou J. Hydrothermal synthesis of silver nanocubes with tunable edge lengths and their size dependent SERS behaviors. J Alloys Compd. 2015;632:140-146. DOI: 10.1016/j.jallcom.2015.01.164.

[48] Sherry LJ, Chang S-H, Schatz GC, Van Duyne RP, Wiley BJ, Xia Y. Localized surface plasmon resonance spectroscopy of single silver Nanocubes. Nano Lett. 2005;5:2034-2038. DOI: 10.1021/n10515753.

[49] Sun Y, Xia Y. Shape-Controlled Synthesis of Gold and Silver Nanoparticles. Science. 2002;298:2176-2179. DOI: 10.1126/science.1077229.

[50] Im SH, Lee YT, Wiley B, Xia Y. Large-scale synthesis of silver nanocubes: the role of $\mathrm{HCl}$ in promoting cube perfection and monodispersity. Angew Chem, Int Ed. 2005;44:2154-2157. DOI: 10.1002/anie.200462208. 
[51] Wang C, Daimon H, Lee Y, Kim J, Sun S. Synthesis of Monodisperse Pt Nanocubes and Their Enhanced Catalysis for Oxygen Reduction. J Am Chem Soc. 2007;129:6974-6975. DOI: 10.1021/ja070440r.

[52] Graf C, van Blaaderen A. Metallodielectric Colloidal Core-Shell Particles for Photonic Applications. Langmuir. 2002;18:524-534. DOI: 10.1021/la011093g.

[53] Kim J-H, Bryan WW, Chung H-W, Park CY, Jacobson AJ, Lee TR. Gold, palladium, and gold-palladium alloy nanoshells on silica nanoparticle cores. ACS Appl Mater Interfaces. 2009;1:1063-1069. DOI: 10.1021/am900039a.

[54] Kim J-H, Bryan WW, Lee TR. Preparation, characterization, and optical properties of gold, silver, and gold-silver alloy nanoshells having silica cores. Langmuir. 2008;24:11147-11152.

[55] Kim J-H, Park J-S, Chung H-W, Boote BW, Lee TR. Palladium nanoshells coated with self-assembled monolayers and their catalytic properties. RSC Adv. 2012;2:3968-3977. DOI: 10.1039/c2ra00883a.

[56] Mejac I, Bryan WW, Lee TR, Tran CD. Visualizing the Size, Shape, Morphology, and Localized Surface Plasmon Resonance of Individual Gold Nanoshells by Near-Infrared Multispectral Imaging Microscopy. Anal Chem. 2009;81:6687-6694. DOI: 10.1021/ ac9007495.

[57] Pham T, Jackson JB, Halas NJ, Lee TR. Preparation and Characterization of Gold Nanoshells Coated with Self-Assembled Monolayers. Langmuir. 2002;18:4915-4920. DOI: 10.1021/la015561y.

[58] Jankiewicz BJ, Jamiola D, Choma J, Jaroniec M. Silica-metal core-shell nanostructures. Adv Colloid Interface Sci. 2012;170:28-47. DOI: 10.1016/j.cis.2011.11.002.

[59] Simpson CR, Kohl M, Essenpreis M, Cope M. Near-infrared optical properties of ex vivo human skin and subcutaneous tissues measured using the Monte Carlo inversion technique. Phys Med Biol. 1998;43:2465-2478.

[60] Khantamat O, Li C-H, Yu F, Jamison AC, Shih W-C, Cai C, et al. Gold NanoshellDecorated Silicone Surfaces for the Near-Infrared (NIR) Photothermal Destruction of the Pathogenic Bacterium E. faecalis. ACS Appl Mater Interfaces. 2015;7:3981-3993. DOI: 10.1021/am506516r.

[61] Michalak GJ, Goodrich GP, Schwartz JA, James WD, O'Neal DP. Murine photoplethysmography for in vivo estimation of vascular gold nanoshell concentration. J Biomed Opt. 2010;15:047007/047001-047007/047005. DOI: 10.1117/1.3454374.

[62] Jin Y. Multifunctional Compact Hybrid Au Nanoshells: A New Generation of Nanoplasmonic Probes for Biosensing, Imaging, and Controlled Release. Acc Chem Res. 2014;47:138-148. DOI: 10.1021/ar400086e. 
[63] Liu S-Y, Liang Z-S, Gao F, Luo S-F, Lu G-Q. In vitro photothermal study of gold nanoshells functionalized with small targeting peptides to liver cancer cells. J Mater Sci: Mater Med. 2010;21:665-674. DOI: 10.1007/s10856-009-3895-x.

[64] Oldenburg SJ, Averitt RD, Westcott SL, Halas NJ. Nanoengineering of optical resonances. Chem Phys Lett. 1998;288:243-247. DOI: 10.1016/s0009-2614(98)00277-2.

[65] Oldenburg SJ, Westcott SL, Averitt RD, Halas NJ. Surface enhanced Raman scattering in the near infrared using metal nanoshell substrates. J Chem Phys. 1999;111:4729-4735. DOI: 10.1063/1.479235.

[66] Oldenburg SJ, Jackson JB, Westcott SL, Halas NJ. Infrared extinction properties of gold nanoshells. Appl Phys Lett. 1999;75:2897-2899. DOI: 10.1063/1.125183.

[67] Loo C, Lin A, Hirsch L, Lee M-H, Barton J, Halas N, et al. Nanoshell-enabled photonics-based imaging and therapy of cancer. Technol Cancer Res Treat. 2004;3:33-40. DOI: $10.1177 / 153303460400300104$.

[68] Averitt RD, Westcott SL, Halas NJ. Linear optical properties of gold nanoshells. J Opt Soc Am B. 1999;16:1824-1832. DOI: 10.1364/josab.16.001824.

[69] Jackson JB, Halas NJ. Silver Nanoshells: Variations in Morphologies and Optical Properties. J Phys Chem B. 2001;105:2743-2746. DOI: 10.1021/jp003868k.

[70] Jiang Z-J, Liu C-Y. Seed-Mediated Growth Technique for the Preparation of a Silver Nanoshell on a Silica Sphere. J Phys Chem B. 2003;107:12411-12415. DOI: 10.1021/ jp035060g.

[71] Deng Z, Chen M, Wu L. Novel Method to Fabricate SiO2/Ag Composite Spheres and Their Catalytic, Surface-Enhanced Raman Scattering Properties. J Phys Chem C. 2007;111:11692-11698. DOI: 10.1021/jp073632h.

[72] Wang K, Zhang X, Niu C, Wang Y. Template-Activated Strategy toward One-Step Coating Silica Colloidal Microspheres with Silver. ACS Appl Mater Interfaces. 2014;6:1272-1278. DOI: 10.1021/am405096z.

[73] Peterson MSM, Bouwman J, Chen A, Deutsch M. Inorganic metallodielectric materials fabricated using two single-step methods based on the Tollen's process. J Colloid Interface Sci. 2007;306:41-49. DOI: 10.1016/j.jcis.2006.10.013.

[74] Ashayer R, Green M, Mannan SH. Synthesis of palladium nanoshell using a layer-bylayer technique. J Nanopart Res. 2010;12:1489-1494. DOI: 10.1007/s11051-009-9721-z.

[75] Kim J-H, Chung H-W, Lee TR. Preparation and characterization of palladium shells with gold and silica cores. Chem Mater. 2006;18:4115-4120. DOI: 10.1021/cm0528882.

[76] Guo S, Zhai J, Fang Y, Dong S, Wang E. Nanoelectrocatalyst based on high-density $\mathrm{Au} / \mathrm{Pt}$ hybrid nanoparticles supported on a silica nanosphere. Chem - Asian J. 2008;3:1156-1162. DOI: 10.1002/asia.200700422. 
[77] Suzuki M, Shinkai M, Kamihira M, Kobayashi T. Preparation and characteristics of magnetite-labeled antibody with the use of poly(ethylene glycol) derivatives. Biotechnol Appl Biochem. 1995;21:335-345.

[78] Tiefenauer LX, Kuhne G, Andres RY. Antibody-magnetite nanoparticles: in vitro characterization of a potential tumor-specific contrast agent for magnetic resonance imaging. Bioconjug Chem. 1993;4:347-352.

[79] Wang L, Luo J, Fan Q, Suzuki M, Suzuki IS, Engelhard MH, et al. Monodispersed Core-Shell $\mathrm{Fe}_{3} \mathrm{O}_{4} @ \mathrm{Au}$ Nanoparticles. J Phys Chem B. 2005;109:21593-21601. DOI: 10.1021/jp0543429.

[80] Sun L, Wang J, Wang Z. Recognition and transmembrane delivery of bioconjugated $\mathrm{Fe}_{2} \mathrm{O}_{3} @ \mathrm{Au}$ nanoparticles with living cells. Nanoscale. 2010;2:269-276. DOI: 10.1039/ b9nr00152b.

[81] Stoeber W, Fink A, Bohn E. Controlled growth of monodisperse silica spheres in the micron size range. J Colloid Interface Sci. 1968;26:62-69. DOI: 10.1016/0021-9797(68)90272-5.

[82] Averitt RD, Oldenburg SJ, Westcott SL, Lee TR, Halas NJ. Optical resonances of gold nanoshells. NASA Conf Publ. 1999;209092:301-306.

[83] Erickson TA, Tunnell JW, editors. Gold nanoshells in biomedical applications2008: Wiley-VCH Verlag GmbH \& Co. KGaA.

[84] Li J-F, Yang Z-L, Ren B, Liu G-K, Fang P-P, Jiang Y-X, et al. Surface-Enhanced Raman Spectroscopy Using Gold-Core Platinum-Shell Nanoparticle Film Electrodes: Toward a Versatile Vibrational Strategy for Electrochemical Interfaces. Langmuir. 2006;22:10372-10379. DOI: 10.1021/la061366d.

[85] Hu J-W, Li J-F, Ren B, Wu D-Y, Sun S-G, Tian Z-Q. Palladium-Coated Gold Nanoparticles with a Controlled Shell Thickness Used as Surface-Enhanced Raman Scattering Substrate. J Phys Chem C. 2007;111:1105-1112. DOI: 10.1021/jp0652906.

[86] Ghosh Chaudhuri R, Paria S. Core/Shell Nanoparticles: Classes, Properties, Synthesis Mechanisms, Characterization, and Applications. Chem Rev. 2012;112:2373-2433. DOI: $10.1021 / \mathrm{cr} 100449$ n.

[87] Izak-Nau E, Kenesei K, Murali K, Voetz M, Eiden S, Puntes VF, et al. Interaction of differently functionalized fluorescent silica nanoparticles with neural stem- and tissue-type cells. Nanotoxicology. 2014;8:138-148. DOI: 10.3109/17435390.2013.864427.

[88] Zhang H, Dunphy DR, Jiang X, Meng H, Sun B, Tarn D, et al. Processing pathway dependence of amorphous silica nanoparticle toxicity: Colloidal vs pyrolytic. J Am Chem Soc. 2012;134:15790-15804. DOI: 10.1021/ja304907c. 
[89] Zhang L, Blom DA, Wang H. Au-Cu2O Core-Shell Nanoparticles: A Hybrid MetalSemiconductor Heteronanostructure with Geometrically Tunable Optical Properties. Chem Mater. 2011;23:4587-4598. DOI: 10.1021/cm202078t.

[90] Dick K, Dhanasekaran T, Zhang Z, Meisel D. Size-dependent melting of silica-encapsulated gold nanoparticles. J Am Chem Soc. 2002;124:2312-2317. DOI: 10.1021/ ja017281a.

[91] Radloff C, Halas NJ. Enhanced thermal stability of silica-encapsulated metal nanoshells. Appl Phys Lett. 2001;79:674-676. DOI: 10.1063/1.1389322.

[92] Ye J, Van de Broek B, De Palma R, Libaers W, Clays K, Van Roy W, et al. Surface morphology changes on silica-coated gold colloids. Colloids Surf, A. 2008;322:225-233. DOI: 10.1016/j.colsurfa.2008.03.033.

[93] Qi Y, Chen M, Liang S, Yang W, Zhao J. Micro-patterns of Au@SiO 2 core-shell nanoparticles formed by electrostatic interactions. Appl Surf Sci. 2008;254:1684-1690. DOI: 10.1016/j.apsusc.2007.07.136.

[94] Qi Y, Chen M, Liang S, Zhao J, Yang W. Hydrophobation and self-assembly of coreshell $\mathrm{Au} @ \mathrm{SiO}_{2}$ nanoparticles. Colloids Surf, A. 2007;302:383-387. DOI: 10.1016/ j.colsurfa.2007.02.069.

[95] Liz-Marzan LM, Giersig M, Mulvaney P. Synthesis of Nanosized Gold-Silica CoreShell Particles. Langmuir. 1996;12:4329-4335. DOI: 10.1021/la9601871.

[96] Poovarodom S, Bass JD, Hwang S-J, Katz A. Investigation of the Core-Shell Interface in Gold@Silica Nanoparticles: A Silica Imprinting Approach. Langmuir. 2005;21:12348-12356. DOI: 10.1021/la052006d.

[97] Alejandro-Arellano M, Ung T, Blanco A, Mulvaney P, Liz-Marzan LM. Silica-coated metals and semiconductors. Stabilization and nanostructuring. Pure Appl Chem. 2000;72:257-267. DOI: 10.1351/pac200072010257.

[98] Li T, Moon J, Morrone AA, Mecholsky JJ, Talham DR, Adair JH. Preparation of $\mathrm{Ag} / \mathrm{SiO}_{2}$ Nanosize Composites by a Reverse Micelle and Sol-Gel Technique. Langmuir. 1999;15:4328-4334. DOI: 10.1021/la970801o.

[99] Fu W, Yang H, Chang L, Li M, Bala H, Yu Q, et al. Preparation and characteristics of core-shell structure nickel/silica nanoparticles. Colloids Surf, A. 2005;262:71-75. DOI: 10.1016/j.colsurfa.2005.03.028.

[100] Lee J, Lee Y, Youn JK, Na HB, Yu T, Kim H, et al. Simple synthesis of functionalized superparamagnetic magnetite/silica core/shell nanoparticles and their application as magnetically separable high-performance biocatalysts. Small. 2008;4:143-152. DOI: 10.1002/smll.200700456.

[101] Aliev FG, Correa-Duarte MA, Mamedov A, Ostrander JW, Giersig M, Liz-Marzan LM, et al. Layer-by-layer assembly of core-shell magnetite nanoparticles. Effect of silica coating on interparticle interactions and magnetic properties. Adv Mater. 
1999;11:1006-1010. $\quad$ DOI: $\quad$ 10.1002/(sici)1521-4095(199908)11:12<1006:aid-adma1006>3.0.co;2-2.

[102] Lien Y-H, Wu T-M. Preparation and characterization of thermosensitive polymers grafted onto silica-coated iron oxide nanoparticles. J Colloid Interface Sci. 2008;326:517-521. DOI: 10.1016/j.jcis.2008.06.020.

[103] He R, You X, Shao J, Gao F, Pan B, Cui D. Core/shell fluorescent magnetic silica-coated composite nanoparticles for bioconjugation. Nanotechnology. 2007;18:315601/315601-315607. DOI: 10.1088/0957-4484/18/31/315601.

[104] Lu Y, Yin Y, Li Z-Y, Xia Y. Synthesis and Self-Assembly of Au@SiO ${ }_{2}$ Core-Shell Colloids. Nano Lett. 2002;2:785-788. DOI: 10.1021/n1025598i.

[105] Ung T, Liz-Marzan LM, Mulvaney P. Controlled Method for Silica Coating of Silver Colloids. Influence of Coating on the Rate of Chemical Reactions. Langmuir. 1998;14:3740-3748. DOI: 10.1021/la980047m.

[106] Li C-H, Jamison AC, Rittikulsittichai S, Lee T-C, Lee TR. In Situ Growth of Hollow Gold-Silver Nanoshells within Porous Silica Offers Tunable Plasmonic Extinctions and Enhanced Colloidal Stability. ACS Appl Mater Interfaces. 2014;6:19943-19950. DOI: 10.1021/am505424w.

[107] Lu X, Liang G, Sun Z, Zhang W. Ferromagnetic $\mathrm{Co} / \mathrm{SiO}_{2}$ core/shell structured nanoparticles prepared by a novel aqueous solution method. Mater Sci Eng, B. 2005;B117:147-152. DOI: 10.1016/j.mseb.2004.11.012.

[108] Ammar M, Mazaleyrat F, Bonnet JP, Audebert P, Brosseau A, Wang G, et al. Synthesis and characterization of core-shell structure silica-coated $\mathrm{Fe}_{29.5} \mathrm{Ni}_{70.5}$ nanoparticles. Nanotechnology. 2007;18:285606/285601-285608. DOI: 10.1088/0957-4484/18/28/285606.

[109] Fu Y, Shearwood C. Characterization of nanocrystalline TiNi powder. Scr Mater. 2003;50:319-323. DOI: 10.1016/j.scriptamat.2003.10.018.

[110] Santra S, Tapec R, Theodoropoulou N, Dobson J, Hebard A, Tan W. Synthesis and Characterization of Silica-Coated Iron Oxide Nanoparticles in Microemulsion: The Effect of Nonionic Surfactants. Langmuir. 2001;17:2900-2906. DOI: 10.1021/la0008636.

[111] Kolhatkar AG, Jamison AC, Litvinov D, Willson RC, Lee TR. Tuning the magnetic properties of nanoparticles. Int J Mol Sci. 2013;14:15977-16009, 15933 pp. DOI: 10.3390/ijms140815977.

[112] Han W, Yi L, Zhao N, Tang A, Gao M, Tang Z. Synthesis and Shape-Tailoring of Copper Sulfide/Indium Sulfide-Based Nanocrystals. J Am Chem Soc. 2008;130:13152-13161. DOI: 10.1021/ja8046393.

[113] Radi A, Pradhan D, Sohn Y, Leung KT. Nanoscale Shape and Size Control of Cubic, Cuboctahedral, and Octahedral $\mathrm{Cu}-\mathrm{Cu}_{2} \mathrm{O}$ Core-Shell Nanoparticles on $\mathrm{Si}(100)$ by 
One-Step, Templateless, Capping-Agent-Free Electrodeposition. ACS Nano. 2010;4:1553-1560. DOI: 10.1021/nn100023h.

[114] Gou L, Murphy CJ. Solution-Phase Synthesis of $\mathrm{Cu}_{2} \mathrm{O}$ Nanocubes. Nano Lett. 2003;3:231-234. DOI: 10.1021/nl0258776.

[115] Huang C-C, Yang Z, Chang H-T. Synthesis of Dumbbell-Shaped Au-Ag Core-Shell Nanorods by Seed-Mediated Growth under Alkaline Conditions. Langmuir. 2004;20:6089-6092. DOI: 10.1021/la048791w.

[116] Li F, Yuan Y, Luo J, Qin Q, Wu J, Li Z, et al. Synthesis and characterization of ZnO$\mathrm{Ag}$ core-shell nanocomposites with uniform thin silver layers. Appl Surf Sci. 2010;256:6076-6082. DOI: 10.1016/j.apsusc.2010.03.123.

[117] Feng L, Wu X, Ren L, Xiang Y, He W, Zhang K, et al. Well-controlled synthesis of $\mathrm{Au} @ \mathrm{Pt}$ nanostructures by gold-nanorod-seeded growth. Chem - Eur J. 2008;14:9764-9771. DOI: 10.1002/chem.200800544.

[118] Min M, Kim C, Lee H. Electrocatalytic properties of platinum overgrown on various shapes of gold nanocrystals. J Mol Catal A: Chem. 2010;333:6-10. DOI: 10.1016/ j.molcata.2010.09.020.

[119] Yang J, Lee JY, Too H-P. Core-Shell Ag-Au Nanoparticles from Replacement Reaction in Organic Medium. J Phys Chem B. 2005;109:19208-19212. DOI: 10.1021/ jp052242x.

[120] Yang L, Guo C, Chen S, Wang F, Wang J, An Z, et al. pH-Sensitive Magnetic Ion Exchanger for Protein Separation. Ind Eng Chem Res. 2009;48:944-950. DOI: 10.1021/ ie800969q.

[121] Bergbreiter DE, Case BL, Liu Y-S, Caraway JW. Poly(N-isopropylacrylamide) Soluble Polymer Supports in Catalysis and Synthesis. Macromolecules. 1998;31:6053-6062. DOI: $10.1021 / \mathrm{ma} 980836 \mathrm{a}$.

[122] Jeong B, Bae YH, Lee DS, Kim SW. Biodegradable block copolymers as injectable drug-delivery systems. Nature. 1997;388:860-862. DOI: 10.1038/42218.

[123] Gupta AK, Gupta M. Synthesis and surface engineering of iron oxide nanoparticles for biomedical applications. Biomaterials. 2005;26:3995-4021. DOI: 10.1016/j.biomaterials.2004.10.012.

[124] Kalambur VS, Han B, Hammer BE, Shield TW, Bischof JC. In vitro characterization of movement, heating and visualization of magnetic nanoparticles for biomedical applications. Nanotechnology. 2005;16:1221-1233. DOI: 10.1088/0957-4484/16/8/041.

[125] Mornet S, Vasseur S, Grasset F, Duguet E. Magnetic nanoparticle design for medical diagnosis and therapy. J Mater Chem. 2004;14:2161-2175. DOI: 10.1039/b402025a. 
[126] Kobayashi T, Kida Y, Tanaka T, Hattori K, Matsui M, Amemiya Y. Interstitial hyperthermia of malignant brain tumors by implant heating system: clinical experience. J Neurooncol. 1991;10:153-163.

[127] Wang F, Tan WB, Zhang Y, Fan X, Wang M. Luminescent nanomaterials for biological labelling. Nanotechnology. 2006;17:R1-R13. DOI: 10.1088/0957-4484/17/1/r01.

[128] Holmes KL, Lantz LM. Protein labeling with fluorescent probes. Methods Cell Biol. 2001;63:185-204.

[129] Lin Y, Weissleder R, Tung C-H. Novel near-infrared cyanine fluorochromes: synthesis, properties, and bioconjugation. Bioconjugate Chem. 2002;13:605-610. DOI: 10.1021/bc0155723.

[130] Frangioni JV. In vivo near-infrared fluorescence imaging. Curr Opin Chem Biol. 2003;7:626-634. DOI: 10.1016/j.cbpa.2003.08.007.

[131] Li W, Yang X, Wang K, Tan W, He Y, Guo Q, et al. Real-Time Imaging of Protein Internalization Using Aptamer Conjugates. Anal Chem. 2008;80:5002-5008. DOI: 10.1021/ac800930q.

[132] Cheon J, Lee J-H. Synergistically Integrated Nanoparticles as Multimodal Probes for Nanobiotechnology. Acc Chem Res. 2008;41:1630-1640. DOI: 10.1021/ar800045c.

[133] Kircher MF, Mahmood U, King RS, Weissleder R, Josephson L. A Multimodal Nanoparticle for Preoperative Magnetic Resonance Imaging and Intraoperative Optical Brain Tumor Delineation. Cancer Res. 2003;63:8122-8125.

[134] Park J-H, von Maltzahn G, Ruoslahti E, Bhatia SN, Sailor MJ. Micellar hybrid nanoparticles for simultaneous magnetofluorescent imaging and drug delivery. Angew Chem, Int Ed. 2008;47:7284-7288. DOI: 10.1002/anie.200801810.

[135] Lee JE, Lee N, Kim H, Kim J, Choi SH, Kim JH, et al. Uniform Mesoporous Dye-Doped Silica Nanoparticles Decorated with Multiple Magnetite Nanocrystals for Simultaneous Enhanced Magnetic Resonance Imaging, Fluorescence Imaging, and Drug Delivery. J Am Chem Soc. 2010;132:552-557. DOI: 10.1021/ja905793q.

[136] Ke J-H, Lin J-J, Carey JR, Chen J-S, Chen C-Y, Wang L-F. A specific tumor-targeting magnetofluorescent nanoprobe for dual-modality molecular imaging. Biomaterials. 2010;31:1707-1715. DOI: 10.1016/j.biomaterials.2009.11.026.

[137] Kim J, Kim HS, Lee N, Kim T, Kim H, Yu T, et al. Multifunctional uniform nanoparticles composed of a magnetite nanocrystal core and a mesoporous silica shell for magnetic resonance and fluorescence imaging and for drug delivery. Angew Chem, Int Ed. 2008;47:8438-8441. DOI: 10.1002/anie.200802469.

[138] Liu H-M, Wu S-H, Lu C-W, Yao M, Hsiao J-K, Hung Y, et al. Mesoporous silica nanoparticles improve magnetic labeling efficiency in human stem cells. Small. 2008;4:619-626. DOI: 10.1002/smll.200700493. 
[139] Lu J, Liong M, Li Z, Zink JI, Tamanoi F. Biocompatibility, Biodistribution, and DrugDelivery Efficiency of Mesoporous Silica Nanoparticles for Cancer Therapy in Animals. Small. 2010;6:1794-1805. DOI: 10.1002/smll.201000538.

[140] Hudson SP, Padera RF, Langer R, Kohane DS. The biocompatibility of mesoporous silicates. Biomaterials. 2008;29:4045-4055. DOI: 10.1016/j.biomaterials.2008.07.007.

[141] Kim BS. Smart Hybrid Core@Shell Nanoparticles: Synthesis, Characterization, and Application. Houston: University of Houston; 2013.

[142] Kim J-H, Lee TR. Thermo- and pH-Responsive Hydrogel-Coated Gold Nanoparticles. Chem Mater. 2004;16:3647-3651. DOI: 10.1021/cm049764u.

[143] Kim J-H, Park HH, Chung SY, Lee TR. Hydrogel-coated shell/core nanoparticles for in vivo drug delivery. PMSE Prepr. 2008;99:730-731.

[144] Kim J-H, Lee TR. Discrete thermally responsive hydrogel-coated gold nanoparticles for use as drug-delivery vehicles. Drug Dev Res. 2006;67:61-69. DOI: 10.1002/ddr. 20068. 



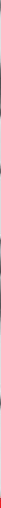

Edited by Mahmood Aliofkhazraei

During the past years, scientists have achieved significant success in the nanoscience and nanotechnology. Nanotechnology is a field of applied sciences which is focused on design, production, detection, and employing the nano-size materials, pieces, and equipment. Advances in nanotechnology lead to improvement of tools and equipment as well as their application in everyday life. In the chemistry this size involves the range of colloids, micelles, polymer molecules, and structures such as very large molecules or dense accumulation of the molecules. In physics of electrical engineering, the nanoscience is strongly related to quantum behaviour or electrons behaviour in structures with nano sizes. Also, in biology and biochemistry, there are interesting cellular components and molecular structures. This book collects new developments about nanoparticles.
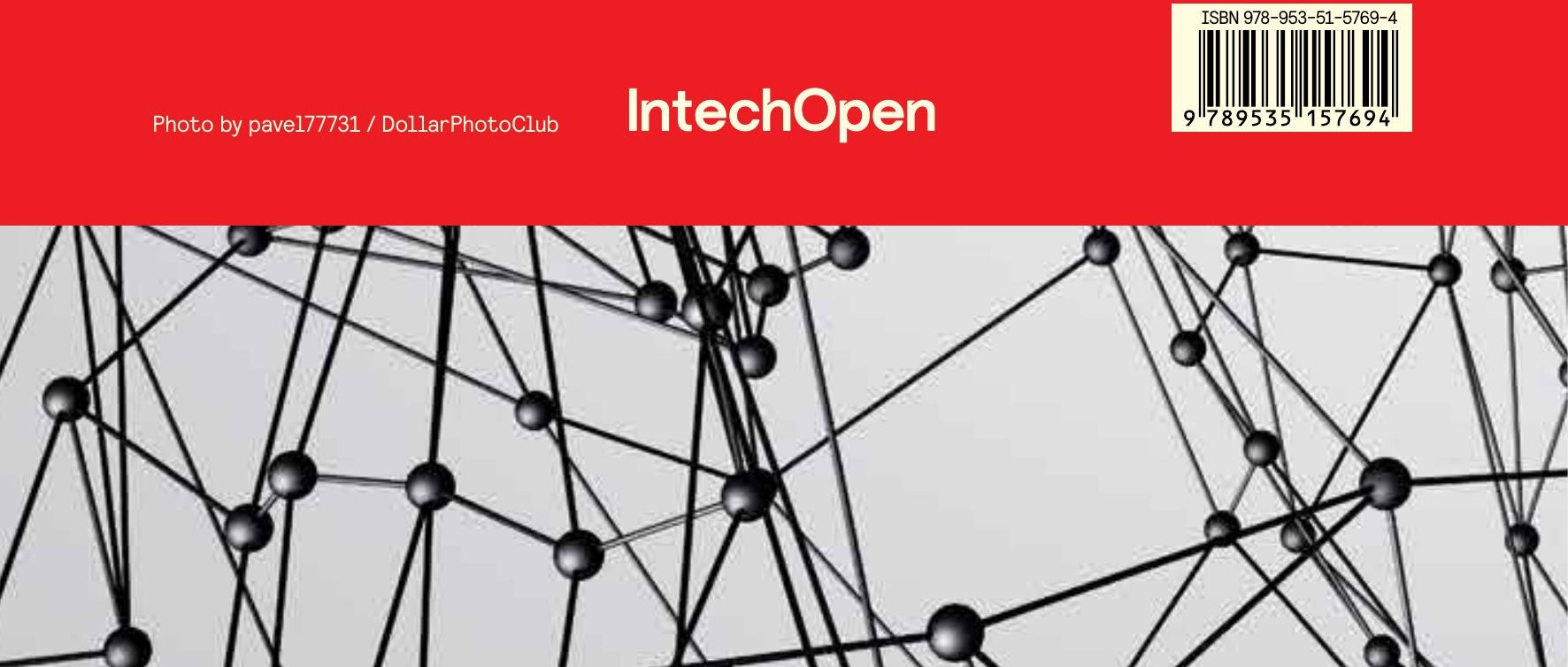